Daniel Henrique Fidelis Pereira

\title{
Análise do comportamento estrutural de ligações em aço entre viga de seção I e pilar de seção tubular circular
}





\section{Daniel Henrique Fidelis Pereira}

\section{Análise do comportamento estrutural de ligações em aço entre viga de seção I e pilar de seção tubular circular}

Dissertação de Mestrado apresentada à Escola de Engenharia de São Carlos da Universidade de São Paulo como parte dos requisitos necessários para a obtenção do título de Mestre em Engenharia de Estruturas

Área de concentração:

Estruturas metálicas

Orientador: Prof. Dr. Roberto Martins Gonçalves

\section{Versão corrigida}

A versão original encontra-se na Escola de Engenharia de São Carlos

São Carlos 
AUTORIZO A REPRODUÇÃO TOTAL OU PARCIAL DESTE TRABALHO, POR QUALQUER MEIO CONVENCIONAL OU ELETRÔNICO, PARA FINS DE ESTUDO E PESQUISA, DESDE QUE CITADA A FONTE.

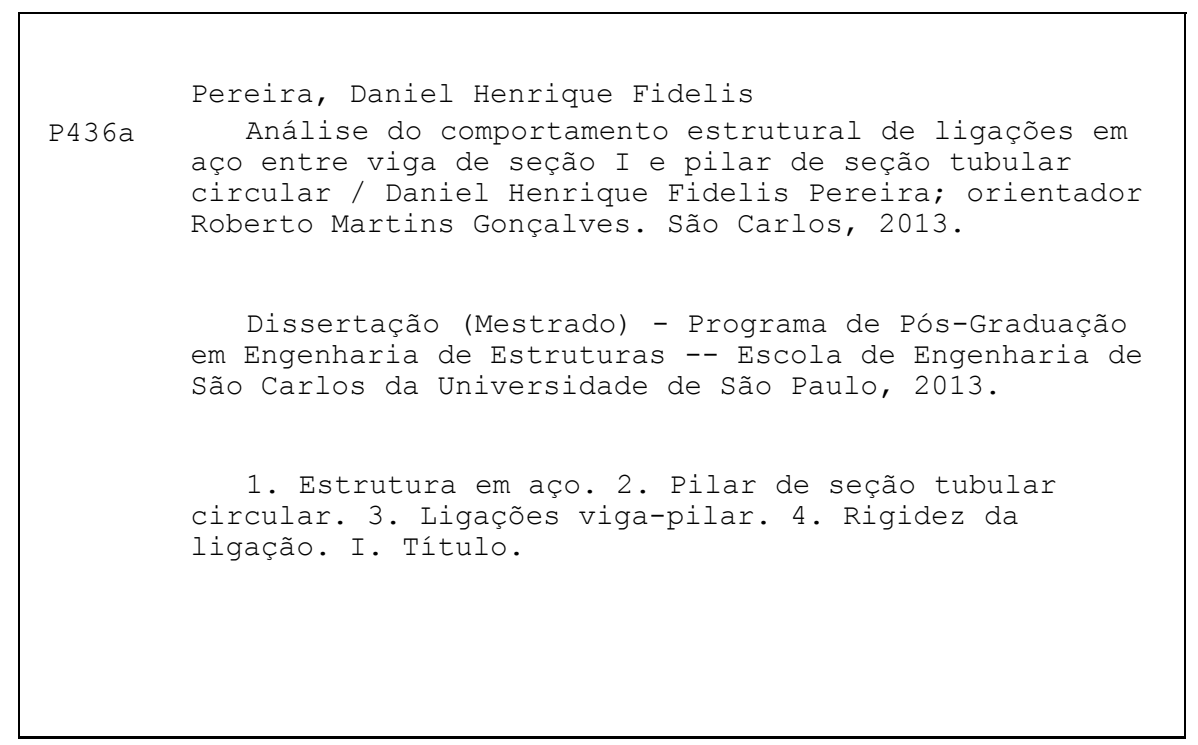




\section{FOLHA DE JULGAMENTO}

\section{Candidato: Engenheiro DANIEL HENRIQUE FIDELIS PEREIRA.}

Título da dissertação: "Análise do comportamento estrutural de ligações em aço entre viga de seção I e pilar de seção tubular circular".

Data da defesa: $08 / 11 / 2013$

\section{Comissão Julgadora:}

Prof. Associado Roberto Martins Gonçalves (Orientador) (Escola de Engenharia de São Carlos/EESC)

Prof. Dr. Alex Sander Clemente de Souza

(Universidade Federal de São Carlos/UFSCar)

Prof. Dr. Julio Fruchtengarten

(Escola Politécnica/USP)
Resultado:

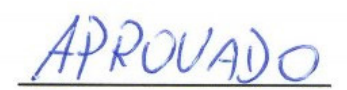

APROUADO

APROUADO

Coordenadora do Programa de Pós-Graduação em Engenharia Civil (Engenharia de Estruturas):

Profa. Associada Ana Lucia Homce de Cresce El Debs

Presidente da Comissão de Pós-Graduação:

Prof. Titular Denis Vinicius Coury 



\section{A Deus,}

Aos meus pais, Vitor e Mariza,

Aos meus irmãos, Talita e Tiago e À minha namorada, Paula. 



\section{AGRADECIMENTOS}

A Deus, o maior responsável por todas as metas que atingi até hoje. Ele que me proporcionou conhecimento, paciência e dedicação, iluminando meu caminho ao longo de toda a vida, me amparando nos momentos difíceis e me fortalecendo para enfrentar os entraves da vida.

Aos meus pais Vitor e Mariza que me educaram sempre incentivando os estudos e a formação profissional. Por me ensinarem a importância dos estudos, das amizades e da religião em minha vida.

Aos meus irmãos Talita e Tiago pela grande amizade e exemplo demonstrado ao longo de minha vida.

À minha namorada Paula por todos os momentos compartilhados, pela força nos momentos difíceis, pela compreensão nas ausências, pelo incentivo irrestrito e pelo amor incondicional.

Ao professor Roberto, pela amizade, críticas, sugestões e liberdade criativa que me proporcionou ao longo de todo o mestrado.

À Universidade Estadual de Londrina e à Universidade de São Paulo pelo capacitado corpo técnico, responsável pela minha formação acadêmica.

Aos engenheiros da Estrutural, em especial ao meu pai Vitor, ao seu sócio Valdir e ao engenheiro Gustavo por todos ensinamentos, incentivo à conclusão do mestrado e por introduzirem de forma única à Engenharia Estrutural em minha vida.

Aos professores do Departamento de Engenharia de Estruturas da EESC pelas aulas exemplares e riquíssimas em conteúdo proporcionadas ao longo do mestrado.

Aos amigos e companheiros de departamento, em especial a Alomir Fávero, Aref Kzam, Bruno Higaki, Daniel Bonfim, Danilo Oliveira, Diogo Oliveira, Elias Testoni, Hugo Oliveira, João Marinho, Matheus Fernandes, Fernando Lins e Paulo Eugenio.

Ao CNPq pelo suporte financeiro. 

"Nearly all men can stand adversity, but if you want to test a man's character, give him power." 



\section{Resumo}

PEREIRA, D. H. F. (2013). Análise do comportamento estrutural de ligações em aço entre viga de seção I e pilar de seção tubular circular. 202 p. Dissertação (Mestrado) - Escola de Engenharia de São Carlos, Universidade de São Paulo, São Carlos, 2013.

Esta pesquisa consiste de uma investigação acerca do comportamento estrutural de ligações entre viga de seção I e pilar de seção tubular circular em situações de pilar de canto e de pilar solicitado por quatro vigas simultaneamente (pilar central). A associação entre a viga de seção I e o pilar de seção tubular circular remete à análise de ligações com comportamento complexo. A partir da análise numérica, via Método dos Elementos Finitos com os softwares ANSYS ${ }^{\circledR}$ e TrueGrid ${ }^{\circledR}$ foi avaliado o comportamento momento-rotação e parâmetros como resistência, rigidez inicial e ductilidade das ligações. Foram analisadas as tipologias de ligação soldada e ligação com a presença do diafragma externo como mecanismo de enrijecimento. Avaliou-se a influência de 6 variáveis, sendo o comprimento da viga, a espessura do pilar, a força aplicada nas vigas dispostas ortogonalmente, a compressão axial do pilar, a espessura do diafragma e o diâmetro dos parafusos do diafragma totalizando 20 modelos numéricos. O aumento da espessura da seção do pilar e a força aplicada simultaneamente nas 4 vigas representou uma melhoria na resistência e rigidez inicial das ligações soldadas. A redução do diâmetro dos parafusos do diafragma foi a principal variável capaz de influenciar negativamente as propriedades de rigidez inicial e resistência das ligações com o diafragma. Todos os modelos analisados

apresentaram comportamento semi-rígido segundo o Eurocode 3 (2005). O dimensionamento analítico pelo Eurocode 3 (2005) e por Winkel (1998) apresentou 
boa aproximação com os resultados da análise numérica. A obtenção da resistência das ligações com diafragma pelo método das componentes apresentou resultados, em média, $20 \%$ inferiores ao verificado na modelagem numérica. A utilização do diafragma como mecanismo de enrijecimento das ligações mostrou-se eficiente. As ligações soldadas apresentaram maior ductilidade comparada às com diafragma. $O$ aumento da espessura do pilar nas ligações soldadas demonstrou-se uma alternativa eficaz no enrijecimento das ligações.

Palavras-chave: estrutura em aço, pilar de seção tubular circular, ligações viga-pilar, rigidez da ligação. 


\section{Abstract}

PEREIRA, D. H. F. (2013). Structural behavior of steel connections between Ibeam and circular hollow section column. 202 p. Dissertação (Mestrado) - Escola de Engenharia de São Carlos, Universidade de São Paulo, São Carlos, 2013.

This research consists of an investigation above the structural behavior of connections between I-beam and circular hollow section (CHS) columns in situation of corner columns and column loaded by 4 beams simultaneously (inside columns). The association between the I-beam and the CHS column presupposes the analysis of connections with a complex structural behavior. Based on a numerical analysis, using the Finite Element Method with ANSYS ${ }^{\circledR}$ and TrueGrid $^{\circledR}$ softwares, the connection parameters like strength, stiffness and ductility was evaluated. The typologies of welded connections and connections with an external diaphragm was analyzed. An amount of 6 variables (beam length, column thickness, force applied on the beams, compression of the column, diaphragm thickness and bolt diameter) was analyzed in a total of 20 numerical specimens. The increase of the column thickness and the force applied simultaneously on the 4 beam ends culminated on a substantial improvement on strength and stiffness of the welded connections. The reduction of the diaphragm bolts diameter was the main reason for the negatively influence on strength and stiffness properties of the diaphragm connections. All specimens presented a semirigid behavior according to the Eurocode 3 (2005). The analytical design, based on the Eurocode 3 (2005) and Winkel (1998), obtained good results in terms of connections strength compared with the numerical analysis. The obtainment of the connections strength with the component method demonstrated results $20 \%$ less than numerical analysis. The external diaphragm as a stiffening mechanism showed effective. The welded connections presented more ductility than the diaphragm ones. The increase 
on the column thickness demonstrated an effective alternative for the connection stiffening.

Keywords: steel structures, circular hollow section column, beam-column connections, connection stiffness. 


\section{Sumário}

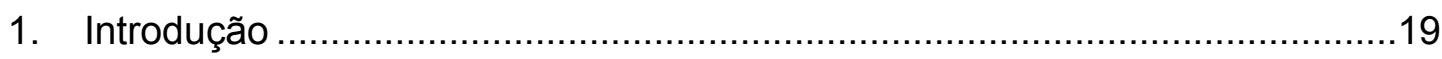

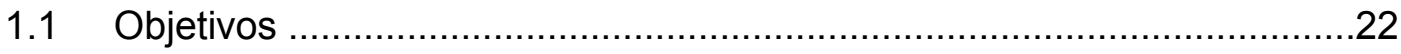

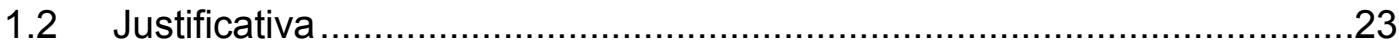

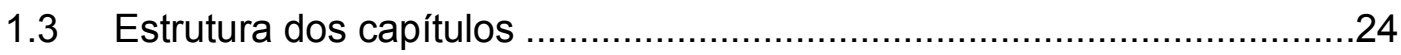

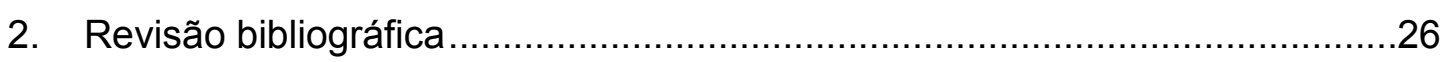

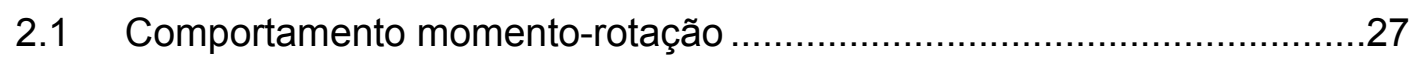

2.1.1 Modelos analíticos para a determinação da curva $M-\theta$.......................31

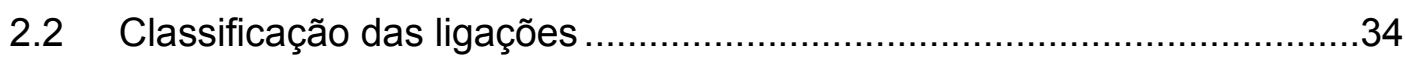

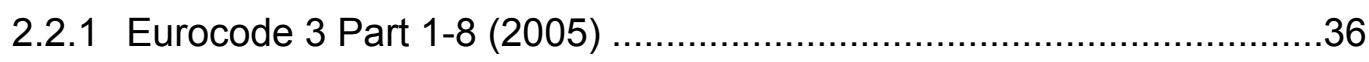

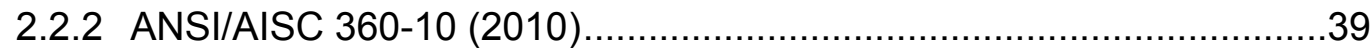

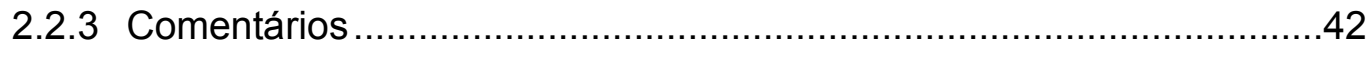

2.3 Modos de falha das ligações entre viga de seção I e pilar CHS ...............44

2.4 Mecanismos para o enrijecimento de ligações entre viga I e pilar CHS ..48

2.5 Histórico das pesquisas de ligações entre viga de seção I e pilar CHS ..53

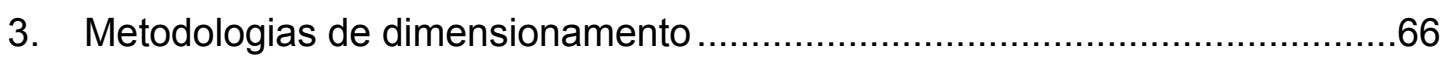

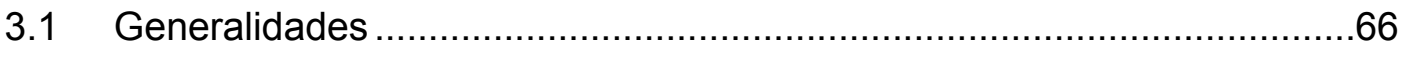

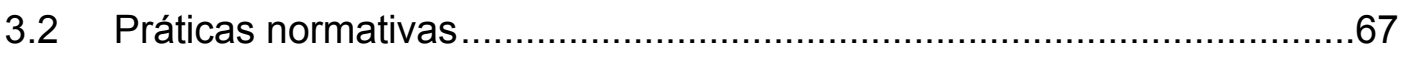

3.3 Metodologias de dimensionamento dos principais autores ......................73

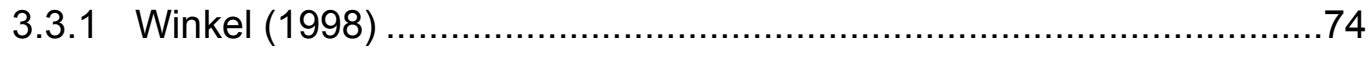

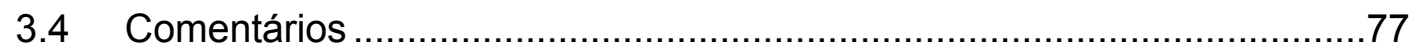

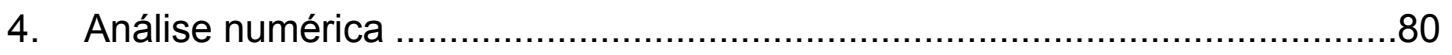


4.1 Critérios adotados na simulação numérica ..................................... 80

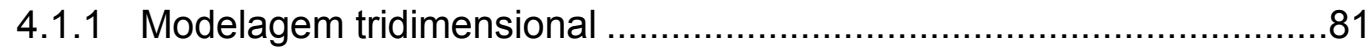

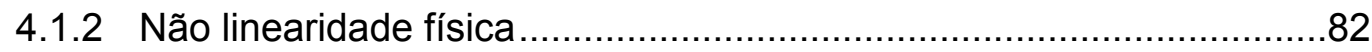

4.1.3 Não linearidade geométrica .................................................... 84

4.2 Preparação dos modelos numéricos …............................................... 85

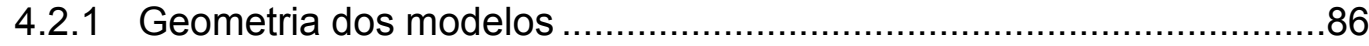

4.2.2 Elementos finitos e discretização ......................................................89

4.2.3 Condições de contorno e de carregamento ......................................97

4.2.4 Critérios de convergência ................................................. 100

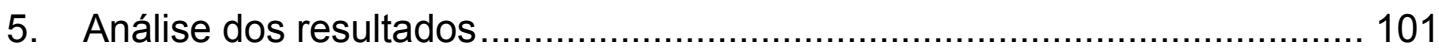

5.1 Comparação entre resultados numéricos e experimentais .................. 102

5.1.1 Modelos com ligações soldadas .............................................. 102

5.1.2 Modelo com a presença de diafragma externo.............................. 109

5.2 Resultados da modelagem numérica ........................................ 115

5.2.1 Distribuição de tensões ............................................................. 116

5.2.2 Análise da força aplicada versus deslocamento........................... 133

5.2.3 Comportamento momento-rotação .......................................... 141

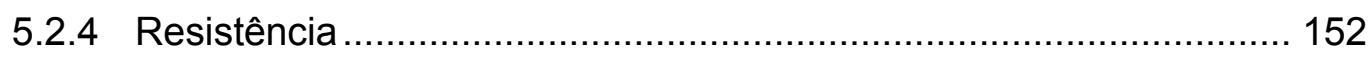

5.2.5 Classificação das ligações ..................................................... 155

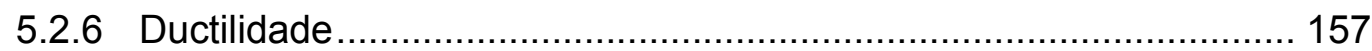

5.3 Análise da influência das variáveis ............................................... 158

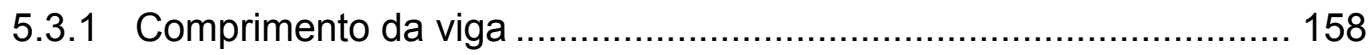

5.3.2 Espessura da parede do pilar ........................................... 164

5.3.3 Força aplicada nas duas direções ortogonais ............................ 170

5.3.4 Compressão axial do pilar................................................. 176

5.3.5 Espessura da chapa do diafragma .................................... 178

5.3.6 Diâmetro dos parafusos do diafragma ................................... 181

5.4 Análise comparativa entre ligações soldadas e com diafragma............ 184 


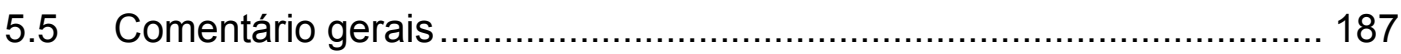

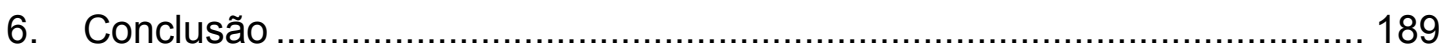

6.1 Validade das expressões analíticas........................................... 189

6.2 Comportamento das ligações ...................................................... 190

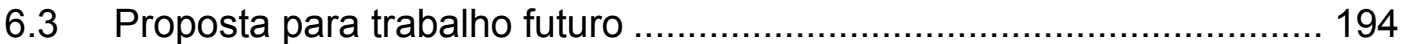

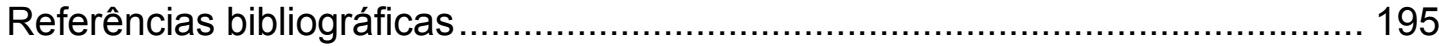





\section{Capítulo}

\section{Introdução}

Historicamente, formas arredondadas são associadas a objetos esteticamente harmoniosos e capazes de promover eficiência e perfeccionismo. A seção circular é a única seção ou arranjo geométrico possível, capaz de abarcar o máximo de conteúdo com o mínimo de perímetro ou superfície. Isto é uma qualidade natural e inerente da circunferência que é utilizada pela natureza, nos caules e nas raízes das plantas, nas artérias e veias do corpo humano.

Em estruturas civis nota-se uma ampla exploração das formas arredondadas, desde a antiguidade nos robustos pilares da arquitetura grega (figura 1.1), até nas estruturas contemporâneas (figura 1.2), onde, o aspecto estético gerado pela seção exposta e a eficiência estrutural proporcionada pela seção circular são fatores essenciais na concepção de uma estrutura.

Figura 1.1 - Partenon, Grécia

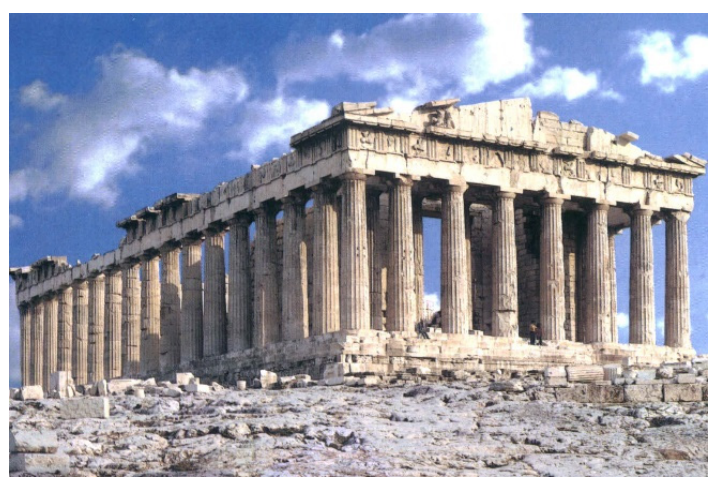

Fonte: http://ifbainfohistoria.blogspot.com.br
Figura 1.2 - Aeroporto de Stuttgart, Alemanha

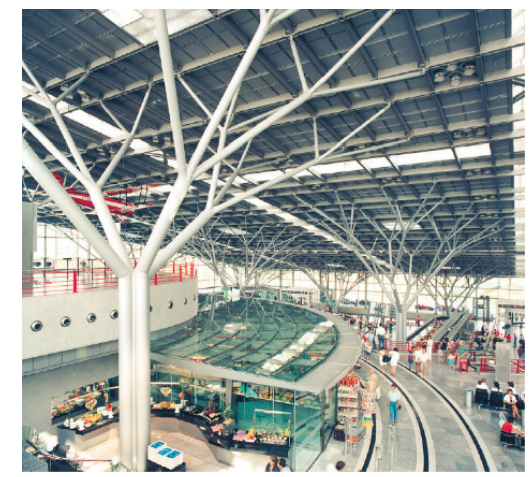

Fonte: Wardenier et al. (2010)

Firmo (2005) destaca o campo visual proporcionado quando da utilização de pilares de seção circular em substituição aos tradicionais retangulares ou de seção I. Como demonstrado na figura 1.3, o espectador, localizado em uma posição central do 
ambiente tem sua visão menos obstruída no caso da utilização de pilares de seção circular (a).

Figura 1.3 - Campo visual conforme a geometria da seção dos pilares

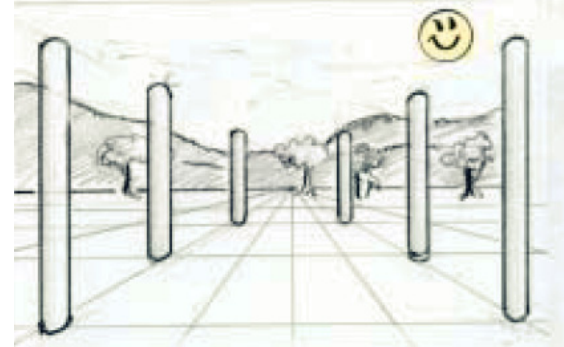

a)

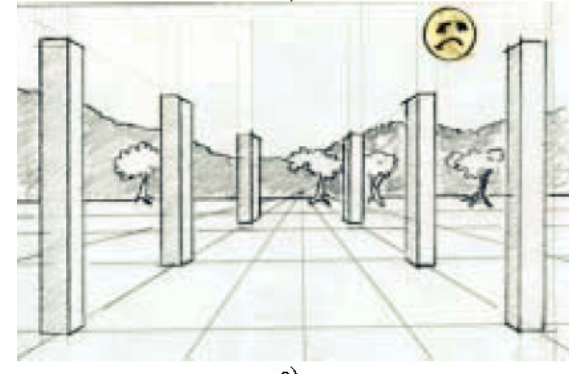

c)

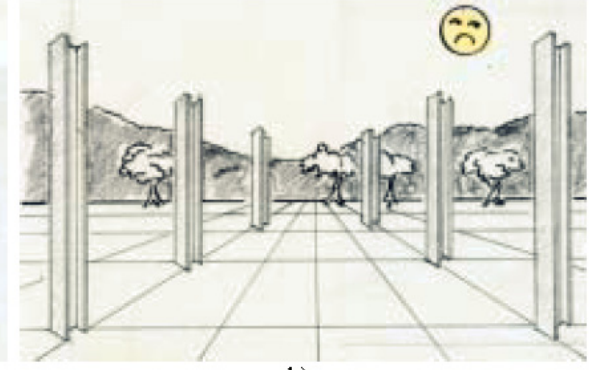

b)

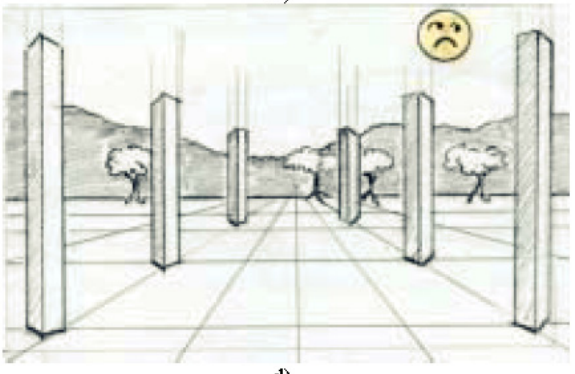

d)

Fonte: Firmo (2005)

Apesar da importância considerável, o aspecto arquitetônico não deve ser considerado isoladamente em uma estrutura. O dimensionamento de uma estrutura deve ser um "[...] processo interativo entre, os requisitos funcionais e arquitetônicos e, aspectos de resistência e fabricação [...]." (WARDENIER, 2010, p.1). A utilização de pilares de seção tubular circular proporciona vantagens em relação às seções abertas como:

a) A possibilidade de preenchimento com concreto, proporcionando assim, alta resistência e estabilidade estrutural, além de boa resistência ao fogo;

b) Os coeficientes de arrasto reduzidos quando expostas aos esforços devido ao vento (figura 1.4) ou água;

Figura 1.4 - Escoamento do vento em seções abertas e tubulares
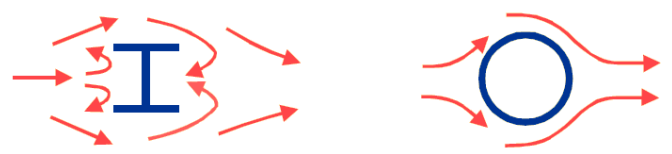

Fonte: Wardenier et al. (2010)

c) A redução da área superficial comparada às seções abertas equivalentes, gerando assim uma superfície menor a receber, por exemplo, pintura; 
d) A alta capacidade de resistir a esforços de compressão, em relação a uma seção aberta com massa linear equivalente;

e) Simetria em qualquer direção que passe pelo seu centro de gravidade. Possui centro de gravidade (CG) e centro de cisalhamento (CC) coincidentes. Devido às características geométricas, apresenta rigidez à torção, consideravelmente, superior à de seções abertas equivalentes.

As propriedades inerentes à seção geométrica circular a credenciam para a utilização em elementos submetidos, essencialmente, a esforços axiais. No esqueleto da estrutura de um edifício de múltiplos pavimentos verifica-se a necessidade da presença de vigas para a sustentação dos pavimentos. Nota-se, neste caso, a predominância de esforços de flexão nas vigas e a necessidade de uma geometria eficiente para este tipo de solicitação.

Segundo os conceitos da Resistência dos Materiais, a seção do tipo I (dentre as comercialmente utilizadas) é a que melhor apresenta aproveitamento do material sob a predominância do momento fletor. A variedade dimensional e o processo de fabricação bem disseminados corroboram na opção por esta seção geométrica nas vigas de uma estrutura metálica. O equilíbrio entre aspectos estruturais e arquitetônicos em uma estrutura de aço sugere a associação entre vigas de seção I e pilares de seção tubular circular em prol de um dimensionamento eficiente.

No cenário atual, o uso de seções tubulares nas estruturas não é muito disseminado, principalmente, pelo detalhamento complexo das suas ligações com outros elementos estruturais, reduzindo a agilidade do processo e culminando no aumento do custo de projeto e construção. O comportamento particular das ligações e a ausência de metodologias de dimensionamento nas principais normas repercute em certa discriminação por parte dos projetistas na utilização da seção tubular circular. Destaca-se ainda, a falta de acesso ao interior das seções tubulares resultando em ligações mais complicadas do ponto de vista de execução.

A avaliação das particularidades citadas e os estudos inerentes a esta pesquisa permitem verificar que existe escassez de pesquisas específicas sobre ligações entre viga I e pilar tubular circular. Visando criar subsídios para futuras prescrições normativas sobre estruturas tubulares, o estudo das ligações entre pilar de seção tubular circular e viga de seção l é o objeto de estudo deste trabalho. 


\subsection{Objetivos}

Esta pesquisa possui caráter de continuidade aos trabalhos desenvolvidos por Freitas (2009) e Masioli (2011) na Universidade de São Paulo (USP), mais especificamente, no departamento de Engenharia de Estruturas da Escola de Engenharia de São Carlos. Freitas (2009) estudou o comportamento estrutural de ligações do tipo X (figura 1.5) e Masioli (2011) realizou uma pesquisa sobre ligações do tipo T (figura 1.6) entre viga I e pilar tubular circular.

Figura 1.5 - Ligação do tipo $X$

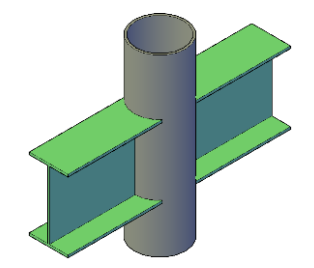

Fonte: Acervo pessoal
Figura 1.6 - Ligação do tipo T

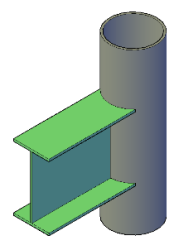

Fonte: Acervo pessoal

O objetivo deste trabalho é avaliar por meio de análise numérica, via Método dos Elementos Finitos (M.E.F.), o comportamento estrutural de ligações do tipo TT (figura 1.7) e tipo XX (figura 1.8) entre viga de seção I e pilar de seção tubular circular. Apresentam-se considerações a respeito das principais metodologias de dimensionamento para este tipo de ligação e sobre a utilização do diafragma externo (figura 1.9) como mecanismo de enrijecimento das ligações.

Figura 1.7 - Ligação do tipo TT soldada

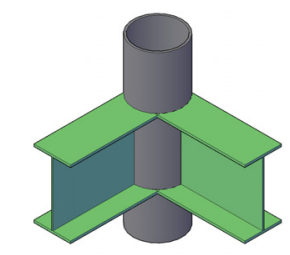

Fonte: Acervo pessoal
Figura 1.8 - Ligação do tipo XX soldada

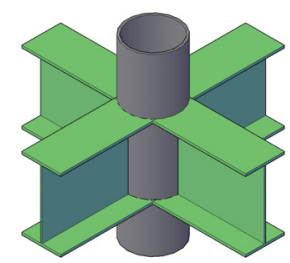

Fonte: Acervo pessoal
Figura 1.9 - Ligação do tipo XX com diafragma

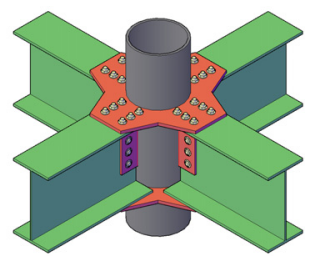

Fonte: Acervo pessoal

Mais especificamente, os objetivos desta pesquisa consistem em:

a) Avaliar o comportamento $M-\theta$ (momento-rotação) e parâmetros como rigidez, ductilidade e resistência das ligações;

b) Verificar a influência das variáveis:

i. Comprimento da viga; 
ii. Espessura da parede do pilar (figura 1.10);

iii. Força aplicada nas duas direções ortogonais (figura 1.11);

iv. Compressão axial do pilar (figura 1.12);

v. Espessura da chapa do diafragma;

vi. Diâmetro dos parafusos do diafragma.

c) Análise comparativa entre ligações soldadas e com diafragma;

d) Avaliar a validade de expressões analíticas para estimar a resistência das ligações;

e) Avaliar a eficiência dos diafragmas em enrijecer as ligações.

Figura 1.10 - Espessura da parede pilar

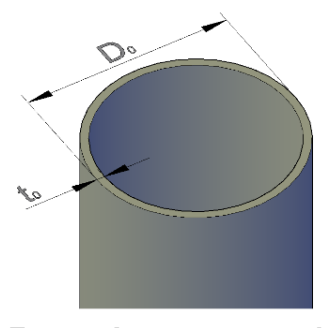

Fonte: Acervo pessoal
Figura 1.11 - Carregamento nas duas direções ortogonais

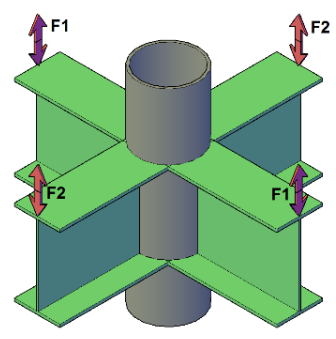

Fonte: Acervo pessoal
Figura 1.12 - Carregamento axial do pilar

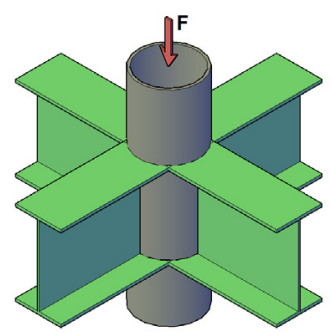

Fonte: Acervo pessoal

\subsection{Justificativa}

A utilização de pilar tubular circular juntamente com a viga I tem se tornado mais frequente nos últimos anos visto as inúmeras vantagens em se utilizar estas geometrias. O desconhecimento do comportamento da ligação entre estes elementos pode ocasionar uma avaliação incorreta das características da ligação, sobretudo, a resistência e a rigidez. Uma análise criteriosa deste tipo de ligação fornece subsídios para o aperfeiçoamento das metodologias analíticas de avaliação do comportamento.

As poucas formulações disponíveis pelas normas internacionais a respeito do dimensionamento de ligações entre viga I e pilar tubular circular deixam a cargo do projetista avaliar os parâmetros de rigidez e resistência das ligações. As incertezas presentes no comportamento complexo das ligações direcionam o engenheiro a uma 
avaliação incorreta ou, na maioria das vezes, a utilização de uma concepção estrutural alternativa.

\subsection{Estrutura dos capítulos}

Considerando os objetivos propostos nesta pesquisa, no capítulo 2 faz-se uma abordagem histórica das pesquisas relacionadas às ligações entre viga de seção I e pilar de seção tubular circular. Este mecanismo fornece subsídios para a utilização correta de pesquisas já realizadas, diminuindo a probabilidade de avaliações repetitivas e evidenciando a contribuição deste trabalho. Apresentam-se também conceitos inerentes ao pleno entendimento do tema.

O capítulo 3 destaca as abordagens relacionadas ao dimensionamento analítico do tipo de ligação em estudo. Enfatizam-se as práticas normativas para estimar a resistência das ligações, além de formulações apresentadas em outras pesquisas, de forma a apresentar, analiticamente, mecanismos para estimar a resistência da ligação.

Na sequência do trabalho (capítulo 4) apresentam-se as considerações adotadas na simulação numérica, via Método dos Elementos Finitos, com os softwares TrueGrid ${ }^{\circledR}$ e ANSYS ${ }^{\circledR}$. Neste capítulo, adotou-se uma metodologia de análise numérica semelhante à realizada por Freitas (2009) e Masioli (2011). Optouse por uma análise numérica tridimensional utilizando elementos finitos sólidos. Considerou-se o comportamento do material com relação às propriedades mecânicas de encruamento e plastificação, além da não linearidade geométrica e de contato do modelo. Esta metodologia instituída por Maggi (2004) reduziu as simplificações na modelagem da ligação evitando uma resposta comportamental imprecisa. Neste capítulo, destacam-se os critérios adotados na modelagem, os elementos finitos utilizados, assim como, a geometria dos modelos e condições de contorno instituídas.

No capítulo 5 destacam-se os resultados da análise numérica desenvolvida conforme as geometrias destacadas no capítulo 4. Em um primeiro momento foram desenvolvidos 6 modelos numéricos de ligação soldada e 1 de ligação com diafragma 
com base nas geometrias dos modelos experimentais de outros autores. Os 7 modelos foram referência para a comparação entre resultados numéricos e experimentais além de gerar a validação da metodologia de análise numérica descrita no capítulo 4.

Na sequência do capítulo 5 são apresentados os resultados dos 10 modelos de ligação soldada e dos 10 modelos de ligação com diafragma propostos para esta pesquisa. Destacam-se de forma comparativa os resultados quanto à distribuição das tensões, o comportamento momento-rotação, a resistência, rigidez inicial e ductilidade das ligações. Apresentam-se os resultados analíticos segundo o Eurocode 3 (2005) referentes à resistência e rigidez inicial das ligações e as respectivas classificações. Avaliam-se, ao final do capítulo, as variáveis destacadas nos objetivos desta pesquisa.

No capítulo 6 apresenta-se uma visão geral quanto à validade das expressões analíticas para estimar a resistência das ligações destacadas no capítulo 3 . Somado a isso, realiza-se uma abordagem específica quanto ao comportamento das ligações observado na análise numérica. Destacam-se ainda, as conclusões gerais da pesquisa, assim como, propostas para trabalhos futuros sobre ligações, em aço, entre viga de seção I e pilar de seção tubular circular. 


\section{Capítulo 2}

\section{Revisão bibliográfica}

As ligações viga-pilar envolvendo seções tubulares, em sua maioria, possuem designação ligeiramente extensa e repetitiva. Em geral, as pesquisas e normas regulamentadoras procuram determinar uma simbologia ou nomenclatura que contemple todo o significado da denominação de forma resumida.

Considerando a necessidade do pleno entendimento das nomenclaturas que serão utilizadas no decorrer desta pesquisa, a figura 2.1 ilustra os quatro tipos básicos de ligações viga-pilar ${ }^{1}$.

Figura 2.1 - Tipos de ligação entre viga de seção I e pilar de seção tubular circular

\begin{tabular}{|c|c|c|c|}
\hline Tipo T & Tipo X & Tipo TT & Tipo XX \\
\hline & & \\
\hline
\end{tabular}

Fonte: Acervo pessoal

As ligações do tipo $\mathrm{T}$ e do tipo $\mathrm{X}$ são conhecidas no meio técnico como ligações uniplanares. A ligação do tipo T caracteriza-se pela presença de apenas uma viga ligada à face do pilar. $O$ tipo $X$ remete à disposição de duas vigas em faces opostas do pilar.

1 No contexto deste trabalho, o termo viga, quando não especificado, refere-se à viga de seção do tipo I. Da mesma maneira, o termo pilar remete ao pilar de seção tubular circular. 
As ligações multiplanares, por sua vez, são representadas pelas ligações do tipo TT e XX. Analogamente ao tipo T, denomina-se ligação do tipo TT quando da presença de duas vigas dispostas ortogonalmente entre si e ligadas à face do pilar. Da mesma forma, a ligação XX (derivada de um duplo tipo $X$ ) caracteriza-se pela presença de 4 vigas perpendiculares entre si e conectadas à face do pilar.

Em relação à geometria da seção tubular, as formas mais comuns são a circular, retangular, quadrada e elíptica. Para o caso específico desta pesquisa, serão estudadas as ligações com a presença de pilar de seção tubular circular. Neste caso, a literatura estrangeira costuma denominar este tipo de seção com o termo, em inglês, circular hollow section ou, simplesmente, por meio da sigla CHS.

O estudo de ligações viga-pilar em estruturas de aço contempla diversos conceitos inerentes ao entendimento de uma pesquisa nesta área de abrangência. Neste capítulo, são apresentados alguns conceitos básicos fundamentais para o desenvolvimento da pesquisa. Atrelado ao propósito da revisão bibliográfica apresenta-se também um breve histórico das pesquisas sobre ligações entre viga de seção I e pilar de seção tubular circular.

\subsection{Comportamento momento-rotação}

Uma das principais características do comportamento da ligação é descrita pela respectiva curva momento-rotação. O comportamento momento-rotação de uma ligação viga-pilar pode ser entendido pela observação da relação entre o momento aplicado e o ângulo relativo entre os elementos conectados.

$O$ ângulo $\theta$ (figura 2.2) corresponde à rotação relativa entre a viga e o pilar quando $M$ é aplicado. A relação entre o momento e o respectivo ângulo $\theta$ descreve uma curva representativa do comportamento da ligação. A esta curva descrita, dá-se o nome de comportamento momento-rotação (figura 2.3). 
Figura 2.2 - Ligação viga-pilar submetida a um momento fletor $M$

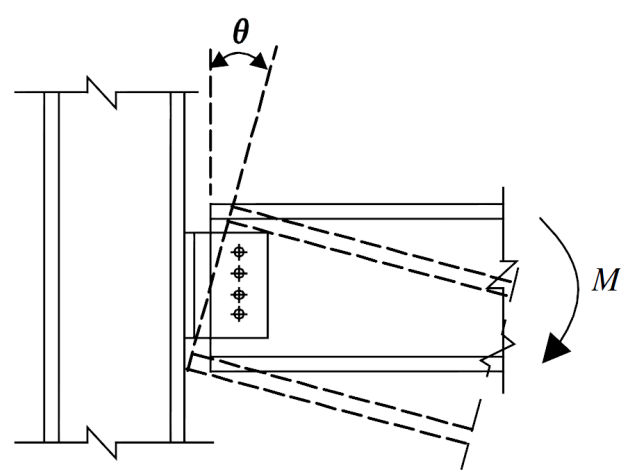

Fonte: Chen e Lui (2005)
Figura 2.3 - Curva momento-rotação e os seus respectivos parâmetros

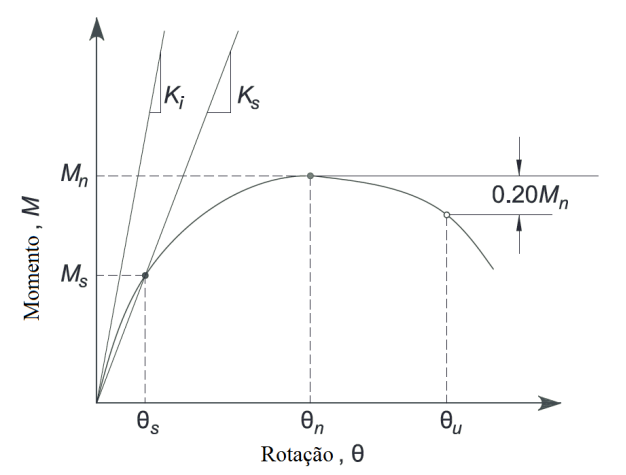

Fonte: ANSI/AISC 360-10 (2010)

Destacam-se a seguir algumas definições para o comportamento momentorotação, descritas por outros autores:

"Uma forma de representar o comportamento de uma ligação à flexão é relacionar o momento fletor a que está solicitada com a rotação relativa entre os elementos conectados. Essa relação pode ser esquematizada graficamente por um diagrama momento-rotação, representando a rigidez rotacional da ligação e caracterizando o comportamento semi-rígido." (MAGGI, 2004, p.27).

"A relação momento-rotação é a principal característica de uma ligação viga-elemento suporte, sendo comumente descrita por uma curva tendo a rotação $(\theta)$ da viga em relação ao elemento suporte no eixo das abscissas e o momento (M) no eixo das ordenadas." (CARVALHO, 2005, p.11).

A determinação da curva $M-\theta$ pode ser feita por meio de um conjunto de dados experimentais, modelos semi-empíricos, modelos analíticos ou simulação numérica. Identificam-se na curva alguns parâmetros fundamentais (figura 2.3) sendo:

- Rigidez inicial $\left(\mathrm{K}_{\mathrm{i}}\right)$ : A rigidez inicial é a inclinação da reta tangente à curva momento-rotação;

- Rigidez secante $\left(K_{s}\right)$ : É obtida pela relação entre o momento fletor $\left(M_{s}\right)$ e a respectiva rotação $\left(\theta_{s}\right)$;

- Momento fletor $\left(\mathrm{M}_{\mathrm{s}}\right)$;

- Momento fletor último $\left(M_{n}\right)$ : Referente ao máximo momento fletor a qual a ligação pode resistir. Valor de "pico" da curva momento-rotação; 
- Rotação em solicitação de serviço $\left(\theta_{s}\right)$;

- Rotação relativa ao momento fletor último $\left(\theta_{n}\right)$;

- Capacidade rotacional $\left(\theta_{u}\right)$ : Definida na classificação do ANSI/AISC 36010 (2010) como o valor onde a resistência ao momento fletor reduz para $80 \%$ de $M_{n}$.

A obtenção da rigidez inicial pode ser compreendida por meio da observação de uma aplicação prática em uma ligação soldada entre viga I e pilar CHS (figura 2.4).

Figura 2.4 - Ligação tipo X soldada

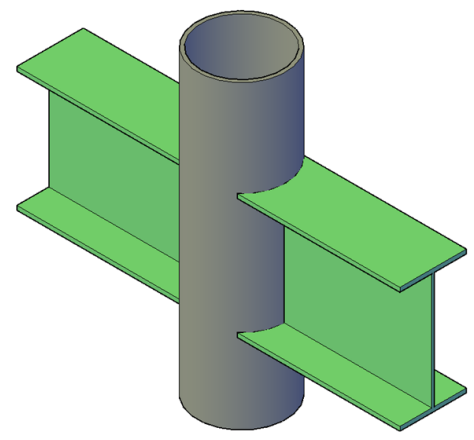

Fonte: Acervo pessoal
Figura 2.5 - Curvas $M-\theta$

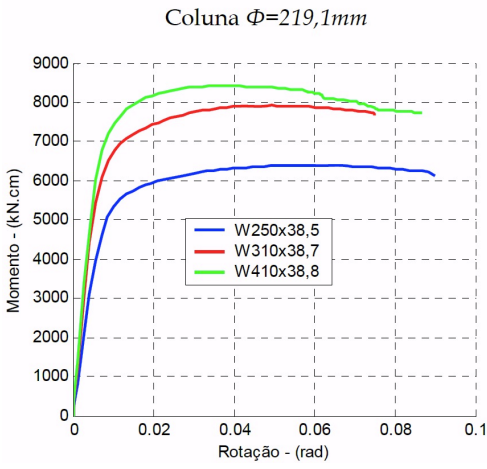

Fonte: Freitas (2009)

Observa-se na figura 2.5 a ilustração de três curvas momento-rotação, uma para cada seção de viga analisada. O aumento da inclinação no trecho inicial das curvas pode ser compreendido como um aumento da rigidez inicial da ligação. Subentende-se, neste caso, que o aumento da altura da seção da viga promove um aumento da rigidez da ligação.

O fato apresentado pode ser comprovado por meio do cálculo da rigidez inicial $\left(\mathrm{K}_{\mathrm{i}}\right)$. A rigidez inicial é tomada como a inclinação inicial da curva momento-rotação, portanto, no caso da ligação ilustrada na figura 2.4 com as seções destacadas na figura 2.5, o cálculo da rigidez inicial conduz aos resultados apresentados na tabela 2.1:

Tabela 2.1 - Cálculo da rigidez inicial em ligações soldadas do tipo X

\begin{tabular}{|c|c|c|c|}
\hline Viga & $M_{y}$ (kN.m) & Rotação (rad) & $\mathrm{K}_{\mathrm{i}}(\mathrm{kN} \cdot \mathrm{m} / \mathrm{rad})$ \\
\hline W250x38,5 & 30,77 & 0,0039 & $7.889,74$ \\
\hline W310x38,7 & 50,47 & 0,0043 & $11.737,21$ \\
\hline W410x38,8 & 59,16 & 0,0045 & $13.146,67$ \\
\hline
\end{tabular}


A tipologia da ligação tende a ser o principal parâmetro influenciador na característica comportamental da ligação viga-pilar, sendo assim, a representação da curva momento-rotação para diferentes tipologias tende a originar curvas distintas entre si quanto aos parâmetros fundamentais. Este fato fica evidenciado pela figura 2.6 que ilustra o comportamento $\mathrm{M}-\theta$ de algumas tipologias de ligações viga-pilar mais comum.

Figura 2.6 - Comportamento momento-rotação para diferentes tipologias de ligação viga-pilar

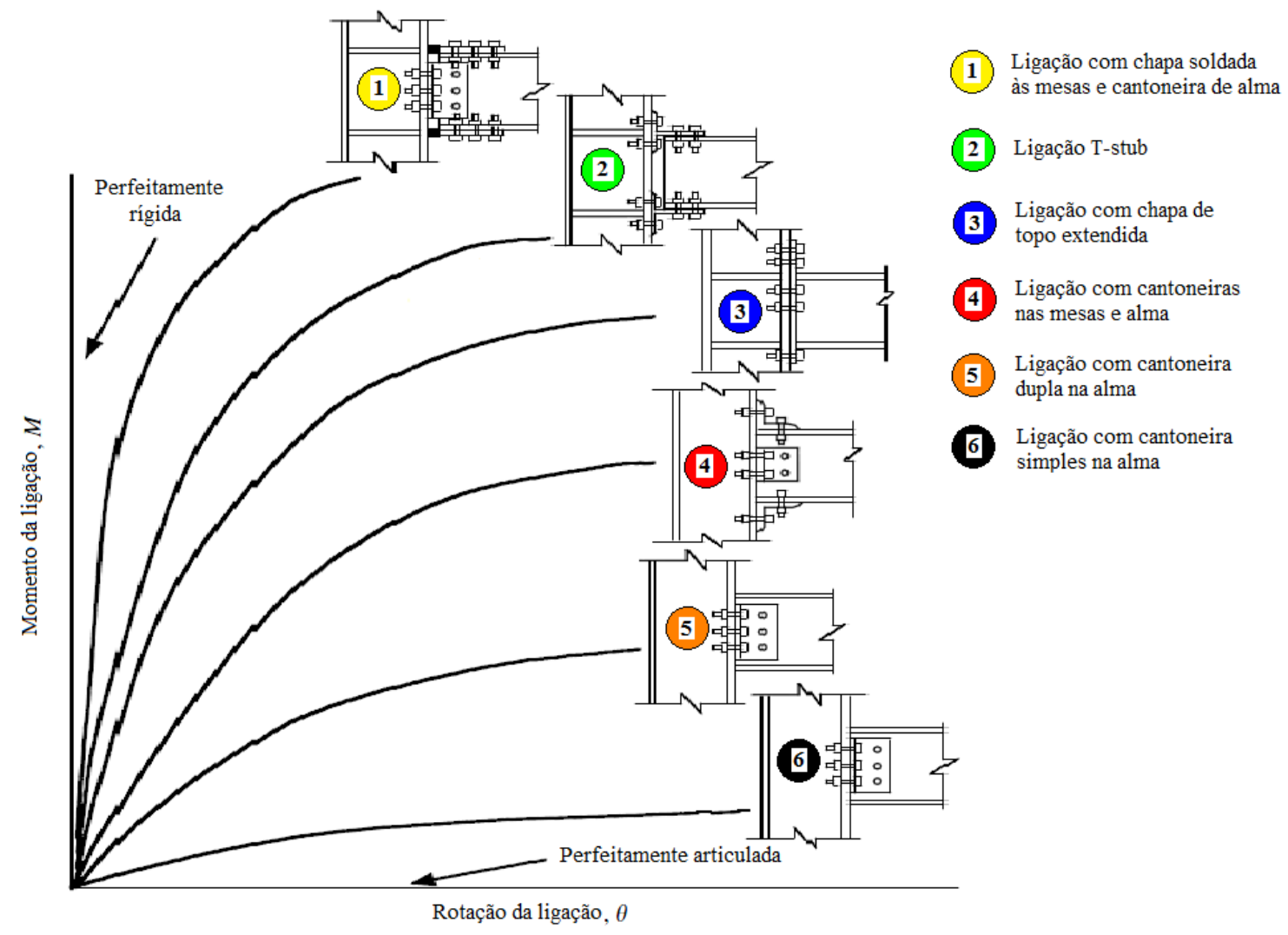

Fonte: Chen e Lui (2005)

Reiterando a importância da análise da relação $M-\theta$ para o estudo do comportamento de ligações, o ANSI/AISC 360-10 (2010, p.262) cita que "[...] a característica comportamental mais importante da ligação pode ser demonstrada pela respectiva curva momento-rotação $(\mathrm{M}-\theta)$.". Os parâmetros fundamentais atrelados à curva e a capacidade de representar o comportamento visualmente e analiticamente são fatores fundamentais na utilização da curva $M-\theta$ na representação do comportamento das ligações. 


\subsubsection{Modelos analíticos para a determinação da curva M- $\theta$}

Nos casos em que o efeito das ligações não pode ser idealizado (como ligação rígida ou articulada) na análise estrutural torna-se necessário um modelo preciso do respectivo comportamento momento-rotação. Chen e Lui (2005) lembram que resultados experimentais demonstraram que existe uma relação não linear entre o momento e a rotação para quase todos os tipos de ligação, durante todo o intervalo de carregamento. A não linearidade se dá, sobretudo, porque a ligação é uma composição de vários elementos que interagem diferentemente em níveis distintos de carregamento. A descontinuidade geométrica na ligação, a plastificação de alguns componentes, dentre outros fatores, contribui para a não linearidade. O principal obstáculo em se incorporar o comportamento das ligações no dimensionamento é a dificuldade de se praticar uma análise simples, visto a não linearidade da relação M$\theta$.

A caracterização da relação $M-\theta$ é um requisito fundamental para qualquer consideração da influência da ligação no comportamento da estrutura. A melhor maneira de se obter o conhecimento do comportamento da ligação de forma confiável e precisa é por meio de uma investigação experimental. Esta técnica costuma ser muito cara para as práticas de projeto e, geralmente, fica restrita às práticas de pesquisa. Uma solução para incorporar o comportamento da ligação na análise estrutural é a simulação por meio de representação matemática da relação $\mathrm{M}-\theta$. Apesar de mais barata, esta técnica apresenta-se dispendiosa com relação à modelagem da relação não linear da curva.

A alternativa é buscar expressões matemáticas simplificadas de forma a melhor aproximar o comportamento não linear da curva. Ao longo dos anos, diversos pesquisadores procuraram estudar formas de melhor aproximar o comportamento da curva M- $\theta$ por meio de métodos analíticos simplificados. Alguns dos modelos estudados são apresentados no quadro 2.1. A decisão por qual critério optar depende, sobretudo, da finalidade para a qual a representação se faz necessária, por exemplo, para uma simulação numérica sofisticada ou, para estudos aproximados do comportamento. 
Quadro 2.1 - Modelos analíticos para a representação da curva M- $\theta$

\begin{tabular}{|c|c|c|c|}
\hline TIPO DE MODELO & $\begin{array}{c}\text { REFERÊNCIA } \\
\text { (apud CHEN; LORENZ; } \\
\text { KATO, 1993) }\end{array}$ & VANTAGENS & DESVANTAGENS \\
\hline Linear & $\begin{array}{c}\text { Baker (1934) } \\
\text { Rathbun (1936) }\end{array}$ & $\begin{array}{l}\text { I) Utilização simples } \\
\text { II) A matriz de rigidez } \\
\text { requer apenas uma } \\
\text { modificação inicial }\end{array}$ & $\begin{array}{l}\text { Impreciso em valores } \\
\text { elevados de rotação }\end{array}$ \\
\hline Bilinear & $\begin{array}{c}\text { Lionberger e } \\
\text { Weaver (1969) } \\
\text { Romstad e } \\
\text { Subramanian (1970) }\end{array}$ & $\begin{array}{l}\text { I) Utilização simples } \\
\text { II) Mais próximo da } \\
\text { curva M- } \theta \text { do que o } \\
\text { modelo linear }\end{array}$ & $\begin{array}{l}\text { Impreciso em alguns } \\
\text { níveis de rotação }\end{array}$ \\
\hline Polinomial & $\begin{array}{c}\text { Sommer (1969) } \\
\text { Frye e Morris (1975) }\end{array}$ & \begin{tabular}{|c|} 
Produz uma \\
aproximação melhor \\
em relação à forma da \\
curva $\mathrm{M}-\theta$
\end{tabular} & $\begin{array}{c}\text { Pode produzir valores } \\
\text { imprecisos para a } \\
\text { rigidez tangente da } \\
\text { ligação (inclusive }\end{array}$ \\
\hline B-spline cúbico & Jones et al. (1980) & $\begin{array}{l}\text { I) Produz uma } \\
\text { aproximação muito boa } \\
\text { para qualquer conjunto } \\
\text { de dados } M-\theta \\
\text { II) Valores precisos da } \\
\text { rigidez da ligação }\end{array}$ & $\begin{array}{l}\text { I) É um modelo não- } \\
\text { linear, portanto, requer } \\
\text { avaliação iterativa } \\
\text { II) Requer procedimentos } \\
\text { numéricos especiais } \\
\text { para a avaliação }\end{array}$ \\
\hline Exponencial & Richard et al. (1980) & $\begin{array}{l}\text { 1) Boa aproximação para } \\
\text { ligações com cantoneira } \\
\text { simples } \\
\text { II) Não testado para } \\
\text { outros tipos mas pode } \\
\text { ser adequado }\end{array}$ & $\begin{array}{l}\text { I) É um modelo não- } \\
\text { linear, portanto, requer } \\
\text { avaliação iterativa } \\
\text { II) Requer ajustamento } \\
\text { das curvas pela técnica } \\
\text { dos mínimos quadrados }\end{array}$ \\
\hline $\begin{array}{l}\text { Ramberg-Osgood } \\
\text { (exponencial) }\end{array}$ & Ang e Morris (1984) & $\begin{array}{l}\text { 1) Boa aproximação para } \\
\text { vários conjuntos de } \\
\text { dados } \\
\text { II) Semelhante ao B- } \\
\text { spline cúbico }\end{array}$ & $\begin{array}{l}\text { I) É um modelo não- } \\
\text { linear, portanto, requer } \\
\text { avaliação iterativa } \\
\text { II) Requer ajustamento } \\
\text { das curvas pela técnica } \\
\text { dos mínimos quadrados }\end{array}$ \\
\hline $\begin{array}{l}\text { Exponencial + } \\
\text { correção }\end{array}$ & Yee (1984) & $\begin{array}{l}\text { 1) Boa aproximação nos } \\
\text { modelos do autor } \\
\text { II) Tem embasamento } \\
\text { semi-analítico }\end{array}$ & $\begin{array}{l}\text { I) É um modelo não- } \\
\text { linear, portanto, requer } \\
\text { avaliação iterativa } \\
\text { II) Não foi testado fora } \\
\text { do intervalo de dados } \\
\text { originais }\end{array}$ \\
\hline
\end{tabular}

Fonte: Chen, Lorenz e Kato (1993)

O quadro 2.1 representa, em ordem cronológica, a evolução na fundamentação teórica dos modelos analíticos. É possível fazer algumas observações segundo Chen, Lorenz e Kato (1993), em relação a alguns dos modelos apresentados:

- Os modelos mais antigos (sem uso de computador) utilizando representações lineares cobrem apenas a rigidez inicial da ligação. Estes modelos não são adequados para análises completas do comportamento, 
superestimando a rigidez da ligação em todos os níveis de rotação do nó, exceto nos mais baixos.

- A evolução mais marcante nos modelos analíticos para a obtenção das curvas M- $\theta$ foi à contribuição de Frye e Morris (1975) que foram os primeiros a sugerirem a utilização de curvas polinomiais aliada às técnicas de calibração para obter soluções melhor aproximadas.

- Dificuldades analíticas associadas à inclinação negativa das curvas polinomiais, que podem ocorrer com certos conjuntos de dados, solicitaram a utilização, mais tarde, da técnica B-spline (Jones et al., 1980).

- As formulações de Ramberg-Osgood (Ang e Morris, 1984) e de Richard (Richard et al., 1980) foram desenvolvidas para geometrias particulares de ligações e modelam a forma da curva relativamente bem.

- Um ajuste para as formulações pode ser obtido introduzindo fatores de correção adicionais sugeridos por Yee (1984).

- Se a necessidade da curva for para uma representação adequada em uma simulação computacional numérica, neste caso, indica-se a técnica Bspline ou a utilização de outro método com a posterior calibração da curva por meio de resultados experimentais.

As observações destacadas visam elucidar algumas das particularidades dos modelos. Vale lembrar que alguns dos modelos apresentados necessitam de um grande número de resultados experimentais para uma boa aproximação da curva.

Santos (1998) apresenta a fundamentação das diferentes possibilidades analíticas (linear, bi-linear, polinomial, b-spline, etc.) em se simular o comportamento das ligações. Funções semi-empíricas como a de Ramberg-Osgood (1991 apud CARVALHO, 2005, p.12) que apresentam boa representatividade são apresentadas no trabalho de Carvalho (2005).

Apesar dos muitos modelos propostos, as pesquisas mais recentes mostram que a melhor forma de simular o comportamento $M-\theta$ é a criação de modelos específicos para o tipo de ligação que se pretende analisar. Levando em consideração o fato de se tornar extremamente caro e impraticável armazenar em um programa de análise a relação $M-\theta$ de todos os tipos e geometria de ligações, Attiogbe e Morris (1991, p.1703) citam como solução, o armazenamento de uma única função M- $\theta$ 
parametrizada para cada tipo de ligação. A função seria então expressa em termos de parâmetros geométricos da ligação, sendo estas, as únicas variáveis nas expressões.

No início do século XXI foram propostos diversos modelos analíticos, específicos para cada tipo de ligação. Geralmente, os modelos são compostos de parâmetros dependentes da resistência, rigidez, ductilidade e geometria de uma dada ligação. Dentre as principais pesquisas, destacam-se a de Lee e Moon (2002), Pirmoz et al. (2009) e Mohamadi-Shore e Mofid (2011) dentre outras encontradas na literatura técnica.

\subsection{Classificação das ligações}

A análise estrutural, cotidianamente, efetuada por projetistas de estruturas fundamenta-se na idealização das ligações viga-pilar considerando-as como perfeitamente articuladas ou perfeitamente rígidas (LEE; MOON, 2002, p.227). Neste contexto, uma ligação é considerada perfeitamente articulada quando não possui mecanismos que sejam capazes de resistir ao momento fletor e, portanto, não geram restrição à rotação relativa entre os elementos conectados (figura 2.7a). Esta ligação é dimensionada apenas para resistir ao esforço cortante, sendo também denominada ligação simples ou flexível.

No outro extremo da idealização estão as chamadas ligações perfeitamente rígidas. Por uma simples analogia já se subentende que uma ligação classifica-se como perfeitamente rígida quando possui mecanismos capazes de resistir à totalidade do momento fletor e restringe completamente a rotação relativa entre os elementos ligados (figura 2.7b). 
Figura 2.7 - Ligação articulada e ligação rígida

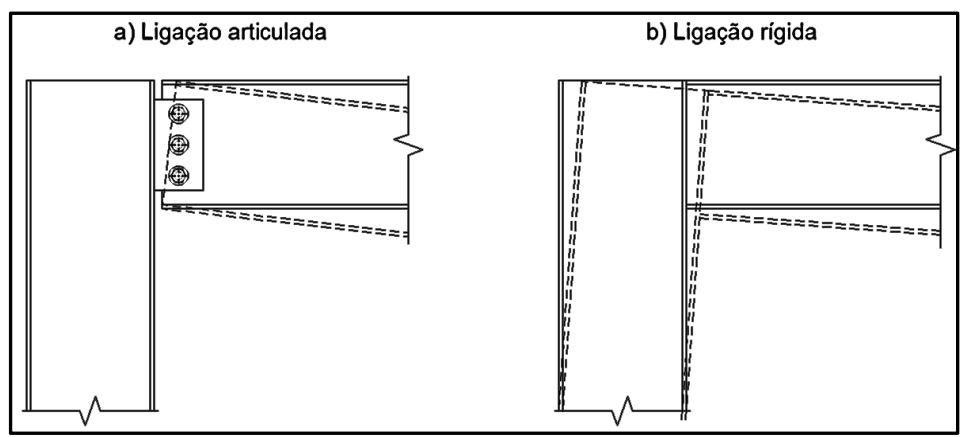

Fonte: Acervo pessoal

Entretanto, desde as pesquisas realizadas no início do século XX com Wilson \& Moore (1917, apud MAGGI, 2000, p.9) apontava-se a existência de uma classificação intermediária aos extremos demonstrados. Observou-se que a obtenção de ligações perfeitamente articuladas ou perfeitamente rígidas só seria possível em uma situação hipoteticamente ideal, distante do ponto de vista prático.

O surgimento do conceito de ligações semi-rígidas e a determinação de intervalos de classificação para as ligações (figura 2.8) tornou possível uma melhor adequação dos sistemas estruturais à realidade do comportamento.

Figura 2.8 - Ligações rígidas, semi-rígidas e flexíveis

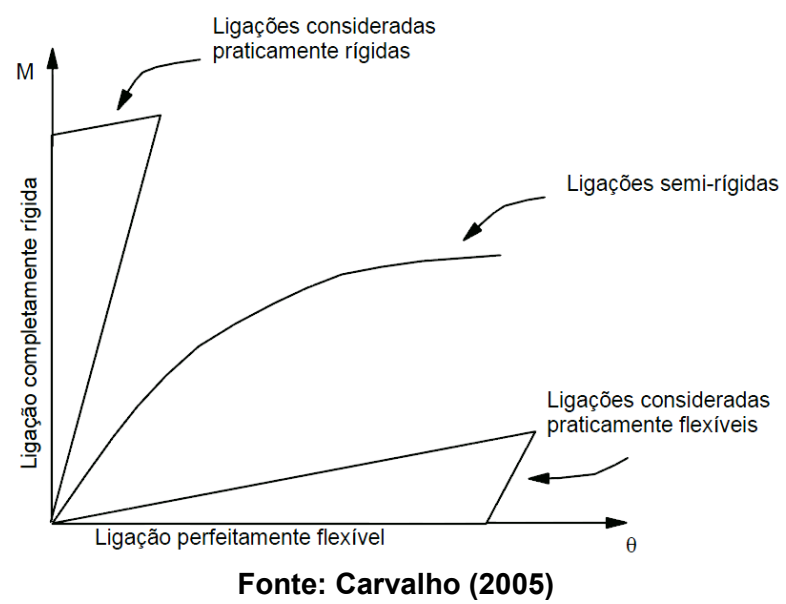

Apesar de uma concordância em relação à existência de uma classificação intermediária, ainda existe certa divergência entre os pesquisadores em relação aos critérios utilizados na classificação. Dentre os principais sistemas de classificação disponíveis na literatura destacam-se os propostos por Stark e Bijlaard (1988), por Bjorhovde, Colson e Brozzetti (1990), por Nethercot, Li e Ahmed (1998) e pelas 
principais normas internacionais, o Eurocode 3 Part 1-8 (2005) e o ANSI/AISC 360-10 (2010).

Em Ribeiro (1998) e Maggi (2000) apresentam-se alguns dos principais sistemas de classificação. Na sequência deste capítulo são demonstrados os critérios utilizados nos sistemas de classificação do Eurocode 3 Part 1-8 (2005) e do ANSI/AISC 360-10 (2010).

\subsubsection{Eurocode 3 Part 1-8 (2005)}

A classificação estabelecida no Eurocode 3 Part 1-8 (2005) parte do princípio da separação entre, a classificação da ligação segundo a rigidez e segundo a resistência. Portanto, quando da utilização da norma europeia, devem-se classificar as ligações conforme ambos os critérios.

\subsubsection{Classificação segundo a rigidez}

O critério de classificação segundo a rigidez baseia-se na rigidez rotacional inicial da ligação representada anteriormente pela sigla $\mathrm{K}_{\mathrm{i}}$, mas que na classificação do Eurocode 3 Part 1-8 (2005) é referenciada pela sigla $S_{\mathrm{j}, \text { ini. }}$ Conforme exposto no tópico referente ao comportamento momento-rotação, o valor de $\mathrm{S}_{\mathrm{j}, \text { ini }}$ pode ser obtido pela relação entre o momento aplicado $(\mathrm{M})$ e a respectiva rotação $(\theta)$ no trecho elástico-linear da curva M- $\theta$ da ligação.

No texto da norma europeia apresenta-se ainda outra metodologia para a obtenção do valor da rigidez rotacional inicial da ligação. Esta metodologia baseia-se no chamado "Método das Componentes" onde, segundo o tipo de ligação e os dispositivos envolvidos, é possível determinar analiticamente o valor de $\mathrm{S}_{\mathrm{j}, \mathrm{ini}}$ para alguns tipos específicos de ligação. 
Conforme apresentado no Eurocode 3 Part 1-8 (2005), após determinar-se o valor da rigidez rotacional inicial é possível classificar a ligação segundo a rigidez. Com base neste critério, a ligação pode ser classificada em articulada, rígida ou semirígida. A classificação é determinada comparando o valor de $\mathrm{S}_{\mathrm{j}, \text { ini }}$ da ligação com os valores apresentados a seguir:

a) $S e S_{j, \text { ini }} \leq 0,5 . E . I_{b} / L_{b}$ : Ligação articulada (zona 3 - figura 2.9).

b) $\operatorname{Se} S_{j, \text { ini }} \geq k_{b}$.E. $I_{b} / L_{b}$ : Ligação rígida (zona 1 - figura 2.9);

c) Todas as ligações situadas na zona 2 (figura 2.9) deverão ser classificadas como semi-rígidas. As ligações nas zonas 1 ou 3 poderão também, facultativamente, ser tratadas como semi-rígidas;

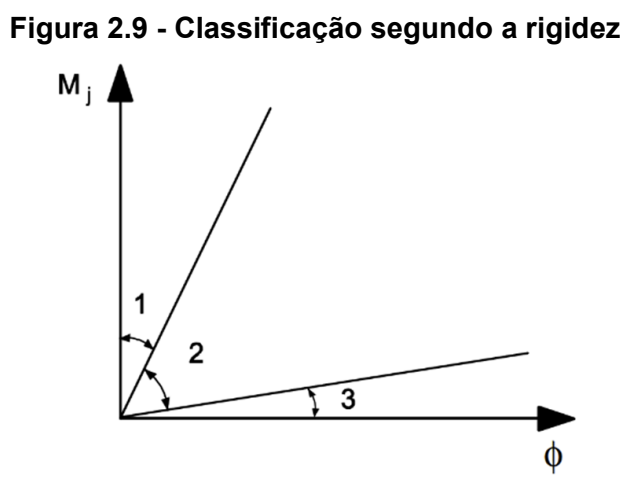

Fonte: Eurocode 3 Part 1-8 (2005)

As variáveis presentes nas expressões possuem os valores apresentados a seguir:

- $\mathrm{k}_{\mathrm{b}}=8$ para pórticos em que o sistema de contraventamento reduz $\mathrm{o}$ deslocamento horizontal em pelo menos $80 \%$;

- $k_{b}=25$ para outro pórticos, desde que em todos os pisos $K_{b} / K_{c} \geq 0,1^{(2)}$;

- $K_{b}$ é o valor médio de $I_{b} / L_{b}$ para todas as vigas (rigidamente ligadas) do nível acima do andar analisado;

- $K_{c}$ é o valor médio de $I_{c} / L_{c}$ para todos os pilares deste andar;

- l lb é o momento de inércia da seção transversal de uma viga;

- $I_{c}$ é o momento de inércia da seção transversal de um pilar;

- L L é o vão de uma viga medido entre os eixos dos pilares;

- $L_{c}$ é a altura do pilar relativa ao pé-direito do pavimento.

2 Para estruturas onde $\mathrm{K}_{b} / \mathrm{K}_{\mathrm{c}}<0,1$, as ligações deverão ser classificadas como semi-rígidas. 
É importante ressaltar que o Eurocode-3 Part 1-8 (2005) faz algumas considerações a respeito da classificação segundo a rigidez:

a) Ligações articuladas

Conforme o Eurocode 3 Part 1-8 (2005, p.54) uma ligação articulada "[...] deve ser capaz de transmitir os esforços internos, sem desenvolver momento fletor considerável que possa afetar negativamente os elementos ou a estrutura como um todo.". Além disso, a ligação deve ser capaz de absorver as rotações resultantes das solicitações externas.

b) Ligações rígidas

Admite-se que uma ligação rígida possui rigidez rotacional suficiente para justificar uma análise baseada em continuidade completa entre os elementos adjacentes à ligação.

c) Ligações semi-rígidas

Considera-se semi-rígida a ligação onde, não se atendam os critérios básicos de uma ligação rígida ou articulada. Este tipo de ligação também deve ser capaz de transmitir esforço cortante e de flexão.

\subsubsection{Classificação segundo a resistência}

De acordo com o Eurocode 3 Part 1-8 (2005, p.55) "[...] a classificação, segundo a resistência, é feita comparando o momento resistente de cálculo $\left(M_{\mathrm{j}, R d}\right)$ da ligação com o momento resistente de cálculo dos elementos adjacentes à ligação.". Seguindo este critério, a norma europeia classifica as ligações, segundo a resistência, em:

a) Articuladas

O Eurocode 3 Part 1-8 (2005, p.56) determina que:

[...] uma ligação deve ser classificada como articulada, segundo a resistência, caso, o momento resistente de cálculo da ligação $\left(\mathrm{M}_{\mathrm{j}, \mathrm{Rd}}\right)$ 
não seja superior à 0,25 vezes o momento resistente requerido para uma ligação completamente resistente, desde que, a ligação tenha também capacidade de rotação suficiente [...].

b) Resistência total

A resistência de cálculo de uma ligação com resistência total não deve ser inferior à resistência dos elementos ligados. Classifica-se como ligação com resistência total caso atenda-se aos seguintes critérios:

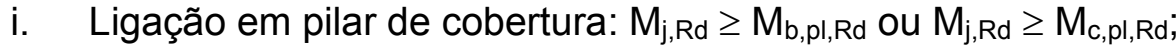

ii. $\quad$ Ligação em pilar de nível intermediário: $M_{j, R d} \geq M_{b, p l, R d}$ ou $M_{j, R d} \geq 2 . M_{c, p l, R d}$.

Onde:

- $\quad M_{j, R d}$ é o valor de cálculo do momento resistente da ligação;

- $\quad M_{b, p l, R d}$ é o valor de cálculo do momento resistente de plastificação de uma viga;

- $M_{c, p l, R d}$ é o valor de cálculo do momento resistente de plastificação de um pilar.

c) Resistência parcial

Com relação às ligações de resistência parcial, o Eurocode 3 Part 1-8 (2005) faz uma analogia às ligações semi-rígidas. Caso a ligação não atenda aos critérios, segundo a resistência, de uma ligação articulada ou de resistência total, esta deve ser classificada como ligação de resistência parcial.

\subsubsection{ANSI/AISC 360-10 (2010)}

Diferentemente da norma europeia, a norma americana parte da suposição de que conceitos de rigidez e resistência da ligação estão atrelados a uma mesma classificação. Considera-se que uma ligação que permite a rotação relativa considerável entre os elementos (viga e pilar), consequentemente não é capaz de absorver uma parcela considerável de momento fletor. Por outro lado, uma ligação que é capaz de restringir a rotação relativa, tornando-a praticamente desprezível, 
absorve uma parcela considerável do esforço de flexão. Partindo deste princípio a norma apresenta o seguinte sistema de classificação:

a) Ligações simples (Simple connections)

No texto do ANSI/AISC 360-10 (2010, p.12) definem-se ligações simples aquelas que "[...] transmitem uma parcela desprezível do momento fletor [...]" e que, portanto, em sua análise estrutural permite-se uma rotação relativa irrestrita entre os elementos conectados da estrutura. Uma ligação simples deve ter capacidade para acomodar a rotação requerida. A norma cita que estas ligações devem ser dimensionadas apenas para resistir ao esforço cortante proveniente das ações externas.

b) Ligações resistentes ao momento fletor (Moment connections)

A norma americana divide às ligações capazes de transmitir uma parcela considerável de momento fletor em dois tipos básicos:

i. Completamente restringidas (Fully restrained - FR)

[...] transmitem momento fletor com uma rotação desprezível entre os elementos ligados. Na análise da estrutura, a ligação deve ser considerada de forma a impedir qualquer rotação relativa. Uma ligação completamente restringida deve ter resistência e rigidez suficiente para manter o ângulo entre os elementos ligados [...]. (ANSI/AISC 36010, 2010, p.12).

ii. Parcialmente restringidas (Partially restrained - PR)

[...] transmitem momento fletor, mas, a rotação entre os elementos ligados não é desprezível. O comportamento de uma ligação parcialmente restringida deve ser obtido por meio de literatura técnica ou, estabelecido por meios analíticos ou experimentais. Os componentes da ligação devem ter resistência, rigidez e capacidade de deformação suficiente [...]. (ANSI/AISC 360-10, 2010, p.12).

As ligações resistentes ao momento fletor devem ser dimensionadas para resistir ao efeito combinado dos esforços resultantes do momento fletor e força cortante. 
- Limites de classificação

A norma americana apresenta os limites (figura 2.10) para a classificação da ligação segundo o comportamento momento-rotação.

Figura 2.10 - Classificação das ligações segundo o ANSI/AISC 360-10 (2010)

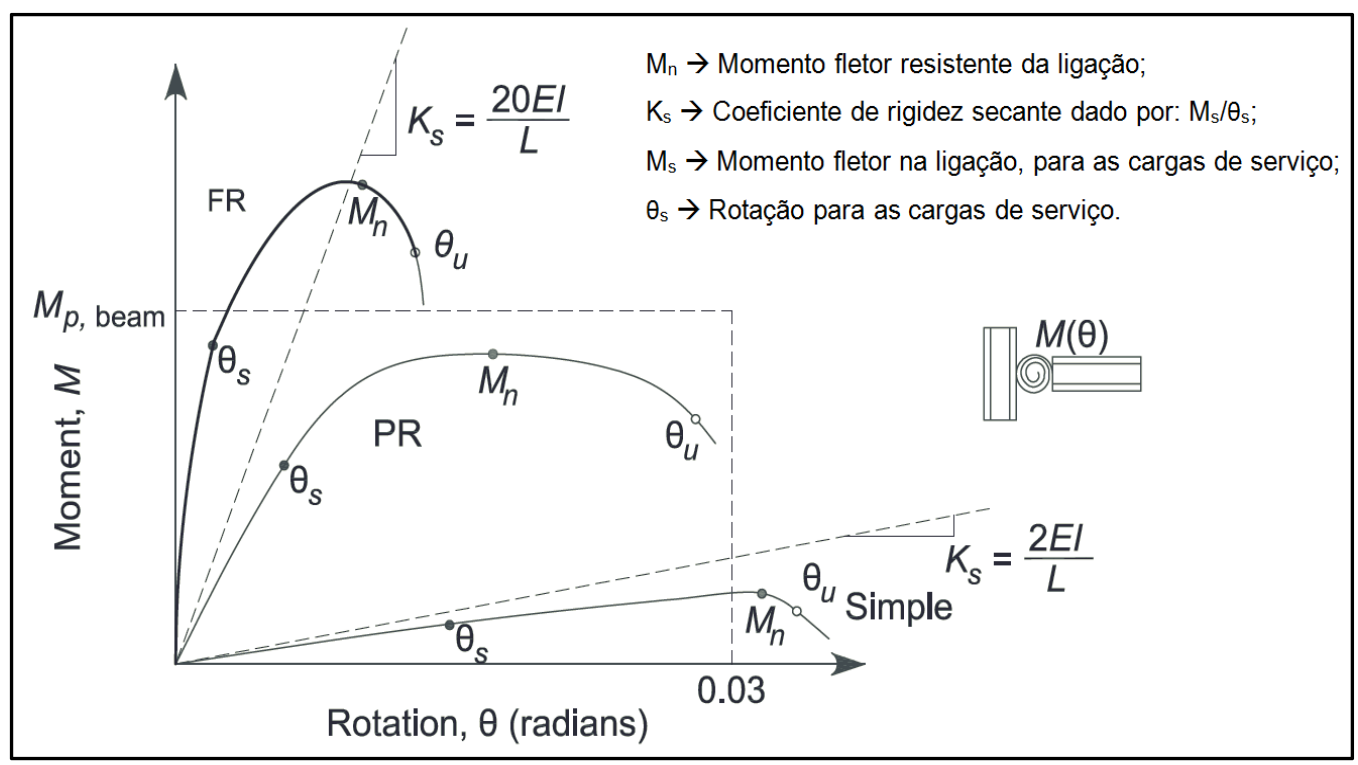

Fonte: ANSI/AISC 360-10 (2010)

Devido ao comportamento não linear da ligação o ANSI/AISC 360-10 (2010) cita que a rigidez inicial da ligação $\left(K_{i}\right)$ não caracteriza adequadamente a resposta da ligação em situação de serviço. Além disso, segundo a norma americana, diversos tipos de ligação não apresentam uma rigidez inicial confiável ou, estas existem apenas para uma faixa muito pequena da curva. Desta maneira, sugere-se a utilização da rigidez secante da ligação $\left(\mathrm{K}_{\mathrm{s}}\right)$ como um índice mais representativo do comportamento da ligação.

A rigidez secante da ligação $\left(K_{s}\right)$ é dada pela equação 2.1 onde, $M_{s}$ é o valor do momento fletor em estado de serviço e $\theta_{\mathrm{s}}$ a respectiva rotação quando da atuação do momento fletor $M_{s}$. Por sua vez, L e El são, respectivamente, o comprimento e a rigidez à flexão da viga.

$$
K_{s}=\frac{M_{s}}{\theta_{s}}
$$

Como recomendação, o ANSI/AISC 360-10 (2010) cita que em várias situações não é necessário incluir os dispositivos de ligação como parte da análise do 
sistema estrutural. Por exemplo, no caso de ligações simples e completamente restringidas pode-se idealizá-las, respectivamente, como articulação perfeita e engaste perfeito para fins de análise estrutural, porém, realizada a análise, as deformações e esforços constatados no nó devem ser utilizados para efetuar a verificação dos dispositivos de ligação.

Em outros casos, a deformação dos elementos da ligação afeta o comportamento da estrutura quando carregada e, neste caso, as ligações devem ser incluídas na análise do sistema estrutural. Este é o caso das ligações ditas parcialmente restringidas onde, a deformabilidade da ligação deve ser estimada e incluída na análise estrutural.

\subsubsection{Comentários}

Uma breve comparação entre as propostas de classificação do Eurocode 3 Part 1-8 (2005) e do ANSI/AISC 360-10 (2010) permite verificar alguns pontos fundamentais que diferem, consideravelmente, estes sistemas de classificação entre si.

Inicialmente, nota-se que a norma europeia realiza a separação dos critérios de rigidez e resistência. A classificação segundo a rigidez baseia-se no coeficiente de rigidez inicial da ligação, enquanto que, a classificação segundo a resistência baseiase no momento fletor resistente da ligação. Por outro lado, a norma americana procura unir os dois conceitos citados em um único critério de classificação, onde o embasamento está no coeficiente de rigidez secante da ligação e na rigidez à flexão da viga.

Apesar do Eurocode 3 Part 1-8 (2005) apresentar classificações separadas quanto à rigidez e quanto a resistência, o texto da norma europeia cita que a determinação de uma classificação para a utilização na análise estrutural deve incorporar os dois conceitos. Uma classificação só deve ser idealizada como articulação perfeita caso atenda aos requisitos de ligação articulada quanto à rigidez e quanto à resistência. No outro extremo, a idealização como engaste perfeito parte 
da premissa de que a ligação classifica-se como rígida (segundo a rigidez) e resistência total (segundo a resistência).

Outro ponto de destaque diz respeito ao coeficiente de rigidez considerado nos sistemas de classificação. Na classificação do Eurocode 3 Part 1-8 (2005) adotase a rigidez inicial da ligação, enquanto que, na norma americana, a rigidez secante é o principal parâmetro para a classificação das ligações. Conforme exposto no texto do ANSI/AISC 360-10 (2010), devido ao comportamento não linear da ligação, a rigidez inicial da ligação, em geral, não é uma variável representativa do comportamento da ligação.

Em alguns pontos importantes dos sistemas de classificação apresentados, as normas americana e europeia são coniventes quanto às considerações, sendo que, dentre as considerações apresentadas é de interesse destacar que:

- A classificação de uma ligação como rígida, semi-rígida ou articulada exige que a ligação atenda requisitos de rigidez e resistência compatíveis com as premissas da classificação;

- Em função da deformabilidade das ligações classificadas no intervalo de semi-rigidez, apenas nos casos em que a classificação das ligações esteja em um dos dois extremos, as mesmas podem ser idealizadas (na análise estrutural) como articulação ou engaste perfeito, conforme o caso.

Apesar da maioria das ligações utilizadas nas estruturas de aço, na realidade, apresentarem comportamento semi-rígido (CHEN; LUI, 2005), ainda existe certa divergência em relação aos limites de classificação. Normas consideradas referências mundiais apresentam conceituação distintas quanto à uma mesma atribuição. Ao longo dos anos, diversos pesquisadores, como Christopher e Bjorhovde (1999), vêm estudando formas de tornar a classificação das ligações o mais prática possível, de forma a serem incorporadas no dia-a-dia dos projetos estruturais, entretanto, ainda há a necessidade de um grande avanço nas pesquisas para simular de forma prática e eficaz o comportamento da ligação classificada como semi-rígida. 


\subsection{Modos de falha das ligações entre viga de seção I e pilar CHS}

As ligações apresentam aspectos localizados que atingido o limite de resistência gera um modo de falha particular. Em teoria, alguns modos são predominantes conforme a natureza das solicitações e as características de cada ligação. Há a possibilidade de ocorrer alguma falha distinta daquela inicialmente esperada e, portanto, passa a ser necessário o conhecimento dos possíveis modos de falha que uma ligação viga-pilar ${ }^{3}$ está sujeita.

Alguns autores procuraram elencar e ilustrar os possíveis modos de falha das ligações envolvendo seções tubulares. Com relação às considerações normativas, o Eurocode 3 Part 1-8 (2005) cita que a resistência de cálculo das ligações viga-pilar, envolvendo pilar tubular e viga de seção aberta, pode ser baseada nos seguintes modos de falha, quando aplicáveis:

a) Plastificação da face ou seção do pilar;

b) Plastificação, amassamento ou instabilidade da face lateral da seção do pilar sob efeito da compressão da viga;

c) Plastificação ou instabilidade por cisalhamento do pilar junto à viga;

d) Ruptura por punção da face do pilar na região tracionada (início de fissuração levando à ruptura na região da ligação viga-pilar);

e) Ruptura ou plastificação na região da solda ou flambagem localizada da viga devido à distribuição não uniforme de tensão;

f) Flambagem local da mesa comprimida da viga ou do pilar na região da ligação.

Em Wardenier et al. (2010), o autor identifica os modos de falha seguindo a transferência de esforços pela ligação. Desta forma verificam-se os seguintes modos de falha:

a) Plastificação ou flambagem local da mesa da viga (figura 2.11);

b) Falha da solda (figura 2.12);

${ }^{3}$ Ligação entre viga de seção I e pilar de seção tubular circular. 

c) Cisalhamento lamelar (figura 2.13);
d) Cisalhamento da face do pilar na região tracionada (figura 2.14);
e) Flambagem local do pilar (figura 2.15);
f) Cisalhamento do pilar (figura 2.16);
g) Plastificação da face ou seção transversal do pilar (figura 2.17).

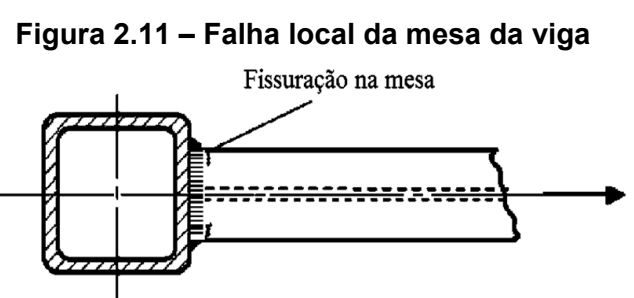

Fonte: Wardenier et al. (2010)

Figura 2.13 - Cisalhamento lamelar

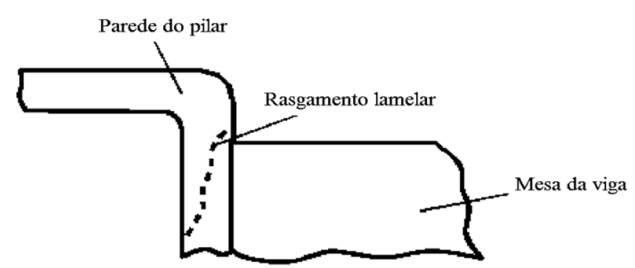

Fonte: Wardenier et al. (2010)

Figura 2.15 - Flambagem local do pilar

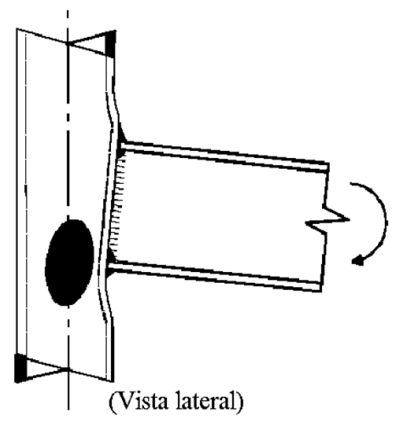

Fonte: Wardenier et al. (2010)
Figura 2.12 - Falha da solda

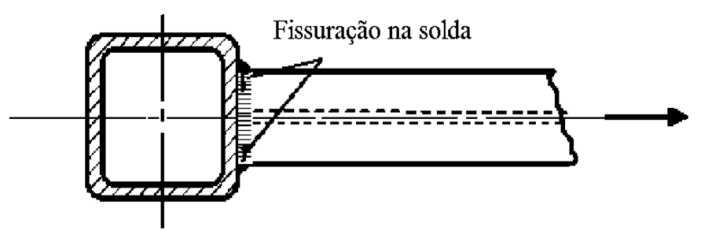

Fonte: Wardenier et al. (2010)

Figura 2.14 - Cisalhamento da face do pilar

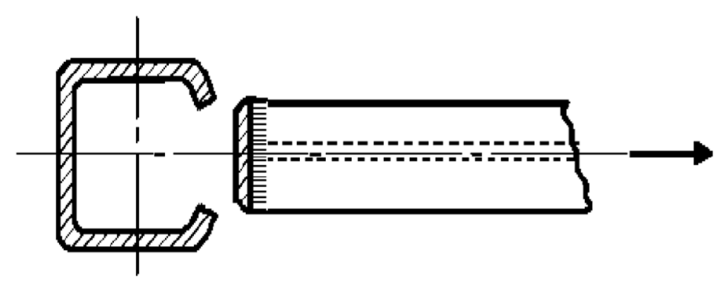

Fonte: Wardenier et al. (2010)

Figura 2.16 - Falha por cisalhamento do pilar

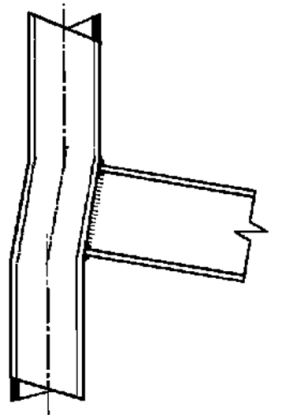

Fonte: Wardenier et al. (2010)

Figura 2.17 - Plastificação da face ou seção transversal do pilar
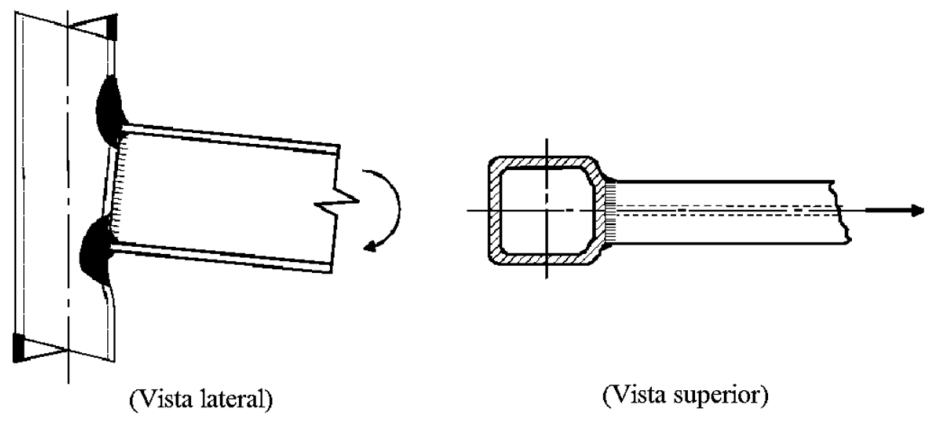

Fonte: Wardenier et al. (2010) 
Apesar das ilustrações apresentadas em Wardenier (2010) descreverem os modos de falha para situações com pilar de seção retangular, é possível fazer uma analogia com o pilar de seção circular, pois, os modos de falha predominantes são muito semelhantes entre si. O autor lembra que alguns dos modos identificados podem ser evitados com as seguintes providências:

- Realizar as soldas com resistência superior à da viga ligada, por exemplo, utilizando filetes duplos. Esta providência evita a consideração do modo de falha da solda;

- Escolha de um material com qualidade adequada, de forma a não ser susceptível ao rasgamento lamelar. Evita-se assim a consideração do modo de falha por rasgamento lamelar;

- Limitação da relação diâmetro-espessura de forma a evitar a consideração do modo de falha por flambagem local do pilar.

Desta forma, o autor limita-se à consideração de quatro modos de falha no dimensionamento:

a) Plastificação ou flambagem local da mesa da viga;

b) Cisalhamento da face do pilar na região tracionada;

c) Cisalhamento do pilar;

d) Plastificação da face ou seção transversal do pilar.

Nos modos de falha descritos pelo Eurocode 3 Part 1-8 (2005) e em Wardenier (2010) deve-se notar que estes estão descritos exclusivamente para a avaliação de ligações soldadas. Em ligações com a presença de dispositivos auxiliares (chapas e parafusos) recomenda-se a avaliação dos respectivos modos de falha, de modo a contemplar todas as situações críticas.

Em Freitas (2009), apresenta-se uma tabela onde são demonstradas as situações a serem verificadas segundo o tipo de ligação. Desta forma, fica ilustrada a avaliação individual dos modos de falha para cada situação. A seguir, apresenta-se o quadro 2.2 descrito no texto do autor, a fim de melhor ilustrar as possibilidades de falha. 
Quadro 2.2 - Verificação da resistência dos componentes em ligações viga-pilar

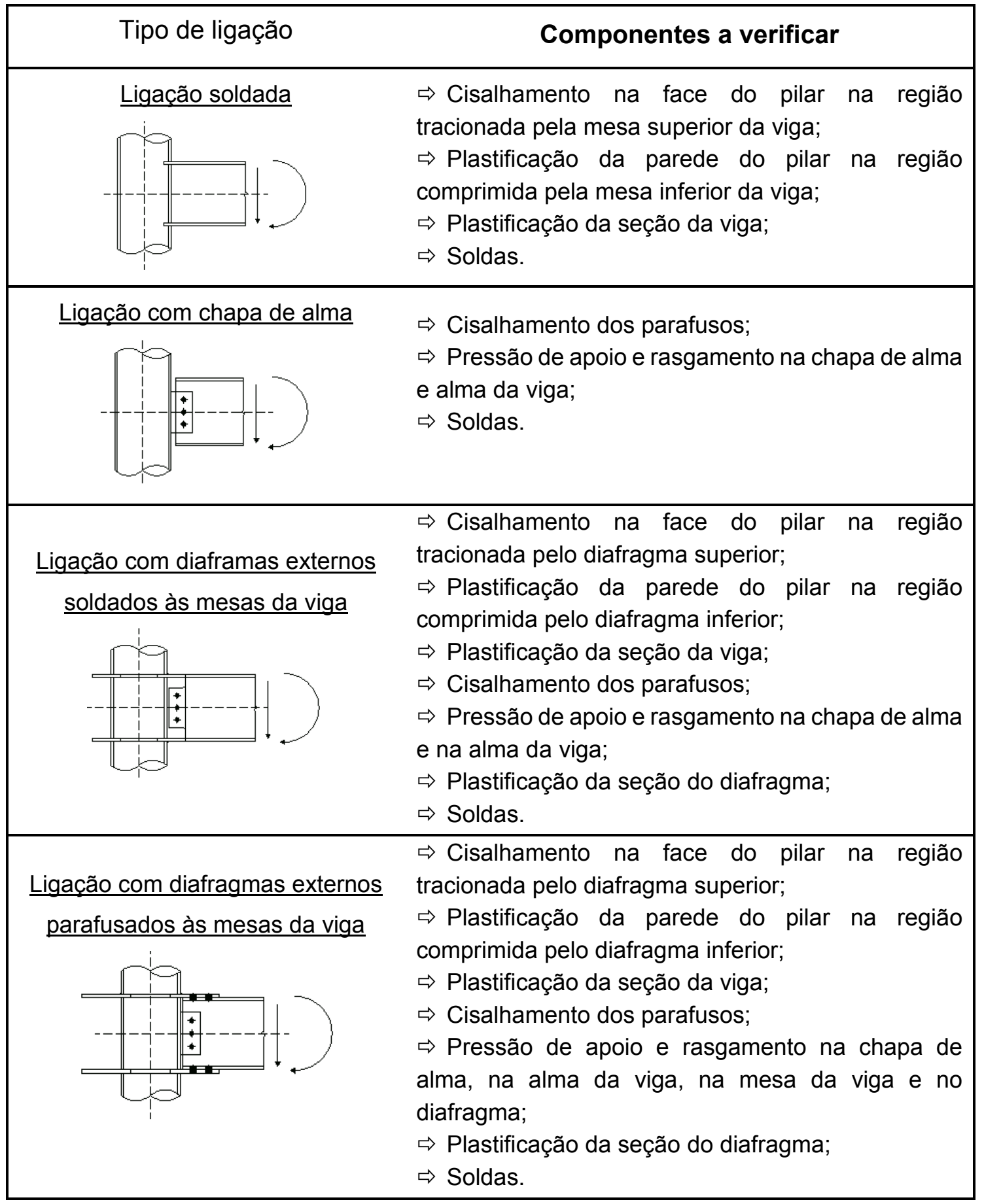

Fonte: Freitas (2009)

Os modos de falha apresentados não devem ser entendidos como possibilidades únicas e sim, gerais. O entendimento e avaliação de qual, ou quais, modos serão predominantes deve ficar a critério do profissional com conhecimento técnico adequado. Para cada tipologia de ligação, a tendência é haver modos predominantes particulares. 


\subsection{Mecanismos para o enrijecimento de ligações entre viga I e pilar CHS}

Em ligações viga-pilar com a presença de seção tubular é extremamente complicado conter, com perfeição, a deformação local da face do pilar devido à força transversal exercida pelas mesas da viga. Packer e Henderson (1997, p.313) reforçam esta constatação lembrando que "[...] as ligações resistentes ao momento fletor em pilares de seção tubular não enrijecidos, têm comportamento semi-rígido e o momento resistente utilizado no dimensionamento é limitado pelo momento de plastificação devido ao carregamento na face do pilar[...]".

Entretanto, em alguns países como o Japão, a presença frequente de sismos recai na necessidade da utilização de ligações com alto grau de enrijecimento. A maioria das ligações estudadas naquele país utilizam-se de dispositivos que visam aumentar a capacidade de absorver momento fletor sem a ocorrência de uma rotação relativa considerável.

Dentre outras formas, as mais comuns para proporcionar o enrijecimento da face do pilar, segundo Kamba e Kanatani (1993) são:

a) Preenchimento do pilar com concreto (armado ou não);

b) Utilização de chapa de reforço na face do pilar;

c) Aumento da espessura da parede do pilar;

d) Promover a continuidade da viga pelo pilar com seção interrompida;

e) Utilização de diafragma soldado junto ao pilar, no nível das mesas da viga (diafragmas passantes ${ }^{4}$ );

f) Aumento da largura das mesas na extremidade da viga ou, a fixação de uma chapa ao redor do pilar ligando as mesas da viga (diafragmas externos).

O preenchimento do pilar com concreto (figura 2.18), a utilização de chapa de reforço na face do pilar (figura 2.19) e o aumento da espessura da parede do pilar são soluções que aumentam a resistência à plastificação do pilar, contudo, segundo

${ }^{4}$ Do termo, em inglês, through diaphragms. 
Kamba e Kanatani (1993) não impedem (quando aplicadas isoladamente) a deformação local a ponto de tornar a ligação completamente rígida.

Figura 2.18 - Pilar tubular preenchido

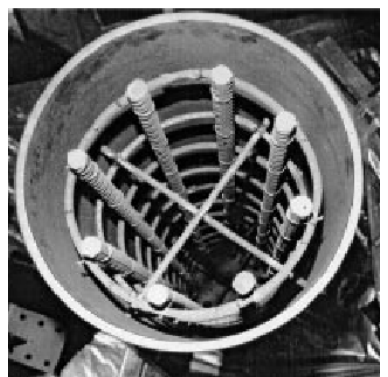

Fonte: Winkel (1998)
Figura 2.19 - Pilar tubular com reforço

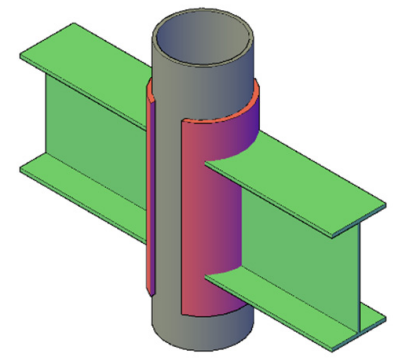

Fonte: Acervo pessoal

Promover a continuidade da viga por meio da interrupção da seção do pilar pela própria viga é uma forma de enrijecimento que, geralmente, apresenta-se eficaz. As vigas atravessam o pilar por cortes feitos a laser. A viga principal atravessa o pilar de um lado ao outro sem interrupção. A viga secundária, geralmente, não é contínua devido à presença da outra viga, neste caso, a ligação entre a viga secundária e o pilar comporta-se como uma ligação articulada, com continuidade apenas do esforço cortante (figura 2.20 e figura 2.21).

Figura 2.20 - Ligação enrijecida por meio da continuidade das vigas pelo pilar

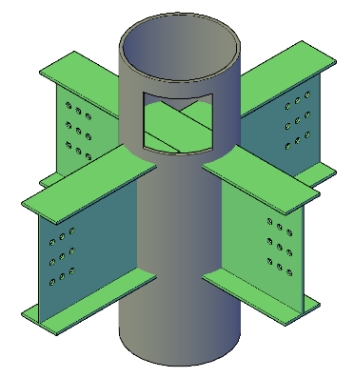

Fonte: Acervo pessoal
Figura 2.21 - Vista superior da ligação apresentada na figura $\mathbf{2 . 2 0}$

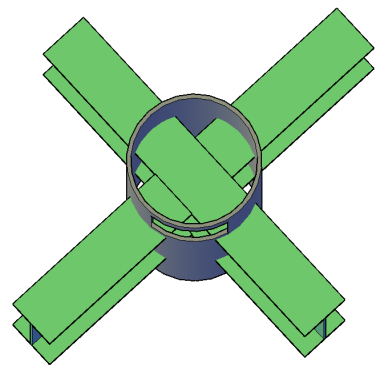

Fonte: Acervo pessoal

Ressalta-se que a ligação da alma da viga secundária com a alma da viga primária deve ser detalhada e executada cuidadosamente. Porém, nem sempre o acesso a esta região é fácil, tornando esta ligação bastante trabalhosa. Uma opção é executar a ligação da viga secundária à face do pilar por meio de chapa de alma já que não há continuidade de momento fletor.

Quando desejável, é possível dar continuidade ao momento fletor da viga secundária. Uma forma de se fazer isso é por meio de chapas adicionais passando por dentro do pilar e soldadas (ou parafusadas) às mesas das vigas. Outra vez, a falta 
de acesso ao interior do tubo é uma tarefa que pode dificultar a execução deste tipo de ligação.

O enrijecimento por meio de diafragmas passantes (through diaphragms) consiste na interrupção completa da seção do pilar em dois níveis, por meio da inserção de duas chapas transversais (figura 2.22 e figura 2.23). As chapas transversais, por sua vez, podem ser parafusadas ou soldadas às mesas da viga.

Figura 2.22 - Ligação viga-pilar por meio de diafragma passante (I/II)

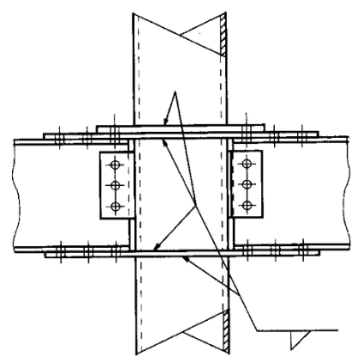

Fonte: Packer e Henderson (1997)

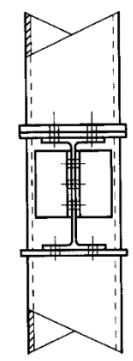

Figura 2.23 - Ligação viga-pilar por meio de diafragma passante (II/II)

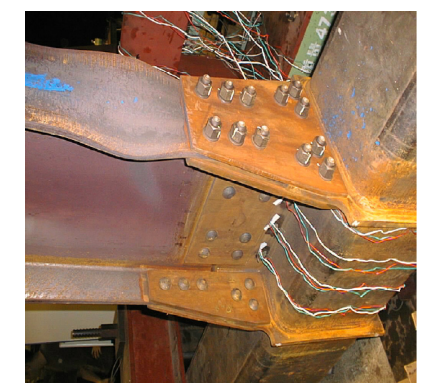

Fonte: Wardenier et al. (2010)

O aumento da largura das mesas na extremidade da viga pode ser feito por meio de enrijecedores em forma de "T" (figura 2.24). No caso de pilar retangular os esforços da mesa são transferidos diretamente para as paredes laterais. No caso da seção circular esta tarefa se torna mais dispendiosa visto a necessidade de se cortar as mesas da seção "T" no formato da face do pilar, além disso, a transferência de esforços para as paredes não é tão direta quanto em um pilar de seção retangular.

Figura 2.24 - Enrijecimento por meio de seções T soldadas às mesas das vigas

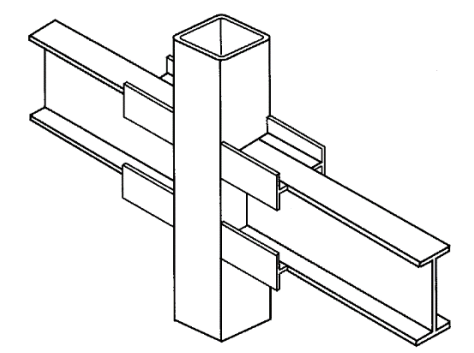

Fonte: Packer e Henderson (1997)

Apesar das várias alternativas apresentadas, o diafragma externo é a maneira mais simples de enrijecer a ligação entre viga I e pilar tubular circular (KAMBA; KANATANI, 1993, p.255). 
Inicialmente estudado por Kato et al. (1981, apud PACKER; HENDERSON, 1997, p.317), este tipo de ligação consiste em envolver uma chapa ao redor do pilar em contato com cada uma das mesas das vigas conectadas. A ligação das vigas ao diafragma pode ser feita por duas maneiras básicas:

a) Soldar ou parafusar a mesa da viga em contato com o diafragma e ligar, por meio de chapa de alma, a alma da viga à face do pilar (figura 2.25 e figura 2.26);

Figura 2.25 - Ligação por meio de diafragma
externo soldado às mesas das vigas

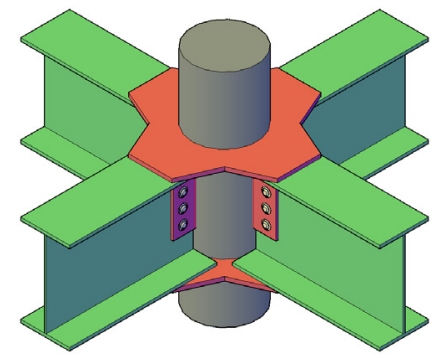

Fonte: Acervo pessoal
Figura 2.26 - Ligação com diafragma externo parafusado às mesas das vigas

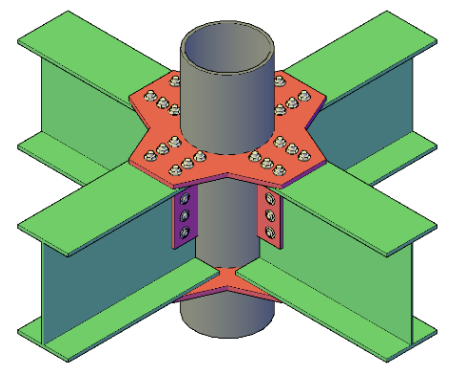

Fonte: Acervo pessoal

b) Soldar ou parafusar a mesa da viga em contato com o diafragma. Utilizar uma chapa transversal soldada, ligando o diafragma superior ao inferior, simulando a alma da viga. Por fim, por meio de chapa de alma, ligar a alma da viga à chapa transversal (figura 2.27 e figura 2.28).

Figura 2.27 - Ligação por diafragma externo soldado (I/II)

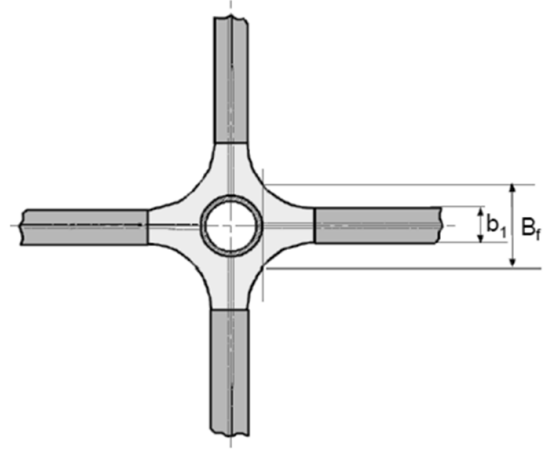

Fonte: Wardenier et al. (2010)
Figura 2.28 - Ligação por diafragma externo soldado (II/II)

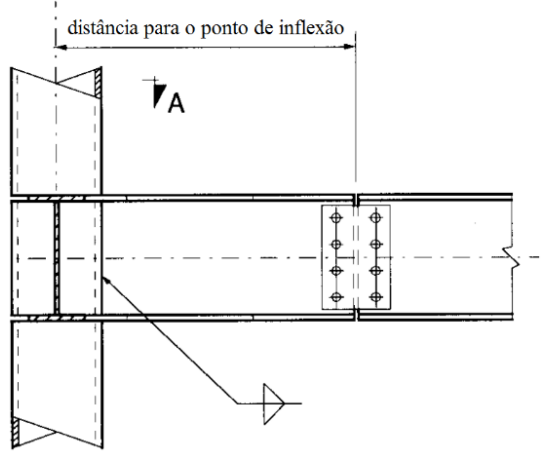

Fonte: Packer e Henderson (1997)

A ligação com o diafragma externo tende a proporcionar um enrijecimento na ligação por meio de um alívio das tensões no pilar, uma vez que, a rigidez do diafragma passa a ser incorporada à rigidez transversal da parede do pilar circular. 
Com relação às formas e geometrias dos diafragmas externos, existem diversas variações que podem ser empregadas. Contudo, deve-se atentar que as ligações com diafragmas externos podem sofrer falha pela fissuração que se inicia nos cantos reentrantes do diafragma ou, na ligação soldada entre o diafragma e a mesa da viga. Portanto, devem-se evitar estes pontos de concentração de tensões (figura 2.29), por meio de cantos mais suaves na composição geométrica conforme demonstrado na figura 2.30 .

Figura 2.29 - Geometrias de diafragmas externos com pontos propícios à concentração de tensões
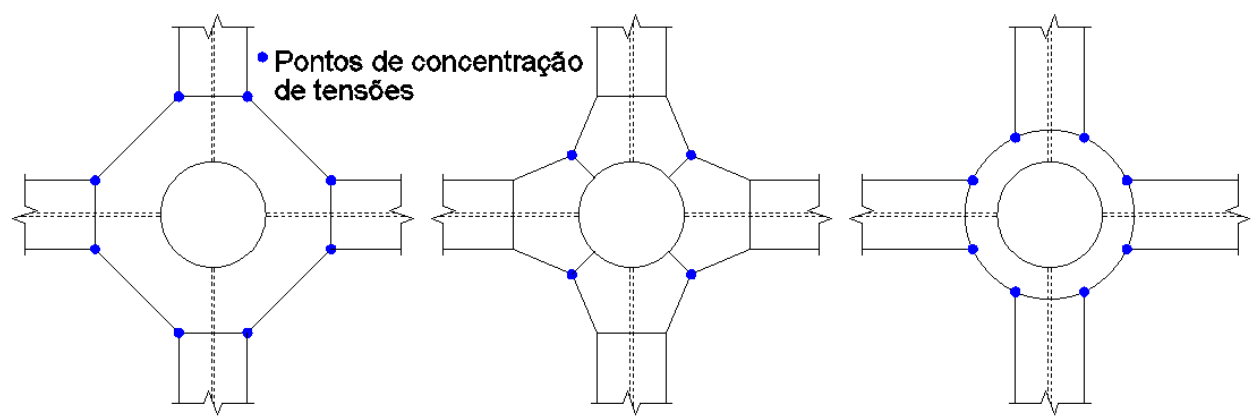

Fonte: Acervo pessoal

Figura 2.30 - Geometrias de diafragmas externos com cantos mais suaves

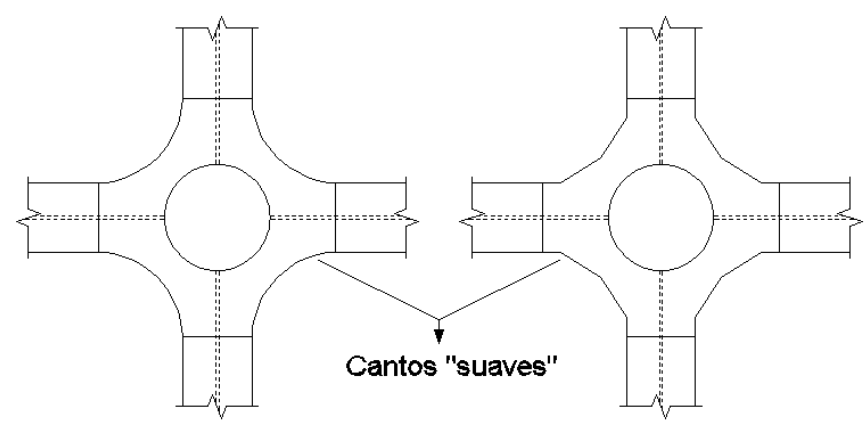

Fonte: Acervo pessoal

Ligações com diafragmas externos foram estudadas em países da Europa e Ásia, sobretudo, no Japão. A universidade de Kobe e o Instituto de Arquitetura do Japão $\left(A \mid J^{5}\right)$ representam os principais órgãos de referência nesta área. Os estudos de Kamba et al. (1983) e de Tabuchi et al. (1985, apud KUROBANE et al., 2004, p.134) foram os primeiros a apresentarem formulações analíticas para o dimensionamento deste tipo de ligação.

${ }^{5}$ Do termo, em inglês, Architectural Institute of Japan. 


\subsection{Histórico das pesquisas de ligações entre viga de seção I e pilar CHS}

O histórico das pesquisas permite uma visão mais ampla do assunto de modo a entender a cronologia dos fatos e das constatações dos pesquisadores ao longo dos anos. Um aceno histórico sobre ligações envolvendo seções tubulares pode ser visto, de forma geral, na pesquisa de Freitas (2009) onde, o mesmo faz uma recapitulação da evolução nas pesquisas em ligações com perfis tubulares desde os primeiros relatos, ainda em meados de 1950 com Stewarts \& Lloyd (1952, apud FREITAS, 2009, p.28).

Uma observação mais atual remete ao ano de 2005, quando o AISC incorporou ao Specification for Structural Steel Buildings a seção K, específica para as ligações envolvendo seções tubulares. No ano de 2010, o mesmo instituto lançou o $24^{\circ}$ guia de dimensionamento da série Steel Design Guide. Esta publicação levou o título de Hollow Structural Section Connections, sendo este um guia de dimensionamento específico para ligações em estruturas metálicas tubulares.

Apesar de algumas importantes referências no assunto, o estudo de ligações entre viga de seção I e pilar CHS ainda é pouco disseminado e a quantidade de publicações nesta área ainda é, relativamente, reduzida.

Nesta pesquisa, apresenta-se uma abordagem histórica especifica aos estudos de ligações entre viga de seção I e pilar de seção tubular circular, excluindose pesquisas relacionadas a ligações em barras de treliça por exemplo. Não são mencionadas as pesquisas com cunho exclusivo à situação de pilar preenchido com concreto ou estrutura em situação de incêndio.

Destacam-se, sobretudo, as pesquisas cujos resultados experimentais serão utilizados na comparação com modelos numéricos, como os de Winkel (1998), Masioli (2011) e Reis (2011). O quadro 2.3 apresenta um breve resumo das pesquisas recentes realizadas, bem como as respectivas particularidades e metodologias adotadas, além dos resultados obtidos e as conclusões destacadas pelos autores. 
Quadro 2.3 - Histórico recente das pesquisas de ligações entre viga I e pilar circular

\section{KAMBA et al. (1982)}

Investigaram, experimentalmente, a falha local de ligações entre viga I e pilar tubular circular, enrijecidas com anéis. Avaliaram o modo de falha das ligações causada pela força normal aplicada pela mesa da viga.

Estudaram a influência da relação diâmetroespessura do pilar e as dimensões e a forma dos enrijecedores e mesas da viga. Avaliaram 29 modelos experimentais simplificados (figura 2.31). A pesquisa tornou mais claro o efeito dos parâmetros geométricos na resistência da ligação e teve como objetivo fornecer resultados para uma futura formulação empírica visando estimar a resistência das ligações.

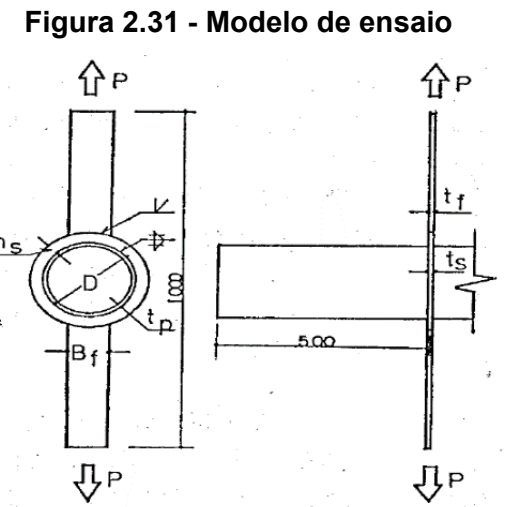

Fonte: Kamba et al. (1982)

\section{KAMBA et al. (1983)}

Dando continuidade aos trabalhos de Kamba et al. (1982) desenvolveram uma formulação empírica (figura 2.32) baseada em parâmetros geométricos (figura 2.33) para prever a resistência local de ligações entre viga I e pilar tubular circular enrijecidas com anéis. Basearam-se nos resultados experimentais de Kamba et al. (1982) e as expressões foram desenvolvidas por meio de análise paramétrica.

Figura 2.32 - Expressão para obtenção da resistência máxima da ligação $\frac{P_{c, \text { máx }}}{\sigma_{y} \cdot R^{2}}=\left(3,81 \cdot \frac{B_{f}}{D}+1,72\right) \cdot\left(\frac{t_{p}}{R}\right)^{0,782} \cdot\left(\frac{t_{s}}{R}\right)^{0,564} \cdot\left(\frac{t_{p}+h_{s}}{R}\right)^{0,386}$

Fonte: Kamba et al. (1983)

Figura 2.33 - Parâmetros geométricos

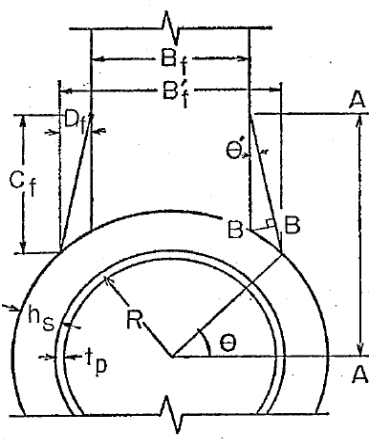

Fonte: Kamba et al. (1983) 
Quadro 2.3 - Histórico recente das pesquisas de ligações entre viga I e pilar circular

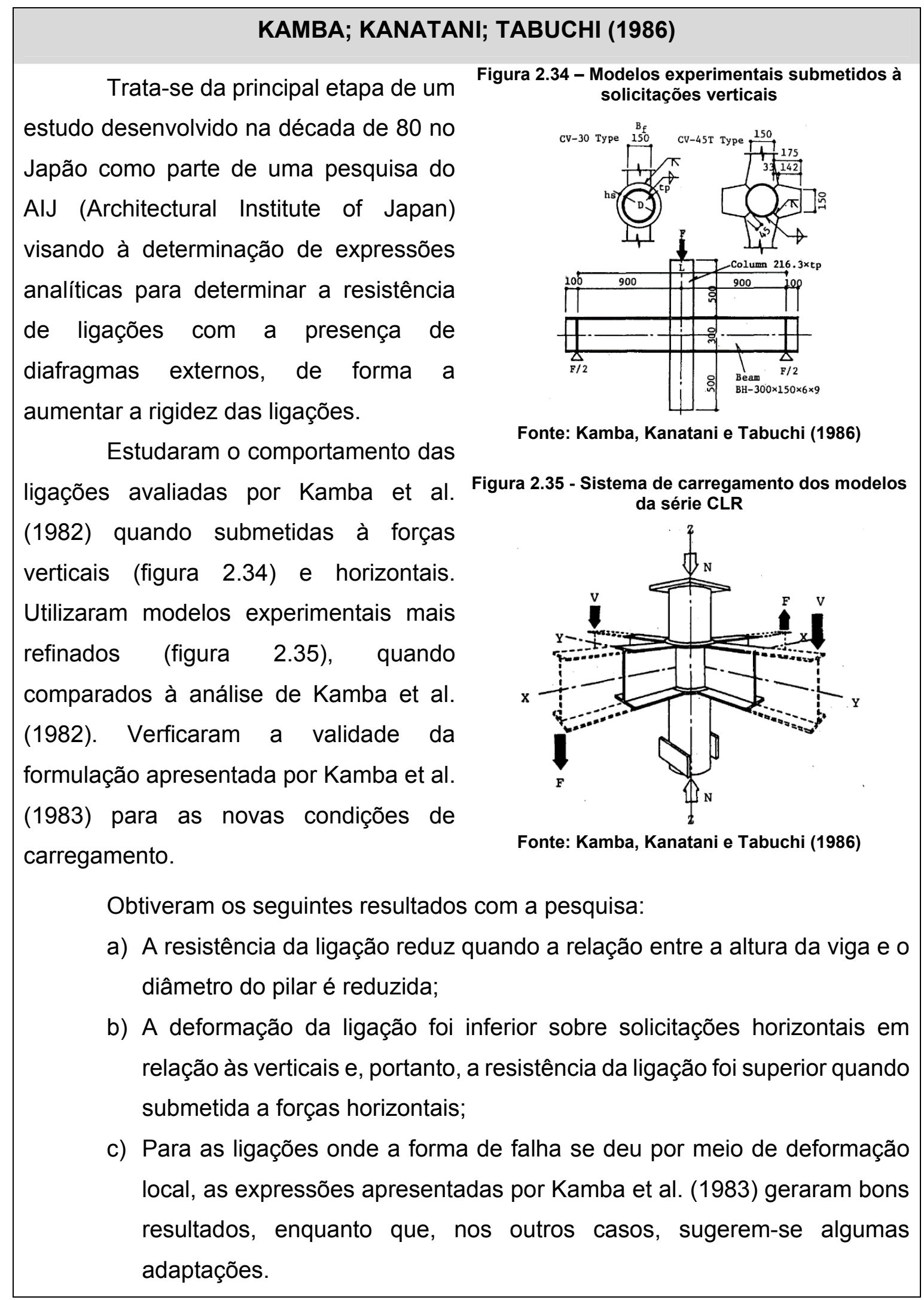


Quadro 2.3 - Histórico recente das pesquisas de ligações entre viga I e pilar circular

\section{WINKEL et al. (1993)}

Relataram o comportamento e a resistência estática de ligações do tipo XX entre viga I e pilar circular carregados por forças na mesma direção. Basearam-se em simulações numéricas que foram, experimentalmente, verificadas. A análise numérica considerou a não linearidade geométrica e do material. Os resultados numéricos apresentaram boa representatividade frente aos experimentais. Com o modelo calibrado, foram analisados casos adicionais de carregamento para investigar a influência das diferentes situações de carregamento na resistência e rigidez das ligações. Os resultados da pesquisa visavam uma futura análise paramétrica.

\section{WINKEL; WARDENIER (1996)}

Descreveram o comportamento e a resistência estática de ligações entre viga I e pilar circular carregados por forças na mesma direção e um pré-carregamento do pilar. Foi realizada uma investigação paramétrica dos mais importantes parâmetros geométricos. Analisaram 24 ligações de pilar central (tipo XX) utilizando análise via elementos finitos considerando a não linearidade geométrica e do material. Determinaram uma expressão que descreve a influência do pré-carregamento utilizando os resultados da análise numérica.

\section{KAMBA; NAMBA; ETOU (1998)}

Investigaram o comportamento elasto-plástico da ligação entre viga I e pilar circular, aumentando a espessura do pilar gradativamente. Realizaram testes experimentais com carregamento vertical e horizontal, além de, uma simulação numérica, via M.E.F. Os resultados demonstraram que é possível restringir a deformação local do pilar apenas aumentando a espessura do pilar, sem a utilização de diafragmas. 
Quadro 2.3 - Histórico recente das pesquisas de ligações entre viga I e pilar circular

\begin{tabular}{|c|}
\hline WINKEL (1998) \\
\hline $\begin{array}{l}\text { Apresentou uma das mais extensas pesquisas na área de ligações entre viga } \\
\text { de seção I e pilar de seção tubular circular até o momento. } \\
\text { Realizou uma revisão bibliográfica } \\
\text { das pesquira } 2.36 \text { - Modelo experimental com } 4 \text { vigas } \\
\text { então, citando o Japão como o maior } \\
\text { representante nesta área. Investigou de } \\
\text { forma numérica e experimental ligações } \\
\text { multiplanares do tipo XX (figura 2.36) } \\
\text { avaliando os seguintes aspectos: }\end{array}$ \\
\hline $\begin{array}{l}\text { a) Comportamento da ligação entre pilar de seção tubular circular e chapa } \\
\text { longitudinal representando apenas as mesas inferiores das vigas; } \\
\text { b) Comportamento da ligação entre viga de seção I e pilar de seção tubular } \\
\text { circular; } \\
\text { - Efeito da geometria com a ligação viga-pilar em vários planos; } \\
\text { - Efeito da força aplicada em vários planos; } \\
\text { c) Efeito da laje em steel deck sem a capa de concreto (estrutura offshore); } \\
\text { d) Efeito da laje mista com o uso de steel deck; } \\
\text { e) Influência do preenchimento dos pilares para as diferentes condições de } \\
\text { carregamento; } \\
\text { f) Influência na capacidade resistente ao momento fletor devido à força } \\
\text { aplicado diretamente no pilar. } \\
\text { A análise numérica via elementos finitos foi feita com o software SDRC- } \\
\text { IDEAS Level V. Os modelos foram divididos em } 4 \text { grupos } 6 \text {. O principal objetivo da } \\
\text { análise experimental foi gerar resultados para serem utilizados na calibração dos } \\
\text { modelos numéricos. Optou por não variar a geometria da seção transversal das vigas } \\
\text { (IPE } 240-1200 \text { ) e do pilar ( } \$ 324 X 9,5 \text { ). Os modelos do grupo } 3 \text { consistem de ligações } \\
\text { multiplanares do tipo XX com as vigas sendo solicitadas por momento fletor atuante } \\
\text { na direção de maior inércia da viga. Verificou neste grupo a influência da presença do }\end{array}$ \\
\hline
\end{tabular}

6 Para fins de comparação com resultados futuros desta pesquisa, apenas os modelos do grupo 3 são de interesse na complementação da descrição da pesquisa de WINKEL (1998). 
Quadro 2.3 - Histórico recente das pesquisas de ligações entre viga I e pilar circular steel deck e o efeito da força aplicada na viga em várias direções. A descrição dos modelos do grupo 3 está apresentada no tabela 2.2.

Tabela 2.2 - Descrição dos modelos da série 3 de Winkel (1998)

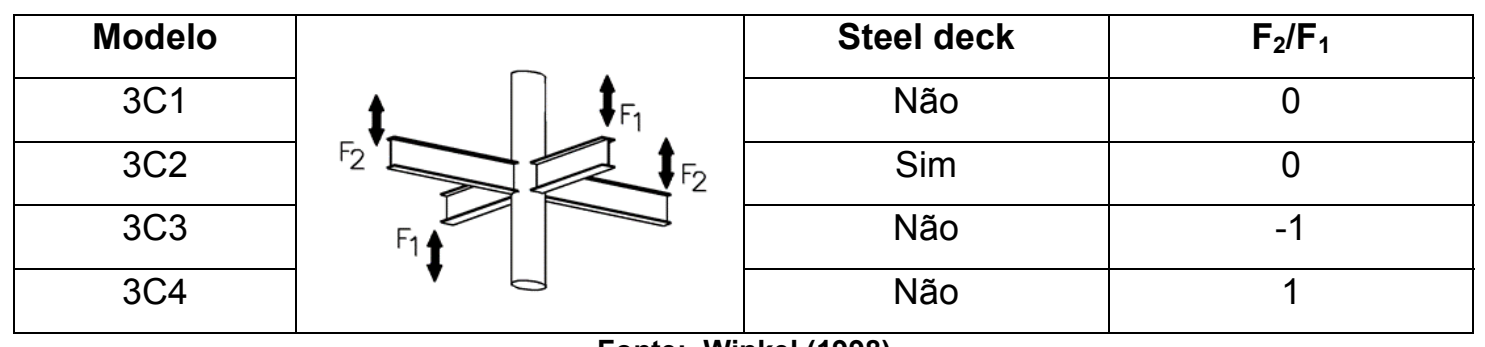

Fonte: Winkel (1998)

Os resultados experimentais do grupo 3 demonstraram a predominância, em todos os modelos, do modo de falha por plastificação da face do pilar (figura 2.37). Para a ligação com a presença da laje em aço (3C2) verificou-se uma maior rigidez e um momento resistente um pouco superior comparado ao modelo $3 \mathrm{C} 1$. Os resultados para o momento último dos 4 modelos estão apresentados na tabela 2.3.

Além das análises experimental e numérica, realizou um estudo paramétrico dos resultados. Os resultados numéricos se mostraram satisfatórios frente aos experimentais e permitiram a determinação de expressões para o cálculo da resistência das ligações com pilar tubular circular para, futuramente, servir de base para as normas de dimensionamento, como o Eurocode 3. A formulação foi calibrada com os resultados da análise numérica utilizando análise por regressão não linear.
Figura 2.37 - Plastificação da face do pilar no modelo $3 \mathrm{C} 4$

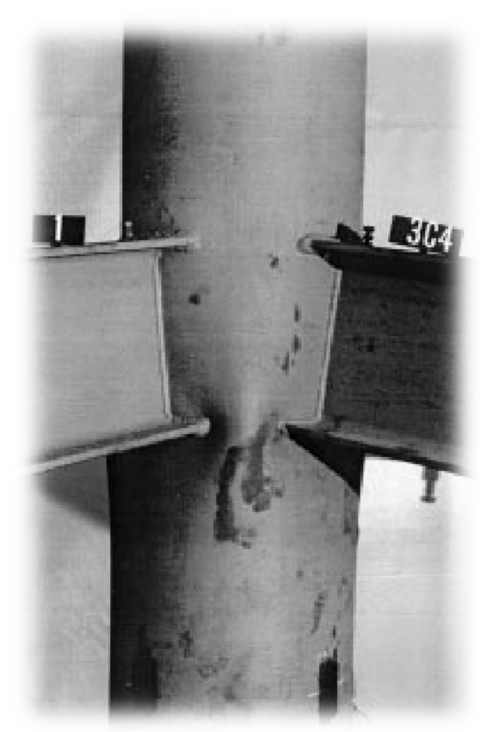

Fonte: Winkel (1998)

Tabela 2.3 - Resultados experimentais

\begin{tabular}{c|c}
\hline Modelo & $\mathbf{M}_{\mathbf{u}}$ (kN.m) \\
\hline $3 C 1$ & 82,5 \\
$3 \mathrm{C} 2$ & 87,6 \\
$3 \mathrm{C} 3$ & 54,1 \\
$3 \mathrm{C} 4$ & 79,0 \\
\hline
\end{tabular}

Fonte: Winkel (1998) 
Quadro 2.3 - Histórico recente das pesquisas de ligações entre viga I e pilar circular

\section{CARVALHO (2005)}

Apresentou uma análise numérica, via M.E.F., acerca do comportamento estrutural de ligações, por chapa de alma, entre viga de seção I e pilar de extremidade (tipo T) de seção tubular circular.

Avaliou a influência da Figura 2.38 - Tipologias analisadas por Carvalho (2005) presença dos diafragmas externos, soldados ou não às mesas da viga (figura 2.38). Adotou um tipo de modelagem tridimensional já testada por pesquisadores tais como Bessa (2004) e Maggi (2000).

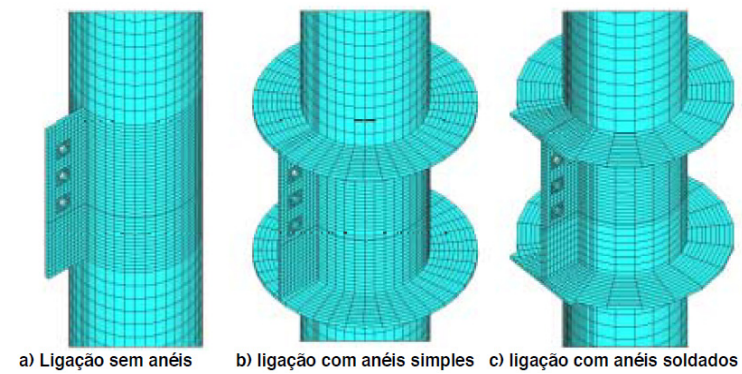

Fonte: Carvalho (2005)

Os modelos numéricos apresentaram comportamento com boa representatividade. Para as configurações sem a presença de anéis ou, naquelas onde estes não são soldados às mesas da viga, observou um comportamento de viga bi-apoiada com os anéis contribuindo para melhor distribuir as tensões que a chapa simples exerce no pilar ao absorver o esforço cortante da viga. Nas situações onde, os anéis são soldados às mesas da viga, verificou um comportamento análogo à situação de viga bi-engastada, fato observado na comparação dos deslocamentos e distribuições de tensões com a situação idealizada.

SUI; YAMANARI (2007)

Desenvolveram expressões analíticas para estimar a rigidez inicial, resistência ao escoamento, rigidez pós-escoamento e resistência última de ligações entre viga I e pilar CHS, com a presença de diafragma externo (figura 2.39). Os resultados obtidos pelas formulações analíticas demonstraram-se bastante representativos frente aos resultados da análise numérica.

Figura 2.39 - Tipo de ligação estudada

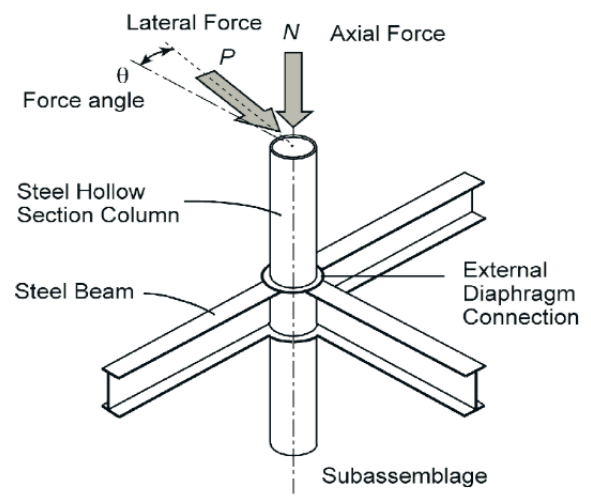

Fonte: Sui e Yamanari (2007) 
Quadro 2.3 - Histórico recente das pesquisas de ligações entre viga I e pilar circular

\section{FREITAS (2009)}

Realizou uma investigação numérica de ligações do tipo $X$, entre, viga de seção I com pilar de seção tubular circular, por meio da avaliação do comportamento $M-\theta$ (momento-rotação) e dos parâmetros que o caracterizam.

A análise numérica foi realizada via M.E.F. por meio dos softwares ANSYS ${ }^{\circledR}$ e TrueGrid ${ }^{\circledR}$. Analisou cinco tipos de ligação cruciforme (Figura 2.40a) diferenciandose entre si pelas peças componentes. Além disso, variou o diâmetro da coluna e altura das vigas em cada tipo de ligação. Avaliou a eficiência do mecanismo de diafragma externo incorporado à ligação. Acrescentou à análise, estudos analíticos com base nas formulações do Eurocode 3 de 2003 e do ANSI/AISC de 2005.

Concluiu que o aumento da altura da seção transversal da viga gerou acréscimo da resistência da ligação, devido ao aumento do binário existente, por outro lado, o aumento do diâmetro da seção do pilar proporcionou variações pequenas nos valores da resistência. Quanto à rigidez, todas as ligações apresentaram comportamento semi-rígido. Os procedimentos normativos analisados apresentaram boa aplicabilidade para avaliar a resistência das ligações. Comprovou, novamente, a eficácia dos anéis externos na distribuição dos esforços provenientes do engastamento parcial da viga. Verificou que a presença de enrijecedor na mesa inferior soldado ao diafragma externo é prejudicial à resistência da coluna devido à força que este exerce na parede da coluna (Figura 2.40b).

Figura 2.40 - Característica da ligação analisada e distribuição de tensões na situação com enrijecedor

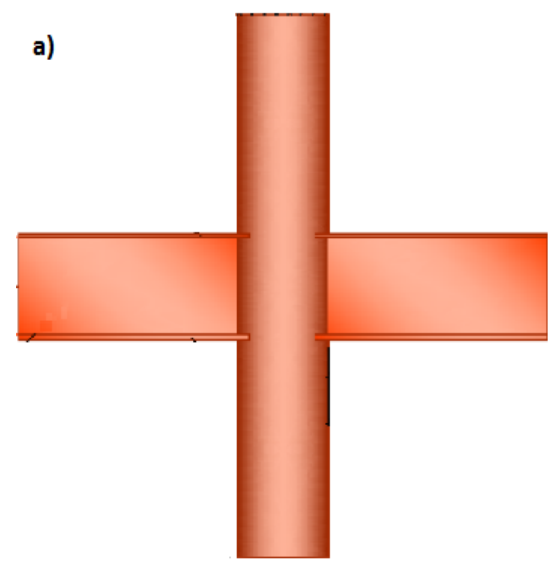

b)

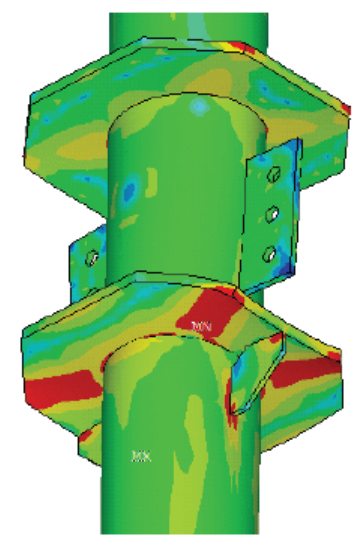

Fonte: Freitas (2009) 
Quadro 2.3 - Histórico recente das pesquisas de ligações entre viga I e pilar circular

\section{SUI; CHEN (2010)}

Avaliaram de forma experimental e numérica modelos tridimensionais de ligações entre viga de seção I e pilar CHS com a presença de diafragmas externos. A pesquisa visou à aplicabilidade destas ligações em estruturas sujeitas ao efeito de sismos. Desta maneira, a análise considerou a presença de carregamentos cíclicos atuando nas vigas para a avaliação do comportamento da ligação e dos dispositivos resistentes auxiliares.

Os resultados da análise numérica com o programa ABAQUS apresentaram boa aproximação em relação aos resultados experimentais. Verificaram por meio da análise da distribuição de tensões, que a análise numérica pode simular satisfatoriamente a plastificação dos elementos componentes da ligação.

Baseados nos resultados das análises tridimensionais reavaliaram expressões analíticas obtidas de análises bidimensionais. A comparação indicou que os resultados da rigidez inicial e a resistência ao escoamento da ligação são idênticos nas análises 2D e 3D. Concluíram assim que para este tipo de ligação, uma análise numérica bidimensional pode estimar satisfatoriamente o comportamento da ligação. 
Quadro 2.3 - Histórico recente das pesquisas de ligações entre viga I e pilar circular

\begin{tabular}{|c|c|}
\hline \multicolumn{2}{|r|}{ MASIOLI (2011) } \\
\hline \multicolumn{2}{|c|}{$\begin{array}{l}\text { Dando continuidade ao trabalho } \\
\text { desenvolvido por Freitas (2009) estudou por meio } 2.41 \text { - Modelo numérico de } \\
\text { ligaça do tipo T } \\
\text { experimental, seis configurações geométricas de } \\
\text { ligações viga-pilar do tipo } \mathrm{T} \text { (figura 2.41). Avaliou } \\
\text { ligações por chapa de alma, soldada e por chapa } \\
\text { de alma com diafragma externo retangular soldado } \\
\text { ou parafusado às mesas da viga. } \\
\text { As duas últimas configurações ainda apresentaram a variação com a } \\
\text { presença de um enrijecedor transversal soldado ao diafragma, junto à mesa inferior } \\
\text { da viga, totalizando assim } 6 \text { tipologias de ligação. } \\
\text { A análise teórica foi realizada por analogia ao Método das Componentes do } \\
\text { Eurocode } 3 \text { (2005) para ligações viga-pilar por chapa de topo. A análise numérica foi } \\
\text { realizada com os softwares ANSYS }{ }^{\circledR} \text { e TrueGrid }{ }^{\circledR} \text {. O programa experimental avaliou } 4 \\
\text { modelos em escala real de ligações do tipo T, variando quanto aos dispositivos } \\
\text { utilizados na ligação conforme apresentado no tabela } 2.4 \text {. } \\
\text { Tabela } 2.4-\text { Descrição dos modelos experimentais de Masioli (2011) }\end{array}$} \\
\hline Modelo & Descrição \\
\hline TCF-B & Ligação parafusada por \\
\hline TCR-W & I0ada. \\
\hline TCR-B & \\
\hline TCRS-B & \\
\hline Os & Fonte: Masioli (2011) \\
\hline
\end{tabular}


Quadro 2.3 - Histórico recente das pesquisas de ligações entre viga I e pilar circular respectiva rotação $\left(\theta_{M n}\right)$, o momento de plastificação $\left(M_{\theta=0,02 r a d}\right)$ e a rigidez inicial da ligação $\left(\mathrm{K}_{\mathrm{i}}\right)$ estão descritos na tabela 2.5 .

Figura 2.42 - Plastificação da mesa comprimida no modelo TCRS-B

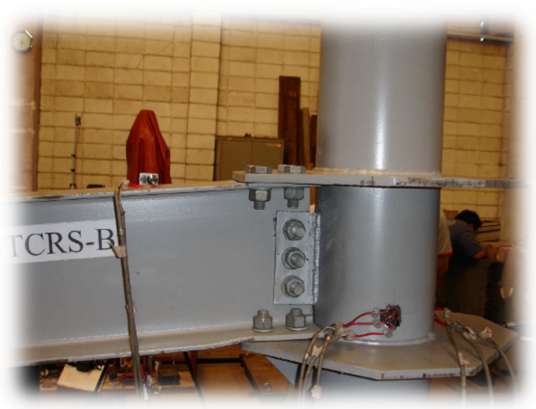

Fonte: Masioli (2011)

Tabela 2.5 - Resultados da análise experimental

\begin{tabular}{c|c|c|c|c}
\hline Modelo & $\mathbf{M}_{\mathbf{n}} \mathbf{( k N . \mathbf { m } )}$ & $\boldsymbol{\theta}_{\mathbf{M n}}(\mathbf{r a d})$ & $\mathbf{M}_{\boldsymbol{\theta}=\mathbf{0}, \mathbf{0 2} \mathbf{r a d}}(\mathbf{k N} \cdot \mathbf{m})$ & $\mathbf{K}_{\mathbf{i}}(\mathbf{k N} . \mathbf{m} / \mathbf{r a d})$ \\
\hline TCF-B & 7,6 & 0,041 & 2,7 & 110 \\
TCR-W & 95,4 & 0,027 & 94,0 & 8.610 \\
TCR-B & 181,3 & 0,037 & 136,6 & 9.990 \\
TCRS-B & 189,6 & 0,036 & 145,6 & 10.860 \\
\hline
\end{tabular}

Fonte: Masioli (2011)

A análise numérica avaliou parâmetros como resistência, rigidez e ductilidade além do comportamento $M-\theta$ (momento-rotação) da ligação. A formulação teórica adaptada apresentou resultados coerentes e a análise numérica foi representativa em relação aos resultados experimentais. Os diafragmas externos apresentaram funcionalidade semelhante à constatada por Carvalho (2005). A adição de enrijecedor ao anel externo não se mostrou eficiente apresentando inclusive desvantagem como a plastificação precoce do pilar. 
Quadro 2.3 - Histórico recente das pesquisas de ligações entre viga I e pilar circular

\begin{tabular}{|c|c|c|c|c|}
\hline \multicolumn{5}{|c|}{ REIS (2011) } \\
\hline \multicolumn{5}{|c|}{$\begin{array}{l}\text { Por meio de análise } \\
\text { experimental e numérica } \\
\text { apresentou um estudo sobre } \\
\text { ligações soldadas entre viga I e } \\
\text { pilar CHS. Os ensaios foram } \\
\text { realizados em protótipos em escala } \\
\text { real (figura 2.43). A análise } \\
\text { experimental visou a obtenção do } \\
\text { comportamento momento-rotação, } \\
\text { solicitação última e modo de } \\
\text { colapso da ligação. Realizou a } \\
\text { comparação entre os resultados } \\
\text { analíticos, numéricos e } \\
\text { experimentais. }\end{array}$} \\
\hline \multicolumn{5}{|c|}{$\begin{array}{l}\text { Realizou um total de cinco ensaios experimentais. Determinou a geometria } \\
\text { das seções transversais por meio de uma análise numérica preliminar visando o } \\
\text { estudo dos parâmetros que definem a rigidez deste tipo de ligação. Os protótipos } \\
\text { ensaiados pelo autor e a respectiva nomenclatura são apresentados na tabela 2.6: } \\
\text { Tabela } 2.6 \text { - Definição e nomenclatura dos protótipos ensaiados }\end{array}$} \\
\hline Modelo & Ensaios & Nomenclatura & Pilar & Viga \\
\hline P1 & 1 & N1 & $219,1 \times 8,2$ & W310 x 38,7 \\
\hline $\mathrm{P} 2$ & 2 & $\begin{array}{l}\text { N2-1 } \\
\text { N2-2 }\end{array}$ & $\begin{array}{l}219,1 \times 9,5 \\
219,1 \times 9,5\end{array}$ & $\begin{array}{l}\text { W310 x 38,7 } \\
\text { W310 x 38,7 }\end{array}$ \\
\hline P3 & 2 & $\begin{array}{l}\text { N3-1 } \\
\text { N3-2 }\end{array}$ & $\begin{array}{l}219,1 \times 8,2 \\
219,1 \times 8,2\end{array}$ & $\begin{array}{l}\text { W250 x 17,9 } \\
\text { W250 × 17,9 }\end{array}$ \\
\hline $\begin{array}{c}\text { Os } \\
\text { europeia. A } \\
\text { consideraçõe }\end{array}$ & $\begin{array}{l}\text { dos analí } \\
\text { e numéricé } \\
\text { análise exp }\end{array}$ & $\begin{array}{l}\text { Fonte: Reis (2011) } \\
\text { s foram basead } \\
\text { ia M.E.F., procur } \\
\text { nental. Utilizou os }\end{array}$ & $\begin{array}{l}\text { nas presc } \\
\text { simular sat }\end{array}$ & $\begin{array}{l}\text { atos da norma } \\
\text { mentais para a }\end{array}$ \\
\hline
\end{tabular}


Quadro 2.3 - Histórico recente das pesquisas de ligações entre viga I e pilar circular

calibração dos modelos numéricos. Obteve boa aproximação entre os resultados experimentais e numéricos e entre os resultados experimentais e os obtidos por meio de expressões analíticas conforme apresentado na tabela 2.7.

Tabela 2.7 - Comparação dos resultados experimentais, numéricos e analíticos

\begin{tabular}{|c|c|c|c|c|c|c|c|c|}
\hline \multirow{2}{*}{ 彭 } & \multirow{2}{*}{$\begin{array}{l}\underset{\Xi}{Z} \\
\underset{z}{z} \\
\underset{z}{z}\end{array}$} & \multicolumn{2}{|c|}{$\mathrm{M}_{\max .}(\mathrm{kN} . \mathrm{m})$} & \multicolumn{2}{|c|}{$\theta_{\max .}(\mathrm{rad})$} & \multicolumn{3}{|c|}{$\begin{array}{c}\text { Rigidez } \\
\text { (kN.m/rad) }\end{array}$} \\
\hline & & Exp. & Num. & Exp. & Num. & Exp. & Num. & Teo. \\
\hline N2-1 & 160,54 & 162,72 & 156,60 & 0,0749 & 0,0613 & 8681,11 & 10103,22 & 8089,23 \\
\hline $\mathrm{N} 2-2$ & 160,54 & 143,66 & 156,60 & 0,0737 & 0,0613 & 9004,27 & 10103,22 & 8089,23 \\
\hline N3-1 & 53,60 & 72,52 & 82,65 & 0,0586 & 0,0466 & 4759,71 & 5165,63 & 3517,36 \\
\hline N3-2 & 53,60 & 71,56 & 82,65 & 0,0500 & 0,0466 & 4045,91 & 5165,63 & 3517,36 \\
\hline
\end{tabular}

Fonte: Reis (2011)

Todas as ligações ensaiadas apresentaram comportamento semirígido. Observou que a largura da mesa da viga influencia o comportamento da ligação quanto à rigidez. Os modos de falha experimentais, numéricos e teóricos foram os mesmos sendo caracterizados pela plastificação da face do pilar (figura 2.44). Verificou que o aumento da altura da viga e/ou o aumento da espessura do pilar acarreta o acréscimo da resistência da

Figura 2.44 - Plastificação da face do pilar devido à compressão exercida pela mesa da viga

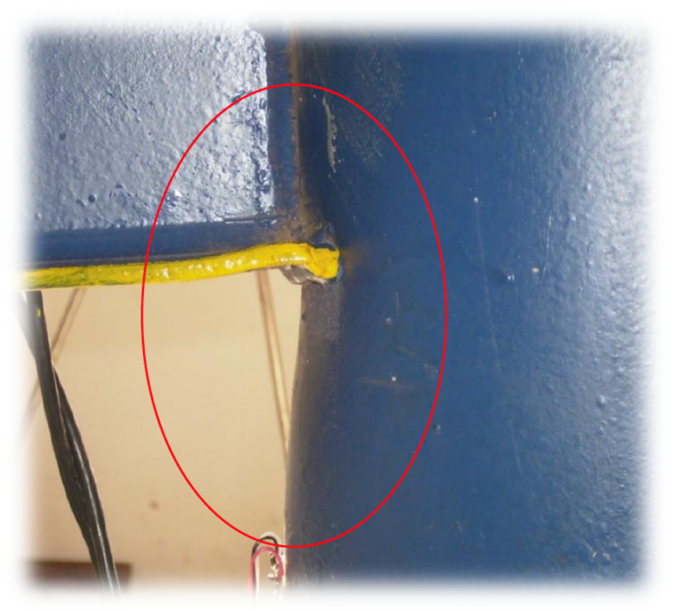

Fonte: Reis (2011) ligação.

A abordagem histórica das pesquisas já realizadas sobre o tema deste trabalho demonstra a evolução nas metodologias de análise numérica e a boa representatividade dos resultados em geral. Na sequência deste trabalho são apresentadas algumas metodologias de dimensionamento analítico de ligações entre viga de seção I e pilar de seção tubular circular. 


\section{Capítulo 3}

\section{Metodologias de dimensionamento}

\subsection{Generalidades}

A análise do comportamento estrutural de ligações tem como principal consideração a verificação de propriedades como resistência e rigidez. A máxima resistência ao momento fletor é tomada como o ponto máximo da curva momentorotação. A rigidez da ligação depende de uma análise do comportamento momentorotação ao longo de um determinado intervalo de carregamento. Visto a facilidade de visualização e quantificação, observam-se mais pesquisas relacionadas à obtenção analítica da propriedade referente à resistência das ligações.

Em se tratando de ligações envolvendo seções tubulares, as incertezas que cercam o comportamento destas, tornam a tarefa de estimar a rigidez das ligações algo praticamente exclusivo de simulações numéricas ou ensaios experimentais. Por outro lado, estimar a resistência deste tipo de ligação por meio de expressões analíticas é algo mais disseminado inclusive em proposições normativas.

Packer e Henderson (1997) foram um dos pioneiros à desenvolverem formulações analíticas para estimar a resistência de ligações soldadas entre viga I e pilar tubular circular. Winkel (1998) desenvolveu uma pesquisa de cunho numéricoexperimental determinando expressões que consideravam a influência da presença de 4 vigas simultaneamente ligadas ao pilar. Os trabalhos de Kurobane et al. (2004), Wardenier et al. (2008), Packer, Sherman e Lecce (2010) e de Wardenier et al. (2010) procuraram apresentar algumas das principais metodologias de dimensionamento 
estudadas até então. Em geral, as expressões desenvolvidas foram calibradas por meio de resultados experimentais ou simulações numéricas.

O Eurocode 3 Part 1-8 (2005) e o ANSI/AISC 360-10 (2010) apresentam formulações específicas para a determinação da resistência de ligações envolvendo seções tubulares. No ano de 2011, a Associação Brasileira de Normas Técnicas (ABNT) reuniu uma comissão de especialistas para dar início ao Projeto de Norma para a criação da norma brasileira de estruturas tubulares em aço, com o nome oficial, até então, de "Projeto de estruturas de aço e estruturas mistas de aço e concreto de edificações com perfis tubulares”. O Projeto de Norma (até o ano de 2013) apresenta considerações semelhantes às descritas no texto do Eurocode 3 Part 1-8 (2005).

Neste capítulo são apresentadas formulações analíticas para estimar a resistência de ligações entre viga I e pilar tubular circular. Considerando a relevância dos esforços de flexão perante aos demais, o dimensionamento analítico procurará avaliar apenas a resistência da ligação ao momento fletor. São apresentadas as principais formulações que consideram a influência de algumas das variáveis relevantes ao escopo desta pesquisa.

\subsection{Práticas normativas}

O dimensionamento de ligações envolvendo seção tubular é algo relativamente novo e pouco disseminado pelas normas vigentes. Algumas das principais referências normativas optam por direcionar este dimensionamento a outras normas que melhor promovem diretrizes para esta tarefa. Este é o caso da NBR 8800 (2008, p.66), na qual se encontra uma importante observação relativa às considerações sobre ligações com perfis de seção tubular:

[...] Muitas das prescrições desta seção podem não se aplicar em parte ou na totalidade a ligações envolvendo um ou mais perfis de seção tubular, as quais apresentam características particulares de comportamento. Recomenda-se, para o dimensionamento dessas ligações, fazendo-se as adaptações necessárias para manter o nível de segurança previsto por esta Norma, a utilização da AWS D1.1, do 
ANSI/AISC 360 ou do Eurocode 3 Part 1-8, na ausência de Norma Brasileira aplicável [...]

Por sua vez, o Eurocode 3 Part 1-8 (2005) apresenta, no capítulo 7, diretrizes para o dimensionamento de ligações soldadas envolvendo viga de seção I e pilar tubular circular. Na tabela 3.1 apresentam-se as formulações adotadas pela norma europeia para a verificação da resistência destas ligações.

Tabela 3.1 - Resistência de cálculo de ligações soldadas entre viga I (ou H) e pilar tubular circular

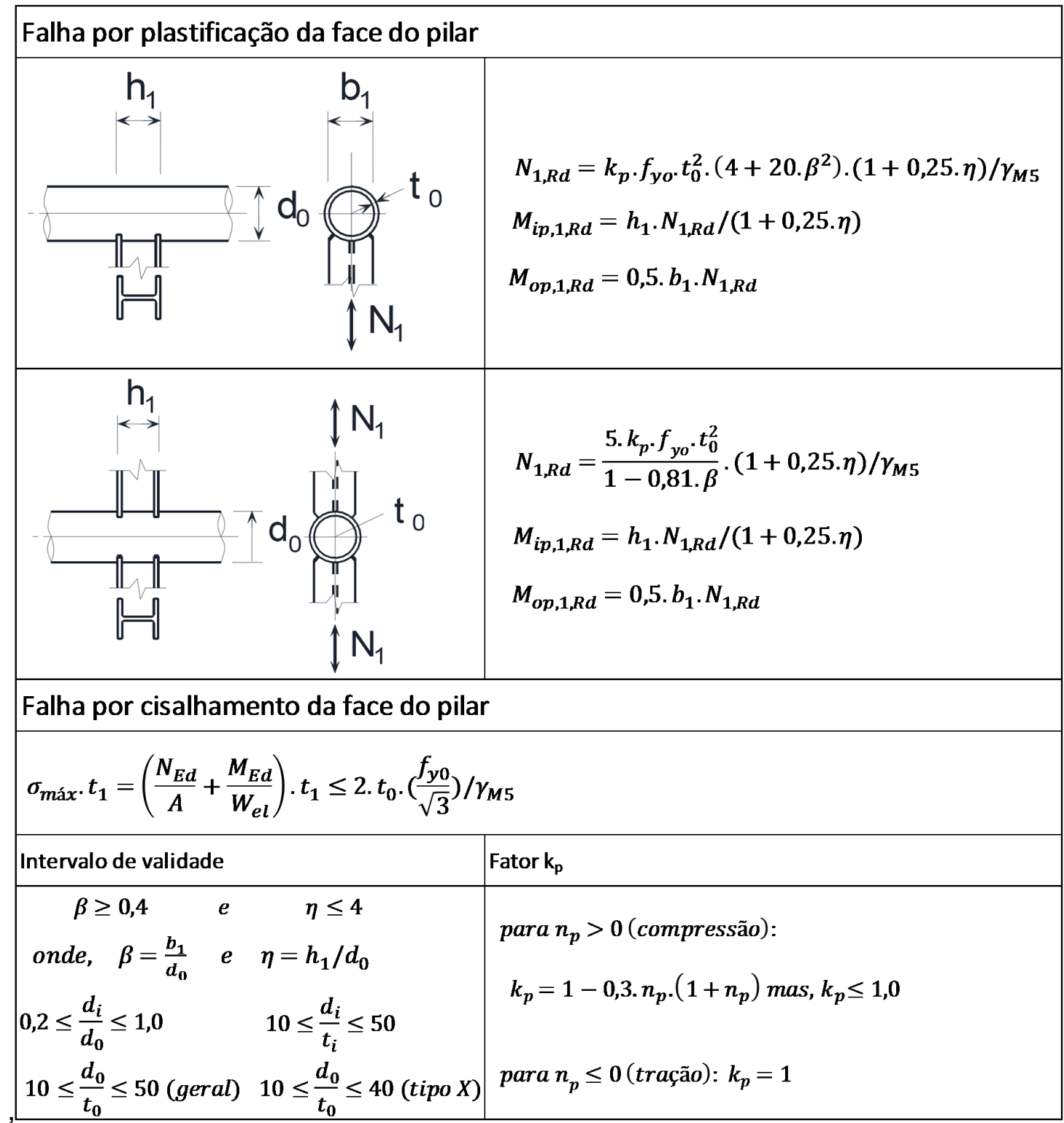

Fonte: Eurocode 3 Part 1-8 (2005)

As expressões analíticas apresentadas na tabela 3.1 foram ajustadas por meio de inúmeros resultados experimentais. As constantes inseridas nas equações 
possuem um significado intrínseco para o tipo de ligação em questão. Desta maneira, fica impraticável derivar as equações para situações fora do intervalo de validade da tabela 3.1. Vale lembrar, que as expressões apresentadas pela norma europeia contemplam a influência que uma possível compressão axial no pilar tenha na resistência da ligação por meio do fator $k_{p}$.

Para o caso de ligações do tipo TT (figura 3.1) ou XX (figura 3.2), o Eurocode 3 Part 1-8 (2005, p.115) introduz o fator $\mu$ que pondera a resistência da ligação considerando a influência da presença de vigas dispostas em outras direções.

Figura 3.1 - Ligação do tipo TT
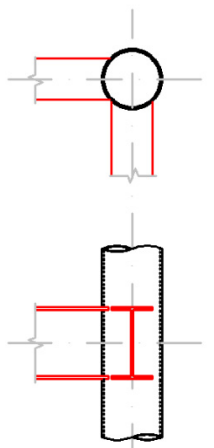

Fonte: Acervo pessoal
Figura 3.2 - Ligação do tipo XX
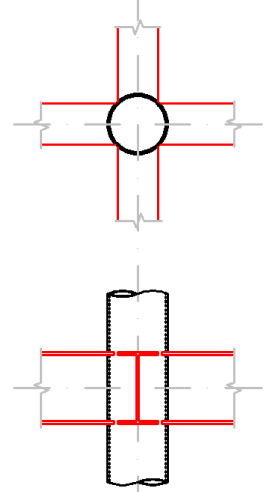

Fonte: Acervo pessoal

O fator $\mu$ leva em consideração a força aplicada simultaneamente nas duas direções ortogonais. No caso das ligações do tipo TT a norma europeia sugere a utilização do fator $\mu$ igual à 1 , visto a menor influência do carregamento simultâneo neste caso. Nas ligações do tipo XX, o Eurocode 3 (2005) sugere a utilização de um fator $\mu$ dado pela equação 3.1 .

$$
\mu=1+0,33 \cdot N_{2, E d} / N_{1, E d} \text { * }
$$

${ }^{*}$ Considera-se o sinal de $N_{1, E d}$ e $N_{2, E d}$, sendo, $\left|N_{2, E d}\right|<\left|N_{1, E d}\right|$

As componentes $\mathrm{N}_{1, \mathrm{Ed}}$ e $\mathrm{N}_{2, \mathrm{Ed}}$ são as componentes (tração ou compressão) do binário gerado pelo momento fletor na ligação conforme a figura 3.3. 
Figura 3.3 - Componentes $\mathrm{N}_{1}$ e $\mathrm{N}_{2}$ nas ligações multiplanares do tipo XX

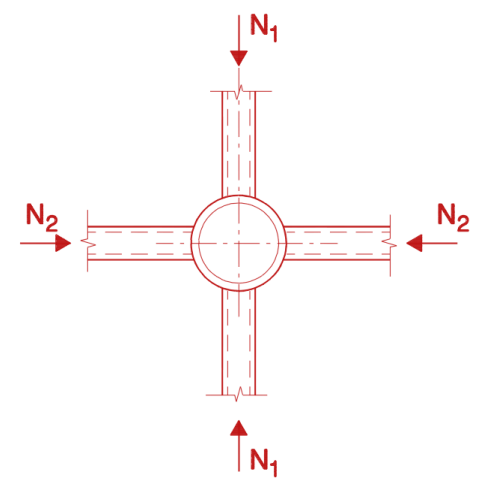

Fonte: Eurocode 3 Part 1-8 (2005)

As vigas 1 e 2 podem exercer um esforço de compressão ou de tração, conforme o sentido da força aplicada. A relação $N_{2}$,Ed $/ N_{1}$,Ed é negativa se um elemento estiver em tração e o outro em compressão. Neste caso, ter-se-ia um fator $\mu$ menor que 1 e, consequentemente, uma redução na resistência da ligação.

Com relação às ligações envolvendo dispositivos auxiliares como, parafusos e chapas, a norma europeia não faz nenhuma referência direta em relação ao procedimento a ser adotado quando da presença de seções tubulares entre os elementos conectados. O capítulo 6 do Eurocode 3 Part 1-8 (2005) apresenta o chamado "Método das Componentes", cujo embasamento teórico, está no modelo de dimensionamento para as ligações T-stub apresentado por Zoetemeijer e deBack (1972 apud ROMANO, 2001, p.21).

Como lembrou Romano (2001, p.14), a essência do método das componentes "[...] está no conceito de que a resposta da ligação é determinada pelas propriedades mecânicas dos seus componentes básicos, considerando-a não como um todo, mas como uma série de elementos básicos [...]" estando estes distribuídos em 3 regiões distintas, sendo elas, a zona tracionada, a zona comprimida e a zona de cisalhamento, conforme ilustrado na figura 3.4. 


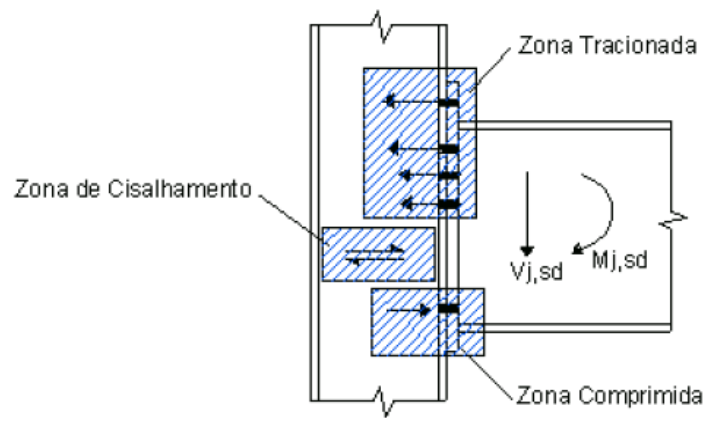

Figura 3.4 - Zonas de verificação para o método das componentes. Fonte: Romano (2001)

O método das componentes permite uma avaliação analítica das propriedades da ligação. A partir do método é possível obter a rigidez inicial e a resistência de todas as partes componentes da ligação e da mesma de modo global, desta forma, é possível determinar como a rigidez e resistência da ligação estão distribuídas entre os componentes. É possível avaliar o modo de colapso da ligação, observar o nível de ductilidade e obter indicativos de como enrijecer ou aumentar a resistência da ligação de um modo mais prático e econômico, quando necessário.

As formulações do Método das Componentes encarregam-se de verificar todos elementos componentes da ligação. No caso da ligação com o diafragma externo as principais verificações a serem feitas são:

a) Ruptura por punção da face do pilar na região tracionada devido à força de tração exercida pelo diafragma superior;

b) Plastificação da face do pilar na região comprimida devido à força de compressão exercida pelo diafragma inferior;

c) Plastificação da seção da alma e mesa da viga na região comprimida;

d) Plastificação da seção da alma da viga na região tracionada;

e) Cisalhamento dos parafusos da alma e do diafragma;

f) Pressão de apoio e rasgamento no diafragma e mesa da viga;

g) Pressão de apoio e rasgamento na chapa de alma e alma da viga.

Em se tratando da abordagem de normas americanas, $\mathrm{o}$ anexo $\mathrm{K}$ do ANSI/AISC 360-10 (2010) apresenta uma metodologia de dimensionamento de ligações soldadas envolvendo seções tubulares. Diferentemente da norma europeia, a norma americana não apresenta expressões diretas para o dimensionamento de ligações envolvendo viga de seção I, mas, apenas as expressões para a resistência da ligação entre uma chapa e o pilar de seção circular, conforme a tabela 3.2. 
Tabela 3.2 - Resistência de ligações soldadas entre chapa e seção tubular circular

\begin{tabular}{|c|c|c|c|}
\hline \multirow{2}{*}{ Tipo de ligação } & \multirow{2}{*}{ Resistência da ligação } & \multicolumn{2}{|c|}{ Flexão da chapa } \\
\hline & & No plano & Fora do plano \\
\hline Chapa transversal - Ligação do tipo T ou X & $\begin{array}{l}\text { Modo de falha: Plastificação da face do pilar } \\
\text { circular devido à força axial da chapa } \\
R_{d} \cdot \operatorname{sen} \theta=0,90 \cdot F_{y} \cdot t^{2} \cdot\left(\frac{5,5}{1-0,81 \cdot \frac{B_{p}}{D}}\right) \cdot Q_{f}\end{array}$ & - & $M_{n}=0,5 \cdot B_{p} \cdot R_{n}$ \\
\hline \multicolumn{4}{|c|}{ Variáveis } \\
\hline \multicolumn{4}{|c|}{$\begin{array}{l}F_{y}-\text { Tensão de escoamento do material do pilar } \\
Q_{f}=1 \text { para pilar tracionado } \\
\quad=1,0-0,3 . U .(1+U) \text { para pilar comprimido } \\
\begin{array}{l}U=\left|\frac{P_{r 0}}{F_{y} \cdot A_{g}}+\frac{M_{r 0}}{F_{y} S}\right| \text { onde, } \\
P_{r 0} \text { e } M_{r 0} \text { são,respectivamente, a resistência à compressão e à flexão do pilar } \\
A_{g} \text { é } a \text { área da seção transversal do pilar } \\
S \text { é o módulo de resistência à flexão }\end{array}\end{array}$} \\
\hline \multicolumn{4}{|c|}{ Limites de aplicação } \\
\hline $\begin{array}{l}\text { Ângulo de carregamento da chapa: } \theta \geq \\
\text { Esbeltez do pilar (relação } \frac{D}{t} \text { ): } \\
\leq 50 \text { para ligações do tipo } T \text { sobre flex } \\
\leq 40 \text { para ligações do tipo X sobre flex } \\
\leq 0,11 \cdot \frac{E}{F_{y}} \\
\text { Relação largura da viga e diâmetro do } \\
\text { Resistência do material: } F_{y} \leq 360 \mathrm{MPa} \\
\text { Ductilidade: } \frac{F_{y}}{F_{u}} \leq 0,8\end{array}$ & $\begin{array}{l}30^{\circ} \\
\text { o ou carregamento axial } \\
\text { o ou carregamento axial } \\
\text { ilar: } 0,2<\frac{B_{p}}{D} \leq 1,0\end{array}$ & & \\
\hline
\end{tabular}

Fonte: ANSI/AISC 360-10 (2010) - Adaptado

Para o tipo de ligação desta pesquisa é possível utilizar a tabela 3.2 fazendo uma analogia à ligação com a viga de seção I, onde as mesas das vigas seriam representadas por um par de chapas transversais, ignorando-se a presença da alma. A resistência ao momento fletor da ligação é obtida a partir da resistência ao esforço normal de uma chapa, multiplicado pela distância entre os centros de gravidade das mesas da viga.

Assim como no Eurocode 3 Part 1-8 (2005), as expressões do ANSI/AISC 360-10 (2010) foram obtidas por meio de ajustes utilizando resultados experimentais. A mesma constatação descrita anteriormente quanto ao intervalo de validade das expressões se aplica na norma americana, sendo assim, qualquer configuração distinta da apresentada na tabela 3.2 deve ser avaliada criteriosamente. Outro ponto 
de relevância é que a norma americana também faz a consideração da compressão axial no pilar (caso exista) na avaliação da resistência da ligação.

\subsection{Metodologias de dimensionamento dos principais autores}

Estudos como os de Packer e Henderson (1997), Winkel (1998), Kurobane et al. (2004), Wardenier et al. (2008), Packer, Sherman e Lecce (2010) e Wardenier et al. (2010) apresentaram expressões analíticas para a determinação da resistência ao momento fletor de ligações soldadas entre viga I e pilar circular.

As ligações envolvendo diafragmas externos foram avaliadas por Kamba et al. (1983), Packer e Henderson (1997), Kurobane et al. (2004), Sui e Yamanari (2007) e Sui e Chen (2010), dentre outros. Os autores mencionados avaliaram a presença do diafragma como componente adicional à ligação tradicionalmente soldada. Apresentam-se nas pesquisas formulações analíticas que consideram uma ligação soldada entre a alma da viga e a face do pilar além da presença do diafragma conectado às mesas das vigas.

Considerando os tipos de ligação analisados (TT e XX) e as principais variáveis inseridas nesta pesquisa (carregamento axial do pilar e sentido da força aplicada nas vigas dispostas nas duas direções ortogonais), as expressões analíticas que melhor atendem ao escopo deste trabalho são as propostas por Winkel (1998) e pelo Eurocode 3 Part 1-8 (2005).

Evitando-se estender demasiadamente o propósito desta pesquisa, são apresentadas neste item apenas as expressões que serão utilizadas no decorrer do trabalho. As demais expressões sugeridas pelos autores mencionados podem ser encontradas nas referências bibliográficas.

Winkel (1998) realizou um estudo em ligações do tipo XX soldadas gerando formulações que contemplam o tipo de ligação (figura 3.5), o carregamento axial do pilar e a geometria da seção transversal das vigas e do pilar. As expressões analíticas 
destacadas no trabalho de Winkel (1998) são apresentadas na sequência deste trabalho.

Figura 3.5 - Tipos de ligação entre viga I e pilar tubular circular

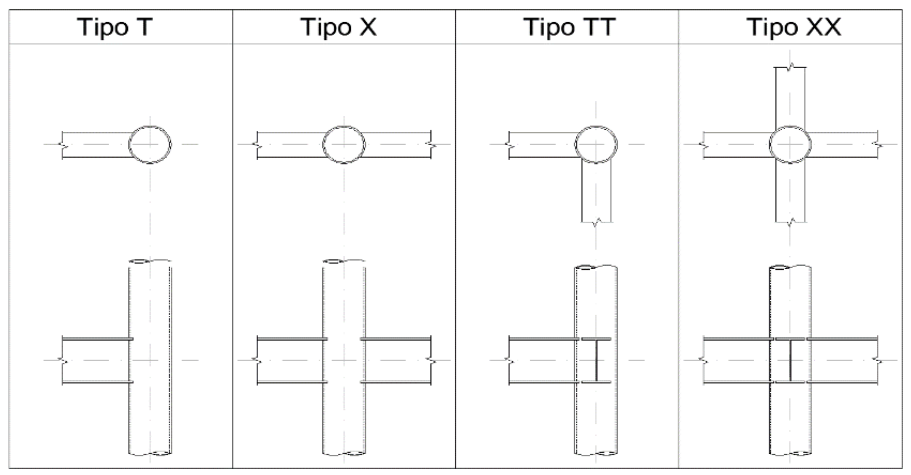

Fonte: Acervo pessoal

\subsubsection{Winkel (1998)}

A figura 3.6 apresenta alguns parâmetros geométricos para a determinação das variáveis $\beta$ (equação 3.2), $\eta$ (equação 3.3) e 2y (equação 3.4), que serão utilizadas nas expressões destacadas posteriormente.

Figura 3.6 - Parâmetros geométricos para a determinação de $\beta$, n e 2y

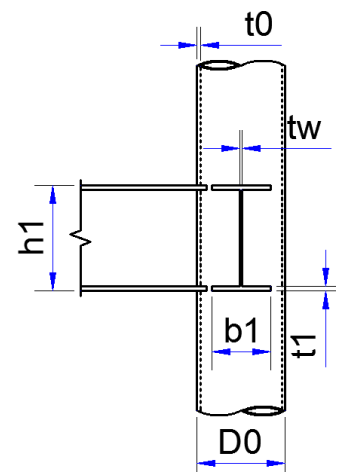

Fonte: Acervo pessoal

$$
\begin{gathered}
\beta=\frac{b_{1}}{d_{0}} \\
\eta=\frac{h_{1}}{d_{0}} \\
2 \gamma=\frac{d_{0}}{t_{0}}
\end{gathered}
$$




\section{a) Ligação do tipo TT}

Em Winkel (1998) não há referência a uma equação específica para estimar a resistência de ligações do tipo TT. Serão apresentadas as expressões para a ligação do tipo $\mathrm{X}$ que, em teoria, melhor aproximam da resistência de ligações do tipo TT.

A pesquisa de Winkel (1998) constatou que o modo de falha predominante para este tipo de ligação é a plastificação da face do pilar, sendo esta, a única verificação a ser realizada na estimativa da resistência. A resistência ao momento fletor $\left(\mathrm{M}_{\mathrm{u}}\right)$ é obtida pela equação 3.5.

$$
M_{u}=\frac{4,9 \cdot \gamma^{\left(1,23 \cdot \beta-1,13 \cdot \beta^{2}\right)}}{1-\beta+\sqrt{(1-\beta)^{2}+\frac{\left(2-\beta^{2}\right)}{\gamma}}} \cdot f(n) \cdot t_{0}^{2} \cdot f_{y, 0} \cdot h_{m}
$$

Onde:

$\beta$, n e y são obtidos, respectivamente, pelas equações 3.2, 3.3 e 3.4;

to é a espessura da parede do pilar;

$f_{y, 0}$ é a tensão de escoamento do material do pilar;

$h_{m}$ é obtido pela equação 3.6;

$$
h_{m}=h_{1}-t_{1}
$$

f(n) é uma função determinada por meio da equação 3.7;

$$
f(n)=1-n^{2} \cdot\left(\beta-\beta^{2}\right) \cdot(2 \cdot \gamma)^{0,3}
$$

n é o fator que leva em consideração a presença de uma força axial no pilar e é calculado pela equação 3.8;

$$
n=\frac{N_{0}}{A_{0} \cdot f_{y, 0}}
$$

No é a força axial solicitante de cálculo aplicada no pilar; $A_{0}$ é a área bruta da seção transversal do pilar. 
b) Ligação do tipo XX

Um dos objetivos da pesquisa de Winkel (1998) foi avaliar a influência da presença de 4 vigas dispostas perpendicularmente entre si (ligação tipo XX) na resistência das ligações.

Por meio de análise experimental e numérica desenvolveu e apresentou a equação 3.9 para estimar a resistência de ligações soldadas do tipo XX, entre viga I e pilar tubular circular.

$$
M(J=0)=\frac{4,89 \cdot \gamma^{\left(1,33 \cdot \beta-1,66 \cdot \beta^{2}\right)}}{\sqrt{1-\beta^{2}}-\beta+\sqrt{(\sqrt{1-\beta}-\beta)^{2}+\frac{2}{\gamma}}} \cdot f(n) \cdot t_{0}{ }^{2} \cdot f_{y, 0} \cdot h_{m}
$$

$\mathrm{O}$ autor ainda recomenda que se avalie a relação entre as forças aplicadas nas duas direções em que as vigas estão dispostas. Conforme o sentido e grandeza da solicitação, a resistência da ligação pode aumentar ou diminuir. Sendo assim, a resistência ao momento fletor $\left(\mathrm{M}_{\mathrm{u}}\right)$ da ligação do tipo XX é então obtida por meio da equação 3.10 .

$$
\frac{M_{u}}{M(J=0)}=1+J \cdot\left(1+\beta-0,372 \cdot \beta^{2}-(2 \cdot \gamma)^{0,0567}\right)+J^{2} \cdot\left(-0,43 \cdot \beta+0,456 \cdot \beta^{2}\right)
$$

Onde:

J é o coeficiente que relaciona a força vertical aplicada nas vigas dispostas em uma direção e a força vertical aplicada nas vigas ortogonais às primeiras. Simplificadamente, é a relação $F_{2} / F_{1}$ conforme a figura 3.7 .

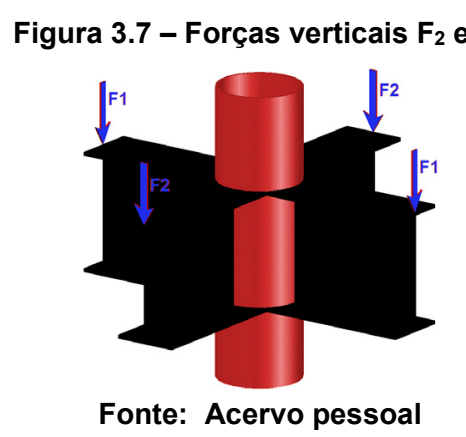

Os limites de aplicação das formulações de Winkel (1998) são apresentados na tabela 3.3. 
Tabela 3.3 - Limites de aplicação das formulações de Winkel (1998)

\begin{tabular}{|c|}
\hline Limites de aplicação - Winkel (1998) \\
\hline $0,2 \leq \beta \leq 0,7$ (ligações multiplanares) \\
$0,2 \leq \beta \leq 0,7$ (ligações multiplanares) \\
$\beta \leq \eta \leq 2 \cdot \beta$ \\
$15 \leq 2 \cdot \gamma \leq 45$ \\
$-1 \leq J \leq+1$ \\
$0 \leq n \leq 0,8$ \\
\hline
\end{tabular}

Fonte: Winkel (1998)

\subsection{Comentários}

As expressões analíticas propostas por Winkel (1998) estimam que ligações do tipo $X$ terão a mesma resistência de ligações do tipo $X X$ para valores pequenos de $\beta\left(b_{1} / d_{0}\right)$. Para $\beta>0,55$ a resistência de ligações do tipo $X X$ será superior.

Em se tratando das solicitações aplicadas nos dois sentidos de uma ligação do tipo XX, Winkel (1998) destaca que um coeficiente J positivo aumenta a resistência da ligação, enquanto que, um valor negativo de $\mathrm{J}$ diminui a resistência. Esta característica é semelhante ao ocorrido com o fator $\mu$ visto nas expressões do Eurocode 3 Part 1-8 (2005). Winkel (1998, p.208) relata ainda que para valores maiores da relação $2 \gamma$, este efeito é mais significante.

A relação entre a natureza das solicitações e a resistência das ligações ocorre devido ao fenômeno de ovalização da seção do pilar. Por exemplo, uma força $F_{2}$ no sentido oposto ao gravitacional gera uma componente de tração na mesa inferior da viga que aumenta a deformação da face do pilar provocada por uma força $F_{1}$ no sentido gravitacional. Por outro lado, quando há forças aplicadas no mesmo sentido, o aumento de $F_{2}$, aumenta a resistência da ligação (expressa em termos de $F_{1}$ ), pois, a ovalização do pilar, devido à força $F_{1}$, é suprimida pela componente de compressão da força $F_{2}$. Ocorre, neste caso, o chamado efeito de confinamento.

Verifica-se, portanto, que os fatores $\mathrm{J}$ em Winkel (1998) e $\mu$ no Eurocode 3 Part 1-8 (2005) são afetados pelo fenômeno de ovalização. Sendo assim, dependendo 
da grandeza e direção dos esforços atuantes nos dois sentidos, pode-se ter um aumento ou uma redução da resistência da ligação, conforme o caso.

As expressões do Eurocode 3 Part 1-8 (2005) levam em consideração as relações geométricas $b_{1} / d_{0}(\beta), h_{1} / d_{0}(\eta) e$, isoladamente, a variável $t_{0}$. Segundo as formulações apresentadas, um aumento de $\beta$, de $\eta$ ou de to resulta em um aumento da resistência das ligações. O aumento da espessura do pilar possui maior relevância na melhoria desta propriedade, seguido do parâmetro $\beta$ e posteriormente o parâmetro ๆ. O Eurocode 3 (2005) considera ainda a compressão axial do pilar (fator $k_{p}$ ), o carregamento simultâneo nas duas direções ortogonais (fator $\mu$ ) e a tensão de escoamento do material do pilar $\left(f_{y 0}\right)$.

Winkel (1998) sugere a utilização de expressões que levam em consideração as relações geométricas $b_{1} / d_{0}(\beta), d_{0} / t_{0}(2 \gamma)$ e, isoladamente, as variáveis $t_{0} e h_{1}$. A relação entre o aumento das variáveis geométricas e o aumento da resistência das ligações apresenta características semelhantes às do Eurocode 3 (2005). As formulações do autor levam em consideração também a compressão axial do pilar (fator $f(n)$ ), o carregamento simultâneo nas duas direções ortogonais (fator $J$ ) e a tensão de escoamento do material do pilar $\left(f_{y 0}\right)$.

Freitas (2009) destaca em sua pesquisa que o aumento da altura da viga $\left(h_{1}\right)$ resulta na melhoria sensível da resistência das ligações em função do aumento do binário existente. Esta constatação é confirmada nas formulações do Eurocode 3 (2005) pela relação direta entre $N_{1, R d}$ e $\eta$ e em Winkel (1998) pela relação entre $M_{u}$ e $\mathrm{h}_{\mathrm{m}}$.

O aumento da largura da mesa da viga, mantendo o diâmetro do pilar, (relação ß) resulta em uma maior área de distribuição da força transversal de compressão exercida pela mesa inferior da viga na parede do tubo. Em ligações soldadas isto representa um aumento da resistência das ligações. As formulações do Eurocode 3 (2005) e de Winkel (1998) procuram dar certa relevância à esta propriedade.

Conforme destacado em Kamba, Namba e Etou (1998), a espessura do pilar é a principal variável capaz de aumentar a resistência das ligações soldadas. As expressões do Eurocode 3 (2005) e de Winkel (1998) enfatizam esta relação por meio da influência considerável da variável geométrica to na resistência das ligações. 
Quanto aos modos de falha verificados nas expressões analíticas para a determinação da resistência de ligações soldadas, notam-se apenas verificações para a resistência à plastificação e ao cisalhamento da face do pilar. Contudo, para que estes sejam os únicos modos de falha possíveis, deve-se atentar que as soldas devem estar executadas e dimensionadas de acordo com as normas e as seções transversais corretamente dimensionadas, a ponto de evitar um modo de flambagem local.

Por fim, por se tratarem de expressões desenvolvidas com bases em resultados experimentais e numéricos, devem-se respeitar os limites de aplicação das formulações. Os limites apresentados, geralmente, representam o intervalo de aplicação dos parâmetros dentro do qual as equações de dimensionamento foram calibradas e, portanto, geram boa aproximação. 


\section{Capítulo 4}

\section{Análise numérica}

A constante necessidade em se obter resultados de maneira rápida e eficaz condiciona a análise numérica à principal ferramenta para a análise de estruturas. Análises experimentais continuam sendo fundamentais em pesquisas científicas, entretanto, a falta de recursos para aquisição de materiais e a alta disseminação de programas computacionais baseados no M.E.F. são fatores que impulsionam a utilização da análise numérica. A presente pesquisa baseia-se na utilização de análise numérica e na sequência deste capítulo são apresentados os principais critérios e particularidades desta análise.

\subsection{Critérios adotados na simulação numérica}

Os critérios mais relevantes adotados na modelagem numérica baseiam-se em pesquisas anteriores de outros autores. Estas pesquisas, com cunho numéricoexperimental obtiveram resultados consideravelmente satisfatórios e os critérios adotados tornaram-se referência ao longo dos anos para outros trabalhos. Dentre os principais trabalhos de referência, destaca-se o de Maggi (2004).

A geração da malha de elementos finitos foi realizada por meio do software TrueGrid $^{\circledR}$, específico para este tipo de tarefa. A grande vantagem da utilização desta ferramenta é a geração paramétrica da malha permitindo, de maneira rápida e eficaz, a modificação de parâmetros geométricos da ligação. Desta forma, utilizou-se o TrueGrid $^{\circledR}$ para a definição da geometria e a construção da malha de elementos finitos. 
Baseada nos trabalhos de Ribeiro (1998), Maggi (2000), Maggi (2004), Freitas (2009) e Masioli (2011), a simulação numérica via Método dos Elementos Finitos foi realizada por meio do software ANSYS $^{\circledR}$. Esta ferramenta, comprovadamente eficiente, permite a utilização de diversos tipos de elementos finitos que são capazes de simular, dentre outras características, as não linearidades físicas e geométricas. A modelagem numérica foi realizada conforme a sequência apresentada na figura 4.1.

Figura 4.1 - Etapas da modelagem numérica. Fonte: Acervo pessoal

\begin{tabular}{|c|c|c|}
\hline $\begin{array}{l}\text { Definição da } \\
\text { geometria } \\
\text { (TrueGrid) }\end{array}$ & $\begin{array}{c}\text { Aplicação das } \\
\text { condições de } \\
\text { contorno }\end{array}$ & $\begin{array}{l}\text { Aplicação da } \\
\text { protensão nos } \\
\text { parafusos }\end{array}$ \\
\hline $\begin{array}{c}\text { Geração e } \\
\text { discretização da } \\
\text { malha de E.F. } \\
\text { (TrueGrid) }\end{array}$ & $\begin{array}{c}\text { Definição dos } \\
\text { modelos } \\
\text { constitutivos } \\
\text { dos materias }\end{array}$ & $\begin{array}{c}\text { Aplicação do } \\
\text { carregamento } \\
\text { na viga }\end{array}$ \\
\hline $\begin{array}{c}\text { Importação do } \\
\text { modelo do } \\
\text { TrueGrid }\end{array}$ & $\begin{array}{c}\text { Definição dos } \\
\text { elementos } \\
\text { finitos }\end{array}$ & $\begin{array}{l}\text { Processamento } \\
\text { e visualização } \\
\text { dos resultados }\end{array}$ \\
\hline
\end{tabular}

\subsubsection{Modelagem tridimensional}

O avanço tecnológico da informática no século XXI, praticamente, eliminou uma das dificuldades encontradas até o início da década de 90 que era o tempo de processamento dos modelos em elementos finitos. Um exemplo de simplificação na análise de ligações pode ser observada no trabalho de Bahaari e Sherbourne (1994 apud MAGGI, 2000, p.17). Verificam-se na pesquisa simplificações como a utilização de elementos finitos de casca para representar vigas, pilar e chapas, juntamente, com elementos finitos de mola para a simulação do comportamento dos parafusos.

Visando eliminar possíveis problemas decorrentes de simplificações e tornar a modelagem mais próxima do modelo físico, optou-se pela utilização de modelos tridimensionais em elementos sólidos. 
Como destaca Maggi (2004, p.143), "[...] há fenômenos que podem ser visualizados e compreendidos com maior facilidade e com um grau elevado de detalhes se modelos tridimensionais forem utilizados [...].". Dentre os fenômenos, Maggi (2004) destaca a distribuição das deformações plásticas ao longo da espessura da chapa que, segundo o autor, pode ser facilmente observada em elementos volumétricos, diferentemente do constatado quando da utilização de elementos de casca.

Com relação aos parafusos, o autor destaca que a utilização de elementos de mola não tornaria possível a visualização das deformações e os esforços de flexão que, geralmente, ocorrem nos parafusos.

\subsubsection{Não linearidade física}

A chamada não linearidade física procura levar em conta a resposta que certo meio possa apresentar para além dos limites do regime elástico-linear idealizado. Quando um elemento é solicitado, conforme o tipo de material, pode aparecer deformações permanentes. Outra possibilidade é a ocorrência de instabilidades de resposta material, manifestadas na forma de deformações localizadas de elevado valor ou na formação de descontinuidades. Em uma análise numérica refinada, estas particularidades do material devem ser consideradas e estão englobadas no conceito de não linearidade física.

Durante certo tempo, procurou-se representar a não linearidade física dos materiais das chapas e parafusos por meio de descrições bilineares que consideravam apenas duas inclinações diferentes, uma para o trecho pré-escoamento e outra após o limite de escoamento do material. Os diagramas bilineares descrevem o modelo constitutivo do material com base no módulo de elasticidade longitunal $(E)$, a tensão de escoamento $\left(f_{y}\right)$ e um módulo plástico $\left(E_{t}\right)$ conforme observado na figura 4.2. 
Figura 4.2 - Representação esquemática da relação bilinear tensão-deformação.

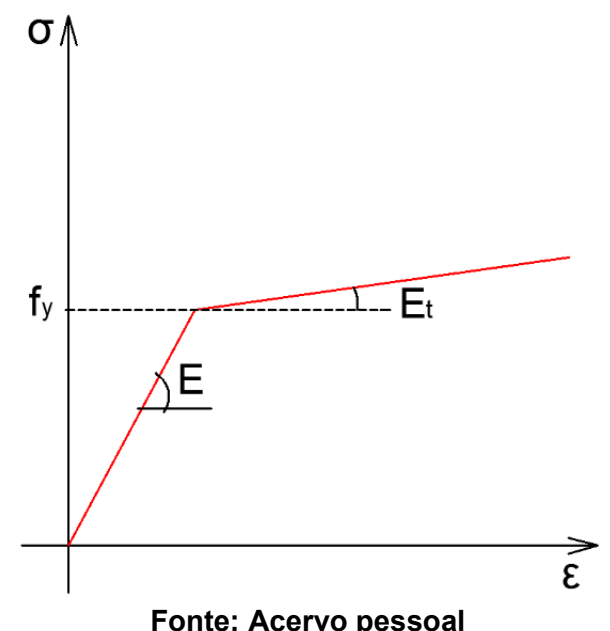

Apesar de representar um avanço na análise considerando a não linearidade física, a representação por meio de uma relação bilinear ainda apresenta grandes simplificações na representação do comportamento do material. Maggi (2004) aperfeiçoou a simulação do comportamento do aço por meio da utilização de um diagrama multilinear da relação tensão-deformação do material. A curva instituída é capaz de simular as diversas etapas da plastificação do aço incluindo patamares de escoamento, os efeitos de encruamento positivo (hardening) ou negativo (softening) e até mesmo os limites de deformação e de tensão para caracterizar o colapso. Assim como nos trabalhos de Freitas (2009) e Masioli (2011), nesta pesquisa foram adotadas as representações introduzidas por Maggi (2004), conforme a figura 4.3 e figura 4.4.

Figura 4.3 - Diagrama multilinear para a representação do material das chapas

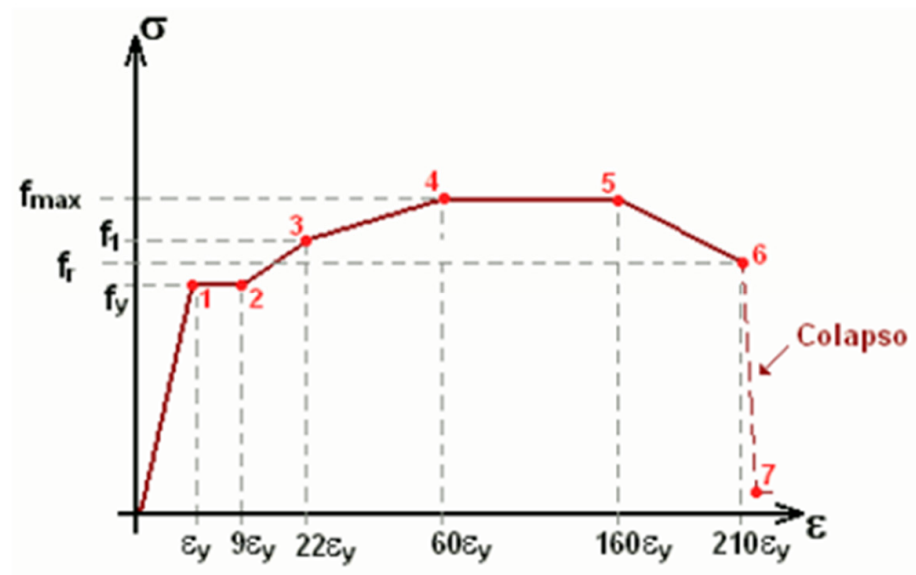

\begin{tabular}{|c|c|c|}
\hline Ponto & $\sigma$ & $\varepsilon$ \\
\hline 1 & $f_{y}$ & $\varepsilon_{y}$ \\
\hline 2 & $f_{y}$ & $9 \varepsilon_{y}$ \\
\hline 3 & $f_{y}+0,5\left(f_{u}-f_{y}\right)$ & $22 \varepsilon_{y}$ \\
\hline 4 & $f_{u}$ & $60 \varepsilon_{y}$ \\
\hline 5 & $f_{u}$ & $160 \varepsilon_{y}$ \\
\hline 6 & $f_{y}+0,2\left(f_{u}-f_{y}\right)$ & $210 \varepsilon_{y}$ \\
\hline 7 & 0,1 & $1,01\left(210 \varepsilon_{y}\right)$ \\
\hline
\end{tabular}

Fonte: Maggi (2004) 
Figura 4.4 - Diagrama multilinear para a representação do material dos parafusos

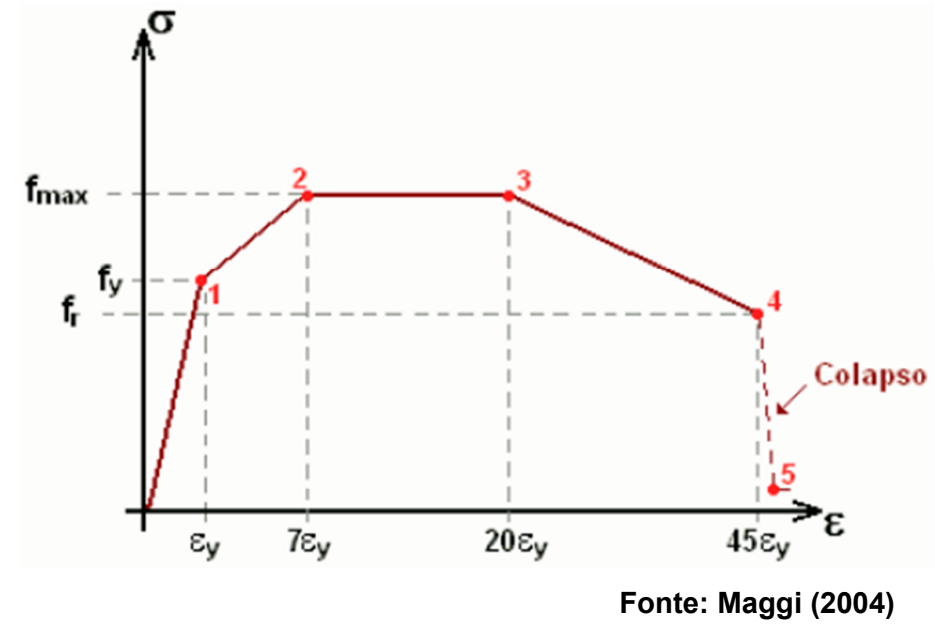

\begin{tabular}{|c|c|c|}
\hline Ponto & $\sigma$ & $\varepsilon$ \\
\hline 1 & $f_{y}$ & $\varepsilon_{y}$ \\
\hline 2 & $f_{y}+0,25\left(f_{u}-f_{y}\right)$ & $7 \varepsilon_{y}$ \\
\hline 3 & $f_{y}+0,25\left(f_{u}-f_{y}\right)$ & $20 \varepsilon_{y}$ \\
\hline 4 & $f_{y}-0,15\left(f_{u}-f_{y}\right)$ & $45 \varepsilon_{y}$ \\
\hline 5 & 0,1 & $1,01\left(45 \varepsilon_{y}\right)$ \\
\hline
\end{tabular}

$\mathrm{Na}$ modelagem optou-se pela utilização de materiais comercialmente mais disseminados. Para as vigas utilizou-se o aço ASTM A572 Gr50, para o pilar o ASTM A618 Gr II, para as chapas o ASTM A36 e para os parafusos o ASTM A325, conforme apresentado na tabela 4.1 .

Tabela 4.1 - Propriedades dos materiais ${ }^{7}$

\begin{tabular}{|c|c|c|c|}
\hline \multicolumn{4}{|c|}{ MATERIAIS } \\
\hline Componente & $\begin{array}{c}\text { Especificação } \\
\text { (ASTM) }\end{array}$ & $\begin{array}{c}\text { Tensão de escoamento } \\
\mathbf{f}_{\mathrm{y}} \text { (MPa) }\end{array}$ & $\begin{array}{c}\text { Tensão última } \\
\mathbf{f}_{\mathrm{u}} \text { (MPa) }\end{array}$ \\
\hline Vigas & ASTM A572 Gr 50 & 345 & 450 \\
\hline Pilar & ASTM A618 Gr II & 350 & 485 \\
\hline Chapas & ASTM A36 & 250 & 400 \\
\hline Parafusos & ASTM A325 & 635 & 825 \\
\hline
\end{tabular}

Fonte: Acervo pessoal

\subsubsection{Não linearidade geométrica}

Pode-se dizer de modo simplificado que os efeitos devidos a não linearidade geométrica são aqueles oriundos da mudança de posição da estrutura no espaço. Esses efeitos são determinados por meio de uma análise na qual se considera a estrutura na sua configuração final de equilíbrio

${ }^{7}$ Propriedades segundo a American Society for Testing and Materials (ASTM). 
Em Proença (2010), a definição apresentada para o conceito de não linearidade geométrica cita que "[...] as variações de geometria que ocorrem na estrutura carregada, comparando-se a posição inicial com a equilibrada, podem implicar na necessidade de se formular a condição de equilíbrio na situação deslocada [...].”. Desconsidera-se assim a hipótese simplificadora de se confundir a posição de equilíbrio após um carregamento com a configuração inicial da estrutura.

A linearidade geométrica corresponde à hipótese de pequenos deslocamentos em modelos de estruturas nos quais as equações de equilíbrio possam ser escritas na configuração não deformada. A não linearidade geométrica parte do princípio da consideração de grandes deslocamentos a fim de melhor representar os fenômenos de instabilidades geométricas localizadas. Em outras palavras, eleva-se a análise considerando o regime de grandes deslocamentos para o estudo do comportamento estrutural.

\subsection{Preparação dos modelos numéricos}

Foram analisados 10 modelos de ligação soldada e 10 modelos de ligação com a presença do diafragma (figura 4.5). As características geométricas e as particularidades inerentes à preparação dos modelos estão descritas na sequência deste capítulo.

Figura 4.5 - Modelos genéricos de ligações soldadas e ligações com diafragma

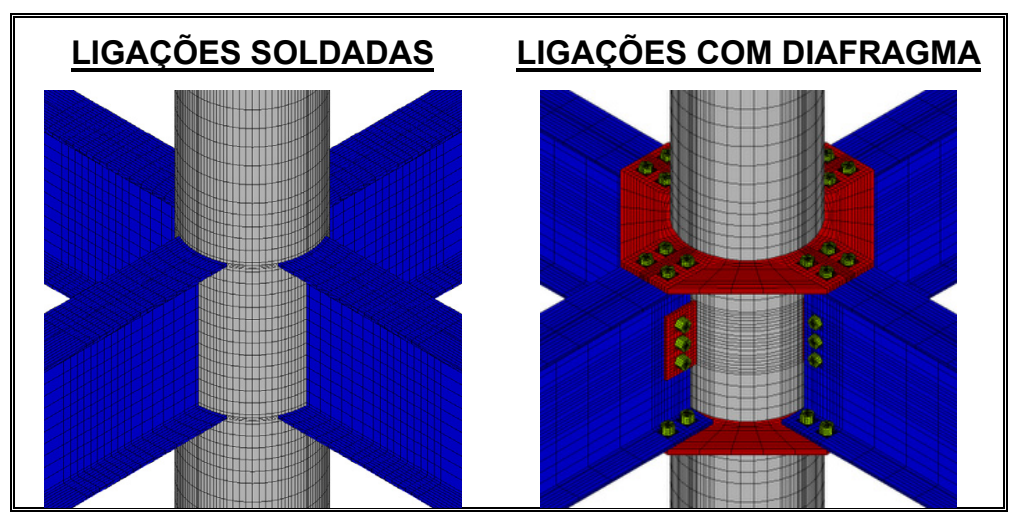

Fonte: Acervo pessoal 


\subsubsection{Geometria dos modelos}

Os protótipos da análise numérica apresentam características geométricas equivalentes nos 20 modelos visando a melhor proximidade em uma futura comparação entre os modelos. As características geométricas dos protótipos analisados estão descritas na figura 4.6.

Figura 4.6 - Geometria dos protótipos de análise

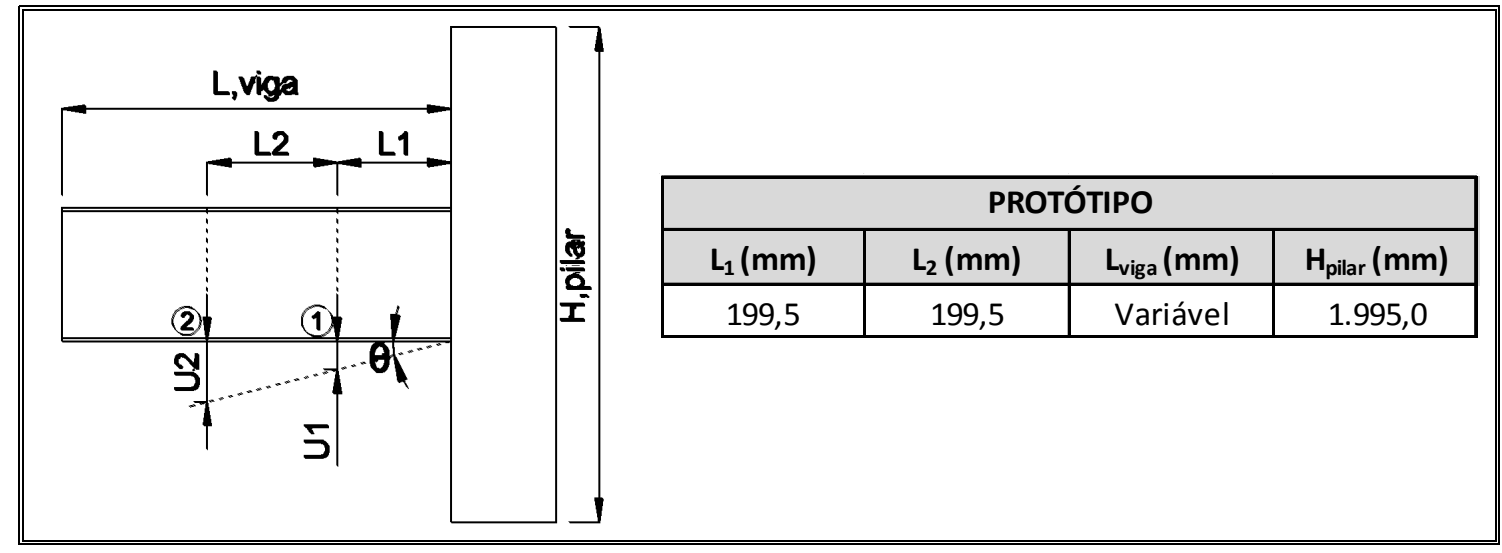

Fonte: Acervo pessoal

Optou-se por realizar a medição da rotação relativa nos pontos 1 e 2 da figura 4.6, respectivamente, à $0,5 . h_{\text {viga }}$ e $h_{\text {viga }}$ da interface viga-pilar. A rotação relativa é obtida pela diferença entre os deslocamentos verticais $U_{2}$ e $U_{1}$, dividido pela distância $\mathrm{L}_{2}$.

Os parâmetros geométricos das seções das vigas e pilar e seus respectivos valores são apresentados na figura 4.7 .

Figura 4.7 - Geometria das vigas e pilar

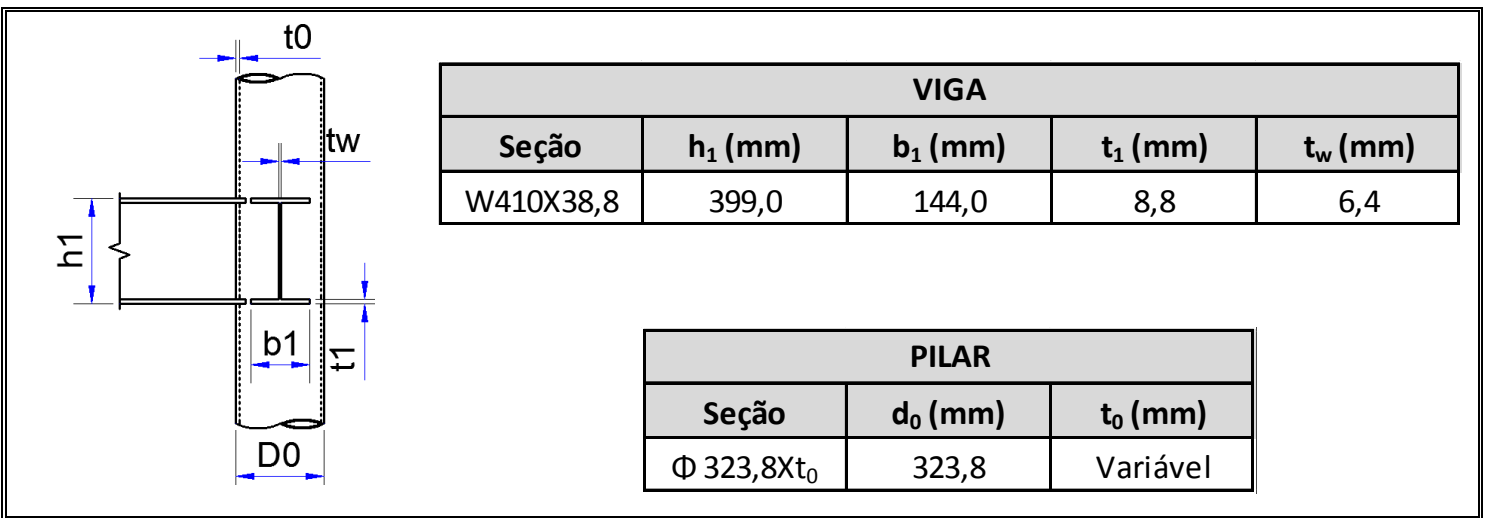

Fonte: Acervo pessoal 
A variável $t_{0}$, referente à espessura da parede do pilar, apresenta valor distinto em alguns dos modelos analisados que será especificado na sequência deste capítulo. Optou-se pela utilização de perfis laminados de abas planas (tipo W) na composição de vigas e pilar.

As chapas de alma dos modelos com diafragma possuem geometria conforme a figura 4.8. A geometria das chapas de alma é dependente da variável $d_{b}$ referente ao diâmetro dos parafusos da chapa do diafragma.

Figura 4.8 - Geometria das chapas de alma

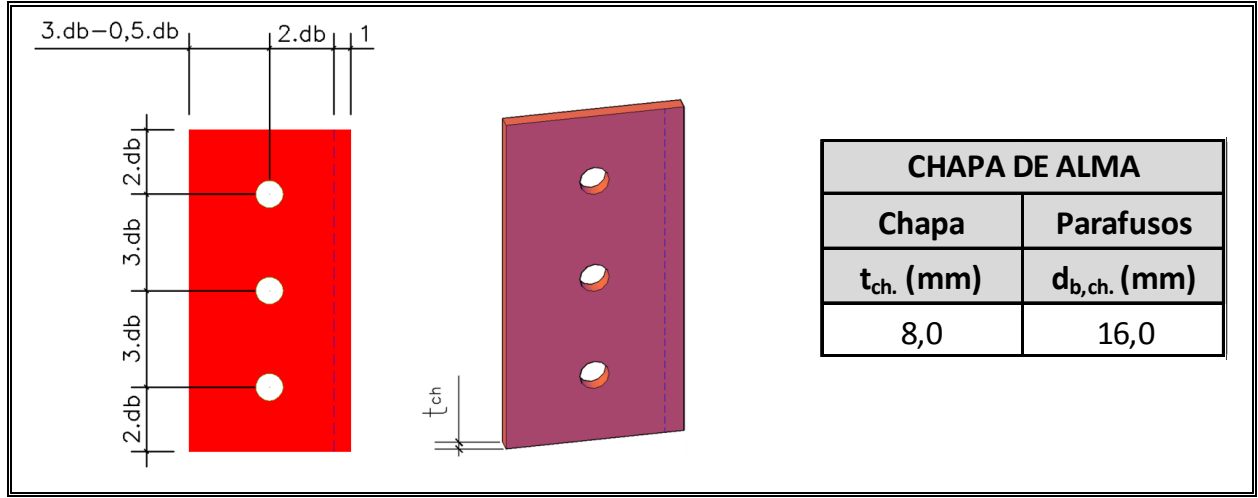

Fonte: Acervo pessoal

As variáveis relativas à geometria das chapas do diafragma estão ilustradas na figura 4.9.

Figura 4.9 - Geometria das chapas do diafragma

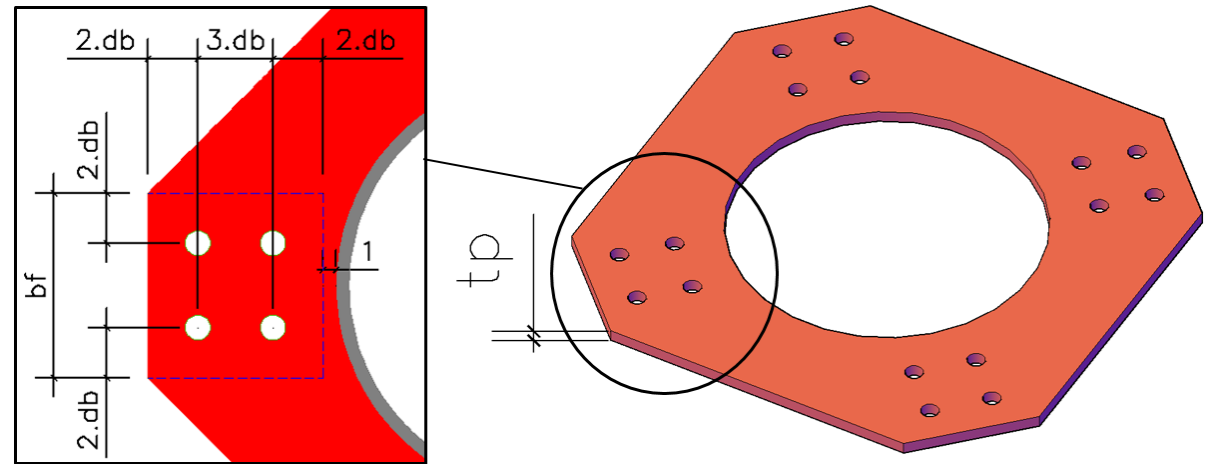

Fonte: Acervo pessoal

Foi avaliada a influência de 4 variáveis nos modelos de ligação soldada. A figura 4.10 apresenta os valores das variáveis e as nomenclaturas propostas para os 10 modelos analisados. 
Figura 4.10 - Parâmetros geométricos dos modelos de ligação soldada

\begin{tabular}{|r|r|r|r|r|}
\hline \multicolumn{7}{|c|}{ MODELOS COM LIGAÇÃO SOLDADA } \\
\hline Modelo & $\mathbf{t}_{\mathbf{0}}(\mathbf{m m})$ & $\begin{array}{c}\text { Compressão } \mathbf{n o} \\
\text { pilar (kN) }\end{array}$ & $\mathbf{F}_{\mathbf{2}} / \mathbf{F}_{\mathbf{1}}$ & $\mathbf{L}_{\text {viga }}(\mathbf{m m})$ \\
\hline XXW-1 & 10,0 & - & 1 & 2.000 \\
\hline XXW-2 & 10,0 & 1.255 & 1 & 2.000 \\
\hline XXW-3 & 14,2 & - & 1 & 2.000 \\
\hline XXW-4 & 7,1 & - & 1 & 2.000 \\
\hline XXW-5 & 10,0 & - & 1 & 500 \\
\hline XXW-6 & 10,0 & - & 1 & 5.000 \\
\hline XXW-7 & 10,0 & - & 0 & 2.000 \\
\hline TTW-1 & 10,0 & - & 1 & 2.000 \\
\hline TTW-3 & 14,2 & - & 1 & 2.000 \\
\hline TTW-7 & 10,0 & - & 0 & 2.000 \\
\hline
\end{tabular}

Fonte: Acervo pessoal

Optou-se por denominar os modelos a partir de uma nomenclatura mnemônica procurando especificar por meio de uma sigla o tipo de modelo analisado. Os modelos de ligação do tipo XX são denominados por meio do prefixo XX. A mesma consideração abrange os modelos do tipo TT. As ligações soldadas estão representadas pela letra $W$, do termo em inglês welded. As ligações com a presença do diafragma como mecanismo de enrijecimento são representadas pela letra $S$, do termo em inglês stiffened.

A relação $F_{2} / F_{1}$ referenciada na figura 4.10 representa a relação entre a força vertical aplicada nas vigas dispostas em direções ortogonais (figura 4.11). Os valores destacados na figura 4.10 são referentes às variáveis físicas ou geométricas distintas em relação ao modelo-base $\mathrm{XXW}-1$.

Figura 4.11 - Força aplicada em direções ortogonais

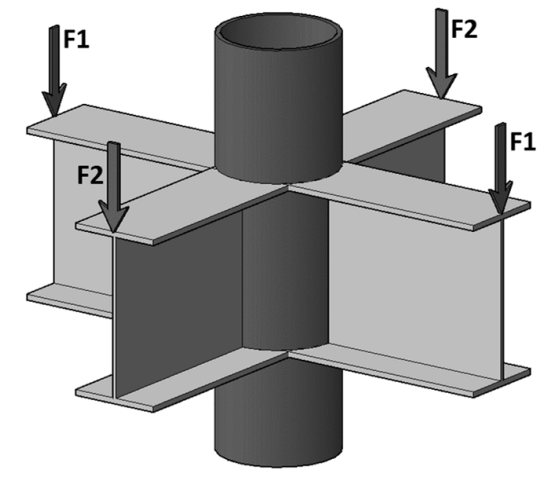

Fonte: Acervo pessoal 
As variáveis físicas e geométricas relativas aos modelos de ligação com diafragma estão apresentados na figura 4.12. Os valores destacados na figura 4.12 são referentes às variáveis físicas ou geométricas distintas em relação ao modelobase XXS-1.

Figura 4.12 - Parâmetros geométricos dos modelos de ligação com diafragma

\begin{tabular}{|c|c|c|c|c|c|}
\hline \multicolumn{6}{|c|}{ MODELOS COM DIAFRAGMA } \\
\hline \multirow[b]{2}{*}{ Modelo } & \multirow[b]{2}{*}{$t_{0}(m m)$} & \multirow[b]{2}{*}{$F_{2} / F_{1}$} & \multirow[b]{2}{*}{$\mathrm{L}_{\text {viga }}(\mathrm{mm})$} & \multicolumn{2}{|c|}{ Diafragma } \\
\hline & & & & $\begin{array}{l}\text { Chapas } \\
t_{p}(m m)\end{array}$ & $\begin{array}{c}\text { Parafusos } \\
d_{b}(\mathrm{~mm})\end{array}$ \\
\hline XXS-1 & 10,0 & 1 & 2.000 & 12,7 & 19,0 \\
\hline $\mathrm{XXS}-2$ & 10,0 & 0 & 2.000 & 12,7 & 19,0 \\
\hline XXS-3 & 7,1 & 1 & 2.000 & 12,7 & 19,0 \\
\hline$X X S-4$ & 10,0 & 1 & 2.000 & 19,0 & 19,0 \\
\hline$X X S-5$ & 10,0 & 1 & 2.000 & 9,5 & 19,0 \\
\hline XXS-6 & 14,2 & 1 & 2.000 & 12,7 & 19,0 \\
\hline XXS-7 & 10,0 & 1 & 2.000 & 12,7 & 12,7 \\
\hline XXS-8 & 10,0 & 1 & 2.000 & 12,7 & 16,0 \\
\hline XXS-9 & 10,0 & 1 & 500 & 12,7 & 19,0 \\
\hline TTS-1 & 10,0 & 1 & 2.000 & 12,7 & 19,0 \\
\hline
\end{tabular}

Fonte: Acervo pessoal

\subsubsection{Elementos finitos e discretização}

A opção pela análise via Método dos Elementos Finitos recai na necessidade de se determinar os elementos finitos a serem utilizados para simular de maneira eficiente e satisfatória o comportamento da estrutura. Para isso, utilizou-se a biblioteca do software ANSYS ${ }^{\circledR}$ em conjunto com trabalhos desenvolvidos anteriormente que obtiveram resultados satisfatórios, para determinar o elemento finito mais adequado para o tipo de análise que se pretende.

$\mathrm{Na}$ sequência deste capítulo destacam-se os elementos escolhidos assim como as características destes. Apresenta-se a discretização adotada na malha de elementos finitos em função do refinamento desejado na solução numérica. 


\subsubsection{Elemento finito tridimensional}

$\mathrm{Na}$ modelagem tridimensional, as vigas, o pilar, as chapas e os parafusos (quando existirem) dos modelos foram discretizados por meio de elementos finitos volumétricos. A biblioteca do software ANSYS ${ }^{\circledR}$ dispõe de uma grande variedade de elementos e a escolha do elemento deve ser de acordo com as premissas relativas à geometria e materiais e as considerações inerentes ao elemento, buscando uma resposta numérica satisfatória.

Para a discretização da geometria dos modelos sem a presença de parafusos utilizou-se o elemento SOLID45 (figura 4.13). O SOLID45 é um elemento hexaédrico composto de oito nós com três graus de liberdade em cada nó, sendo estes as translações nos eixos globais $\mathrm{X}, \mathrm{Y}$ e $\mathrm{Z}$.

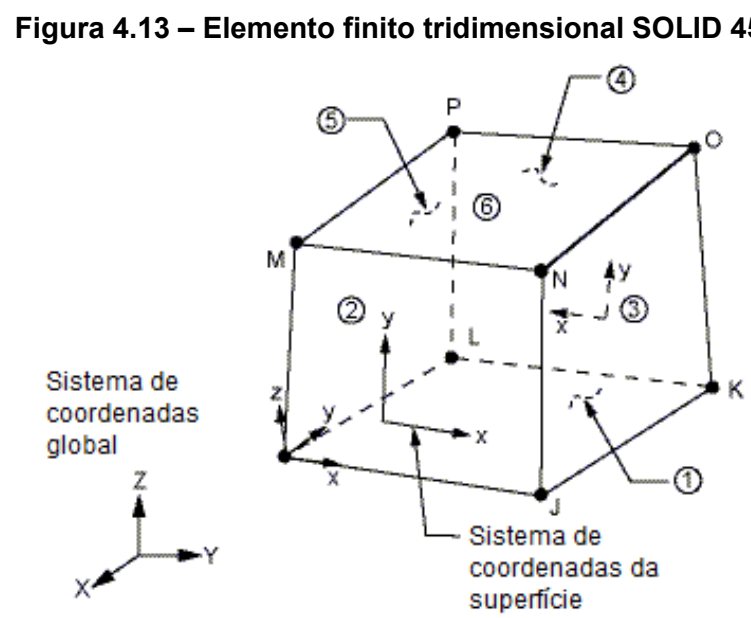

Fonte: ANSYS ${ }^{\circledR}$

Para os modelos com a presença de parafusos optou-se por realizar uma modelagem mais refinada adotando o elemento finito SOLID95. O SOLID95 é uma versão aprimorada do elemento finito SOLID45, diferenciando-se pela presença dos nós intermediários totalizando um elemento finito com 20 nós conforme a figura 4.14. Este elemento tolera formas irregulares sem grandes perdas de precisão. 
Figura 4.14 - Elemento finito tridimensional SOLID95. Fonte:

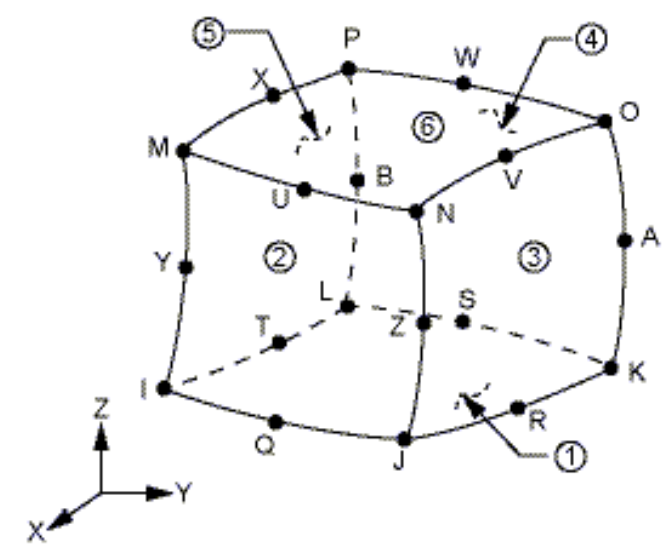

Fonte: ANSYS ${ }^{\circledR}$

A escolha por estes elementos (SOLID45 e SOLID95) permite a consideração de premissas essenciais nesta análise como a não linearidade física, por meio da consideração da plasticidade e do encruamento, e a não linearidade geométrica considerando grandes deslocamentos e deformações.

\subsubsection{Elementos de contato}

Em modelos tridimensionais de ligações há a presença de descontinuidades geométricas devido à ligação entre as vigas, chapas, parafusos e pilar. Neste ponto de descontinuidade existe o contato entre os elementos gerando uma tendência de penetração de um corpo no outro. Verifica-se então uma região com transferência de esforços por meio de contato, havendo a necessidade da utilização dos chamados elementos finitos de contato a fim de simular esta interação entre os componentes da ligação.

Em termos numéricos, a presença dos elementos de contato, como lembrou Masioli (2011, p.85) "[...] introduz novos termos na matriz de rigidez possibilitando a geração de esforços quando uma superfície é comprimida à outra - tendência de penetração - e possibilitando a separação das superfícies quando houver solicitações de tração [...]". 
Nos modelos com a presença de chapas e parafusos considerou-se a presença de elementos finitos de contato para representar a interface entre estes elementos. Por outro lado, nos modelos com ligações soldadas, optou-se por não considerar a espessura da solda, admitindo-se assim, que haverá um dimensionamento correto da solda não havendo falha da ligação devido à falha da solda. Esta consideração simplifica a discretização da interface e segue as premissas estipuladas pelo Eurocode 3 Part 1-8 (2005) quanto ao dimensionamento das soldas.

Adotando uma metodologia semelhante à de Maggi (2004), Freitas (2009) e Masioli (2011) foram utilizados elementos de contato para representar a interação superfície-superfície. Segundo esta metodologia, são necessários dois tipos de elementos finitos da biblioteca do software ANSYS ${ }^{\circledR}$, um que define a superfície alvo da interface (TARGE170) e outro que define a superfície na qual o contato será inspecionado (CONTA174). A superfície alvo é aquela que sofrerá a ação da outra superfície, enquanto que, a superfície na qual o contato será inspecionado é aquela que exerce a ação sobre a superfície alvo. Esse par de superfícies trabalha em associação sendo denominadas pares de contatos, conforme demonstrado na figura 4.15 e figura 4.16 .
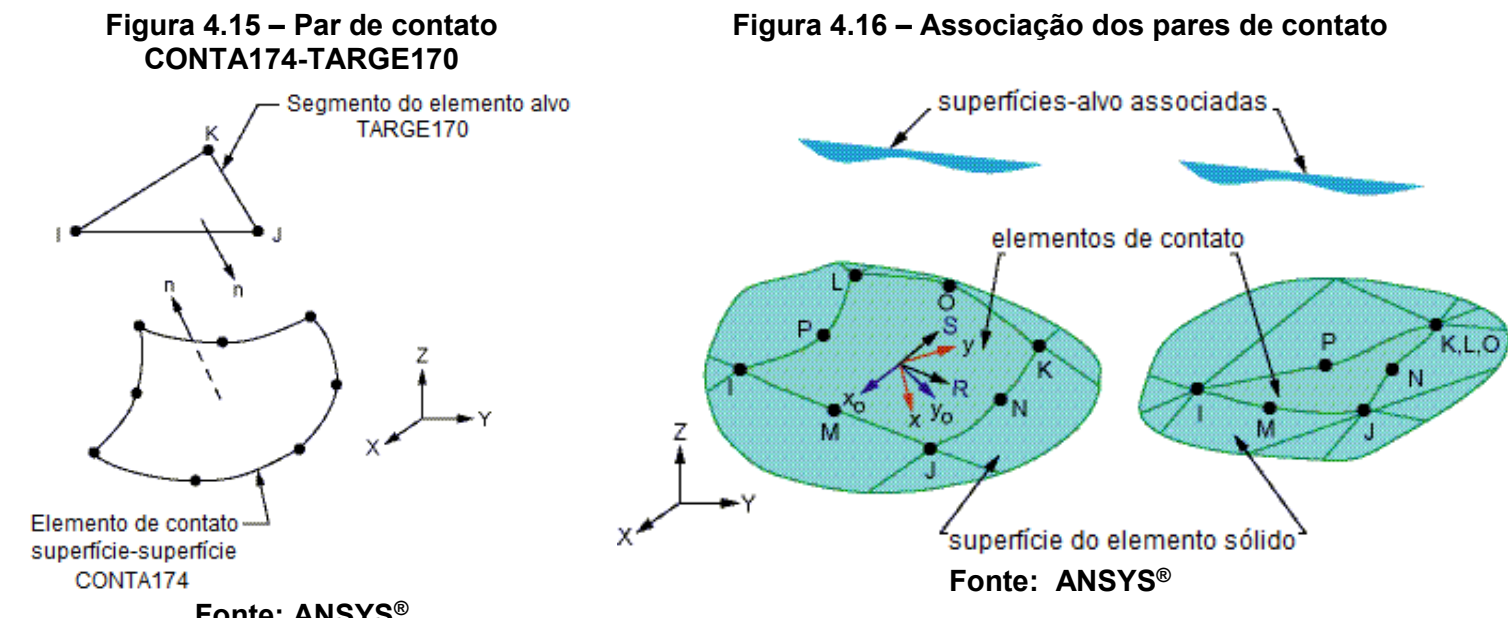

Fonte: ANSYS ${ }^{\circledR}$

O mecanismo de funcionamento dos pares de contato considera que os elementos de contato (CONTA174) envolvem o sólido descrevendo o contorno de um corpo deformável. Por sua vez, estes elementos estão potencialmente em contato com a superfície alvo, definida pelo elemento TARGE170. Desta forma, sugere-se que o elemento TARGE170 possua a mesma característica geométrica da face do elemento sólido ao qual ele está associado (figura 4.16), isto é, um elemento com 8 
nós. A associação entre o TARGE170 e o respectivo par CONTA174 é feita por meio da definição de constantes reais inerentes e exclusivas ao referido par de contato.

Dentre as constantes reais definidas para os pares de contato tem-se o coeficiente de rigidez normal, a tolerância de penetração e o coeficiente de atrito estático entre as superfícies. Seguindo recomendações do software ANSYS $^{\circledR}$ e adotando uma metodologia semelhante aos trabalhos de Maggi (2004), Freitas (2009) e Masioli (2011), adotou-se o coeficiente de atrito estático igual a 0,3 e as rigidezes de contato, normal e tangencial, com seus valores unitários.

\subsubsection{Discretização}

O Método dos Elementos Finitos parte do princípio de que a solução do problema passa a ser mais próxima do modelo físico conforme se aumenta a subdivisão dos elementos de um determinado modelo. Além disso, sabe-se que a partir de certo número de subdivisões, a solução aprimorada passa a não ser uma aproximação melhor do que a anteriormente utilizada. A solução ideal é aquela que melhor aproxima à solução exata (mais próxima do modelo físico) e, ao mesmo tempo, não sobrecarrega o modelo numericamente.

Buscando um processo de otimização da malha de elementos finitos optouse por aumentar o refinamento da malha apenas nas regiões mais importantes do modelo em termos de comportamento estrutural. Nas demais regiões utilizou-se uma malha com um refinamento inferior, isto é, elementos geometricamente maiores.

A malha de elementos finitos foi gerada por meio do software TrueGrid ${ }^{\circledR}$. O TrueGrid ${ }^{\circledR}$ adota um procedimento em que o refinamento passa a ser uma das últimas tarefas na geração da malha. Inicialmente, definem-se pontos chaves dentre os quais serão gerados os elementos finitos sem quaisquer refinamentos. Em uma etapa posterior é fornecida ao programa a quantidade de divisões que se deseja fazer no trecho especificado, discretizando adequadamente a malha e refinando a solução numérica. 
a) Discretização das vigas, pilar e chapas

A discretização das malhas das vigas, pilar e chapas seguiu um raciocínio inerente às condições da análise numérica. Considerando a influência das propriedades de plastificação do material inseridos no contexto da análise, sabe-se que é um fator determinante para se avaliar a qualidade da resposta numérica haver uma discretização mais criteriosa nas regiões onde se espera uma ordem de grandeza de tensões considerável.

As regiões com concentração de tensões e, consequentemente, sujeitas a níveis elevados de plastificação possuem uma malha mais refinada, ou seja, com maior número de elementos finitos. A região em questão é a interface entre os elementos ligados.

O refinamento das vigas foi aprimorado na região próxima ao pilar e, gradativamente, reduziu-se o refinamento (elementos maiores) com o distanciamento da face do pilar (figura 4.17).

Figura 4.17 - Discretização das vigas
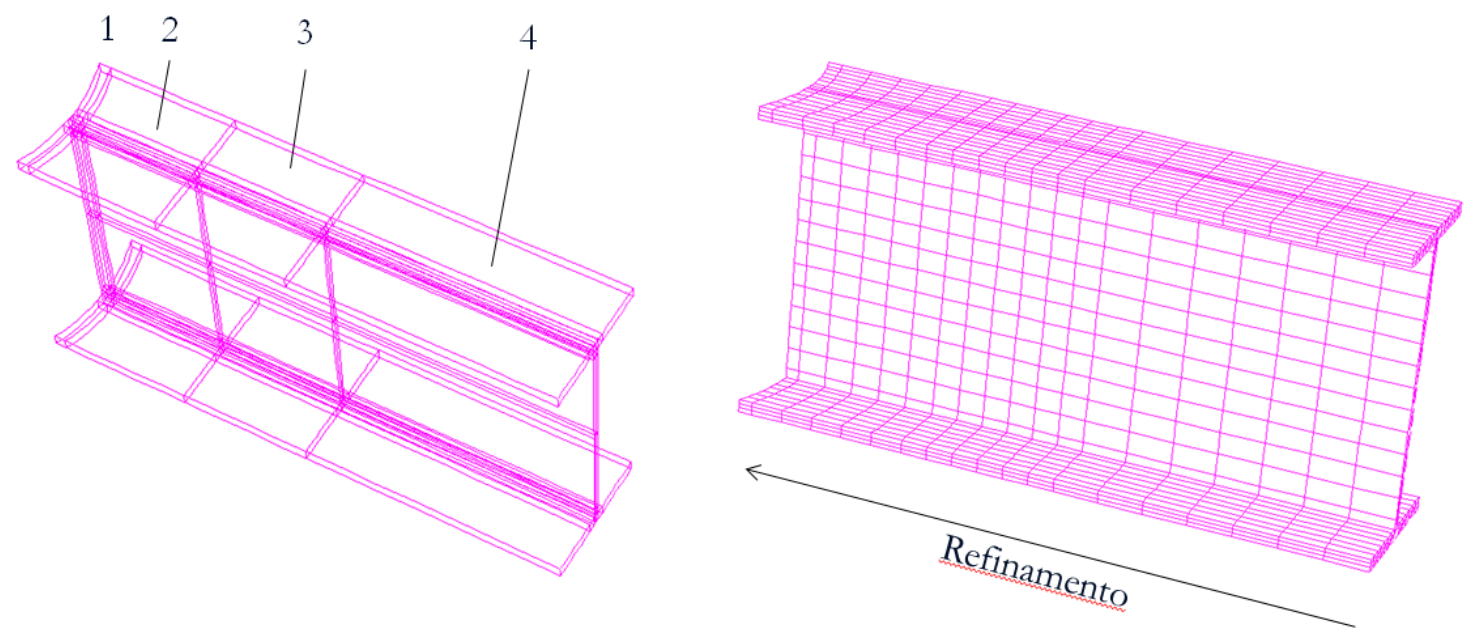

Fonte: Acervo pessoal

Nos pilares a discretização foi mais criteriosa na região de ligação com as almas e mesas das vigas (figura 4.18). 
Figura 4.18 - Discretização do pilar

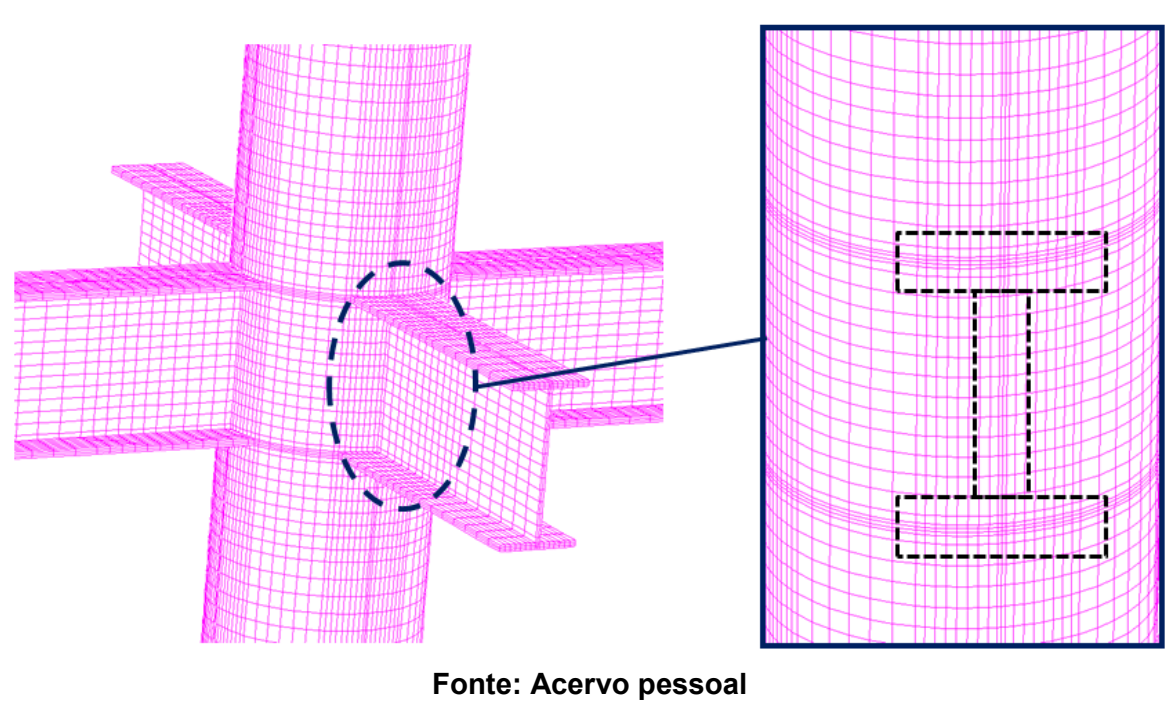

Nas chapas do diafragma externo seguiu-se o refinamento imposto pelo pilar, exceto na região dos furos onde, devido à ligação parafusada ocasionar tensões elevadas, aumentou-se o refinamento. Seguindo este mesmo critério, nas chapas de alma deu-se maior atenção à região dos furos gerando uma malha com elementos de tamanho reduzido (figura 4.19).

Figura 4.19 - Discretização das chapas
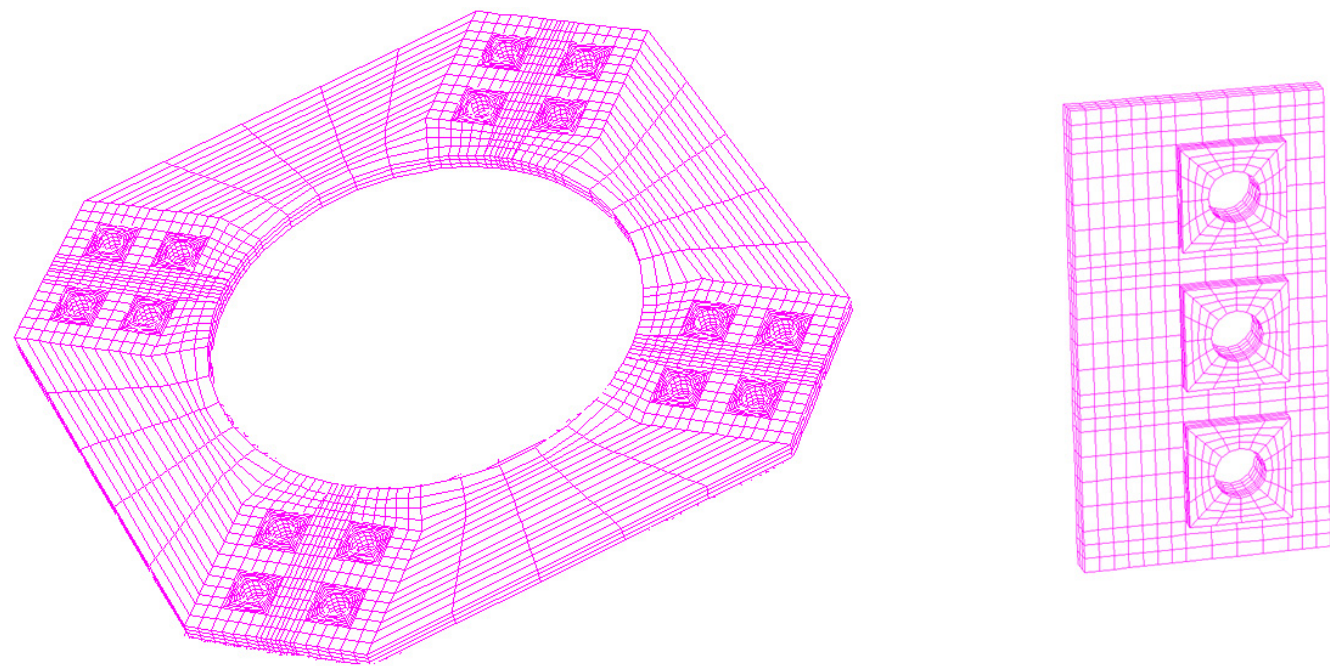

Fonte: Acervo pessoal 
b) Discretização dos parafusos

A discretização dos parafusos busca uma representação geométrica adequada à simulação numérica, visto que, os parafusos reais (figura 4.20) não são geometricamente homogêneos, devido à existência da rosca.

Figura 4.20 - Parafuso sextavado em sua geometria original

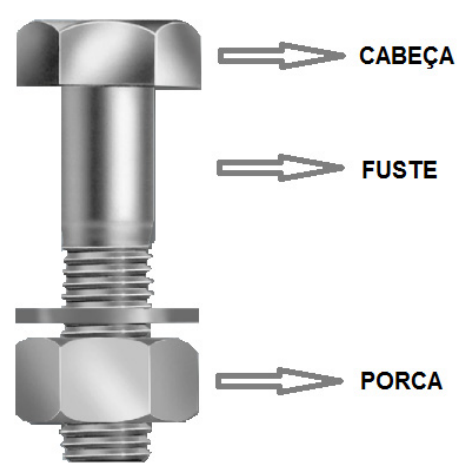

Fonte: ciser.com.br

$\mathrm{Na}$ simulação numérica adotou-se pequenas simplificações para a representação dos parafusos. A seguir, apresentam-se as considerações e simplificações adotadas na discretização dos parafusos:

- Foram adotados parafusos hexaédricos (sextavados);

- Os parafusos foram construídos considerando o conjunto porca-parafuso como um único elemento sólido (figura 4.21);

- As roscas foram desconsideradas visto à dificuldade de implementação no modelo e a reduzida influência na resposta numérica;

- O fuste (circular) do parafuso no modelo numérico possui o diâmetro nominal do parafuso real. Assim, o contato entre o fuste e os furos pode ser simulado adequadamente;

- O comprimento do fuste foi adotado como sendo à soma das espessuras das chapas situadas entre a cabeça e a porca. 
Figura 4.21 - Discretização dos parafusos

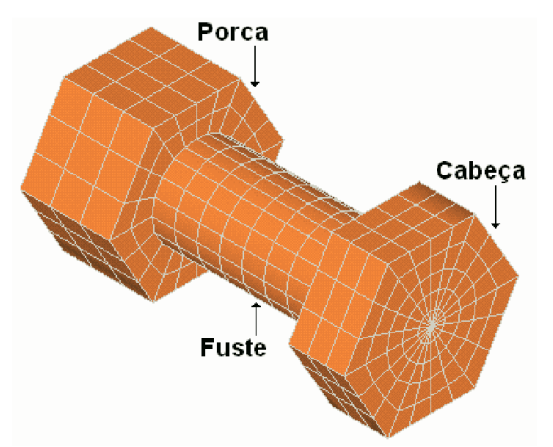

Fonte: Maggi (2004)

Salienta-se que a simplificação quanto à desconsideração das roscas não considera a redução da área da seção transversal do parafuso na região destas e que isto deve ser levado em consideração em uma avaliação mais detalhada.

\subsubsection{Condições de contorno e de carregamento}

\subsubsection{Parafusos}

$\mathrm{Na}$ análise numérica são impostas restrições que buscam representar de maneira adequada o comportamento estrutural do modelo. Nos modelos com a presença de chapas foram utilizados parafusos de alta resistência. Quando da utilização destes, a NBR 8800 (2008) obriga a aplicação de uma protensão inicial mínima adequada a cada diâmetro e tipo de parafuso utilizado. Segundo a NBR 8800 (2008) a força de protensão equivale a, aproximadamente, $70 \%$ da força de tração resistente nominal do parafuso.

No modelo numérico a aplicação da protensão nos parafusos é simulada por meio de um gradiente negativo de temperatura imposto ao fuste dos parafusos. $O$ objetivo desta analogia é gerar uma retração no fuste do parafuso que, por sua vez, tem a cabeça e porca restringida pelo contato com as chapas, gerando assim tensões de protensão no parafuso. 
$\mathrm{Na}$ análise numérica há a necessidade de transformar a força de protensão, determinada pela NBR 8800 (2008), em um valor de variação de temperatura a ser aplicada que enfim gerem tensões no fuste equivalentes à protensão determinada.

Esta tarefa fica facilitada por meio da utilização dos diagramas elaborados por Maggi (2004). Com base na força total de protensão desejada, obtém-se a variação total de temperatura com o comprimento total do fuste dos parafusos (figura 4.22), cujo valor é a soma das espessuras das chapas conectadas.

Figura 4.22 - Diagramas temperatura-comprimento para a aplicação da protensão

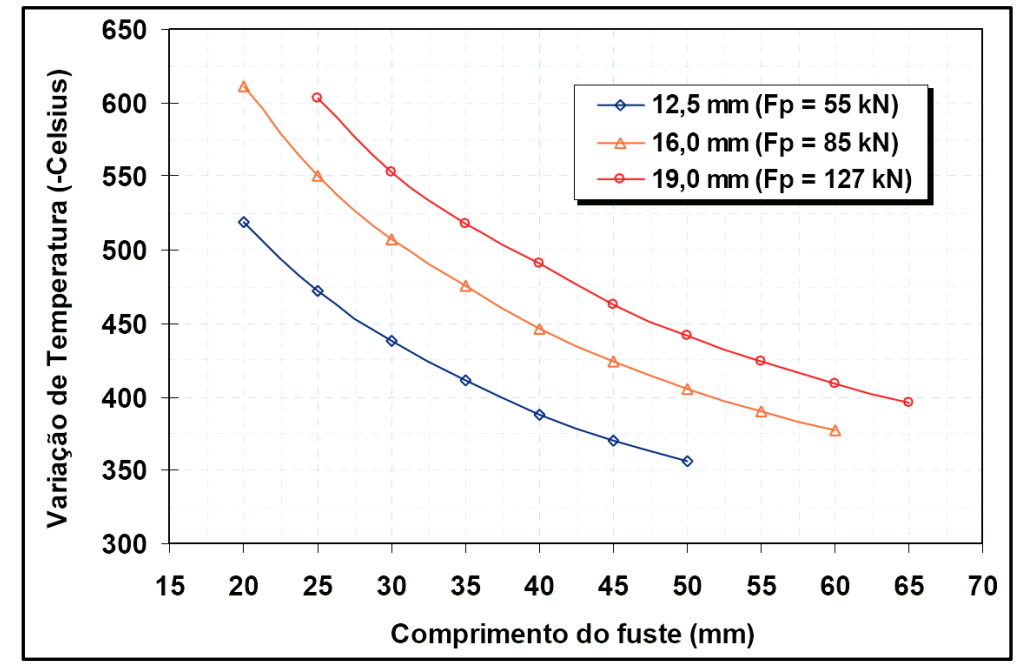

Fonte: Maggi (2004)

Ressalta-se que as características do material do parafuso não são dependentes da temperatura, sendo assim, a aplicação da variação de temperatura não altera as características mecânicas do material.

\subsubsection{Pilar}

Considerou-se a presença de um engaste nas extremidades do pilar, a uma distância considerável da ligação viga-pilar, de forma que estas restrições não influenciem a distribuição de tensões na região da ligação viga-pilar. Todos os nós situados na extremidade inferior do pilar foram impedidos de transladar e rotacionar em X, Y e Z. 
No modelo XXW-2 foi aplicada uma força de compressão axial no pilar em uma fase anterior ao carregamento da viga. A força aplicada é equivalente à $40 \%$ da capacidade resistente do pilar à compressão. A força é transformada em deslocamento equivalente, ou seja, foi calculado o deslocamento axial capaz de gerar a força necessária. A compressão axial do pilar foi feita em termos de deslocamentos e aplicada em uma de suas extremidades.

\subsubsection{Vigas}

O esforço mais relevante ao qual a ligação será solicitada é proveniente da aplicação de uma força na extremidade da viga gerando esforços de flexão e cisalhamento na região da ligação.

Neste trabalho, o carregamento foi aplicado por meio de deslocamento imposto na direção vertical (UY). Aplicou-se o deslocamento no nó da extremidade inferior direita de cada viga (figura 4.23) e, por meio de um artifício no software ANSYS $^{\circledR}$ realizou-se a compatibilização dos deslocamentos dos nós da extremidade de cada viga (figura 4.24) para garantir um comportamento homogêneo nestas regiões.

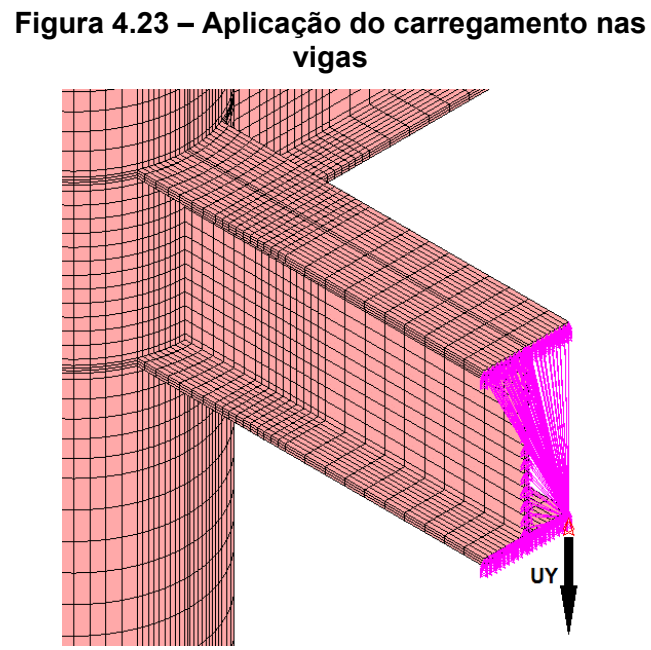

Fonte: Acervo pessoal
Figura 4.24 - Compatibilização dos deslocamentos na extremidade das vigas

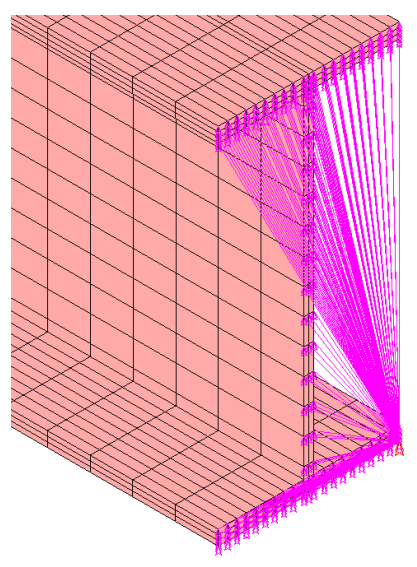

Fonte: Acervo pessoal

A viga foi solicitada por meio de passos de carga até o estágio de não haver mais a convergência do modelo em iterações consecutivas. Caracteriza-se a não 
convergência do modelo por regiões em estágio avançado de plastificação, isto é, em nível de colapso.

Considerando uma abordagem geral dos modelos, a aplicação dos carregamentos foi realizada em três etapas, sendo a primeira a aplicação da protensão nos parafusos, a segunda o carregamento axial do pilar e a terceira o carregamento na extremidade das vigas por meio de incrementos de carregamento até atingir o deslocamento vertical proposto ou o estado limite último da ligação.

\subsubsection{Critérios de convergência}

O colapso nos modelos numéricos é obtido pela não convergência da solução numérica, o que geralmente ocorre em estágios avançados de carregamento. Nos modelos de ligação soldada optou-se por carregar o modelo por meio de um deslocamento vertical até o limite de $16 \mathrm{~cm}$. Nas ligações com o diafragma o carregamento foi realizado até um limite de $8 \mathrm{~cm}$.

Os carregamentos foram realizados por meio de incrementos, caracterizando uma solução incremental-iterativa. No software ANSYS ${ }^{\circledR}$ adotou-se um método aproximado para a solução de problemas não lineares numa estratégia onde aplicase uma solicitação de forma incremental e faz-se uma estimativa inicial elástica da solução. O processo iterativo encerra-se quando a diferença entre a solução estimada e a solução numérica atende a uma tolerância especificada, admite-se então que a estrutura está em equilíbrio. A tolerância imposta foi de $1 \times 10^{-3}$ mostrando-se adequada para a análise.

O valor de cada incremento tem sua importância destacada, uma vez que o processo iterativo ocorre em cada subdivisão do carregamento. Neste caso, padronizaram-se incrementos iniciais de $0,33 \%$ para a fase de protensão dos parafusos e de $0,1 \%$ e $0,05 \%$, respectivamente, para a aplicação dos carregamentos nas ligações analisadas. 


\section{Capítulo 5}

\section{Análise dos resultados}

Nos capítulos iniciais deste trabalho procurou-se detalhar de forma breve alguns conceitos inerentes ao estudo de ligações entre viga de seção I e pilar de seção tubular circular. No capítulo 4, foram apresentados os critérios adotados para a modelagem numérica proposta para esta pesquisa, assim como, a geometria dos modelos analisados. A partir deste presente capítulo, dá-se destaque aos resultados obtidos na análise numérica e às respectivas considerações.

A análise numérica foi realizada em duas etapas consecutivas:

I) Análise numérica de modelos com as características de modelos experimentais de outros autores;

II) Análise numérica de modelos com as características propostas por este autor.

A primeira etapa consiste na análise numérica de modelos de ligação vigapilar ${ }^{8}$ com características físicas e geométricas semelhantes às adotadas em modelos experimentais de referência. $O$ objetivo desta análise é realizar a comparação entre resultados numéricos e experimentais, de forma a evidenciar a eficiência dos critérios adotados na simulação numérica.

Em um segundo momento (etapa II) são analisados os resultados da análise numérica dos modelos propostos por este autor, com as características descritas no capítulo 4. Esta etapa tem como principal objetivo a avaliação da influência de algumas variáveis no comportamento estrutural das ligações.

${ }^{8}$ Conforme destacado ao longo deste trabalho, no contexto desta pesquisa, o termo ligação viga-pilar remete-se à ligação entre viga de seção do tipo I e pilar de seção tubular circular. 


\subsection{Comparação entre resultados numéricos e experimentais}

Pesquisas experimentais são mais dispendiosas no que diz respeito a custo e tempo de trabalho. Apesar de mais escassos, os resultados obtidos em pesquisas experimentais são importantes para a confirmação e incorporação de metodologias utilizadas em simulações numéricas.

Na sequência são apresentadas as características dos modelos de referência analisados e os resultados comparativos visando avaliar o comportamento obtido na análise numérica, comparativamente, com o comportamento verificado no âmbito experimental.

\subsubsection{Modelos com ligações soldadas}

Por meio de uma vasta pesquisa em bases de dados, escolheram-se os resultados experimentais dos modelos com ligações soldadas dos seguintes autores:

a) Winkel (1998)

b) Reis (2011)

c) Masioli (2011)

Winkel (1998) realizou a análise experimental de ligações soldadas do tipo "XX"9. O autor nomeou os modelos em 3C1, 3C3 e 3C4, diferindo entre si apenas pelo sentido do carregamento conforme ilustram, respectivamente, a figura 5.1 , figura 5.2 e figura 5.3.

9 A ligação do tipo XX caracteriza-se pela presença de 4 vigas perpendiculares entre si conectadas à face do pilar. 
Figura 5.1 - Modelo 3C1

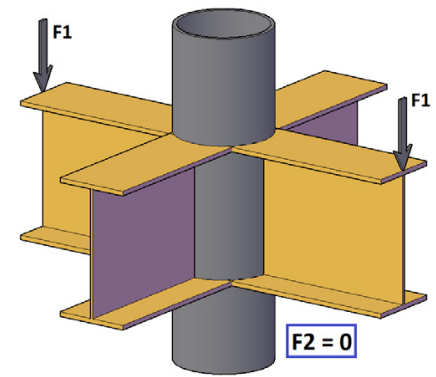

Fonte: Acervo pessoal
Figura 5.2 - Modelo 3C3

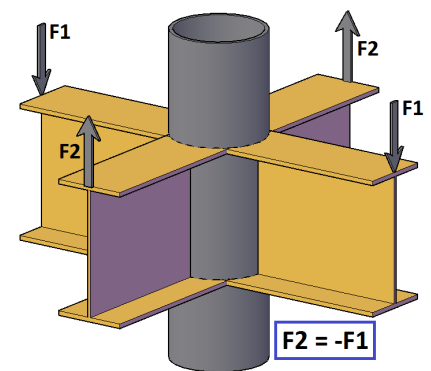

Fonte: Acervo pessoal
Figura 5.3 - Modelo 3C4

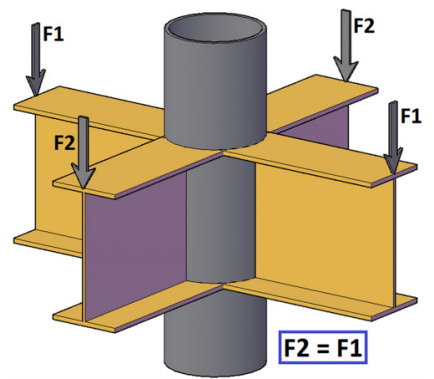

Fonte: Acervo pessoal

Reis (2011) e Masioli (2011) desenvolveram pesquisas experimentais em ligações do tipo "T"10. Os modelos P2 e P3 de Reis (2011) diferem-se, entre si, com relação às propriedades geométricas das seções transversais. Masioli (2011) realizou ensaio experimental em apenas um único modelo de ligação soldada, o TCR-W.

\subsubsection{Características físicas e geométricas}

As variáveis geométricas das seções transversais e dos protótipos ensaiados estão ilustradas, respectivamente, na figura 5.4 e na figura 5.5 .

Figura 5.4 - Parâmetros geométricos das seções transversais

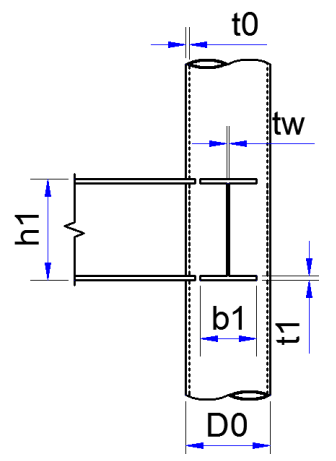

Fonte: Acervo pessoal
Figura 5.5 - Parâmetros geométricos do protótipo de ensaio

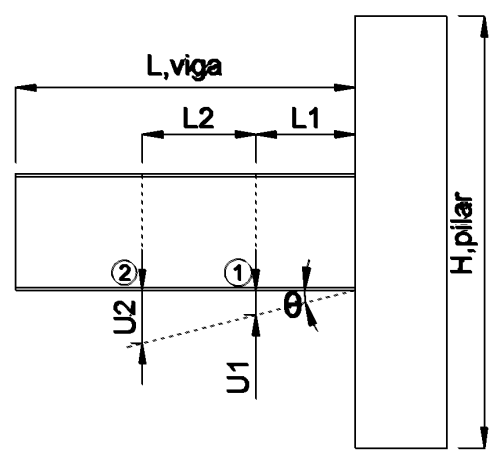

Fonte: Acervo pessoal

Winkel (1998), Reis (2011) e Masioli (2011) realizaram a análise de modelos de ligações com as propriedades geométricas destacadas na tabela 5.1.

${ }^{10}$ Ligações do tipo T são evidenciadas pela presença de uma única viga ligada à face do pilar. 
Tabela 5.1 - Propriedades geométricas das seções e do protótipo de ensaio dos modelos experimentais

\begin{tabular}{|c|c|c|c|c|c|c|c|c|c|c|c|}
\hline \multirow{3}{*}{ AUTOR } & \multirow{3}{*}{ MODELO } & \multicolumn{2}{|c|}{ PILAR } & \multicolumn{4}{|c|}{ VIGA(S) } & \multicolumn{4}{|c|}{ PROTÓTIPO DE ENSAIO } \\
\hline & & $\mathrm{d}_{0}$ & $t_{0}$ & $h_{1}$ & $\mathbf{b}_{1}$ & $\mathbf{t}_{1}$ & $\mathbf{t}_{\mathrm{w}}$ & $\mathbf{H}_{\text {pilar }}$ & $\mathbf{L}_{\text {viga }}$ & $\mathrm{L}_{1}$ & $\mathbf{L}_{2}$ \\
\hline & & $(\mathrm{mm})$ & $(\mathrm{mm})$ & $(\mathrm{mm})$ & $(\mathrm{mm})$ & $(\mathrm{mm})$ & $(\mathrm{mm})$ & $(\mathrm{mm})$ & $(\mathrm{mm})$ & $(\mathrm{mm})$ & $(\mathrm{mm})$ \\
\hline Winkel (1998) & $3 \mathrm{C} 1$ & 324,3 & 9,4 & 242,1 & 120,0 & 9,8 & 6,6 & $2.187,9$ & $1.210,7$ & 350,0 & 400,0 \\
\hline Winkel (1998) & $3 C 3$ & 324,3 & 9,4 & 242,0 & 120,4 & 9,8 & 6,6 & $2.187,8$ & $1.210,1$ & 350,0 & 400,0 \\
\hline Winkel (1998) & $3 C 4$ & 324,3 & 9,4 & 242,0 & 120,4 & 9,8 & 6,6 & $2.187,8$ & $1.210,1$ & 350,0 & 400,0 \\
\hline Reis (2011) & P2 & 219,1 & 9,5 & 310,0 & 165,0 & 9,7 & 5,8 & $1.500,0$ & $1.500,0$ & 290,0 & 580,0 \\
\hline Reis (2011) & P3 & 219,1 & 8,2 & 251,0 & 101,0 & 5,3 & 4,8 & $1.500,0$ & $1.500,0$ & 290,0 & 580,0 \\
\hline Masioli (2011) & TCR-W & 219,1 & 8,2 & 258,0 & 146,0 & 9,1 & 6,1 & $2.400,0$ & $1.550,0$ & 250,0 & 575,0 \\
\hline
\end{tabular}

Fonte: Acervo pessoal

As propriedades físicas dos materiais utilizados nos modelos experimentais dos três autores são apresentadas na tabela 5.2 .

Tabela 5.2 - Propriedades dos materiais dos modelos experimentais com ligação soldada

\begin{tabular}{|c|c|c|c|c|c|c|c|}
\hline \multirow{3}{*}{ AUTOR } & \multirow{3}{*}{ MODELO } & \multirow{3}{*}{\begin{tabular}{|c|} 
Mod. Elast. \\
$\mathrm{E}$ \\
(MPa) \\
\end{tabular}} & \multirow{3}{*}{$\begin{array}{c}\text { Poisson } \\
v\end{array}$} & \multicolumn{2}{|c|}{ PILAR } & \multicolumn{2}{|c|}{ VIGA(S) } \\
\hline & & & & $f_{y}$ & $f_{u}$ & $f_{y}$ & $f_{u}$ \\
\hline & & & & (MPa) & (MPa) & (MPa) & (MPa) \\
\hline Winkel (1998) & $3 \mathrm{C} 1$ & \multirow{6}{*}{200.000} & \multirow{6}{*}{0,3} & 387 & 510 & 421 & 516 \\
\hline Winkel (1998) & $3 C 3$ & & & 387 & 510 & 433 & 526 \\
\hline Winkel (1998) & $3 \mathrm{C} 4$ & & & 387 & 510 & 433 & 526 \\
\hline Reis (2011) & P2 & & & 374 & 571 & 345 & 450 \\
\hline Reis (2011) & P3 & & & 385 & 582 & 345 & 450 \\
\hline Masioli (2011) & TCR-W & & & 330 & 473 & 400 & 513 \\
\hline
\end{tabular}

Fonte: Acervo pessoal

\subsubsection{Resultados comparativos}

A comparação dos resultados experimentais dos autores destacados, com os resultados numéricos da presente pesquisa apresenta-se sobre três aspectos:

a) Sobreposição das curvas momento-rotação experimentais e numéricas;

b) Comparação entre os valores obtidos para a resistência ${ }^{11}$ das ligações;

c) Confronto entre imagens dos modelos experimentais e numéricos ao fim da análise

${ }^{11}$ Quando não especificado, o termo resistência refere-se à resistência ao momento fletor das ligações. 
Apresentam-se na figura 5.6 as curvas momento-rotação experimentais e numéricas dos 6 modelos de ligação soldada analisados.

Figura 5.6 - Comportamento momento-rotação dos modelos experimentais analisados
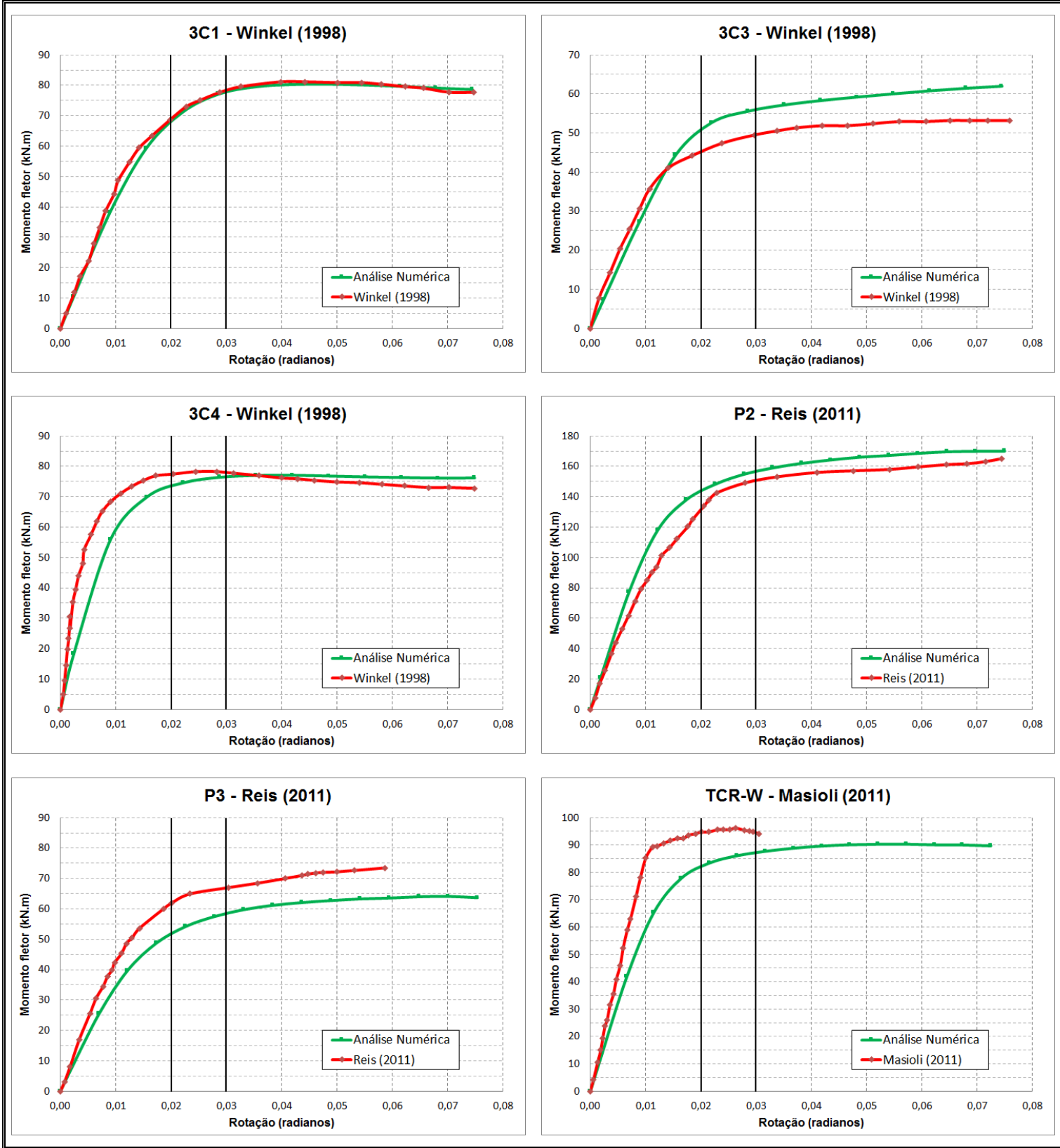

Fonte: Acervo pessoal

Em uma primeira análise, a observação do comportamento momento-rotação dos seis modelos apresentados permite verificar que os resultados experimentais e numéricos apresentaram boa aproximação entre si em todos os modelos. A rotação de 0,03 radianos (destacada nas curvas) representa a rotação requerida para ligações em estruturas sujeitas a sismos conforme determinado no ANSI/AISC 360-10 (2010). 
Nota-se nos seis modelos que, para rotações de até 0,01 radianos $\left(0,57^{\circ}\right)$, as curvas experimentais e numéricas apresentaram boa aproximação. Isto permite dizer que, em termos de rigidez inicial, o modelo numérico representa bem 0 comportamento da ligação.

O comportamento momento-rotação permite ainda avaliar a resistência das ligações. Segundo o ANSI/AISC 360-10 (2010), a resistência à plastificação da ligação pode ser tomada como o momento fletor obtido na curva momento-rotação para uma rotação de 0,02 radianos $\left(1,15^{\circ}\right)$. A tabela 5.3 apresenta, comparativamente, os resultados experimentais e numéricos para a resistência à plastificação $\left(M_{y}\right)$ com a rotação de 0,02 radianos.

Tabela 5.3 - Resistência das ligações nos modelos experimentais e numéricos com ligações soldadas

\begin{tabular}{|c|c|c|c|c|}
\hline \multirow[b]{2}{*}{ AUTOR } & \multirow[b]{2}{*}{ MODELO } & \multicolumn{3}{|c|}{$\mathrm{M}_{\mathrm{y}(0,02 \mathrm{rad})}(\mathrm{kN} . \mathrm{m})$} \\
\hline & & Experimental & Numérico & $\begin{array}{c}\text { Experimental / } \\
\text { Numérico }\end{array}$ \\
\hline Winkel (1998) & $3 C 1$ & 68,9 & 67,4 & 1,02 \\
\hline Winkel (1998) & $3 C 3$ & 45,2 & 50,2 & 0,90 \\
\hline Winkel (1998) & $3 C 4$ & 77,4 & 73,0 & 1,06 \\
\hline Reis (2011) & $\mathrm{P} 2$ & 131,6 & 143,1 & 0,92 \\
\hline Reis (2011) & P3 & 61,8 & 51,5 & 1,20 \\
\hline Masioli (2011) & TCR-W & 94,7 & 81,7 & 1,16 \\
\hline
\end{tabular}

Permite-se concluir que, a boa aproximação entre os resultados numéricos e experimentais, demonstra a boa representatividade da simulação numérica na obtenção da resistência das ligações.

Apresentam-se na sequência imagens comparativas da situação dos modelos numéricos desta pesquisa e os modelos experimentais de Winkel (1998), Reis (2011) e Masioli (2011) ao final dos ensaios.

As imagens ilustrativas (figura 5.7 e figura 5.8) dos resultados no modelo $3 \mathrm{C} 4$ de Winkel (1998) demonstram a ocorrência de deformações consideráveis na face do pilar em decorrência da força de compressão exercida pela mesa inferior da viga. 
Figura 5.7 - Configuração deformada do modelo 3C4 ao final do ensaio experimental

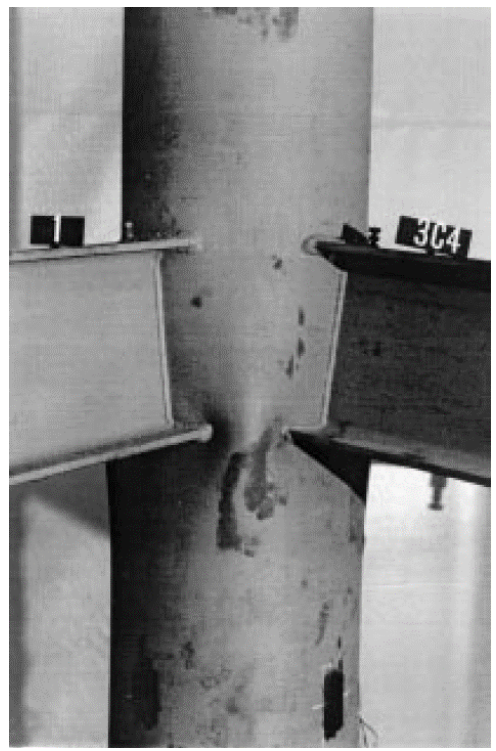

Fonte: Winkel (1998)
Figura 5.8 - Situação deformada do modelo $3 \mathrm{C} 4$ ao final da análise

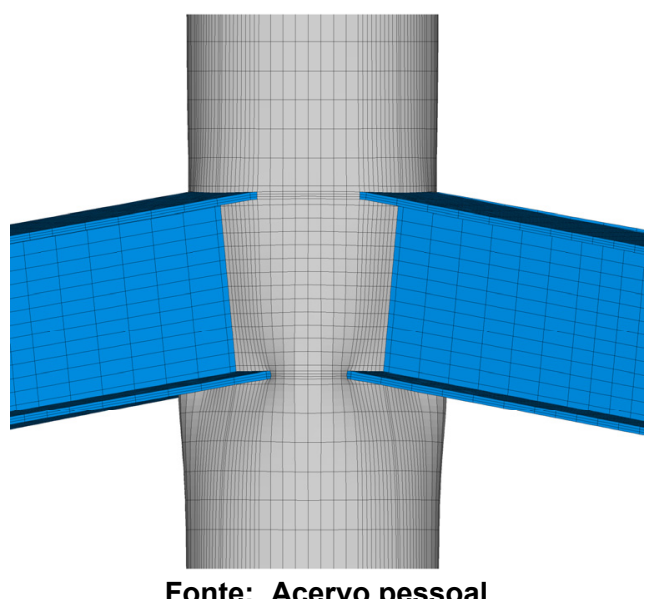

Figura 5.9 - Distribuição das tensões de Von Mises do modelo $3 \mathrm{C} 4$ ao final da análise

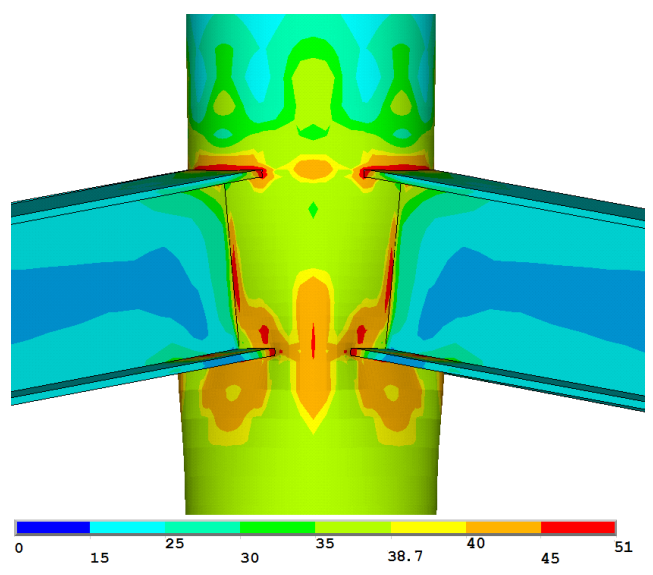

Notas: Tensões em $\mathrm{kN} / \mathrm{cm}^{2} ; f_{\mathrm{y}, \text { pilar }}=38,7 \mathrm{kN} / \mathrm{cm}^{2}$ Fonte: Acervo pessoal

A observação da figura 5.9 permite verificar que a deformação excessiva originou-se do fenômeno de plastificação da seção do pilar nesta região.

A distribuição das tensões ${ }^{12}$ na figura 5.9 demonstra que a tensão limite de escoamento para o aço do pilar $\left(38,7 \mathrm{kN} / \mathrm{cm}^{2}\right)$ foi atingida em alguns pontos específicos, como a região de contato com as vigas e também na região localizada entre vigas.

Winkel (1998) destaca em seu trabalho que o critério de falha para as ligações soldadas analisadas foi a plastificação da face do pilar. As ilustrações apresentadas

12 Neste capítulo, o termo tensões, quando não especificado, se refere às tensões equivalentes segundo o critério de Von Mises. 
comprovam a observação de Winkel (1998) e ainda demonstram certa concentração de tensões na mesa da viga que evidenciam o início da flambagem local da mesa.

No modelo P2 de Reis (2011) observa-se, pela figura 5.10, um fenômeno de instabilidade local na mesa da viga. Confrontando com a figura 5.11 é possível verificar uma concentração de tensões neste mesmo ponto, onde, a tensão (na ordem de 37,4 $\mathrm{kN} / \mathrm{cm}^{2}$ ) na região da mesa próxima a face do pilar supera os $34,5 \mathrm{kN} / \mathrm{cm}^{2}$, valor do limite de escoamento do aço da viga.

Figura 5.10 - Flambagem local da mesa da viga no modelo P2 ao final do ensaio

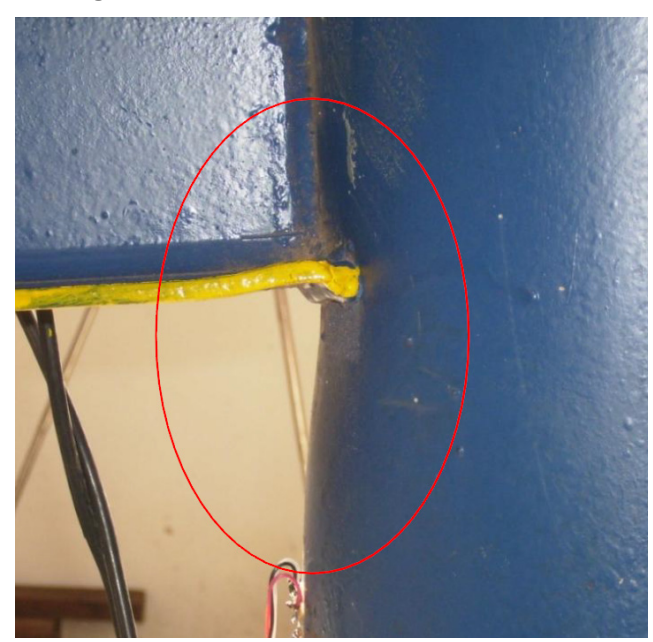

Fonte: Reis (2011)
Figura 5.11 - Distribuição das tensões de Von Mises no modelo numérico P2 ao final da análise

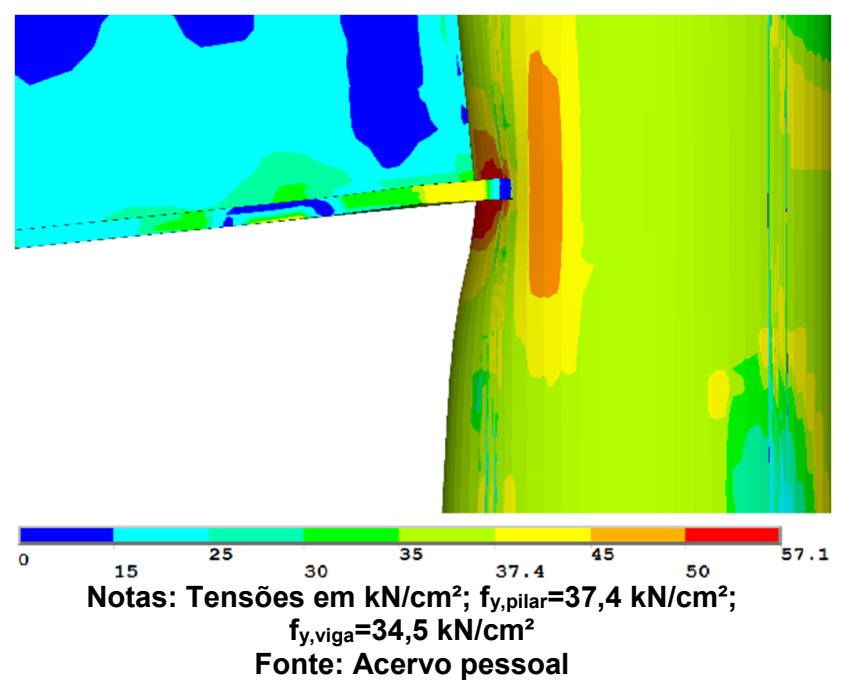

Apesar da eminência em ocorrer a falha pela flambagem local da mesa, o modelo P2 apresentou o mesmo modo de falha do modelo 3C4 de Winkel (1998). A plastificação da região da face do pilar em contato com a mesa inferior da viga tornase mais eminente à medida em que há um aumento do carregamento até atingir a tensão última do material do pilar.

A pesquisa experimental realizada por Masioli (2011) no modelo TCR-W apresenta resultados semelhantes aos verificados por Reis (2011) no modelo P2 quanto à distribuição de tensões e modo de falha.

A figura 5.12 ilustra a plastificação da face do pilar oriunda de um esforço de compressão aplicado pela mesa inferior da viga. A constatação fica melhor evidenciada pela observação da distribuição de tensões representada na figura 5.13. Apesar da falha da ligação ocorrer pela plastificação da face do pilar nota-se a concentração de tensões na mesa inferior da viga na região próxima a face do pilar. 
Figura 5.12 - Modelo experimental TCR-W ao final do ensaio

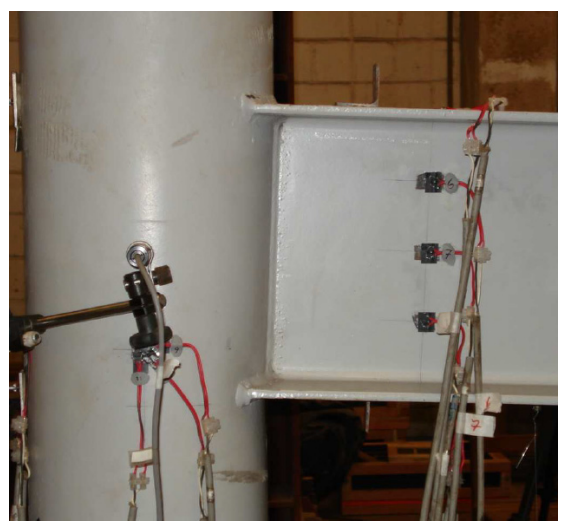

Fonte: Masioli (2011)
Figura 5.13 - Distribuição das tensões de Von Mises no modelo numérico TCR-W ao final da análise

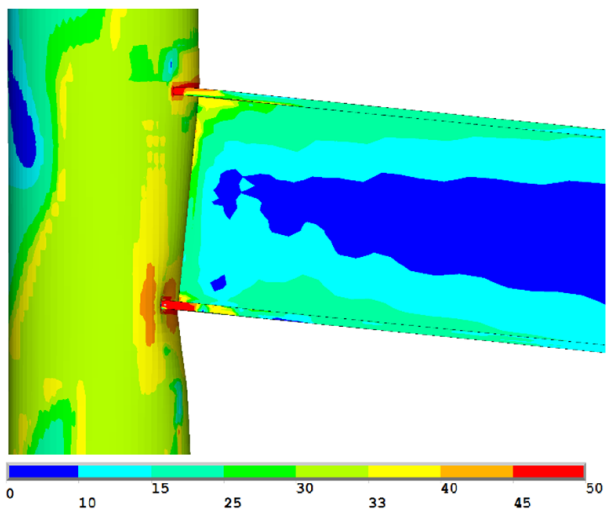

Notas: Tensões em kN/cm $; f_{y, p i l a r}=33 \mathrm{kN} / \mathrm{cm}^{2} ; f_{y, v i g a}=40$ $\mathrm{kN} / \mathrm{cm}^{2}$

Fonte: Acervo pessoal

Observa-se que no modelo TCR-W a concentração de tensões na mesa da viga ocorreu mais próxima da interface viga-pilar indicando uma menor predominância de ocorrer a flambagem local da mesa, situação distinta da observada no modelo P2.

O comportamento momento-rotação, a resistência das ligações e o patamar de distribuição de tensões dos seis modelos numéricos representam com boa aproximação o comportamento estrutural da ligação.

Conclui-se que a metodologia de análise numérica utilizada neste trabalho apresenta bons resultados e, portanto, pode ser estendida ao escopo desta pesquisa, ou seja, o estudo desta tipologia de ligação (soldada) com a abordagem de outras variáveis de interesse.

\subsubsection{Modelo com a presença de diafragma externo}

O diafragma externo, constituído por uma chapa soldada ao redor do pilar e parafusada às mesas da viga, é uma alternativa que busca enrijecer a ligação e aumentar a resistência ao momento fletor, redistribuindo as tensões provenientes da viga para todo o perímetro do pilar.

O modelo TCR-B (figura 5.14) de Masioli (2011) representa a única referência experimental utilizada neste trabalho para ligações com a presença do diafragma 
externo parafusado às mesas das vigas. A análise numérica procurou adotar as mesmas considerações destacadas na pesquisa do autor.

Figura 5.14 - Modelo TCR-B

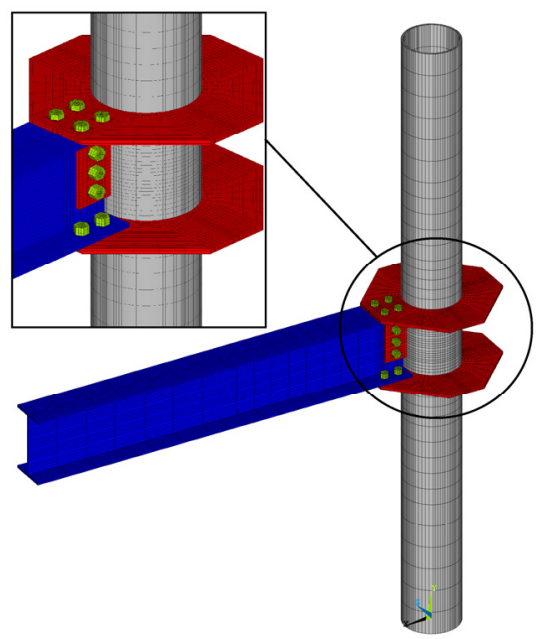

Fonte: Acervo pessoal

O modelo experimental TCR-B caracteriza-se pela presença de uma única viga ligada ao pilar. A ligação se dá por meio de uma chapa soldada ao redor do pilar (diafragma) e parafusada às mesas da viga e outra chapa soldada à face do pilar e parafusada à alma da viga.

\subsubsection{Características físicas e geométricas}

As características físicas e geométricas do modelo TCR-B são idênticas às adotadas no modelo TCR-W apresentado neste capítulo. A diferença está na presença da chapa de alma e das chapas do diafragma cujas características geométricas estão ilustradas, respectivamente, na figura 5.15 e figura 5.16 . 
Figura 5.15 - Características geométricas da chapa de alma do modelo TCR-B

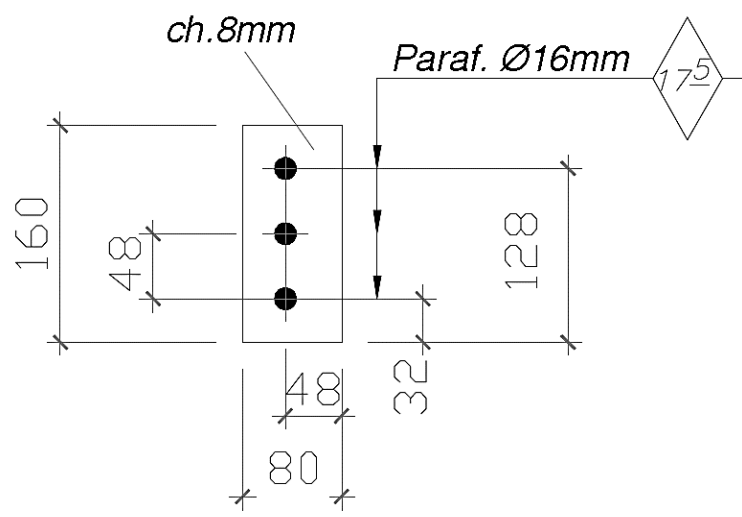

Fonte: Masioli (2011)
Figura 5.16 - Características geométricas das chapas do diafragma do modelo TCR-B

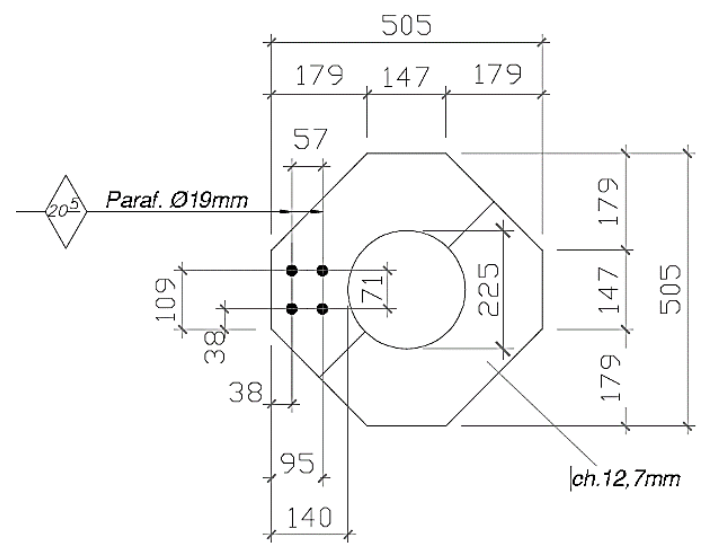

Fonte: Masioli (2011)

As propriedades do material utilizado nas chapas estão apresentadas na tabela 5.4, sendo $f_{y}$ e $f_{u}$, respectivamente, os valores médios das tensões de escoamento e de ruptura obtidos no ensaio de todos os corpos-de-prova.

Tabela 5.4 - Propriedades dos materiais de chapas e parafusos do modelo TCR-B

\begin{tabular}{|c|c|c|c|c|c|}
\hline \multirow{2}{*}{ AUTOR } & \multirow{2}{*}{ MODELO } & Mod. Elast. & Poisson & \multicolumn{2}{|c|}{ CHAPAS } \\
\cline { 3 - 5 } & & $\mathbf{E}$ & \multirow{2}{*}{$\mathbf{v}$} & $\mathbf{f}_{\mathbf{y}}$ & $\mathbf{f}_{\mathbf{u}}$ \\
\cline { 3 - 3 } \cline { 5 - 6 } & & $\mathbf{( M P a )}$ & & $\mathbf{( M P a )}$ & $(\mathbf{M P a})$ \\
\hline Masioli (2011) & TCR-B & 205.000 & 0,3 & 385 & 468 \\
\hline
\end{tabular}

Fonte: Acervo pessoal

Foram utilizados 3 parafusos de $16 \mathrm{~mm}$ de diâmetro na ligação da alma da viga com a chapa de alma. Para as ligações nas mesas superior e inferior da viga com a chapa do diafragma foram utilizados 4 parafusos de $19 \mathrm{~mm}$ em cada mesa. Masioli (2011) utilizou parafusos de alta resistência $\operatorname{ASTM}^{13} \mathrm{~A} 325\left(\mathrm{f}_{\mathrm{u}}=825 \mathrm{MPa}\right)$.

\subsubsection{Resultados comparativos}

A figura 5.17 ilustra as curvas referentes ao comportamento momento-rotação da modelagem numérica e do ensaio experimental realizado por Masioli (2011).

${ }^{13}$ ASTM - American Society for Testing and Materials 
Figura 5.17 - Curvas momento-rotação para o modelo TCR-B

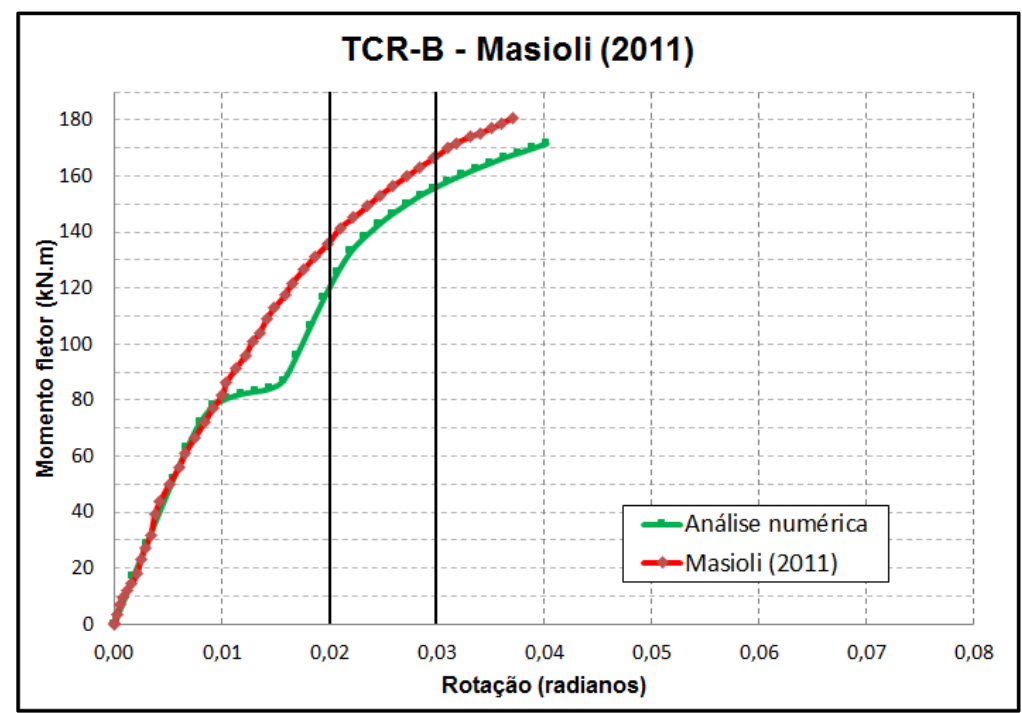

Fonte: Acervo pessoal

Em uma rotação de 0,01 radianos observa-se na curva representativa da análise numérica o aumento da rotação relativa sem o acréscimo do momento fletor aplicado. Esta particularidade ocorre, pois, a modelagem sem a existência de imperfeições geométricas procura simular a folga entre o parafuso e a borda do furo.

A partir do momento em que atinge-se a força limite de atrito, ocorre 0 deslizamento dos parafusos até que haja o contato entre o parafuso e a chapa. Este deslizamento resulta em uma respectiva rotação, ao mesmo tempo em que, não há acréscimo considerável de resistência, resultando no comportamento verificado.

O ensaio experimental de Masioli (2011) não respeitou a folga mínima imposta pela NBR 8800 (2008). Masioli (2011) cita em sua pesquisa que "[...] os protótipos experimentais apresentaram imperfeições geométrica decorrentes da fabricação, portanto, a inexistência de folgas entre parafusos e chapas não produziu o mesmo fenômeno. [...]".

Destaca-se ainda a ótima aproximação entre as curvas numéricas e experimentais para o trecho inicial dos ensaios, mostrando grande representatividade no que diz respeito à rigidez inicial dos modelos. Após o deslizamento dos parafusos as curvas voltam a apresentar boa concordância entre si.

A resistência da ligação no modelo TCR-B (tabela 5.5) apresentou boa aproximação entre os resultados numéricos e experimentais. 
Tabela 5.5 - Resistência das ligações no modelos experimentais e numéricos com ligações parafusadas

\begin{tabular}{|c|c|c|c|c|}
\hline \multirow{2}{*}{ AUTOR } & \multirow{2}{*}{ MODELO } & \multicolumn{3}{|c|}{$\mathbf{M}_{\mathbf{y}(0,02 ~ r a d)}$ (kN.m) } \\
\cline { 3 - 5 } & & Experimental & Numérico & $\begin{array}{c}\text { Experimental / } \\
\text { Numérico }\end{array}$ \\
\hline Masioli (2011) & TCR-B & 136,4 & 120,1 & 1,14 \\
\hline
\end{tabular}

Fonte: Acervo pessoal

$\mathrm{Na}$ análise numérica, o modelo TCR-B apresentou um patamar de distribuição de tensões bastante distinto do observado nos modelos com ligação soldada. A figura 5.18 obtida no trabalho de Masioli (2011) destaca o ponto de rotação que a chapa do diafragma gera na viga e a figura 5.19 ilustra a concentração de tensões neste ponto.

Figura 5.18 - Deformação na região da mesa comprimida no modelo experimental TCR-B

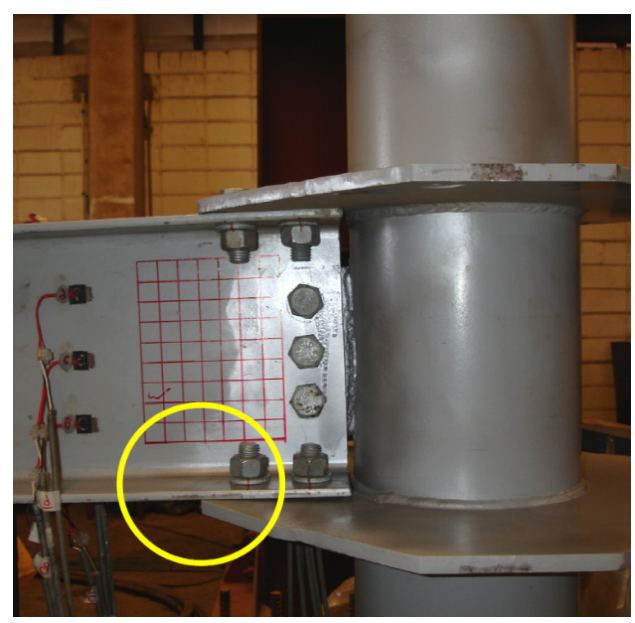

Fonte: Masioli (2011)
Figura 5.19 - Distribuição das tensões de Von Mises no modelo numérico TCR-B ao final da análise

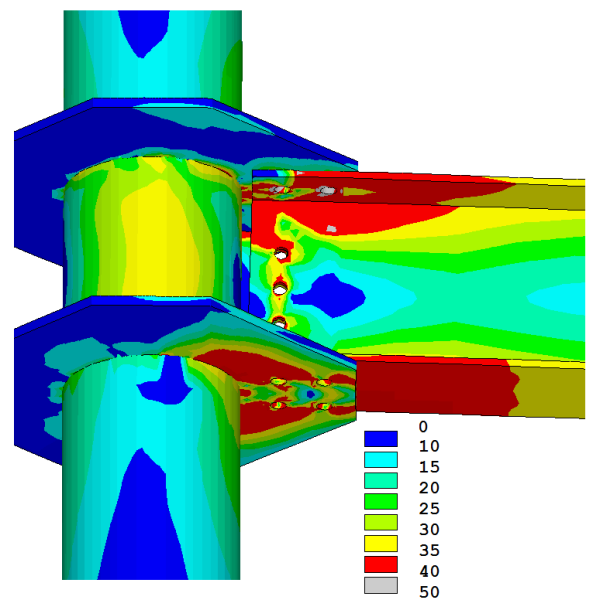

Notas: Tensões em kN/cm²; $f_{y, p i l a r}=33 \mathrm{kN} / \mathrm{cm}^{2} ; f_{y, v i g a}=40$ $\mathrm{kN} / \mathrm{cm}^{2} ; \mathrm{f}_{\mathrm{y}, \mathrm{chapa}}=38,5 \mathrm{kN} / \mathrm{cm}^{2}$

Fonte: Acervo pessoal

A força aplicada na extremidade da viga tem a tendência ao giro, enquanto que, a chapa do diafragma (no ponto destacado) apresenta a restrição a esse giro. A restrição ao giro remete à presença de uma força de reação que resulta na concentração de tensões na mesa da viga, observada na figura 5.19. A tensão, em torno de $40 \mathrm{kN} / \mathrm{cm}^{2}$ supera o valor limite para a tensão de escoamento do material da viga.

Masioli (2011) destaca ainda o alargamento dos furos na região da chapa tracionada (figura 5.20) ao final do ensaio experimental. A evolução das tensões de Von Mises (figura 5.21) demonstra a grande concentração de tensões na região dos furos desde os estágios iniciais de carregamento. 
Figura 5.20 - Alargamento dos furos na região da chapa tracionada no modelo TCR-B

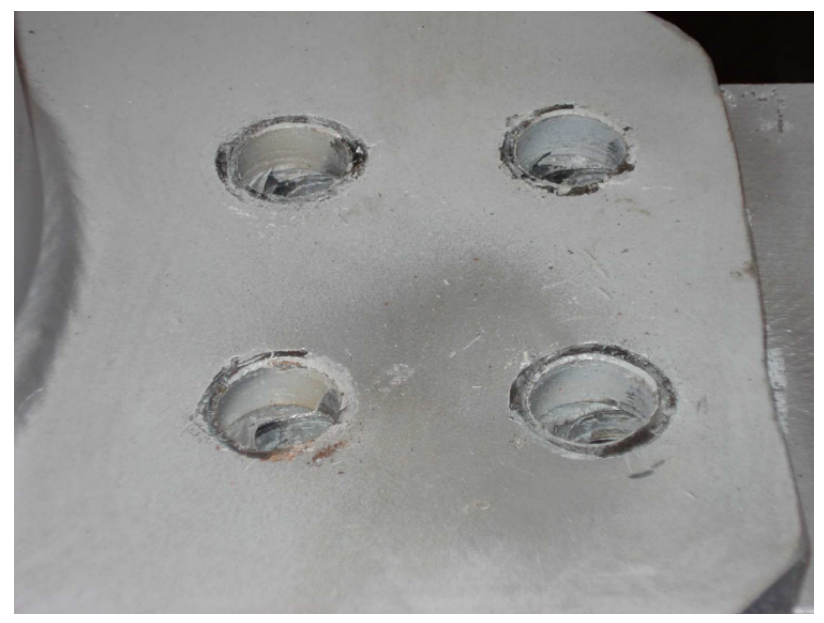

Fonte: Masioli (2011)
Figura 5.21 - Evolução das tensões de Von Mises na chapa tracionada do diafragma no modelo TCR-B
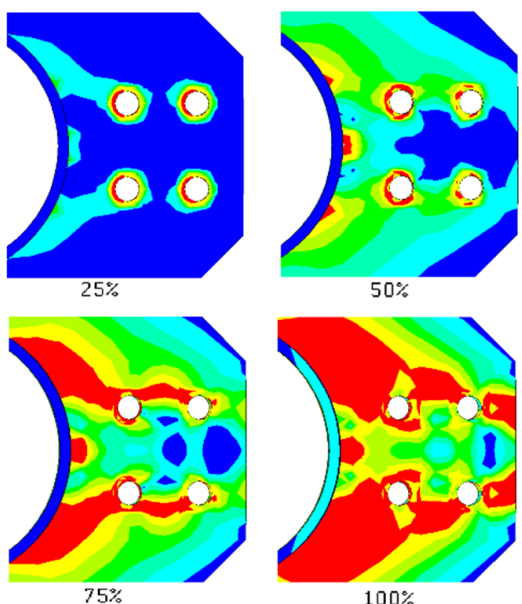

$100 \%$

Notas: Tensões em kN/cm²; $f_{y, c h a p a}=38,5 \mathrm{kN} / \mathrm{cm}^{2}$ Fonte: Acervo pessoal

A concentração de tensões na região dos furos na chapa do diafragma tracionado superou a tensão última do material e limitou a análise pela não convergência do modelo numérico.

Destaca-se que a tentativa de enrijecer a ligação por meio da utilização do diafragma apresentou bons resultados do ponto de vista do ganho de resistência e rigidez inicial. A tipologia escolhida, as propriedades físicas dos materiais e a geometria dos elementos na região da ligação ocasionaram a concentração de tensões na região dos furos da chapa tracionada (superior) e na região da mesa inferior da viga em contato com a chapa comprimida.

É importante ressaltar que o comportamento complexo desta tipologia de ligação nem sempre resultará no modo de falha na ligação parafusada das mesas das vigas, conforme visualizado no modelo TCR-B. Somente uma escolha otimizada dos elementos que compõem a ligação permitiria uma conclusão geral a respeito do modo de falha predominante para este tipo de ligação.

A condição deformada do modelo numérico ao final do ensaio (figura 5.22 e figura 5.23) ilustra outro ponto importante da análise. Apesar da rotação relativa apresentar um valor reduzido (em torno de $2,29^{\circ}$ ), em termos de deslocamento vertical esta rotação representa uma flecha de 6,3 centímetros na extremidade da viga. 
Figura 5.22 - Rotação da viga ao final da análise no modelo TCR-B

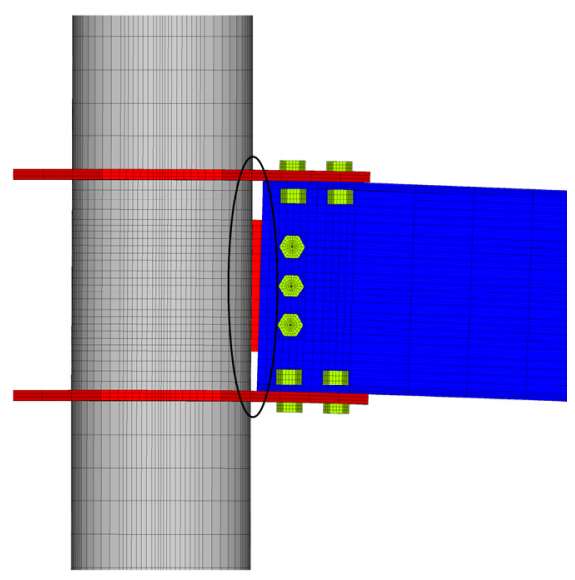

Fonte: Acervo pessoal
Figura 5.23 - Tensões de Von Mises ao final da análise na situação deformada do modelo TCR-B

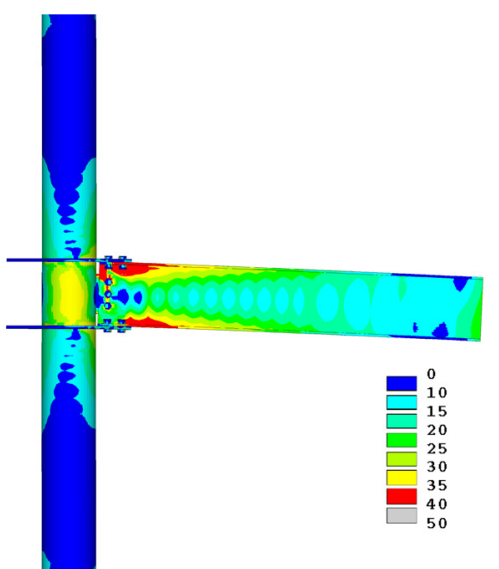

Notas: Tensões em kN/cm²; $\mathrm{f}_{\mathrm{y}, \mathrm{viga}}=40 \mathrm{kN} / \mathrm{cm}^{2}$ Fonte: Acervo pessoal

Considerando que a extremidade da viga se localiza à 1,55 metros da face do pilar, a rotação de $2,29^{\circ}$ (0,04 radianos) representa um deslocamento vertical de L/25, onde L é o comprimento da viga. Este valor está muito acima dos limites impostos pelo anexo C da NBR 8800 (2008). Apesar do anexo C tratar do Estado Limite de Serviço e o modelo numérico tratar do Estado Limite Último, esta comparação serve de parâmetro para se obter uma ordem de grandeza dos deslocamentos observados.

\subsection{Resultados da modelagem numérica}

A análise comparativa realizada nos 6 modelos de ligação soldada e no modelo TCR-B com a presença do diafragma mostrou boa aproximação entre os resultados numéricos e experimentais, enfatizando a boa representatividade dos critérios determinados para a modelagem numérica.

No capítulo 4 foram apresentadas as geometrias dos modelos numéricos analisados por este autor. Apresenta-se na sequência os resultados da modelagem numérica referentes aos seguintes aspectos:

a) Distribuição das tensões equivalentes ao final da análise, segundo o critério de Von Mises;

b) Curvas força aplicada versus deslocamento; 
c) Comportamento momento versus rotação (M- $\theta$ );

d) Classificação das ligações segundo o Eurocode 3;

e) Resistência das ligações;

f) Ductilidade das ligações.

Os resultados são representados por meio de ilustrações acompanhadas de breves comentários de forma a gerar uma observação geral dos resultados obtidos. Por se tratar de um grande número de modelos, adotou-se este critério de forma a não se estender os comentários a pontos não relevantes ao objetivo deste trabalho e, além disso, torna-se possível uma comparação visual entre os resultados dos modelos.

\subsubsection{Distribuição de tensões}

Apresentam-se neste trabalho as tensões equivalentes segundo o critério de Von Mises, as quais consideram a interação entre tensões normais e tensões tangenciais para materiais com comportamento dúctil. A teoria do critério de Von Mises afirma que um material dúctil começa a escoar em um local onde a tensão de Von Mises se torna igual ao limite de tensão determinado, sendo este, o limite de escoamento do material.

Os resultados apresentados a seguir são ilustrativos da situação do modelo ao final da análise e a escala de tensões está representada na unidade $\mathrm{kN} / \mathrm{cm}^{2}$. Destaca-se novamente que foi utilizado um pilar com $323,8 \mathrm{~mm}$ de diâmetro e uma viga de seção I com a especificação "W410X38,8".

\subsubsection{Ligações soldadas}

As imagens apresentadas na figura 5.24 e na figura 5.25 ilustram a distribuição das tensões de Von Mises $\left(\mathrm{em} \mathrm{kN} / \mathrm{cm}^{2}\right)$ dos modelos com ligação soldada ao final da análise. As variáveis atribuídas nas ligações soldadas foram a presença de 
compressão axial no pilar, a espessura do pilar ( $\left.t_{\text {pilar }}\right)$, o comprimento da viga (Lviga) e a relação entre a força vertical aplicada nas vigas das duas direções ortogonais $\left(\mathrm{F}_{2} / \mathrm{F}_{1}\right)$.

Figura 5.24 - Tensões de Von Mises nos modelos de ligação soldada ao final da análise (I/II)

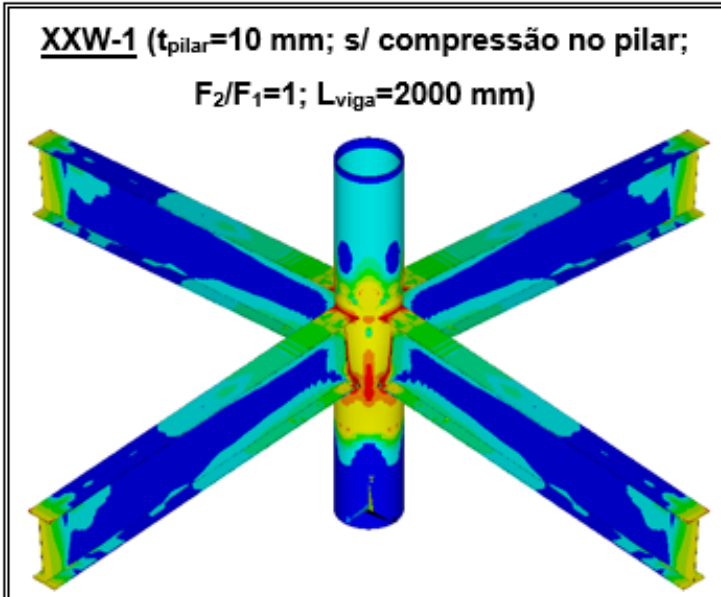

$\underline{X X W-3}\left(t_{\text {pilar }}=14,2 \mathrm{~mm}\right)$ $\underline{\text { XXW-2 }}$ (c/ compressão no pilar)

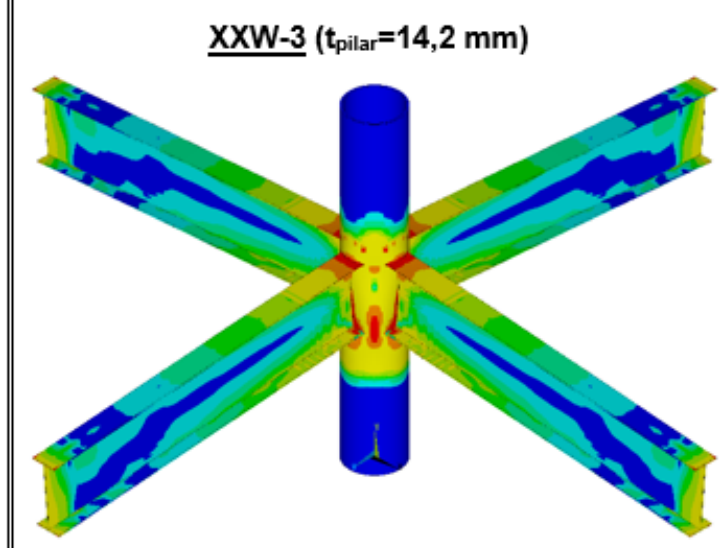

$\underline{X X W-5}\left(L_{\text {viga }}=500 \mathrm{~mm}\right)$
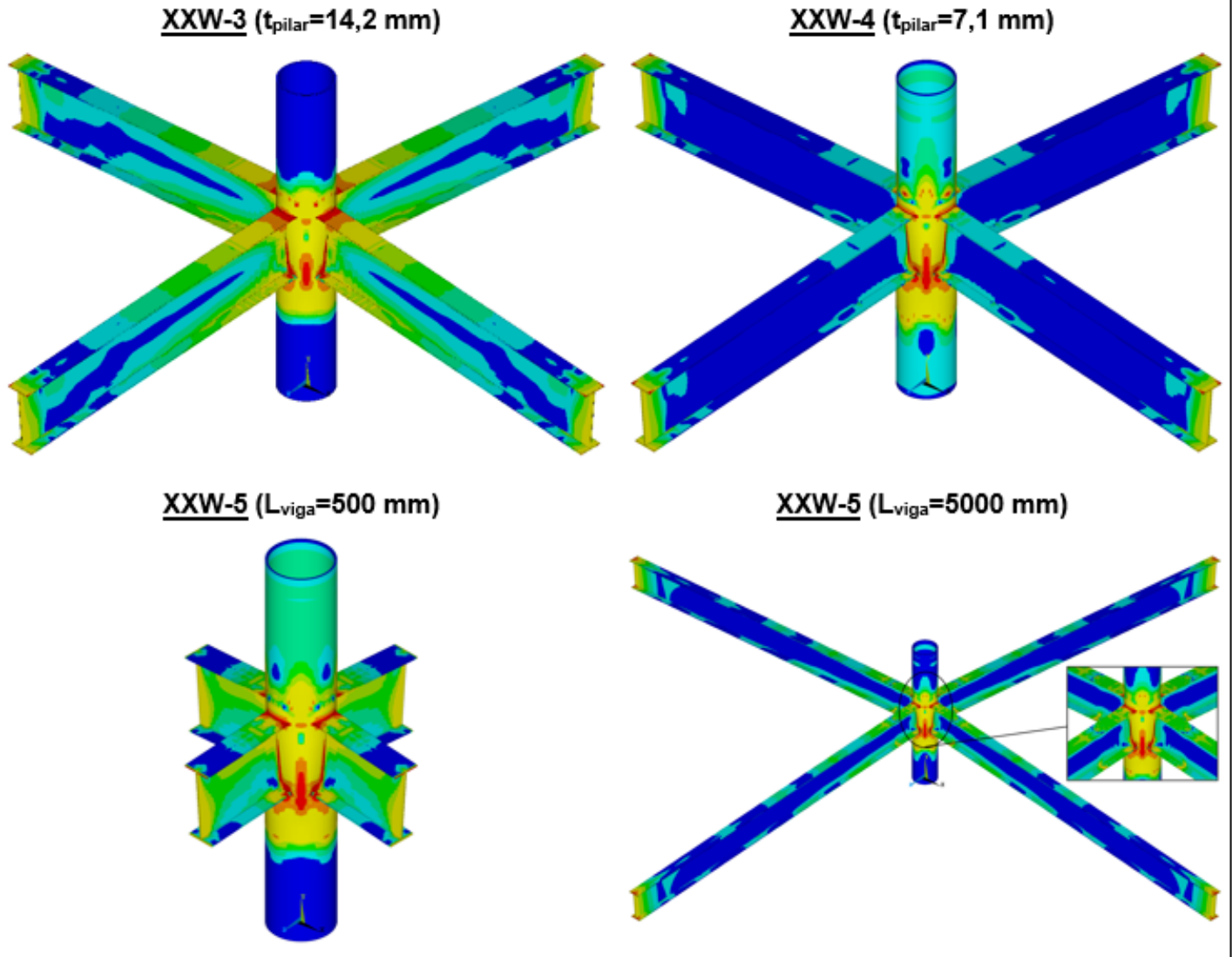

$\underline{X X W-5}\left(L_{\text {viga }}=5000 \mathrm{~mm}\right)$

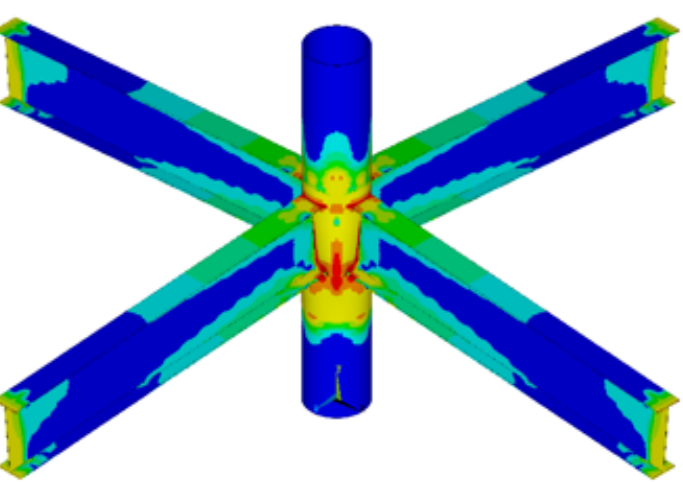

$\underline{X X W-4}\left(t_{\text {pilar }}=7,1 \mathrm{~mm}\right)$
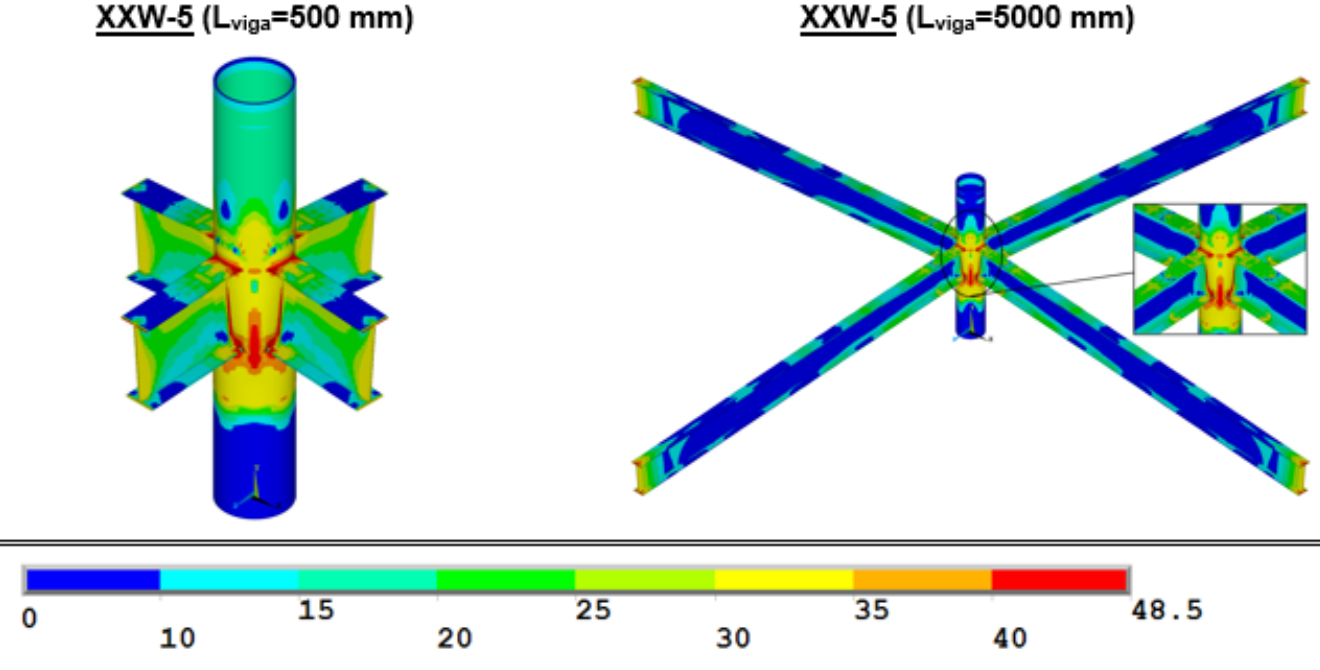

Notas: Tensões em kN/cm${ }^{2} ; f_{y, v i g a}=34,5 \mathrm{kN} / \mathrm{cm}^{2} ; f_{y, p i l a r}=35,0 \mathrm{kN} / \mathrm{cm}^{2}$ Fonte: Acervo pessoal 
Figura 5.25 - Tensões de Von Mises nos modelos de ligação soldada ao final da análise (II/II)

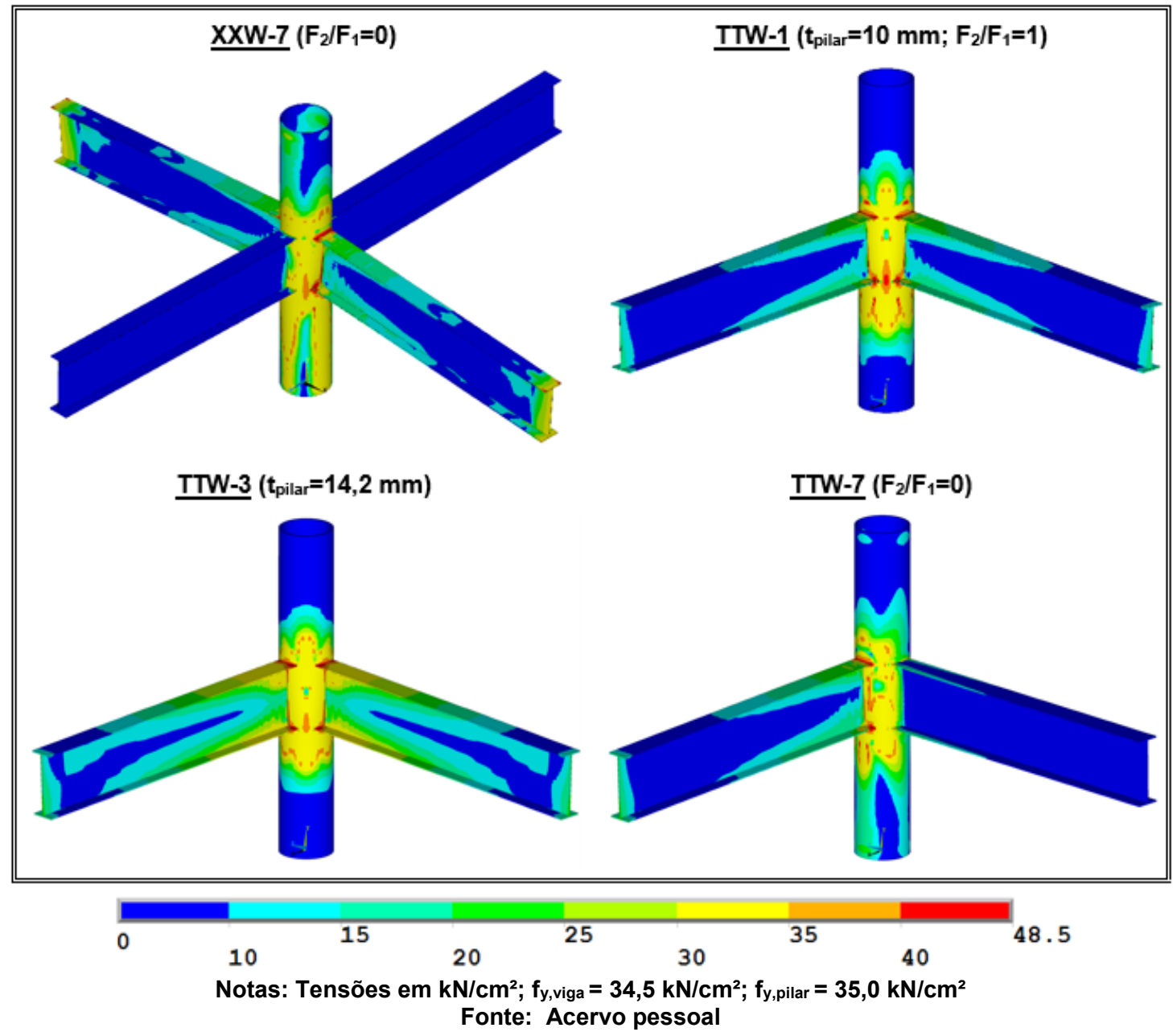

Os modelos XXW-1 e TTW-1 são os modelos utilizados como referência na atribuição das demais variáveis mencionadas na figura 5.24 e na figura 5.25.

As tensões nas vigas, em todos os modelos, concentraram-se na extremidade onde o carregamento foi aplicado e, sobretudo, nas mesas junto a interface viga-pilar. Observou-se, em todos os modelos de ligações soldadas analisados, a possibilidade de ocorrer a instabilidade local na mesa (F.L.M. ${ }^{14}$ ) inferior das vigas, em decorrência da reação à compressão exercida no pilar conforme ilustrado na figura 5.26.

14 FLM é a sigla designada para o termo "Flambagem Local da Mesa", segundo as disposições da NBR 8800 (2008). 
Figura 5.26 -Tensões de Von Mises na mesa inferior da viga nos modelos de ligação soldada ao final da análise

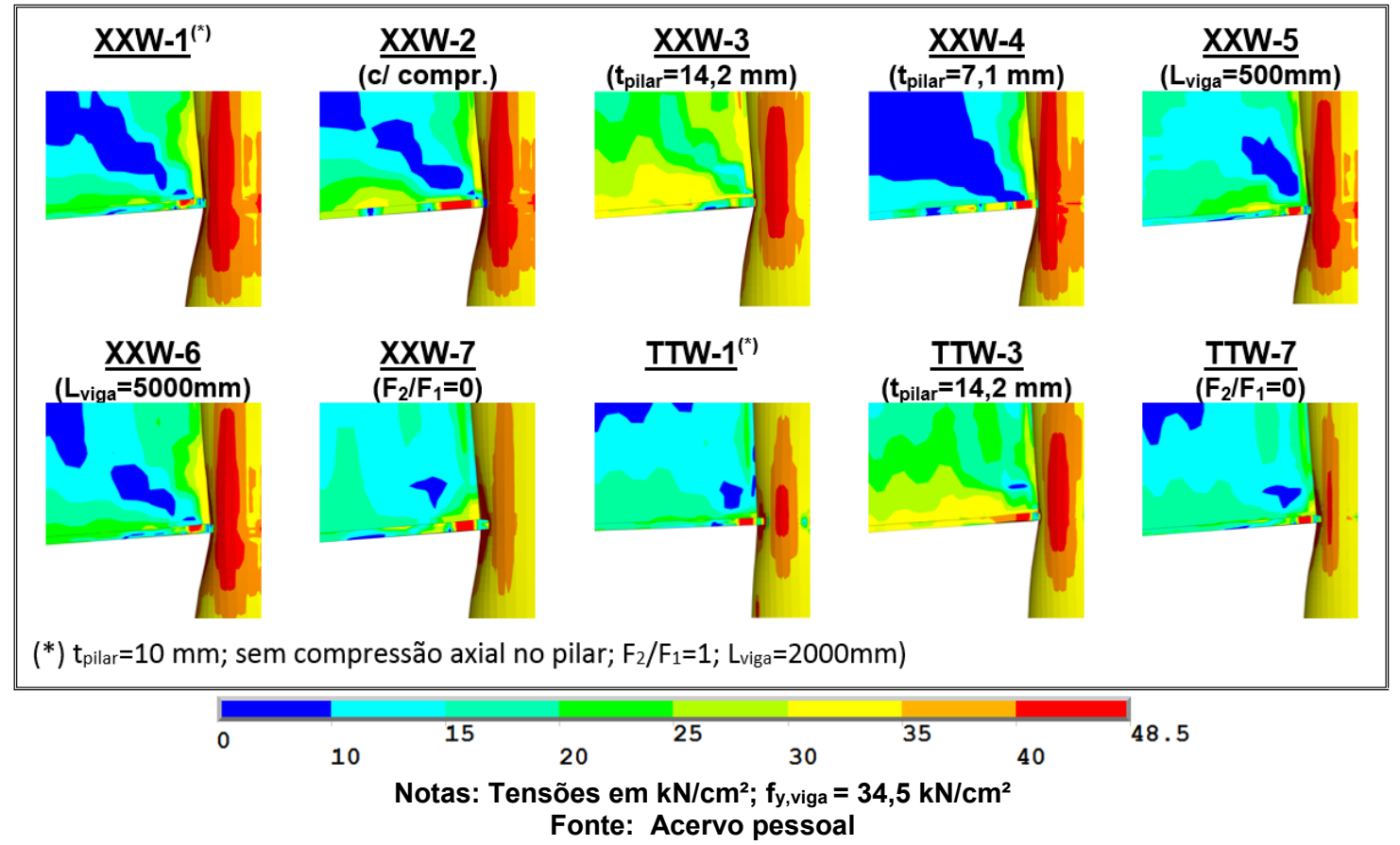

Apresenta-se no quadro 5.1 os comentários com relação à distribuição das tensões de Von Mises (ao final da análise) em cada um dos 10 modelos de ligação soldada:

Quadro 5.1 - Tensões de Von Mises nos modelos de ligação soldada

\section{XXW-1}

( $t_{\text {pilar }}=10 \mathrm{~mm}$; sem compressão axial no pilar; $F_{2} / F_{1}=1 ; L_{\text {viga }}=2000 \mathrm{~mm}$ )

No modelo XXW-1 observou-se a concentração das tensões de Von Mises na região do pilar entre duas vigas ortogonais (figura 5.27). A força vertical aplicada na extremidade da viga resultou na compressão da parede do tubo pela mesa inferior e evidenciou a concentração de tensões na face do pilar. A compressão exercida simultaneamente nas duas direções resultou na redistribuição dos esforços para a região do pilar localizada entre duas vigas ortogonais.

Figura 5.27 - Distribuição das tensões de Von Mises, ao final da análise, no modelo XXW-1

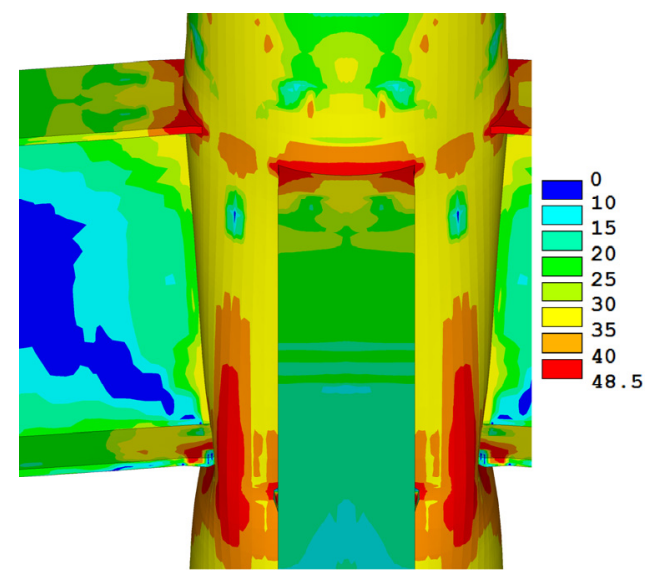

Notas: Tensões em $\mathrm{kN} / \mathrm{cm}^{2}$; $f_{y, \text { viga }}=34,5 \mathrm{kN} / \mathrm{cm}^{2} ; f_{y, p i l a r}=35 \mathrm{kN} / \mathrm{cm}^{2}$ Fonte: Acervo pessoal 
Quadro 5.1 - Tensões de Von Mises nos modelos de ligação soldada

\section{XXW-2}

( $t_{\text {pilar }}=10 \mathrm{~mm}$; com compressão axial no pilar; $F_{2} / F_{1}=1 ;$ viga $=2000 \mathrm{~mm}$ )

O efeito da compressão axial do pilar é mais perceptível nos estágios iniciais de carregamento. A aplicação da compressão axial no pilar no modelo XXW-2 resultou na plastificação da parede do pilar na região entre vigas ortogonais com, cerca de $75 \%$ do carregamento final (figura 5.28). Ao final da análise, o patamar de distribuição das tensões se assemelha com o observado no modelo XXW-1.
Figura 5.28 - Distribuição das tensões de Von Mises com $75 \%$ do carregamento no modelo XXW-2

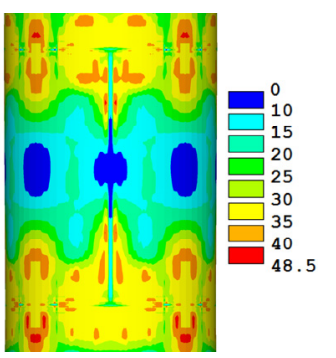

Notas: Tensões em $\mathrm{kN} / \mathrm{cm}^{2}$; $f_{y, \text { pilar }}=35 \mathrm{kN} / \mathrm{cm}^{2}$

Fonte: Acervo pessoal

\section{XXW-3}

( $\underline{t}_{\text {pilar }}=14,2 \mathrm{~mm}$; sem compressão axial no pilar; $F_{2} / F_{1}=1$; $L_{\text {viga }}=2000 \mathrm{~mm}$ )

No modelo XXW-3 a força vertical aplicada para ocasionar a plastificação da face do pilar apresentou maior intensidade em relação aos demais modelos de ligação soldada. O aumento da força aplicada e o consequente aumento do binário nas mesas da viga evidenciou a flambagem local da mesa inferior da viga, conforme observado na figura 5.29
Figura 5.29 - Flambagem local da mesa no modelo XXW-3 ao final da análise

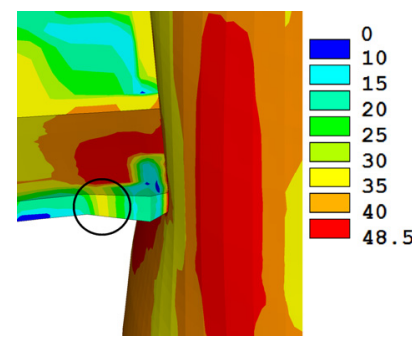

Notas: Tensões em $\mathbf{k N} / \mathrm{cm}^{2}$; $f_{y, v i g a}=34,5 \mathrm{kN} / \mathrm{cm}^{2}$; $f_{y, p i l a r}=35 \mathrm{kN} / \mathrm{cm}^{2}$ Fonte: Acervo pessoal

\section{XXW-4}

( $\underline{t}_{\text {pilar }}=7,1 \mathrm{~mm}$; sem compressão axial no pilar; $F_{2} / F_{1}=1 ; L_{\text {viga }}=2000 \mathrm{~mm}$ )

No modelo XXW-4 a redução na capacidade do pilar em absorver esforços resultou na redistribuição dos esforços para a região localizada entre as vigas ortogonais. A figura 5.30 demonstra a concentração de tensões na mesa inferior da viga na região próxima a extremidade lateral. Observa-se uma deformação considerável da face do pilar em decorrência da força de compressão aplicada pela mesa da viga.

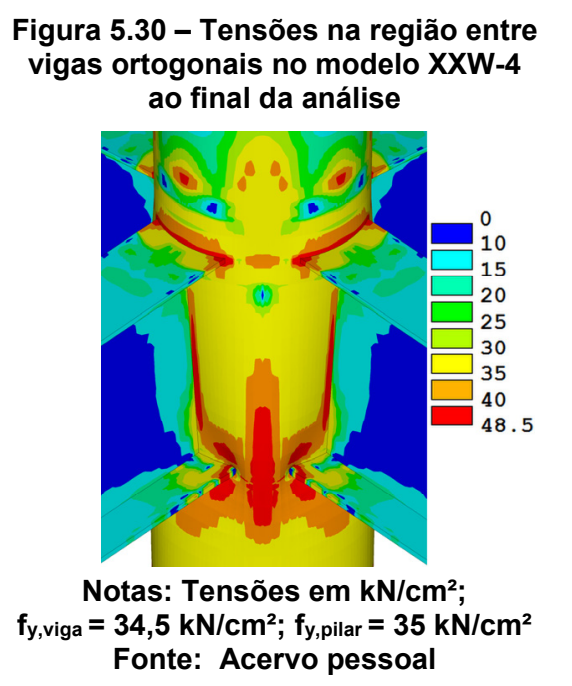

Figura 5.30 - Tensões na região entre ao final da análise 
Quadro 5.1 - Tensões de Von Mises nos modelos de ligação soldada

Verificou-se tensões de intensidade reduzida na mesa da viga em função da redução da capacidade resistente do pilar, resultando na predominância pelo modo de falha por plastificação da face do pilar.

\section{XXW-5}

( $t_{\text {pilar }}=10,0 \mathrm{~mm}$; sem compressão axial no pilar; $F_{2} / F_{1}=1 ; \underline{\text { Liga }}=500 \mathrm{~mm}$ )

A utilização de uma viga com comprimento reduzido no modelo XXW-5 resultou em uma força vertical de maior intensidade para gerar o momento fletor capaz de ocasionar a plastificação da face do pilar. Tem-se, desta maneira, uma força cortante de maior intensidade que proporcionou a concentração de tensões na alma da viga conforme a figura 5.31. Verificou-se o modo de falha pela plastificação da face do pilar na região da mesa comprimida.

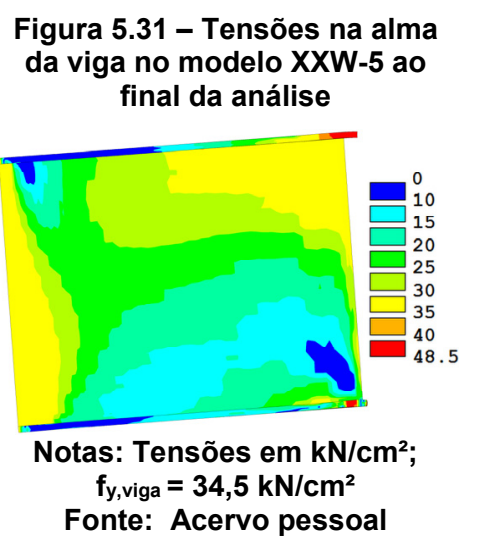

\section{XXW-6}

( $t_{\text {pilar }}=10,0 \mathrm{~mm}$; sem compressão axial no pilar; $F_{2} / F_{1}=1$; $\underline{\text { viga }}=5000 \mathrm{~mm}$ )

O aumento do comprimento da viga observado no modelo $\mathrm{XXW}-6$ recai na presença de uma força cortante de intensidade reduzida resultando, predominantemente, na ocorrência de esforços de flexão na ligação. A predominância do momento fletor fica caracterizada, na figura 5.32, pela concentração de tensões nas regiões próximas das mesas das vigas.
Figura 5.32 - Tensões de Von Mises no modelo XXW-6 ao final da análise

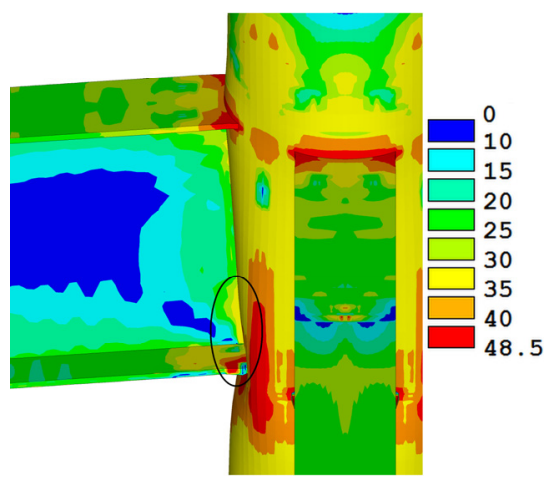

Notas: Tensões em kN/cm²; $f_{y, \text { viga }}=34,5 \mathrm{kN} / \mathrm{cm}^{2} ; f_{y, p i l a r}=35 \mathrm{kN} / \mathrm{cm}^{2}$ Fonte: Acervo pessoal

\section{XXW-7}

( $t_{\text {pilar }}=10,0 \mathrm{~mm}$; sem compressão axial no pilar; $\underline{F_{2} / F_{1}=0} ; L_{\text {viga }}=2000 \mathrm{~mm}$ )

No modelo XXW-7 avaliou-se a influência que o carregamento nas vigas de apenas uma direção tem sobre o comportamento da ligação. A força vertical aplicada na extremidade das vigas de apenas uma direção resultou na compressão unidirecional da seção do pilar. Ao sofrer a compressão e atingir o estado plástico, a seção do pilar se deforma na direção ortogonal à comprimida. A ausência do 
Quadro 5.1 - Tensões de Von Mises nos modelos de ligação soldada

carregamento nas vigas da direção ortogonal não gerou restrição à deformação da seção do pilar, resultando no fenômeno de ovalização da seção transversal deste.

A figura 5.33 ilustra a concentração de tensões na face do pilar em contato com as vigas carregadas. Observa-se também 0 fenômeno de ovalização da seção transversal do pilar e o surgimento de tensões na região do pilar em contato com as vigas que não foram carregadas. A compressão transversal do pilar originou o modo de falha pela plastificação da face do pilar.

Figura 5.33 - Ovalização do pilar do modelo XXW-7 ao final da análise

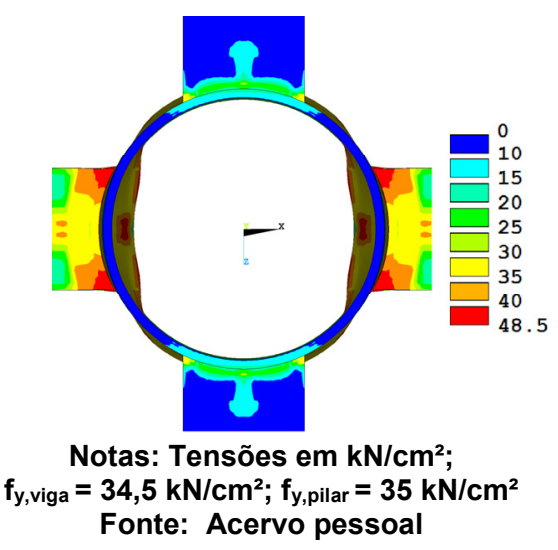

\section{TTW-1}

( $t_{\text {pilar }}=10 \mathrm{~mm}$; sem compressão axial no pilar; $F_{2} / F_{1}=1 ; L_{\text {viga }}=2000 \mathrm{~mm}$ )

Nos modelos de ligação soldada do tipo TT, a compressão simultânea de duas vigas na face do pilar, sem a restrição à deformação por vigas situadas nas faces opostas, resultou na concentração de tensões na região do pilar entre as duas vigas. A figura 5.34 ilustra a concentração de tensões na face do pilar em função da compressão exercida pela mesa inferior das vigas. No modelo TTW-1 a falha da ligação ocorreu pela plastificação da face do pilar.

Figura 5.34 - Tensões de Von Mises no modelo TTW-1 ao final da análise

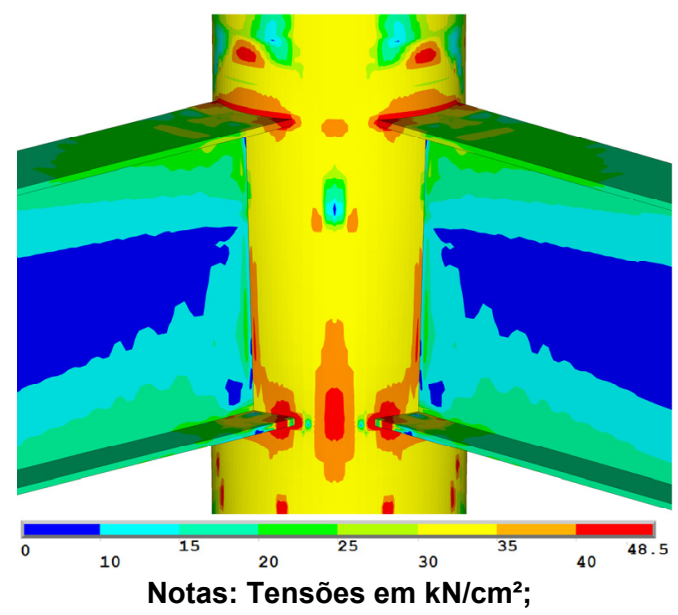
$f_{y, \text { viga }}=34,5 \mathrm{kN} / \mathrm{cm}^{2} ; f_{y, p i l a r}=35 \mathrm{kN} / \mathrm{cm}^{2}$ Fonte: Acervo pessoal

\section{TTW-3}

( $\mathbf{t}_{\text {pilar }}=14,2 \mathrm{~mm}$; sem compressão axial no pilar; $F_{2} / F_{1}=1 ; L_{\text {viga }}=2000 \mathrm{~mm}$ )

A utilização de um pilar de espessura maior, no modelo TTW-3, teve como objetivo evitar a plastificação precoce da parede do pilar. O aumento da resistência do pilar tornou a ligação capaz de suportar uma força vertical aplicada de maior intensidade, resultando em uma reação de compressão nas mesas das vigas capaz de evidenciar a instabilidade local desses elementos resultando na flambagem local da mesa. 
Quadro 5.1 - Tensões de Von Mises nos modelos de ligação soldada

No modelo TTW-3, a utilização de um pilar de maior espessura e a ausência de vigas restringindo a deformação do pilar tornou evidente uma deformação assimétrica da seção do pilar conforme observado na figura 5.35 .

A figura 5.35 ilustra a concentração de tensões na mesa superior das vigas e a deformação da seção transversal do pilar. Apesar da espessura elevada verificou-se o modo de falha pela plastificação da face do pilar.
Figura 5.35 - Tesnões de Von Mises no modelo TTW-3 ao final da análise

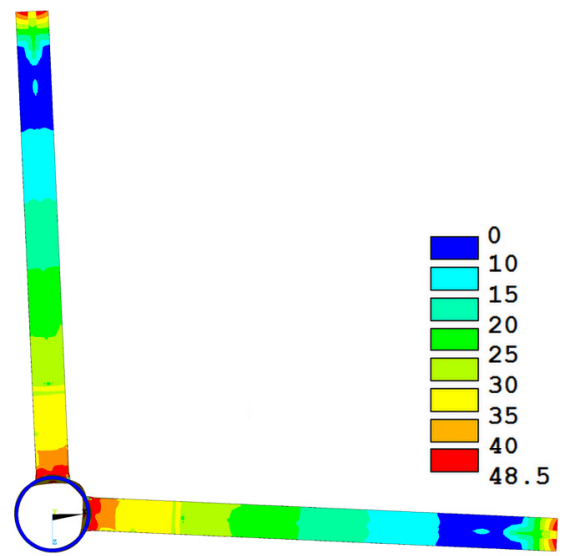

Notas: Tensões em $\mathbf{k N} / \mathrm{cm}^{2}$; $f_{y, \text { viga }}=34,5 \mathrm{kN} / \mathrm{cm}^{2} ; f_{\mathrm{y}, \text { pilar }}=35 \mathrm{kN} / \mathrm{cm}^{2}$ Fonte: Acervo pessoal

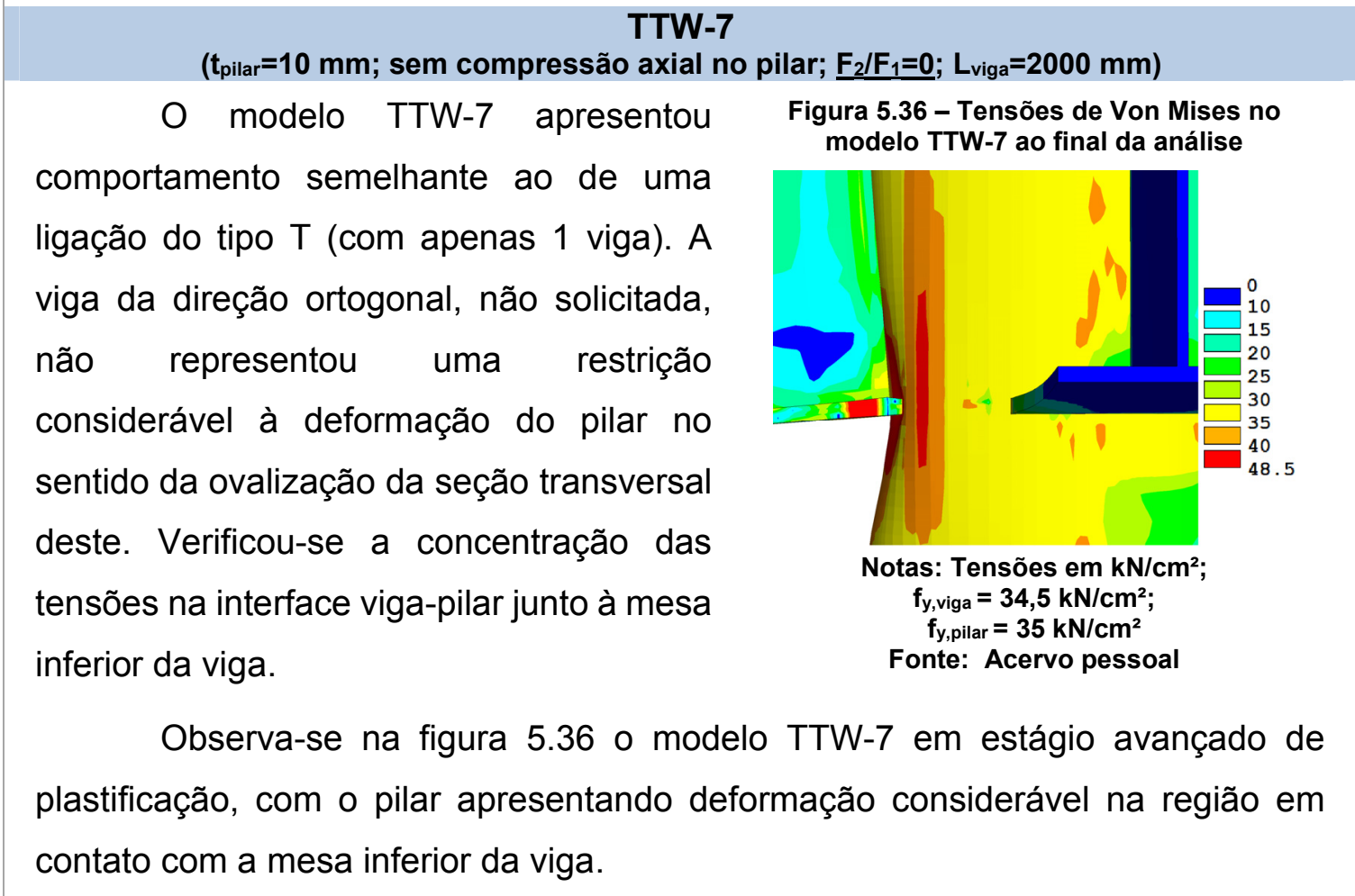




\subsubsection{Ligações com a presença do diafragma externo}

A distribuição das tensões de Von Mises $\left(\mathrm{em} \mathrm{kN} / \mathrm{cm}^{2}\right.$ ), ao final da análise, nos modelos com a presença do diafragma externo, estão ilustradas na figura 5.37 e figura 5.38. As variáveis atribuídas nas ligações com diafragma foram a relação entre a força vertical aplicada nas vigas das duas direções ortogonais $\left(F_{2} / F_{1}\right)$, a espessura do pilar ( $\left.t_{\text {pilar }}\right)$, a espessura da chapa do diafragma $\left(t_{p}\right)$, o diâmetro dos parafusos do diafragma $\left(d_{b}\right)$ e o comprimento da viga ( $\left.L_{\text {viga }}\right)$.

Figura 5.37 - Tensões de Von Mises nos modelos de ligação com diafragma ao final da análise (I/II)

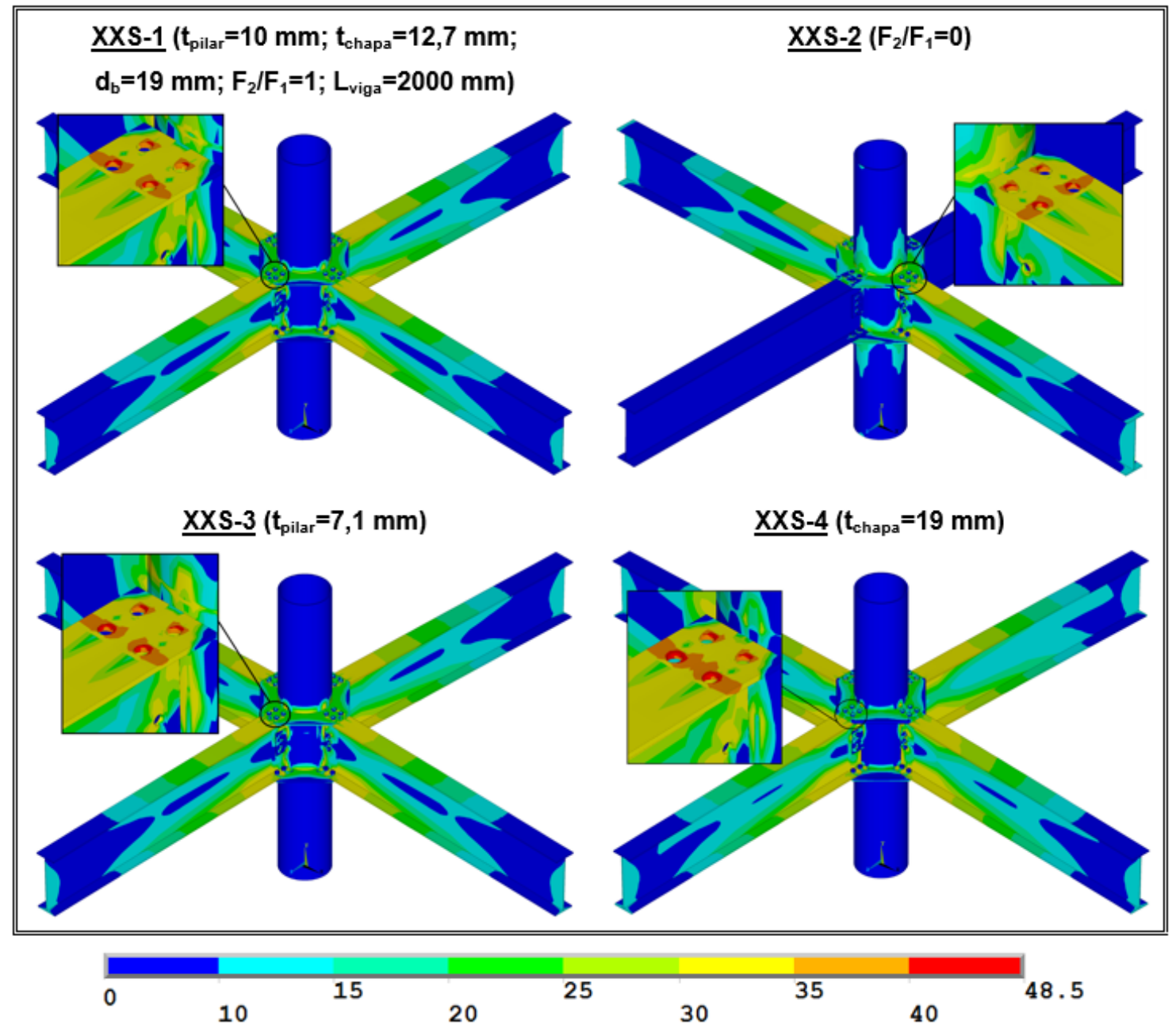

Notas: Tensões em kN/cm²; $f_{y, v i g a}=34,5 \mathrm{kN} / \mathrm{cm}^{2} ; f_{y, p i l a r}=35,0 \mathrm{kN} / \mathrm{cm}^{2} ; f_{y, c h a p a}=25,0 \mathrm{kN} / \mathrm{cm}^{2}$

Fonte: Acervo pessoal 
Figura 5.38 - Tensões de Von Mises nos modelos de ligação com diafragma ao final da análise (II/II)

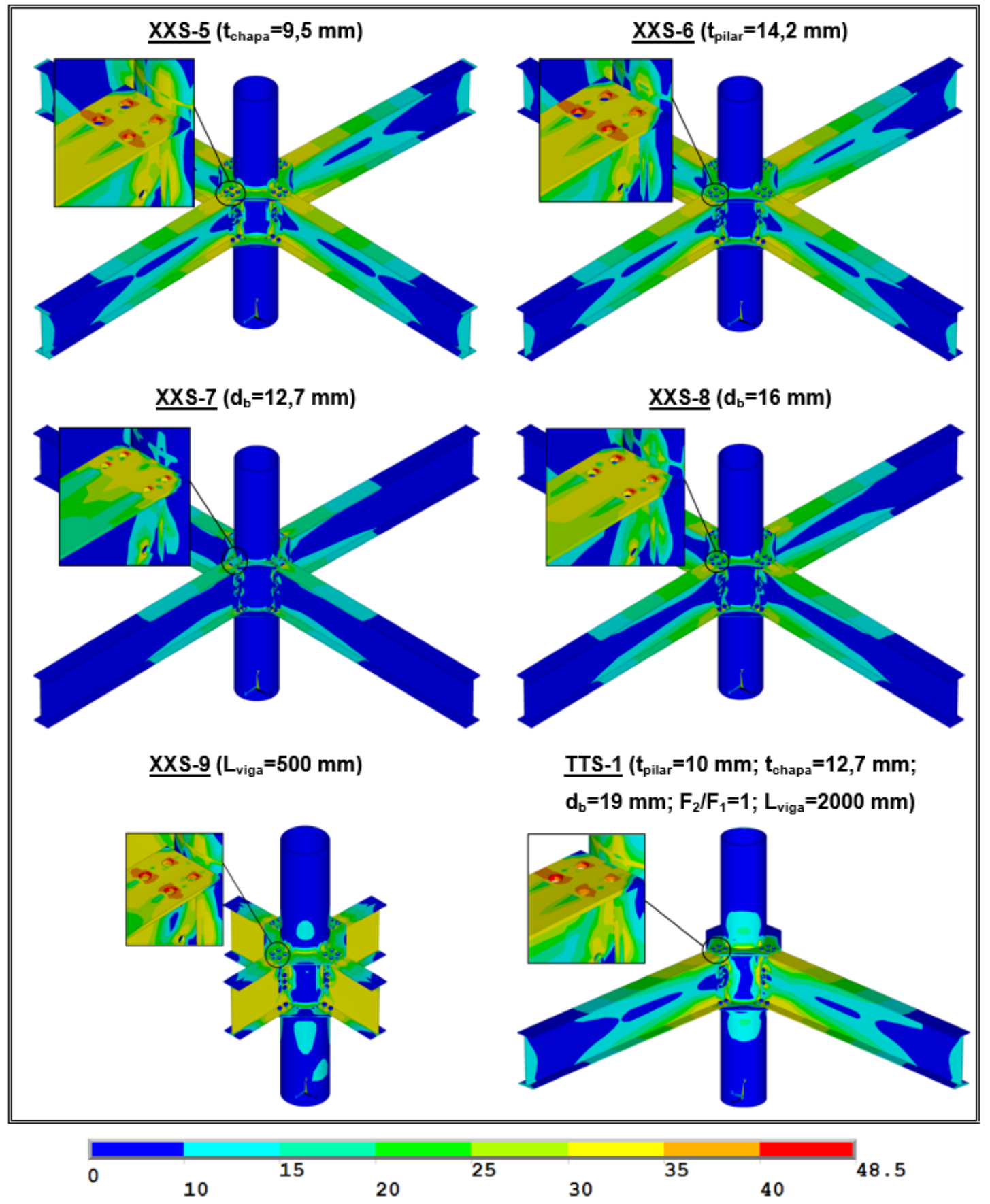

Notas: Tensões em kN/cm²; $f_{y, v i g a}=34,5 \mathrm{kN} / \mathrm{cm}^{2} ; f_{y, p i l a r}=35,0 \mathrm{kN} / \mathrm{cm}^{2} ; f_{y}$, chapa $=25,0 \mathrm{kN} / \mathrm{cm}^{2}$ Fonte: Acervo pessoal

A observação da distribuição de tensões nos modelos com a presença do diafragma (figura 5.37 e figura 5.38) evidencia a concentração das tensões nas mesas das vigas, sobretudo, na região dos furos.

A figura 5.39 apresenta o efeito localizado da concentração de tensões na mesa superior das vigas próximo aos furos da ligação com o diafragma. 
Figura 5.39 - Tensões de Von Mises na mesa superior das vigas dos modelos com diafragma ao final da análise

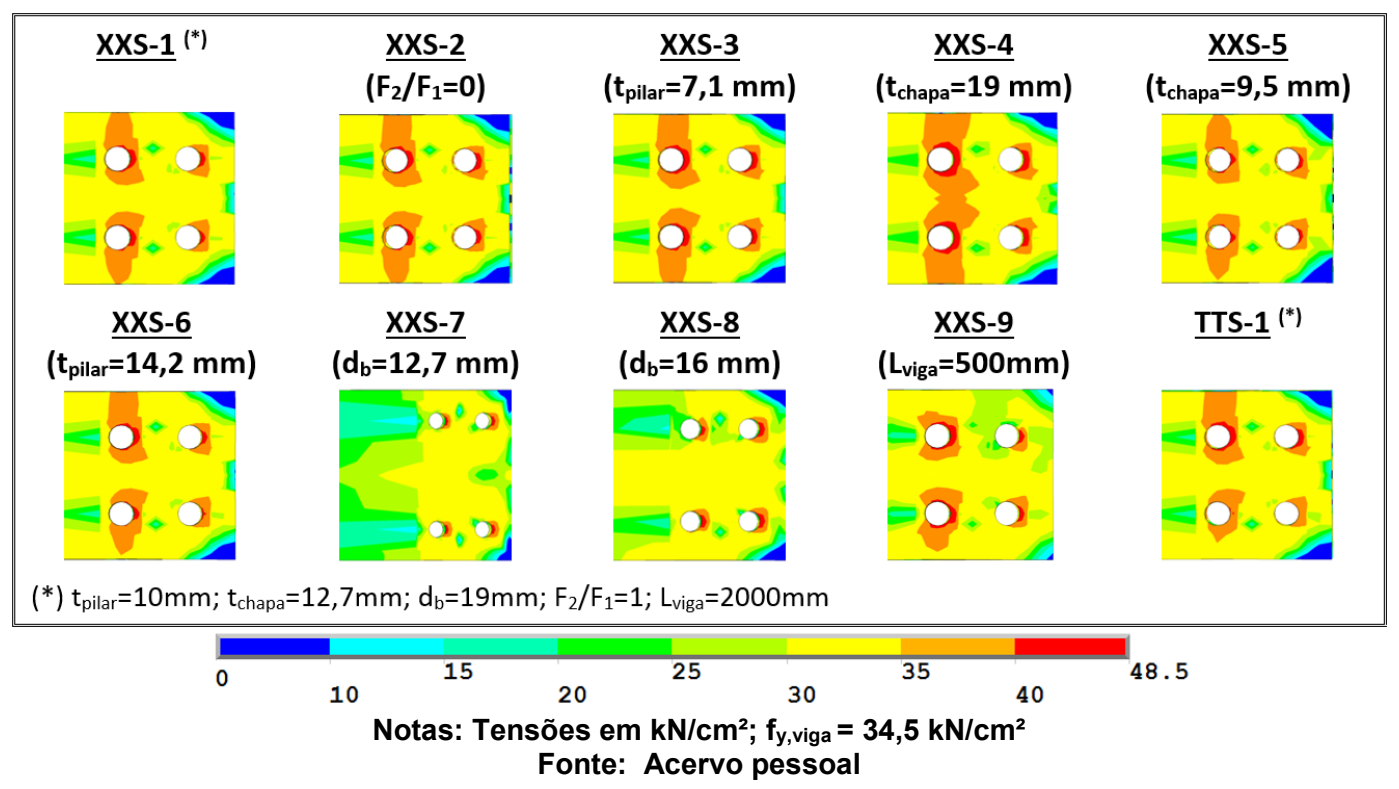

A intensidade das tensões na mesa superior das vigas (figura 5.39) demonstra a ocorrência da plastificação da região do furo em todos os modelos. No modelo XXS4 a tensão acima de $34,5 \mathrm{kN} / \mathrm{cm}^{2}$ (limite de escoamento do material da viga) se estendeu por toda a seção transversal da mesa da viga configurando a plastificação desta região.

O modo de falha predominante para esta tipologia de ligação, com as características estudadas, ocorreu na ligação parafusada do diafragma com a mesa superior das vigas. A intensidade das tensões na mesa das vigas (figura 5.39) e no fuste dos parafusos (figura 5.40) evidenciou a predominância pelo modo de falha pelo cisalhamento dos parafusos, a plastificação da seção do diafragma ou a plastificação da mesa da viga. 
Figura 5.40 - Tensões de Von Mises no fuste do parafuso do diafragma superior ao final da análise

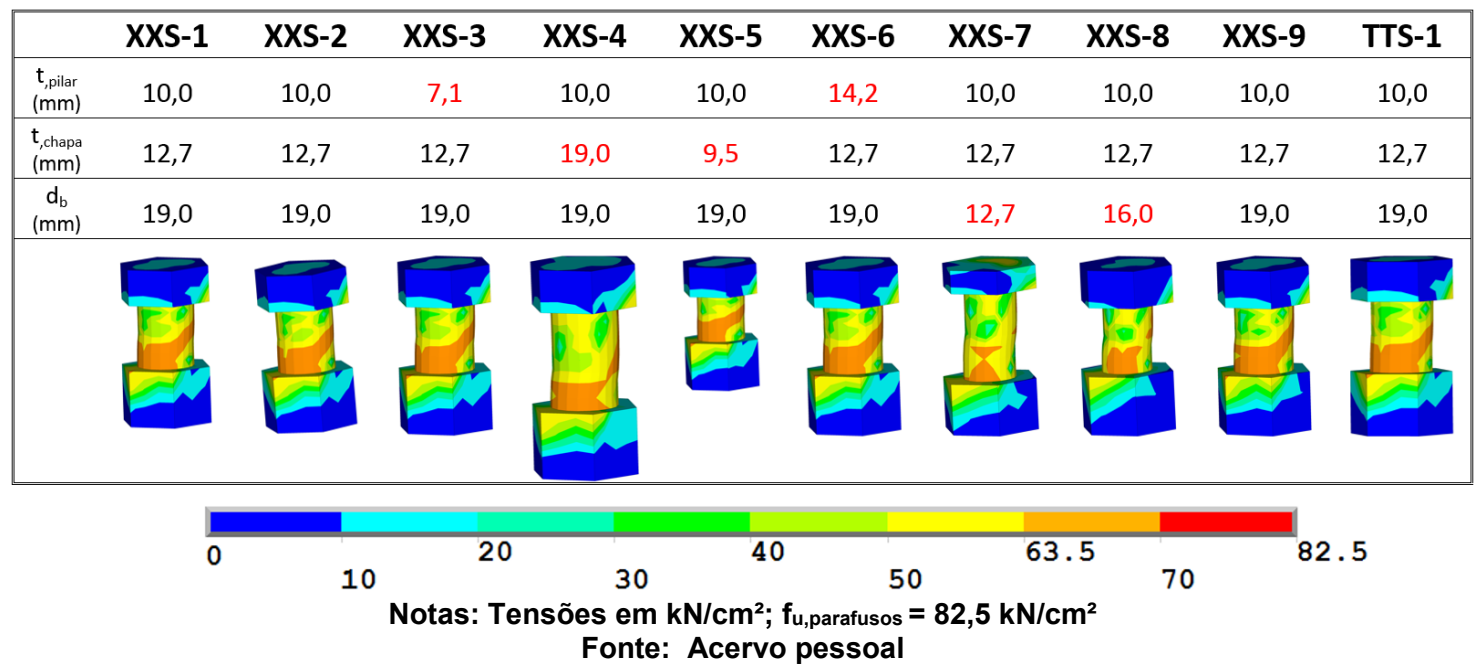

Nos 10 modelos analisados a plastificação da face do pilar não foi o modo de falha predominante para as ligações com o diafragma. O diafragma soldado ao redor do pilar gera uma superfície de transmissão da força de compressão maior do que a obtida do contato direto com a mesa inferior da viga, conforme ocorria nas ligações soldadas. As tensões na face do pilar apresentaram intensidade inferior ao limite de escoamento do material em todos os modelos, conforme ilustrado na figura 5.41.

Figura 5.41 - Tensões de Von Mises na face do pilar dos modelos com diafragma ao final da análise

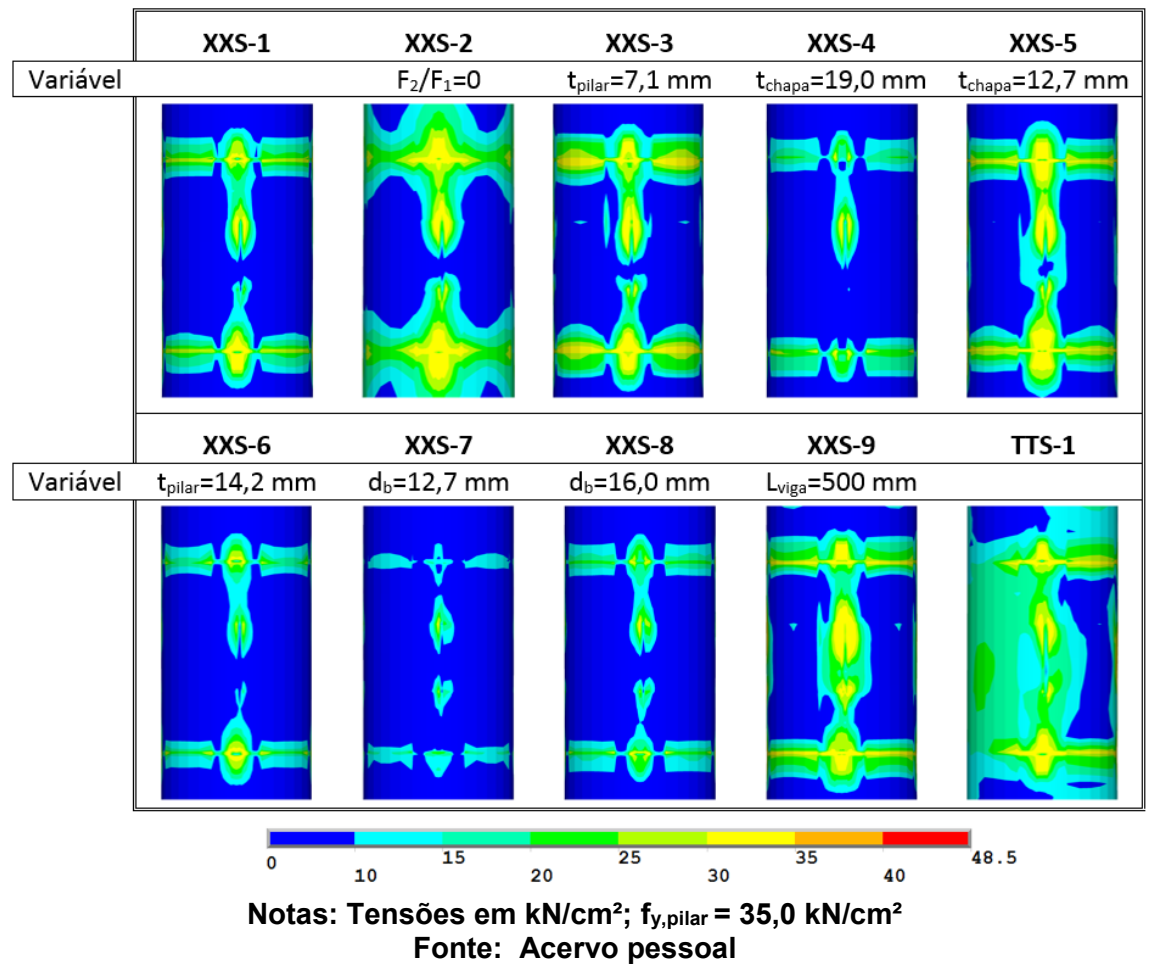


Na sequência deste capítulo, apresentam-se no quadro 5.2 os resultados mais relevantes, em termos de distribuição de tensões, em cada um dos 10 modelos de ligação com diafragma avaliados na análise numérica.

Quadro 5.2 - Tensões de Von Mises nos modelos de ligação soldada

\section{XXS-1}

( $t_{\text {pilar }}=10 \mathrm{~mm} ; t_{\text {chapa }}=12,7 \mathrm{~mm} ; d_{b}=19 \mathrm{~mm} ; F_{2} / F_{1}=1 ; L_{\text {viga }}=2000 \mathrm{~mm}$ )

As tensões de Von Mises no

modelo XXS-1, ao final da análise, ilustram a concentração de tensões na região dos furos da mesa superior das vigas. Nota-se pela figura 5.42 que o diafragma soldado ao redor do pilar foi capaz de redistribuir as tensões por todo o perímetro do tubo. A força vertical aplicada na extremidade da viga não foi capaz de proporcionar a plastificação da seção do pilar, sendo este fenômeno restrito à região dos furos da mesa da viga.
Figura 5.42 - Distribuição das tensões de Von Mises, ao final da análise, no modelo XXW-1

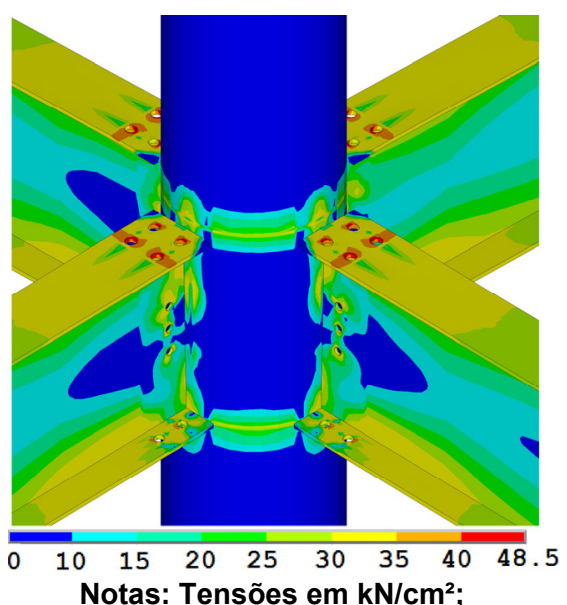

$f_{y, v i g a}=34,5 \mathrm{kN} / \mathrm{cm}^{2} ; f_{y, p i l a r}=35 \mathrm{kN} / \mathrm{cm}^{2}$ Fonte: Acervo pessoal

\begin{tabular}{|c|c|}
\hline \multicolumn{2}{|c|}{$\begin{array}{c}X X S-2 \\
\left(t_{\text {pilar }}=10 \mathrm{~mm} ; t_{\text {chapa }}=12,7 \mathrm{~mm} ; d_{b}=19 \mathrm{~mm} ; \underline{F}_{2} / F_{1}=0 ; L_{v i g a}=2000 \mathrm{~mm}\right)\end{array}$} \\
\hline $\begin{array}{l}\text { O carregamento nas vigas de apenas uma } \\
\text { direção resultou na concentração de tensões nos } \\
\text { parafusos da direção solicitada, nos furos da mesa } \\
\text { da viga e da chapa do diafragma e na região da } \\
\text { chapa do diafragma em contato com o pilar (figura } \\
5.43 \text { ). Verificou-se no modelo XXS-2 que a } \\
\text { ausência do carregamento nas vigas da direção } \\
\text { ortogonal representou uma menor restrição à } \\
\text { deformação do pilar e do diafragma nesta direção. } \\
\text { O modelo XXS-2 apresentou um comportamento } \\
\text { semelhante ao de uma ligação do tipo X, exceto } \\
\text { pela ligeira restrição exercida pelas vigas situadas } \\
\text { na direção ortogonal. }\end{array}$ & $\begin{array}{c}\text { Notas: Tensões em kN/cm²; } \\
f_{\mathrm{y}, \text { chapa }}=25 \mathrm{kN} / \mathrm{cm}^{2} \\
\text { Fonte: Acervo pessoal }\end{array}$ \\
\hline
\end{tabular}


Quadro 5.2 - Tensões de Von Mises nos modelos de ligação soldada

\section{XXS-3}

( $t_{\text {pilar }}=7,1 \mathrm{~mm} ; t_{\text {chapa }}=12,7 \mathrm{~mm} ; d_{b}=19 \mathrm{~mm} ; F_{2} / F_{1}=1 ; L_{v i g a}=2000 \mathrm{~mm}$ )

Nas ligações com diafragma estudadas neste trabalho, a espessura (t apresentou-se uma variável capaz de influenciar, consideravelmente,

Figura 5.44 - Tensões na face do pilar, ao final da análise, do modelo XXS-3.

comportamento da ligação. O diafragma soldado ao redor do pilar gerou uma redistribuição das tensões por todo o perímetro do tubo e proporcionou um efeito de confinamento na seção transversal deste. No modelo XXS-3, a espessura reduzida da parede do pilar resultou em tensões da ordem de 35 $\mathrm{kN} / \mathrm{cm}^{2}$ ao longo da seção do pilar (figura 5.44).

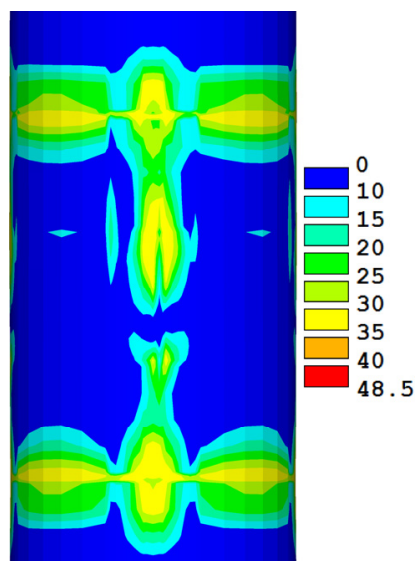

Notas: Tensões em $\mathbf{k N} / \mathrm{cm}^{2}$; $f_{y, v i g a}=34,5 \mathrm{kN} / \mathrm{cm}^{2}$; $f_{y, \text { pilar }}=35 \mathrm{kN} / \mathrm{cm}^{2}$

Fonte: Acervo pessoal

As tensões na região dos furos da mesa superior das vigas atingiram o limite de ruptura do aço (em torno de $48,5 \mathrm{kN} / \mathrm{cm}^{2}$ ), enquanto que, as tensões na parede do pilar estão, ainda, na eminência de gerar a plastificação da seção do tubo. Verificou-se no modelo XXS-3, a plastificação da região dos furos da mesa superior das vigas e o cisalhamento dos parafusos do diafragma como modos de falha predominantes.

\section{XXS-4}

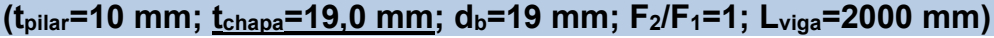

No modelo XXS-4, o enrijecimento da ligação pelo aumento da espessura da chapa aumentou a resistência da ligação e a força vertical aplicada na extremidade da viga. A figura 5.45 demonstra tensões acima do limite de escoamento do material da viga ao longo da seção transversal próxima aos furos. A força vertical aplicada no modelo XXS-4 resultou na plastificação da seção transversal da mesa

Figura 5.45 - Tensões na mesa superior das vigas, ao final da análise, no modelo XXS-4

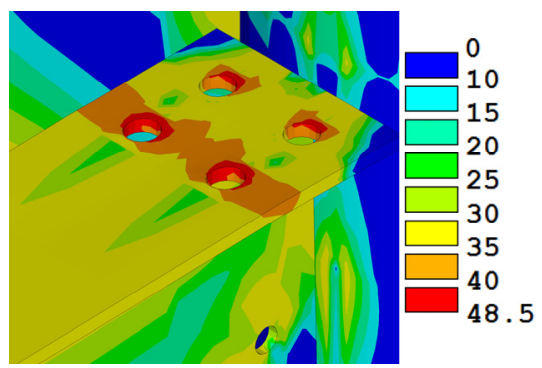

Notas: Tensões em kN/cm²; $f_{y, v i g a}=34,5 \mathrm{kN} / \mathrm{cm}^{2} ; f_{y, p i l a r}=35 \mathrm{kN} / \mathrm{cm}^{2}$ Fonte: Acervo pessoal superior da viga. 
Quadro 5.2 - Tensões de Von Mises nos modelos de ligação soldada

XXS-5

( $t_{\text {pilar }}=10 \mathrm{~mm} ; \underline{t_{\text {chapa }}=9,5 \mathrm{~mm}} ; d_{b}=19 \mathrm{~mm} ; F_{2} / F_{1}=1 ; L_{v i g a}=2000 \mathrm{~mm}$ )

A figura 5.46 ilustra as tensões de Von

Figura 5.46 - Tensões na chapa superior, ao final da análise, do modelo XXS-5

Mises na chapa superior do diafragma do modelo XXS-5. A utilização de uma chapa com espessura reduzida resultou na concentração de tensões neste elemento. A intensidade das tensões na chapa superior superou o limite de escoamento do material na região junto à ligação com a mesa superior das vigas. As tensões acima de $25 \mathrm{kN} / \mathrm{cm}^{2}$ caracterizam a plastificação da seção da chapa junto aos furos.

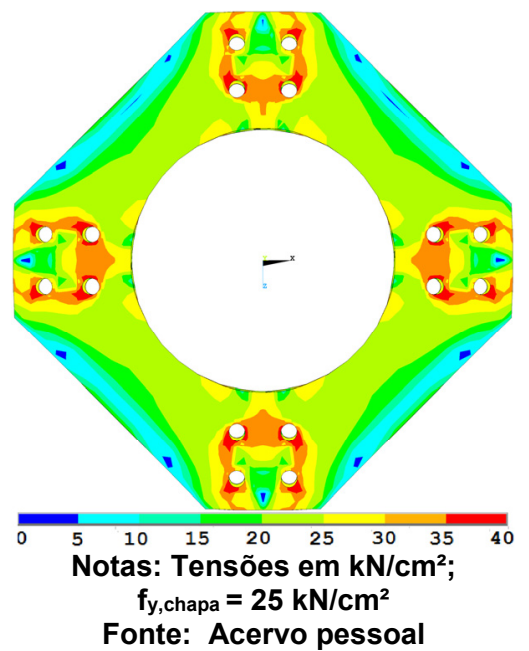

\section{XXS-6}

( $t_{\text {pilar }}=14,2 \mathrm{~mm} ; t_{\text {chapa }}=12,7 \mathrm{~mm} ; d_{b}=19 \mathrm{~mm} ; F_{2} / F_{1}=1 ; L_{\text {viga }}=2000 \mathrm{~mm}$ )

No modelo XXS-6 verificou-se um sub aproveitamento da seção do pilar quando da utilização de uma seção com espessura elevada.

A figura 5.47 demonstra tensões em torno de $20 \mathrm{kN} / \mathrm{cm}^{2}$ ao redor do pilar, com pontos de concentração apenas na interface viga-pilar. $\mathrm{O}$ aumento da espessura do pilar, sem a alteração da geometria de outros componentes, não representou uma melhoria do comportamento da ligação, pois a análise limitou-se pela não convergência da solução numérica em função das tensões elevadas na região dos furos e no fuste dos parafusos do diafragma.
Figura 5.47 - Tensões de Von Mises na face do pilar, ao final da análise, do modelo XXS-6.

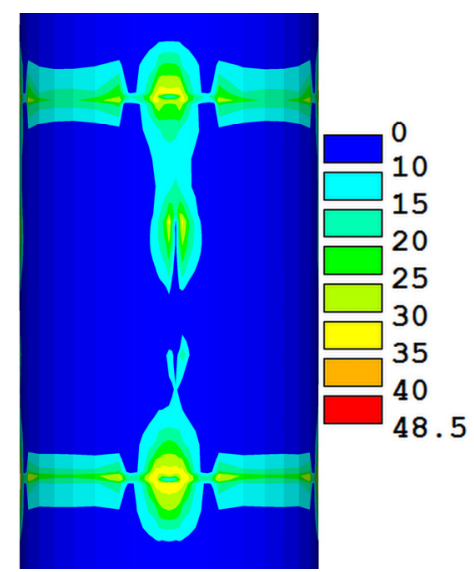

Notas: Tensões em $\mathrm{kN} / \mathrm{cm}^{2}$; $f_{y, \text { viga }}=34,5 \mathrm{kN} / \mathrm{cm}^{2} ; f_{y, p i l a r}=35 \mathrm{kN} / \mathrm{cm}^{2}$ Fonte: Acervo pessoal

\footnotetext{
XXS-7

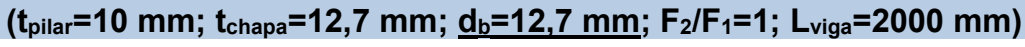

A opção pela utilização de parafusos com diâmetro reduzido no modelo XXS-7 resultou em uma ligação com resistência reduzida, culminando em uma falha precoce do modelo em função do cisalhamento dos parafusos na ligação com
} 
Quadro 5.2 - Tensões de Von Mises nos modelos de ligação soldada

a mesa superior das vigas. A figura 5.48 apresenta as tensões de Von Mises no modelo XXS-7 ao final da análise. A distribuição de tensões demonstra a intensidade reduzida das tensões nas vigas, pilar e chapas do modelo. A baixa resistência dos parafusos reduziu a resistência global da ligação verificando-se uma força vertical aplicada de menor intensidade e, consequentemente, esforços de menor magnitude nos demais elementos. Observa-se pela figura 5.48 que a relação geométrica entre os componentes da ligação do modelo XXS-7 resultou em um baixo aproveitamento das seções das vigas, pilar e chapas, visto a intensidade das tensões atuantes neste elemento frente ao limite de escoamento do material.

Figura 5.48 - Tensões de Von Mises, ao final da análise, no modelo XXS-7

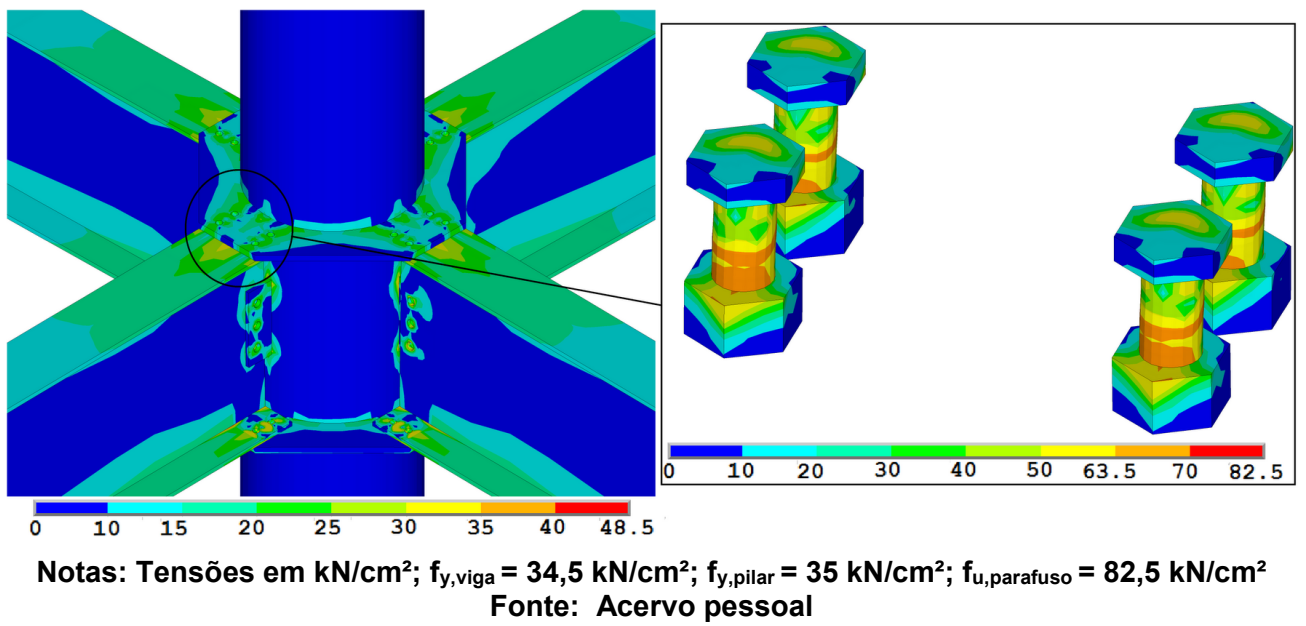

XXS-8

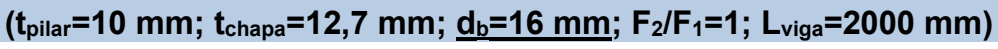

A figura 5.49 ilustra as tensões de Von Mises ao final da análise no modelo XXS-8. A distribuição das tensões demonstra a concentração de tensões na região dos furos da mesa superior das vigas. A baixa resistência dos parafusos limitou a análise pela não convergência da solução numérica devido à ruptura dos parafusos. Nota-se pelas tensões no fuste dos parafusos a ocorrência de valores próximos da tensão de ruptura material $\left(82,5 \mathrm{kN} / \mathrm{cm}^{2}\right)$. 
Quadro 5.2 - Tensões de Von Mises nos modelos de ligação soldada

\begin{tabular}{|c|c|}
\hline 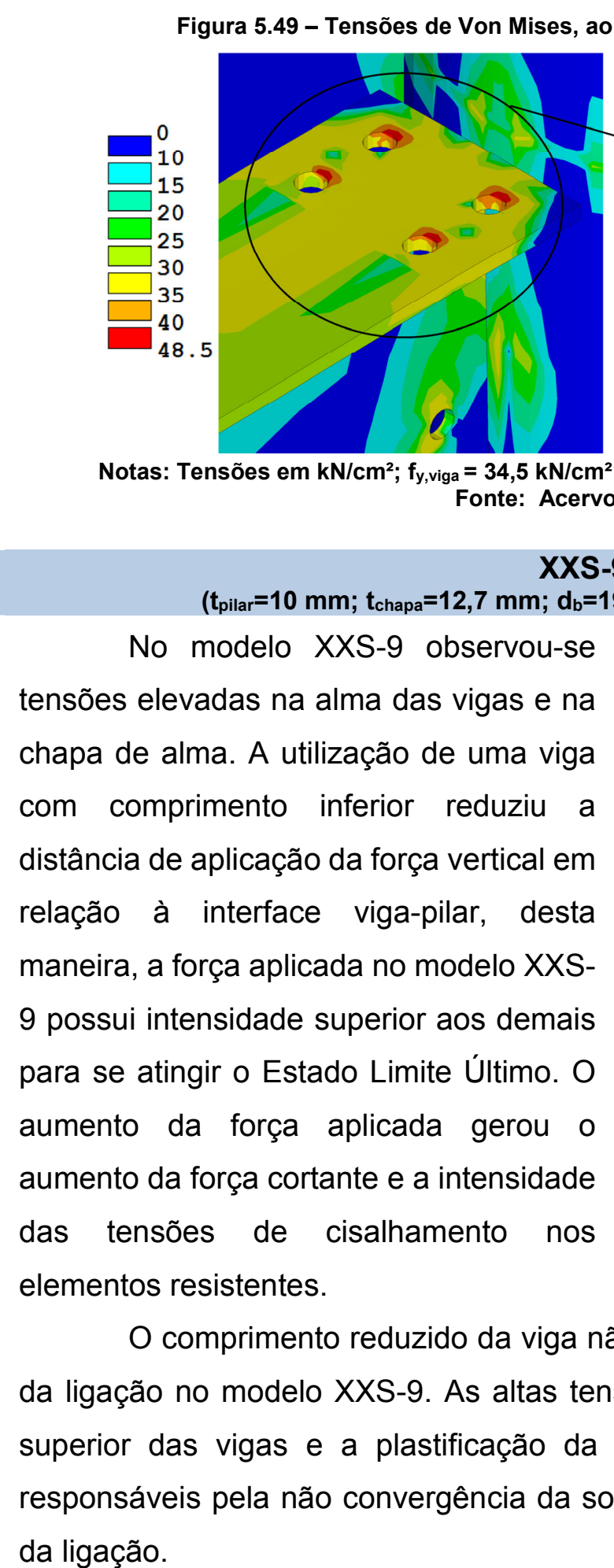 & 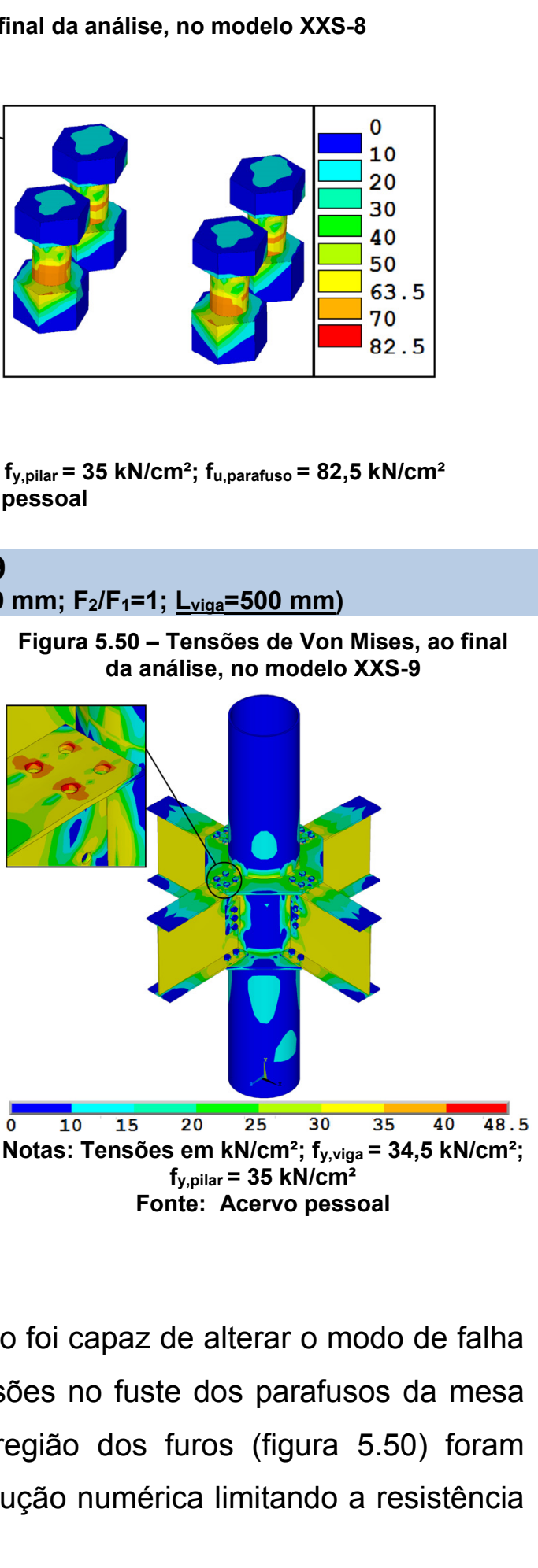 \\
\hline
\end{tabular}


Quadro 5.2 - Tensões de Von Mises nos modelos de ligação soldada

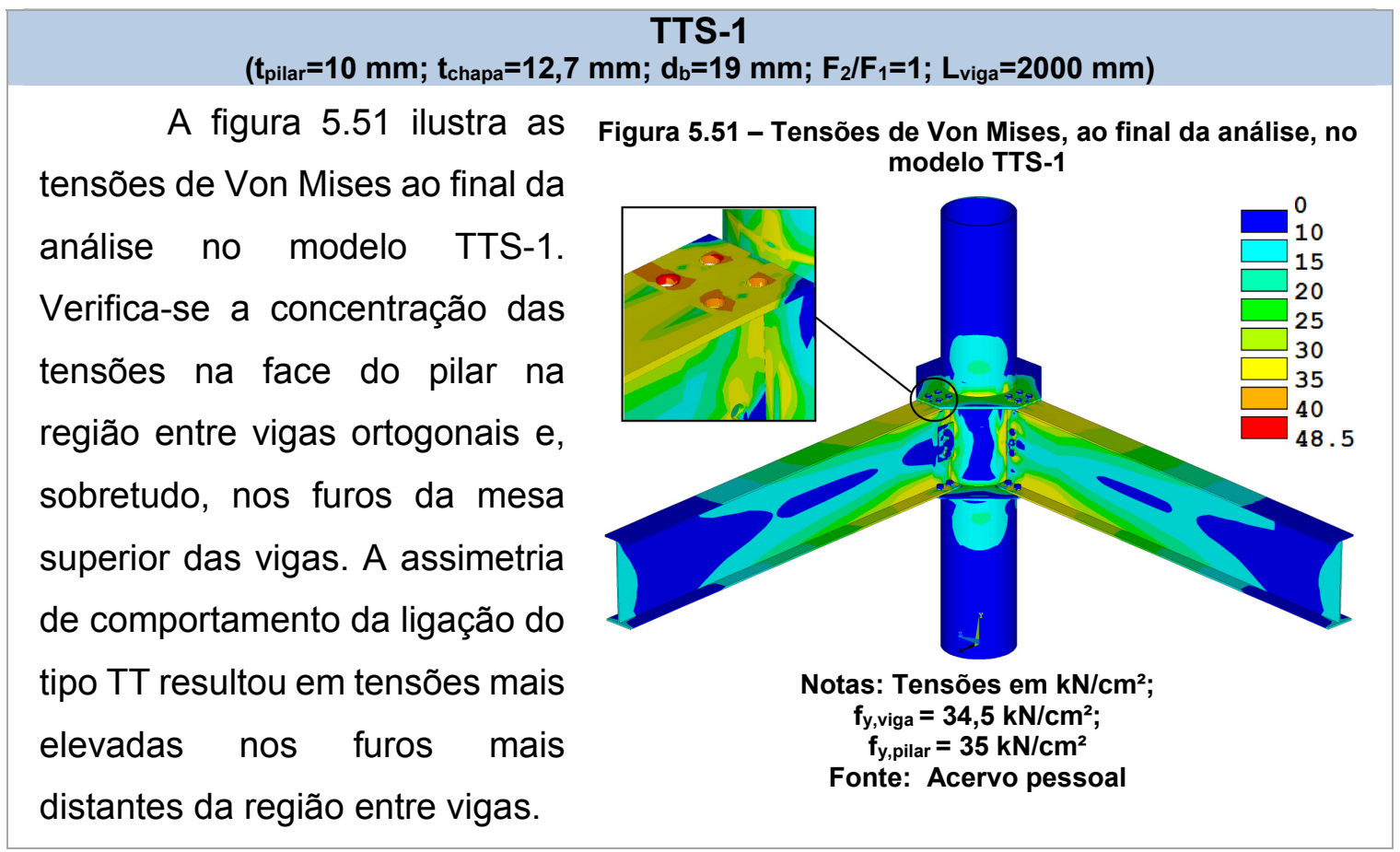

\subsubsection{Análise da força aplicada versus deslocamento}

As curvas apresentadas na sequência deste trabalho descrevem 0 comportamento dos modelos numéricos do ponto de vista da aplicação da força e o respectivo deslocamento ao longo da análise. As curvas ilustram os resultados referentes ao ponto de aplicação da força, no caso, a extremidade da viga. Os resultados referentes à força e deslocamento estão expressos, respectivamente, em $\mathrm{kN}$ e $\mathrm{cm}$.

\subsubsection{Ligações soldadas}

As curvas que descrevem o comportamento dos modelos de ligação soldada em termos de força e deslocamento estão representadas na figura 5.52 e figura 5.53. 
Figura 5.52 - Curvas força versus deslocamento para os modelos com ligação soldada (I/II)
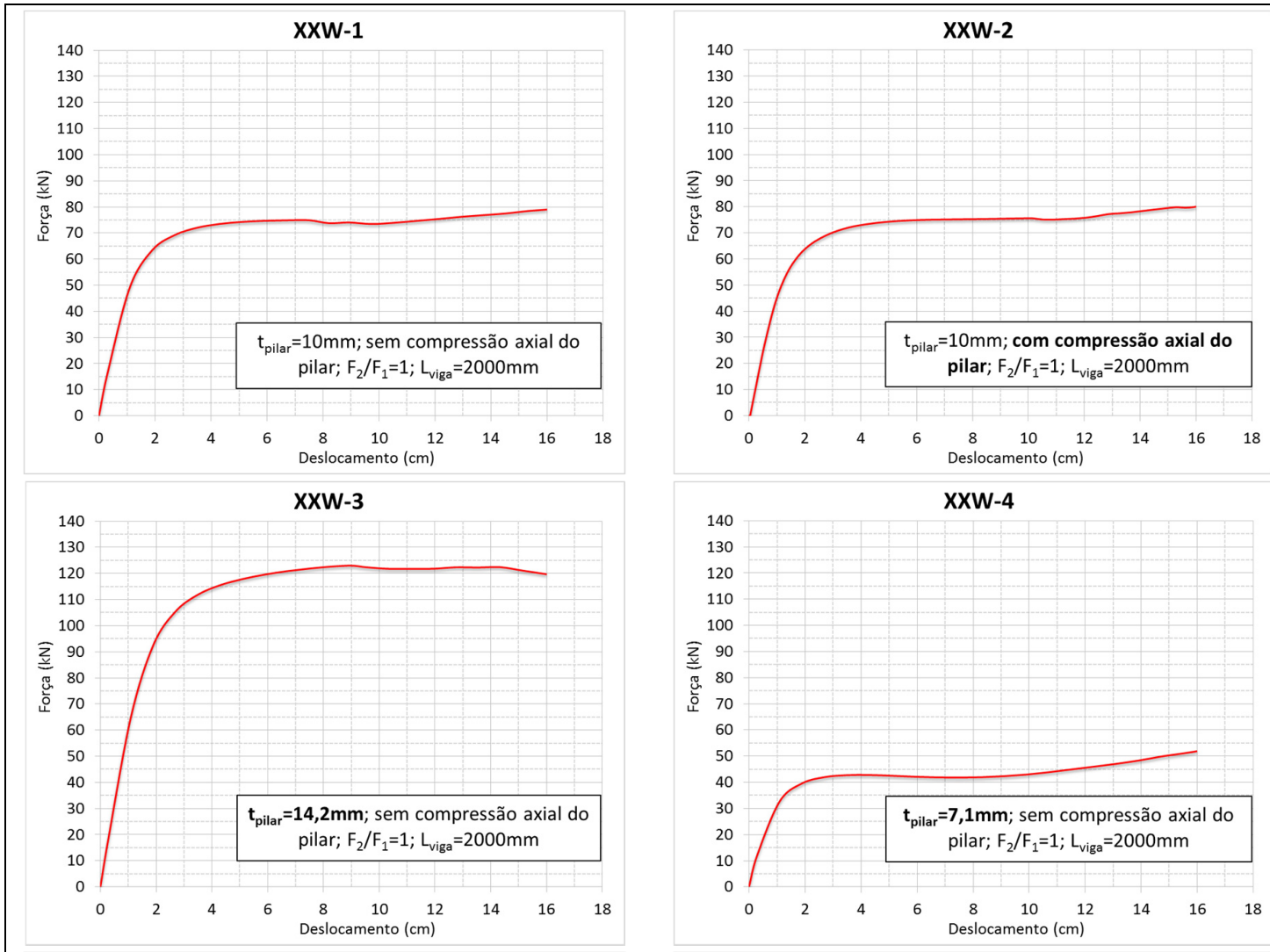

XXW-5
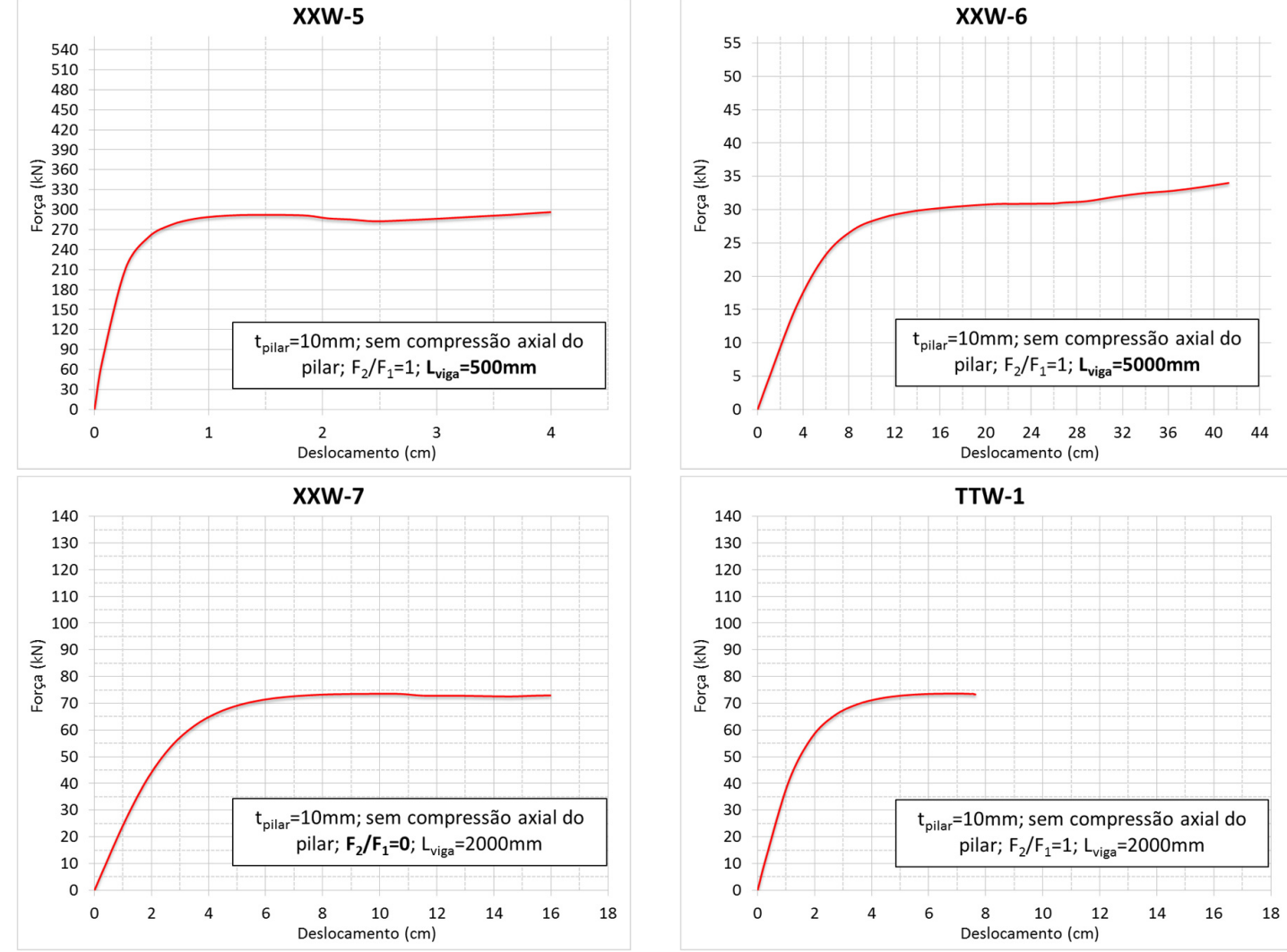

Modo de falha: Plastificação da face do pilar na região comprimida pela mesa inferior da viga Fonte: Acervo pessoal 
Figura 5.53 - Curvas força versus deslocamento para os modelos com ligação soldada (II/II)

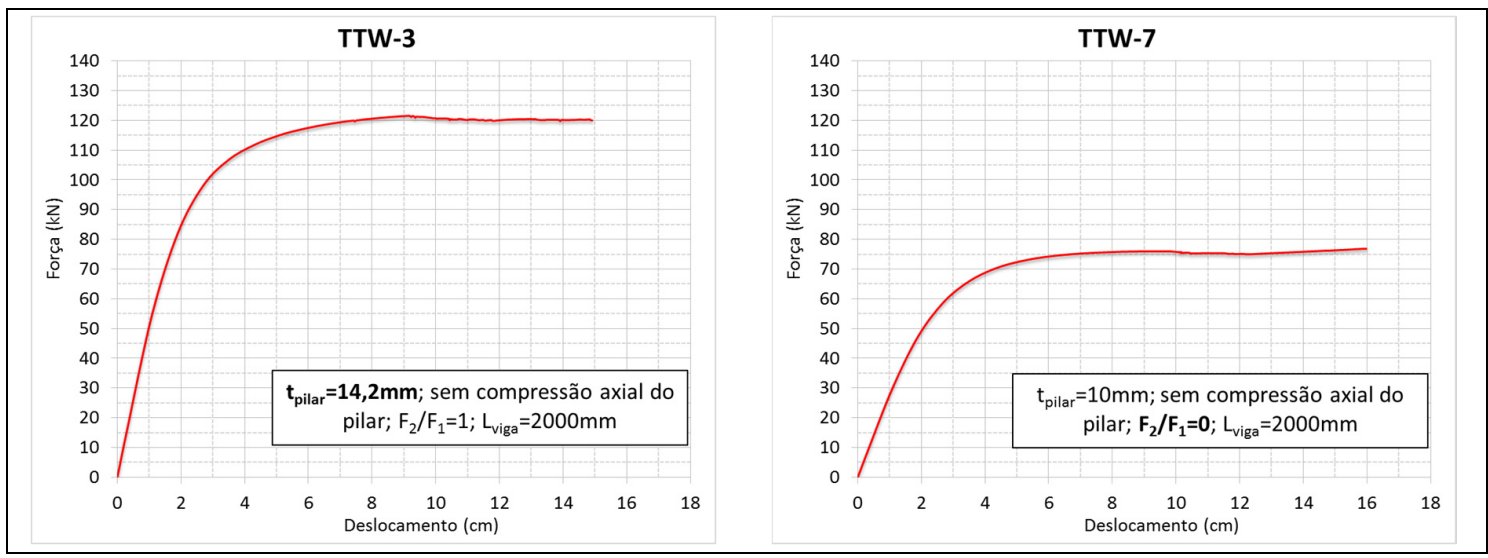

Modo de falha: Plastificação da face do pilar na região comprimida pela mesa inferior da viga Fonte: Acervo pessoal

Os modelos com ligação soldada e com comprimento da viga de $200 \mathrm{~cm}$ foram analisados para um deslocamento vertical máximo de 16 centímetros na extremidade da viga. Visto a grande capacidade de deformação dos modelos, optou-se por utilizar um valor de referência que representasse satisfatoriamente o comportamento das ligações. Alguns dos modelos analisados apresentaram-se incapazes de resistir aos esforços relativos a este deslocamento e, neste caso, verificou-se a não convergência da solução numérica. A tabela 5.6 apresenta os resultados obtidos para força e deslocamento vertical máximos atuantes e o quadro 5.3. um breve comentário a respeito das curvas força-deslocamento em cada um dos 10 modelos de ligação soldada.

Tabela 5.6 - Força e deslocamento vertical máximos nos modelos com ligação soldada

\begin{tabular}{|c|c|c|c|}
\hline MODELO & $\begin{array}{l}\text { FORÇA MÁXIMA } \\
\qquad(k N)\end{array}$ & $\begin{array}{c}\text { MOMENTO } \\
\text { FLETOR (kN.m) }\end{array}$ & $\begin{array}{l}\text { DESLOCAMENTO } \\
\text { VERTICAL DE } \\
\text { REFERÊNCIA }(\mathrm{cm})\end{array}$ \\
\hline $\begin{array}{l}\underline{X X W-1}\left(t_{\text {pilar }}=10 \mathrm{~mm} ; \mathrm{s} / \text { compressão }\right. \\
\text { no pilar; } F_{2} / F_{1}=1 ; L_{\text {viga }}=2000 \mathrm{~mm} \text { ) }\end{array}$ & 79,0 & 158,0 & 16,0 \\
\hline XXW-2 (com compressão no pilar) & 79,9 & 159,9 & 16,0 \\
\hline$\underline{X X W-3}\left(t_{\text {pilar }}=14,2 \mathrm{~mm}\right)$ & 123,0 & 246,1 & 16,0 \\
\hline$\underline{X X W-4}\left(t_{\text {pilar }}=7,1 \mathrm{~mm}\right)$ & 51,8 & 103,6 & 16,0 \\
\hline$\underline{X X W-5}\left(L_{\text {viga }}=500 \mathrm{~mm}\right)$ & 296,8 & 148,4 & 4,0 \\
\hline$\underline{X X W-6}\left(L_{\text {viga }}=5000 \mathrm{~mm}\right)$ & 34,1 & 170,3 & 40,0 \\
\hline$\underline{X X W-7}\left(F_{2} / F_{1}=0\right)$ & 73,6 & 147,2 & 16,0 \\
\hline $\begin{array}{l}\text { TTW-1 }\left(t_{\text {pilar }}=10 \mathrm{~mm} ; \mathrm{s} / \text { compressão }\right. \\
\left.\text { no pilar; } F_{2} / F_{1}=1 ; L_{\text {viga }}=2000 \mathrm{~mm}\right)\end{array}$ & 73,6 & 147,3 & 7,7 \\
\hline TTW-3 $\left(t_{\text {pilar }}=14,2 \mathrm{~mm}\right)$ & 121,6 & 243,3 & 14,9 \\
\hline TTW-7 $\left(F_{2} / F_{1}=0\right)$ & 76,9 & 153,9 & 16,0 \\
\hline
\end{tabular}

Fonte: Acervo pessoal 
Quadro 5.3 - Análise das curvas força-deslocamento dos modelos de ligação soldada

\begin{tabular}{|c|c|}
\hline $\begin{array}{c}\quad \underline{\mathbf{X X W}-1} \\
\left(\mathrm{t}_{\text {pilar }}=10 \mathrm{~mm} ; \text { sem }\right. \\
\text { compressão axial } \\
\text { no pilar; } F_{2} / F_{1}=1 ; \\
\left.L_{\text {viga }}=2000 \mathrm{~mm}\right)\end{array}$ & $\begin{array}{l}\text { - A força vertical de até } 50 \mathrm{kN} \text { (deslocamento de } 1,1 \mathrm{~cm} \text { ) resultou } \\
\text { em um comportamento, praticamente, elástico-linear da curva } \\
\text { força-deslocamento. Neste ponto atingiu-se o estado plástico do } \\
\text { modelo verificando-se um pequeno acréscimo de resistência até } \\
\text { o deslocamento de } 16 \mathrm{~cm} \text {; } \\
\text { - A máxima força vertical aplicada na extremidade da viga foi de } \\
79 \mathrm{kN} \text { representando um momento fletor de } 158 \mathrm{kN} . \mathrm{m} \text {. }\end{array}$ \\
\hline $\begin{array}{r}\underline{X X} \\
\left(t_{\text {pilar }}=10 r\right. \\
\text { compı } \\
\text { axial } n \\
F_{2} / F \\
L_{\text {viga }}=2 C\end{array}$ & $\begin{array}{l}\text { - A força vertical de até } 48 \mathrm{kN} \text { (deslocamento de } 1,0 \mathrm{~cm} \text { ) resultou } \\
\text { em um comportamento, praticamente, elástico-linear da curva } \\
\text { força-deslocamento; } \\
\text { - Superado o limite de plastificação do material, o modelo } \\
\text { apresentou deformação plástica até uma força vertical de } 79,9 \mathrm{kN} \\
\text { e o respectivo momento fletor de } 159,9 \mathrm{kN} \text {.m. }\end{array}$ \\
\hline $\begin{array}{r}\underline{X X} \\
\left(t_{\text {pilar }}=1\right. \\
\text { sem con } \\
\text { axial } n \\
F_{2} / F \\
L_{\text {viga }}=2(\end{array}$ & $\begin{array}{l}\text { - A curva força-deslocamento do modelo XXW-3 apresentou } \\
\text { amplitude elevada em função da espessura considerável do pilar; } \\
\text { - O trecho com comportamento próximo ao elástico-linear } \\
\text { estendeu-se do início de aplicação da força vertical até a } \\
\text { intensidade de } 85 \mathrm{kN} \text { e deslocamento de } 1,8 \mathrm{~cm} \text {; } \\
\text { - A máxima força vertical aplicada }(123 \mathrm{kN}) \text { na extremidade da } \\
\text { viga representou um deslocamento de } 9 \mathrm{~cm} \text { e um momento fletor } \\
\text { de } 246 \text { kN.m. A partir deste ponto o modelo apresentou uma } \\
\text { deformação plástica mais considerável e perda de resistência até } \\
\text { o deslocamento de referência de } 16 \mathrm{~cm} \text {. }\end{array}$ \\
\hline $\begin{array}{r}\underline{\mathbf{X X}} \\
\left(\mathbf{t}_{\text {pilar }}=7\right. \\
\text { sem con } \\
\text { axial } n \\
\mathrm{~F}_{2} / \mathrm{F} \\
\mathrm{L}_{\text {viga }}=2(\end{array}$ & $\begin{array}{l}\text { - A curva força-deslocamento do modelo XXW-4 apresentou } \\
\text { amplitude reduzida em função da utilização de um pilar com } \\
\text { pouca espessura; } \\
\text { - Verificou-se um comportamento elástico-linear apenas nos } \\
\text { estágios iniciais de carregamento até uma força aplicada de } 15 \\
\text { kN e deslocamento vertical de } 0,4 \mathrm{~cm} \text {; } \\
\text { - O modelo XXW-4 apresentou um momento resistente de } 103,6 \\
\text { kN.m para uma força vertical de } 51,8 \mathrm{kN} \text { e deslocamento de } 16 \\
\mathrm{~cm} \text {. }\end{array}$ \\
\hline
\end{tabular}


Quadro 5.3 - Análise das curvas força-deslocamento dos modelos de ligação soldada

\begin{tabular}{|c|c|}
\hline $\begin{array}{c}\underline{\mathbf{X X W}-\mathbf{5}} \\
\left(\mathrm{t}_{\text {pilar }}=10,0 \mathrm{~mm} ;\right. \\
\text { sem compressão } \\
\text { axial no pilar; } \\
\quad \mathrm{F}_{2} / \mathrm{F}_{\mathbf{1}}=1 ; \\
\mathrm{L}_{\text {viga }}=\mathbf{5 0 0 \mathrm { mm } )}\end{array}$ & $\begin{array}{l}\text { - A análise do modelo XXW-5 limitou-se a um deslocamento de } \\
4 \mathrm{~cm} \text { na extremidade da viga, de modo a manter a } \\
\text { proporcionalidade entre as análises dos modelos de ligação } \\
\text { soldada em função do comprimento da viga; } \\
\text { - Foi necessária uma força de } 230 \mathrm{kN} \text { (deslocamento de } 0,3 \mathrm{~cm} \text { ) } \\
\text { na extremidade da viga para que o modelo XXW- } 5 \text { apresentasse } \\
\text { deformação plástica, a ponto de evidenciar a alteração da } \\
\text { inclinação da curva; } \\
\text { - Após o início da plastificação da face do pilar, o modelo } \\
\text { passou a se deformar sem um acréscimo considerável na força } \\
\text { aplicada, até o limite de } 296,8 \mathrm{kN} \text { (momento fletor de } 148,4 \mathrm{kN} \text {.m) } \\
\text { e o respectivo deslocamento de } 4 \mathrm{~cm} \text { na extremidade da viga. }\end{array}$ \\
\hline $\begin{array}{r}\underline{\mathbf{X}} \\
\left(\mathrm{t}_{\text {pilar }}=\right. \\
\text { sem co } \\
\text { axial } \\
\mathrm{F}_{2} \\
\mathrm{~L}_{\text {viga }}=\end{array}$ & $\begin{array}{l}\text { - A análise do modelo XXW-6 limitou-se a um deslocamento de } \\
40 \mathrm{~cm} \text { na extremidade da viga de modo a manter a } \\
\text { proporcionalidade entre os modelos; } \\
\text { - A curva do modelo XXW- } 6 \text { apresentou inclinação considerável } \\
\text { no trecho inicial em função do comprimento do balanço; } \\
\text { - O modelo apresentou comportamento próximo ao elástico- } \\
\text { linear até a força aplicada de } 20 \mathrm{kN} \text { que originou um } \\
\text { deslocamento de } 5 \mathrm{~cm} \text { na extremidade da viga; } \\
\text { - A força aplicada de } 33,9 \mathrm{kN} \text { (momento fletor de } 169,5 \mathrm{kN} . \mathrm{m} \text { ) } \\
\text { na extremidade da viga resultou no deslocamento de } 40 \mathrm{~cm} \text {, } \\
\text { tomado como referência para a interrupção da análise. }\end{array}$ \\
\hline $\begin{array}{c}\underline{\mathbf{X X W}-\mathbf{7}} \\
\left(\mathrm{t}_{\text {pilar }}=10,0 \mathrm{~mm} ;\right. \\
\text { sem compressão } \\
\text { axial no pilar; } \\
\quad \mathbf{F}_{\mathbf{2}} / \mathbf{F}_{\mathbf{1}}=\mathbf{0} ; \\
\text { Lviga }=2000 \mathrm{~mm})\end{array}$ & $\begin{array}{l}\text { - A curva força-deslocamento do modelo XXW-7 apresentou } \\
\text { inclinação acentuada no trecho inicial de carregamento, } \\
\text { verificando-se um comportamento, praticamente, elástico-linear } \\
\text { até a força aplicada de } 40 \mathrm{kN} \text { e deslocamento de } 1,8 \mathrm{~cm} \text {; } \\
\text { - O modelo XXW-7 obteve a máxima força de } 73,6 \mathrm{kN} \text {, aplicada } \\
\text { na extremidade da viga e o respectivo deslocamento vertical de } \\
9,9 \mathrm{~cm} \text {. A partir deste ponto o modelo passou a perder resistência } \\
\text { até o deslocamento de referência de } 16 \mathrm{~cm} \text {. }\end{array}$ \\
\hline
\end{tabular}


Quadro 5.3 - Análise das curvas força-deslocamento dos modelos de ligação soldada

\begin{tabular}{|c|c|}
\hline $\begin{array}{c}\text { TTW-1 } \\
\left(\mathrm{t}_{\text {pilar }}=10,0 \mathrm{~mm} ;\right. \\
\text { sem compressão } \\
\text { axial no pilar; } \\
\mathrm{F}_{2} / \mathrm{F}_{1}=1 ; \\
\left.\mathrm{L}_{\text {viga }}=2000 \mathrm{~mm}\right)\end{array}$ & $\begin{array}{l}\text { - No modelo TTW-1 a solução numérica não apresentou } \\
\text { convergência, resultando na falha da ligação para uma força } \\
\text { vertical de } 73,1 \mathrm{kN} \text { e deslocamento de } 7,65 \mathrm{~cm} \text { na extremidade } \\
\text { da viga; } \\
\text { - A curva força-deslocamento exibiu comportamento elástico- } \\
\text { linear até a força aplicada de } 40 \mathrm{kN} \text { (deslocamento de } 1 \mathrm{~cm} \text { ); } \\
\text { - Ao final da análise verificou-se um momento fletor resistente } \\
\text { de } 146,2 \mathrm{kN} \text {.m. }\end{array}$ \\
\hline $\begin{array}{c}\text { TTW-3 } \\
\left(t_{\text {pilar }}=14,2 \mathrm{~mm} ;\right. \\
\text { sem compressão } \\
\text { axial no pilar; } \\
\mathrm{F}_{2} / \mathrm{F}_{1}=1 ; \\
\left.\mathrm{L}_{\text {viga }}=2000 \mathrm{~mm}\right)\end{array}$ & $\begin{array}{l}\text { - O enrijecimento proporcionado pela utilização de um pilar com } \\
\text { espessura considerável resultou em uma curva com grande } \\
\text { amplitude no modelo TTW-3; } \\
\text { - A análise do modelo TTW-3 limitou-se pela não convergência } \\
\text { da solução numérica, verificando-se ao final da análise um } \\
\text { deslocamento máximo de } 14,92 \mathrm{~cm} \text { na extremidade da viga; } \\
\text { - A máxima força vertical aplicada no modelo TTW-3 foi de } 121 \\
\text { kN (momento fletor de } 243 \text { kN.m), resultando em um } \\
\text { deslocamento de } 9,3 \mathrm{~cm} \text { na extremidade da viga. }\end{array}$ \\
\hline $\begin{array}{c}\text { TTW-7 } \\
\left(t_{\text {pilar }}=10,0 \mathrm{~mm} ;\right. \\
\text { sem compressão } \\
\text { axial no pilar; } \\
\mathbf{F}_{2} / \mathbf{F}_{1}=\mathbf{0} ; \\
\text { L viga }=2000 \mathrm{~mm})\end{array}$ & $\begin{array}{l}\text { - A ausência da restrição à deformação do pilar imposta pela } \\
\text { viga carregada no sentido ortogonal resultou em uma deformação } \\
\text { considerável no trecho inicial de carregamento; } \\
\text { - A curva força-deslocamento do modelo TTW-7 apresentou } \\
\text { comportamento elástico-linear até a força aplicada de } 35 \mathrm{kN} \text { e } \\
\text { deslocamento de } 1,2 \mathrm{~cm} \text { na extremidade da viga. Atingido o } \\
\text { estado plástico o modelo se deformou até a máxima força vertical } \\
\text { de } 76,9 \mathrm{kN} \text { (momento fletor de } 153,8 \mathrm{kN} \text {.m) com o deslocamento } \\
\text { de referência de } 16 \mathrm{~cm} \text {. }\end{array}$ \\
\hline
\end{tabular}

\subsubsection{Ligações com a presença de diafragma externo}

As curvas força versus deslocamento para os modelos de ligação com o diafragma estão representadas na figura 5.54 e na figura 5.55 . 
Figura 5.54 - Curvas força versus deslocamento para os modelos de ligação com diafragma (I/II)
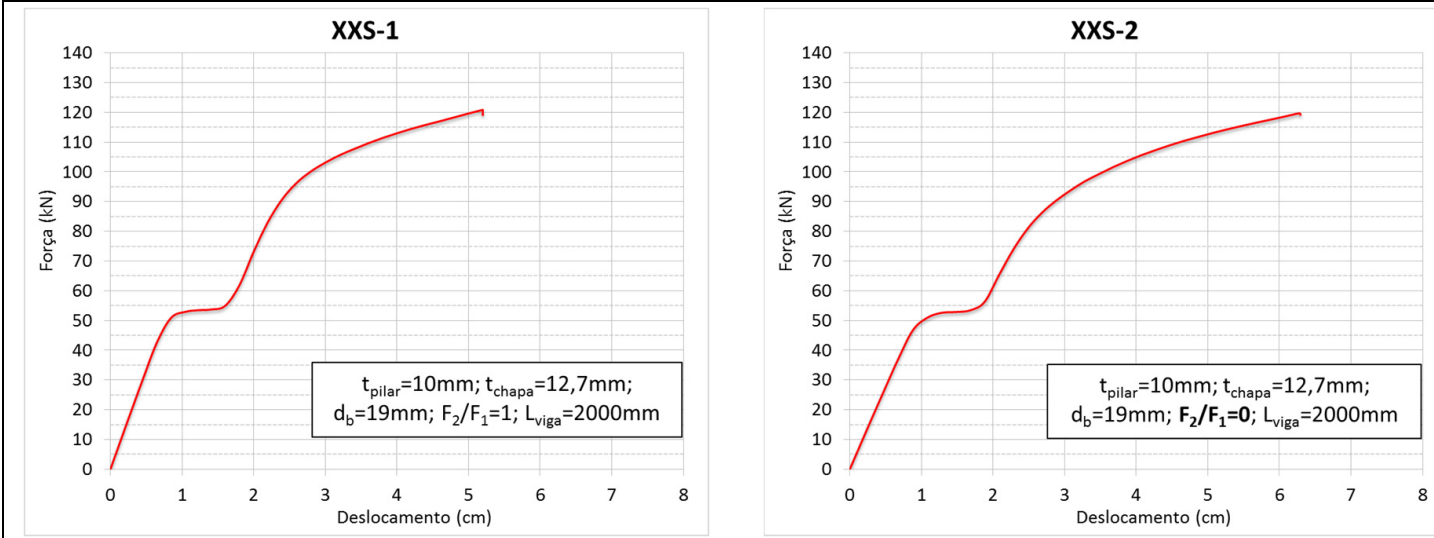

XXS-3
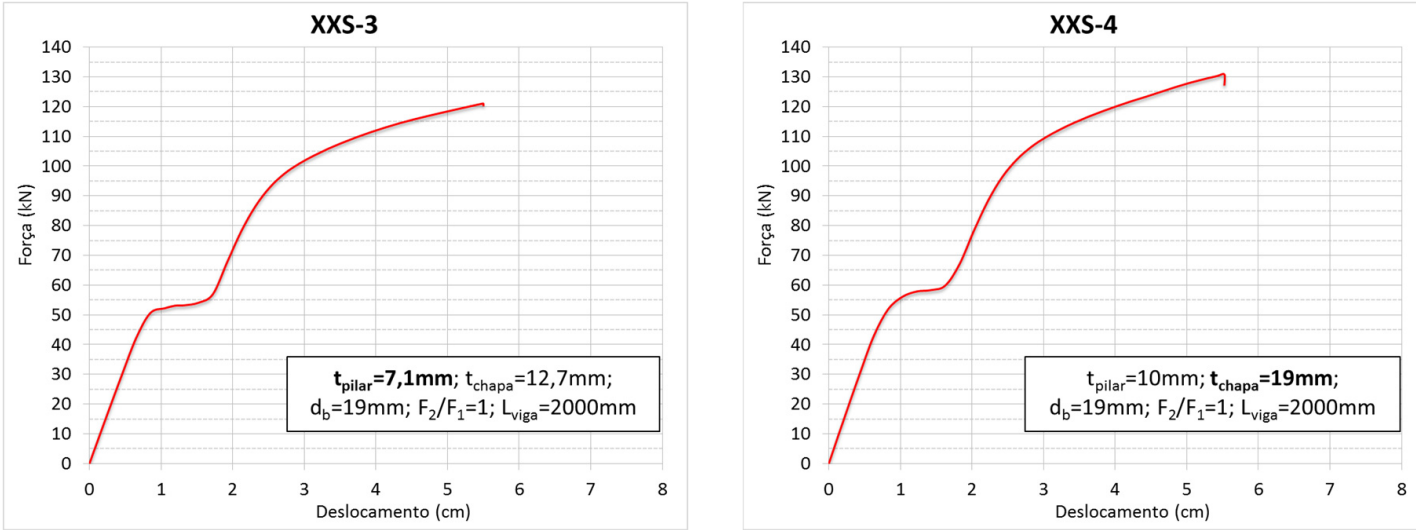

XXS-5
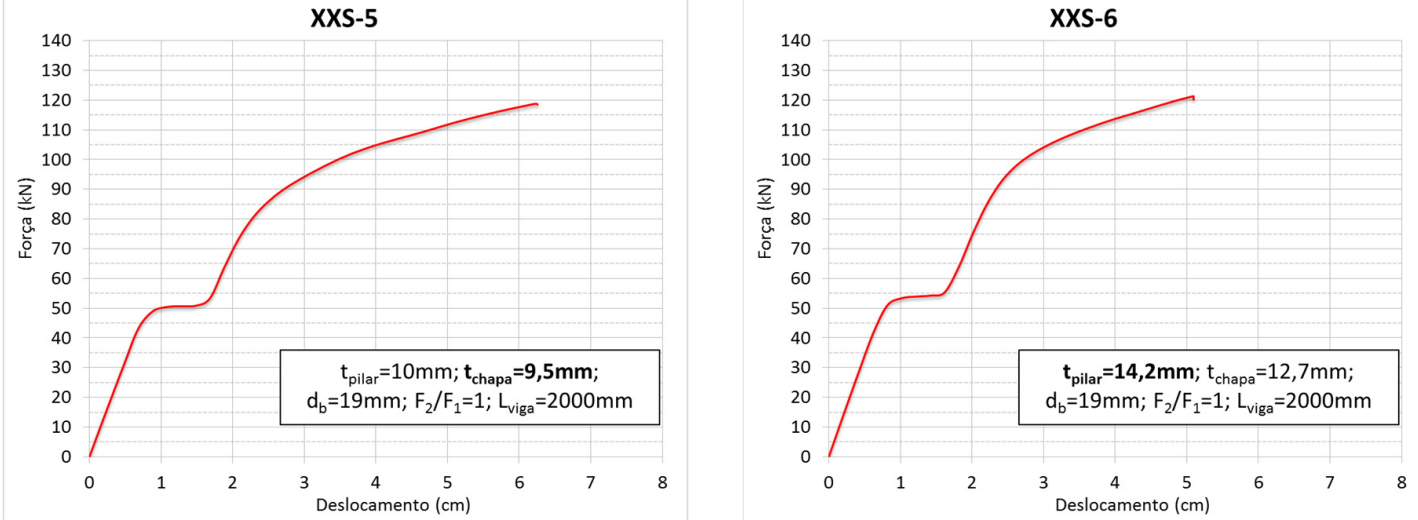

Modo de falha: Cisalhamento dos parafusos na ligação do diafragma com a mesa superior das vigas Fonte: Acervo pessoal 
Figura 5.55 - Curvas força versus deslocamento para os modelos de ligação com diafragma (II/II)

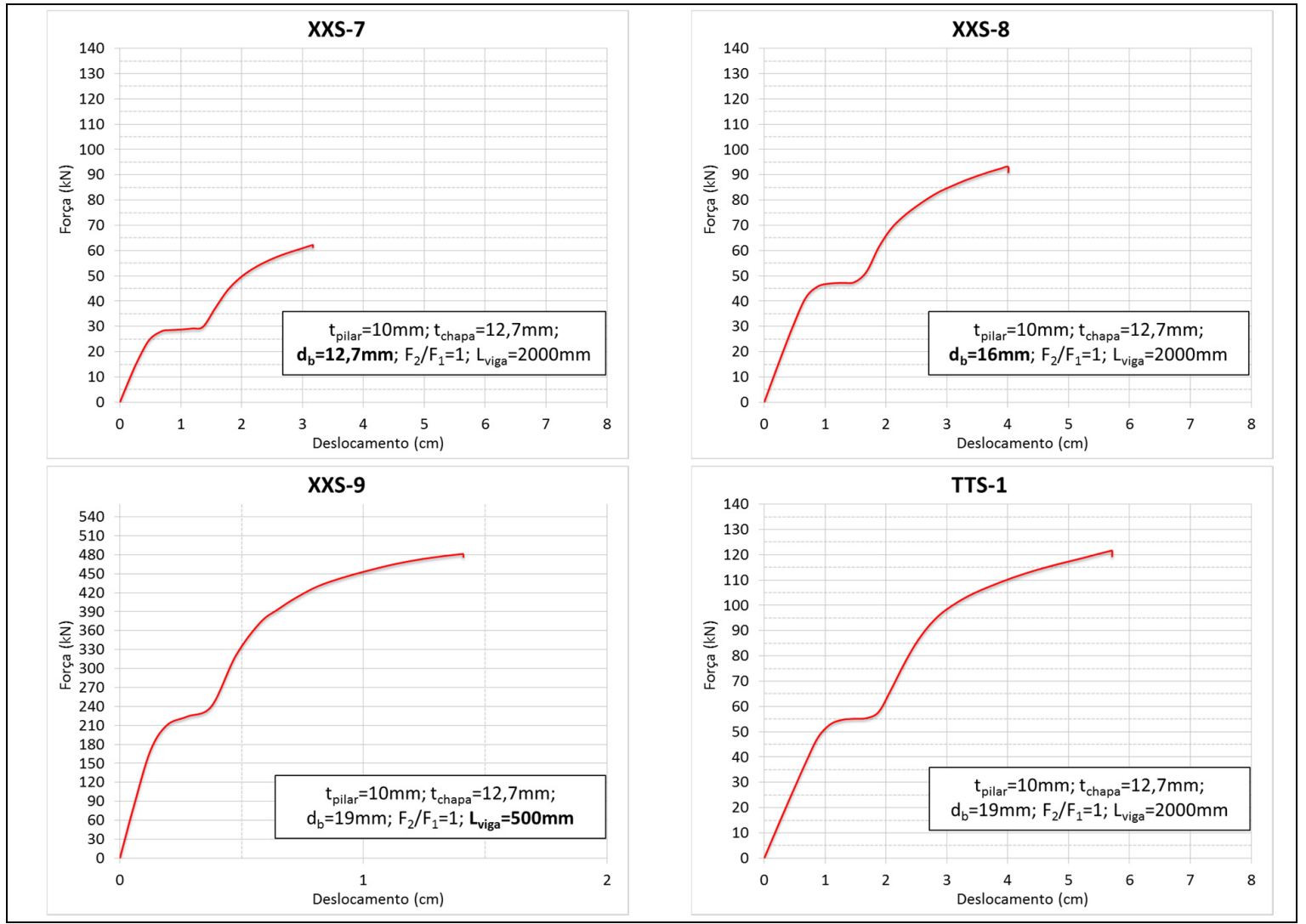

Modo de falha: Cisalhamento dos parafusos na ligação do diafragma com a mesa superior das vigas Fonte: Acervo pessoal

Os modelos de ligação com a presença do diafragma foram analisados até o estado limite último caracterizado pela não convergência da solução numérica. Notase no ponto final de todas as curvas apresentadas uma redução localizada da força aplicada. A redução observada representa o final da análise em consequência da incapacidade do modelo em resistir a um acréscimo de carregamento.

Em função da ocorrência de modos de falha semelhantes, os modelos XXS1, XXS-2 (força aplicada nas vigas de uma direção apenas), XXS-3 ( $\mathrm{t}_{\text {pilar }}=10 \mathrm{~mm}$ ), XXS-4 $\left(\mathrm{t}_{\text {chapa }}=19 \mathrm{~mm}\right), \mathrm{XXS}-5\left(\mathrm{t}_{\text {chapa }}=9,5 \mathrm{~mm}\right)$ e XXS-6 $\left(\mathrm{t}_{\text {pilar }}=14,2 \mathrm{~mm}\right)$ apresentaram curvas força versus deslocamento próximas entre si, visto a menor influência das variáveis aplicadas nestes modelos.

A curva força-deslocamento do modelo XXS-9 $\left(\mathrm{L}_{\text {viga }}=50 \mathrm{~cm}\right)$ apresentou força aplicada de maior intensidade e deslocamento inferior ao observado nos demais modelos. No modelo XXS-9 optou-se por reduzir o comprimento da viga de $200 \mathrm{~cm}$ 
para $50 \mathrm{~cm}$ e, portanto, a relação força-deslocamento apresentou uma modificação para o mantimento da relação de proporcionalidade entre os modelos.

Os modelos XXS-7 $\left(d_{b}=12,7 \mathrm{~mm}\right)$ e XXS-8 $\left(d_{b}=16 \mathrm{~mm}\right)$ demonstraram a influência que o diâmetro dos parafusos das mesas das vigas têm no comportamento da ligação em termos de força e deslocamento. O modelo XXS-1, com parafusos de $19 \mathrm{~mm}$ de diâmetro, foi capaz de resistir à uma força aplicada superior à observada nos modelos XXS-7 e XXS-8 (tabela 5.7).

Tabela 5.7 - Força e deslocamento vertical máximos nos modelos de ligação com diafragma

\begin{tabular}{|c|c|c|c|}
\hline MODELO & $\begin{array}{l}\text { FORÇA MÁXIMA } \\
\qquad(\mathbf{k N})\end{array}$ & $\begin{array}{c}\text { MOMENTO } \\
\text { FLETOR (kN.m) }\end{array}$ & $\begin{array}{c}\text { DESLOCAMENTO } \\
\text { VERTICAL DE } \\
\text { REFERÊNCIA }(\mathrm{cm}) \\
\end{array}$ \\
\hline $\begin{array}{l}\underline{X X S-1}\left(t_{\text {pilar }}=10 \mathrm{~mm} ; \mathrm{t}_{\text {chapa }}=12,7 \mathrm{~mm} ;\right. \\
\left.d_{b}=19 \mathrm{~mm} ; F_{2} / F_{1}=1 ; L_{\text {viga }}=2000 \mathrm{~mm}\right)\end{array}$ & 121,0 & 242,0 & 5,2 \\
\hline$\underline{X X S-2}\left(F_{2} / F_{1}=0\right)$ & 119,8 & 239,6 & 6,3 \\
\hline$\underline{\mathrm{XXS}-3}\left(\mathrm{t}_{\text {pilar }}=7,1 \mathrm{~mm}\right)$ & 121,0 & 241,9 & 5,5 \\
\hline$\underline{X X S}-4\left(t_{\text {chapa }}=19,0 \mathrm{~mm}\right)$ & 130,8 & 261,5 & 5,5 \\
\hline$\underline{X X S-5}\left(t_{\text {chapa }}=9,5 \mathrm{~mm}\right)$ & 118,7 & 237,5 & 6,3 \\
\hline$\underline{\mathrm{XXS}-6}\left(\mathrm{t}_{\text {pilar }}=14,2 \mathrm{~mm}\right)$ & 121,3 & 242,7 & 5,1 \\
\hline$\underline{X X S-7}\left(d_{b}=12,7 \mathrm{~mm}\right)$ & 62,2 & 124,5 & 3,2 \\
\hline$\underline{X X S-8}\left(d_{b}=16,0 \mathrm{~mm}\right)$ & 93,3 & 186,6 & 4,0 \\
\hline$\underline{X X S-9}\left(L_{\text {viga }}=500 \mathrm{~mm}\right)$ & 481,6 & 240,8 & 1,4 \\
\hline $\begin{array}{l}\text { TTS-1 }\left(t_{\text {pilar }}=10 \mathrm{~mm} ; t_{\text {chapa }}=12,7 \mathrm{~mm} ;\right. \\
\left.d_{b}=19 \mathrm{~mm} ; F_{2} / F_{1}=1 ; L_{\text {viga }}=2000 \mathrm{~mm}\right)\end{array}$ & 121,5 & 243,0 & 5,7 \\
\hline
\end{tabular}

Fonte: Acervo pessoal

O deslocamento vertical máximo limitou-se pela resistência da ligação parafusada da mesa da viga com o diafragma em todos os modelos. Nos modelos XXS-7 $\left(d_{b}=12,7 \mathrm{~mm}\right)$ e XXS-8 $\left(d_{b}=16 \mathrm{~mm}\right)$ a influência da resistência dos parafusos demonstrou a maior relevância desta variável na resistência das ligações. A curva força-deslocamento do modelo TTS-1 não apresentou grandes modificações em relação ao modelo XXS-1.

\subsubsection{Comportamento momento-rotação}

Ao longo deste trabalho vêm-se destacando a fundamental importância do comportamento momento-rotação $(\mathrm{M}-\theta)$ na análise do comportamento das ligações. 
A curva permite uma observação analítica do comportamento da ligação ao longo da análise ilustrando parâmetros como rigidez, resistência e ductilidade da ligação.

O ANSI/AISC 360-10 (2010) cita que em ligações onde não se verifica grande perda de resistência até a ocorrência de grandes deformações (acima de 0,03 radianos), os resultados obtidos em níveis elevados de deformação devem ser analisados com maior critério e, de preferência, desprezados do ponto de vista de dimensionamento.

Apesar de algumas ligações apresentarem rotações de até 0,15 radianos sem perda considerável de resistência, optou-se por utilizar a representação das curvas momento-rotação para rotações de no máximo 0,08 radianos (4,6 graus).

\subsubsection{Ligações soldadas}

A figura 5.56 e a figura 5.57 ilustram o comportamento momento-rotação para os modelos com ligação soldada.

Figura 5.56 - Curvas momento-rotação para os modelos com ligação soldada (I/II)

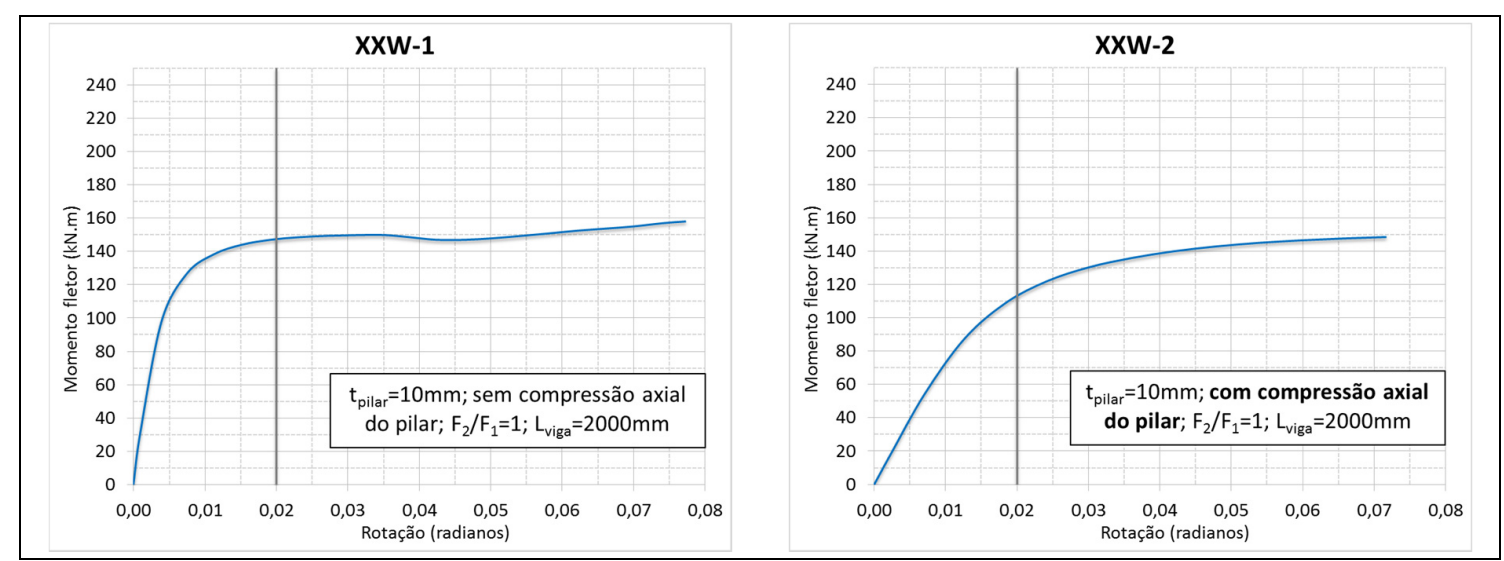

Modo de falha: Plastificação da face do pilar na região comprimida pela mesa inferior da viga Fonte: Acervo pessoal 
Figura 5.57 - Comportamento momento-rotação para os modelos com ligação soldada (II/II)

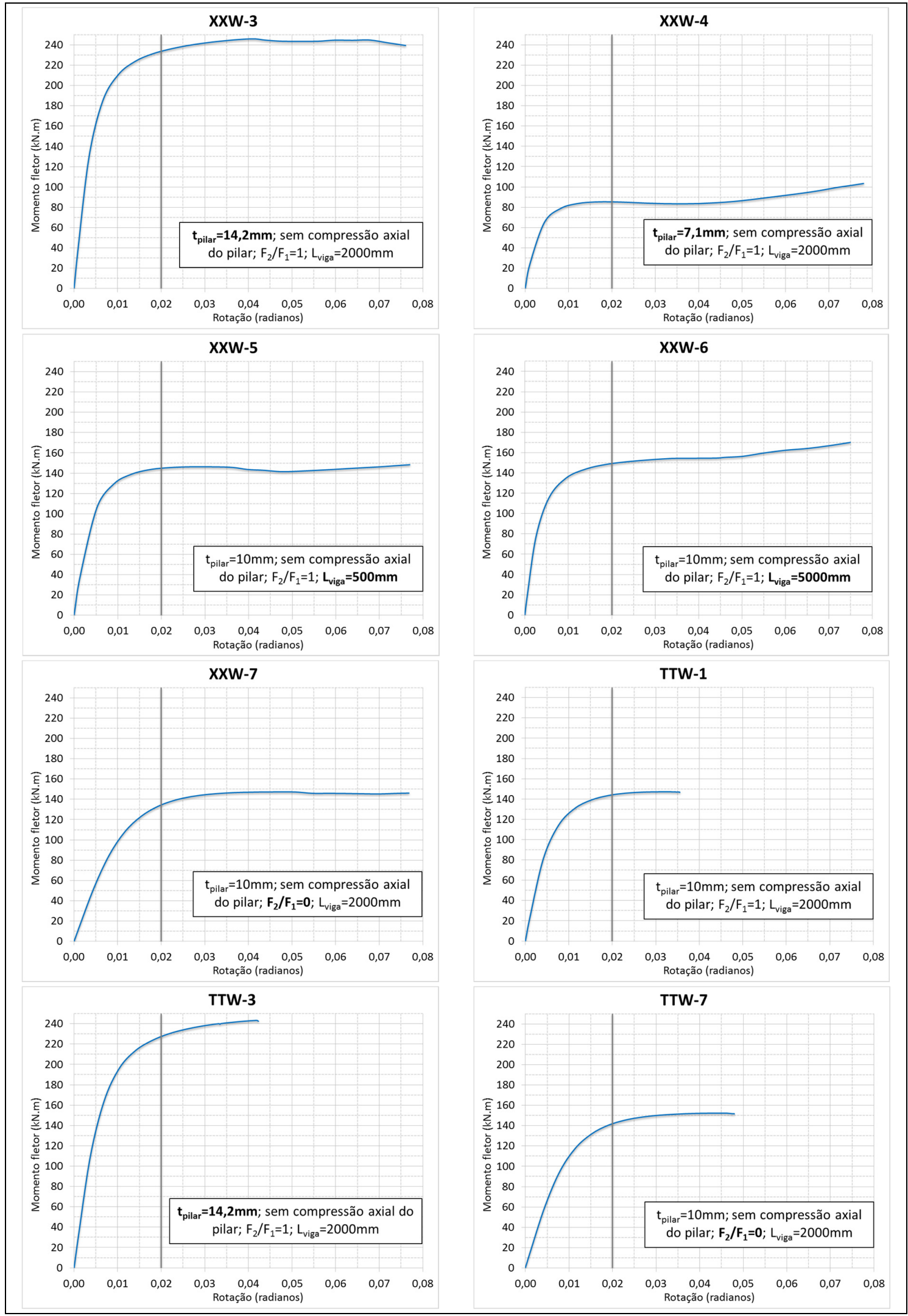

Modo de falha: Plastificação da face do pilar na região comprimida pela mesa inferior da viga Fonte: Acervo pessoal 
O quadro 5.4 apresenta os comentários a respeito das curvas ilustrativas do comportamento momento-rotação dos 10 modelos de ligação soldada.

Quadro 5.4 - Análise do comportamento momento-rotação dos modelos de ligação soldada

\begin{tabular}{|c|c|}
\hline $\begin{array}{c}\quad \underline{\mathbf{X X W}-1} \\
\left(\mathrm{t}_{\text {pilar }}=10 \mathrm{~mm} \text {; sem }\right. \\
\text { compressão axial } \\
\text { no pilar; } \mathrm{F}_{2} / \mathrm{F}_{1}=1 ; \\
\left.\mathrm{L}_{\text {viga }}=2000 \mathrm{~mm}\right)\end{array}$ & $\begin{array}{l}\text { - O comportamento M- } \theta \text { do modelo XXW-1 ilustra um } \\
\text { comportamento elástico-linear até o momento fletor de } 100 \mathrm{kN} . \mathrm{m} \\
\text { sem a ocorrência de uma rotação considerável; } \\
\text { - A medida em que aumentou-se o carregamento, iniciou-se a } \\
\text { plastificação do modelo verificando-se uma rotação relativa } \\
\text { elevada e baixo acréscimo de resistência; } \\
\text { - Verificou-se uma rigidez inicial de } 32.354 \mathrm{kN} \cdot \mathrm{m} / \mathrm{rad} \text {; } \\
\text { - O modelo XXW-1 apresentou resistência de } 147 \mathrm{kN} \text {.m para a } \\
\text { rotação de } 0,02 \text { radianos e } 158 \mathrm{kN} . \mathrm{m} \text { como valor máximo } \\
\text { verificado na análise. }\end{array}$ \\
\hline $\begin{array}{c}\underline{X X W-2} \\
\left(t_{\text {pilar }}=10 \mathrm{~mm} ; \text { com }\right. \\
\text { compressão } \\
\text { axial no pilar; } \\
F_{2} / F_{1}=1 ; \\
\left.L_{\text {viga }}=2000 \mathrm{~mm}\right)\end{array}$ & $\begin{array}{l}\text { - No modelo XXW-2 foi aplicada uma força de compressão axial } \\
\text { equivalente a } 40 \% \text { da resistência do tubo; } \\
\text { - A compressão do pilar resultou em uma pequena capacidade } \\
\text { da ligação em absorver esforços provenientes da força aplicada } \\
\text { na extremidade da viga, verificando-se uma inclinação reduzida } \\
\text { no trecho inicial da curva e, respectivamente, uma baixa rigidez } \\
\text { inicial da ligação ( } 7.856 \text { kN.m/rad); } \\
\text { - O modelo XXW-2 apresentou resistência de } 112 \text { kN.m para a } \\
\text { rotação de } 0,02 \text { radianos e } 154 \text { kN.m como valor máximo } \\
\text { verificado na análise. }\end{array}$ \\
\hline $\begin{array}{c}\underline{X X W-3} \\
\left(t_{\text {pilar }}=14,2 \mathrm{~mm} ;\right. \\
\text { sem compressão } \\
\text { axial no pilar; } \\
F_{2} / F_{1}=1 ; \\
\left.L_{\text {viga }}=2000 \mathrm{~mm}\right)\end{array}$ & $\begin{array}{l}\text { - A utilização de um pilar com espessura elevada no modelo } \\
\text { XXW-3 resultou em um trecho com comportamento elástico-linear } \\
\text { com amplitude e rigidez inicial ( } 42.876 \mathrm{kN} \text {.m/rad) elevados. } \\
\text { - A partir do momento fletor de } 160 \mathrm{kN} \cdot \mathrm{m} \text { observou-se o início } \\
\text { da plastificação e o modelo passou então a obter um aumento } \\
\text { gradual de resistência, porém, com um aumento considerável da } \\
\text { rotação; } \\
\text { - O modelo XXW-3 apresentou resistência de } 233 \mathrm{kN} \text {.m para a } \\
\text { rotação de } 0,02 \text { radianos e } 246 \mathrm{kN} \text {.m como valor máximo } \\
\text { verificado na análise. }\end{array}$ \\
\hline
\end{tabular}


Quadro 5.4 - Análise do comportamento momento-rotação dos modelos de ligação soldada

\begin{tabular}{|c|c|}
\hline $\begin{array}{c}\underline{X X W-4} \\
\left(t_{\text {pilar }}=7,1 \mathrm{~mm} ;\right. \\
\text { sem compressão } \\
\text { axial no pilar; } \\
\mathrm{F}_{2} / \mathrm{F}_{1}=1 ; \\
\left.\mathrm{L}_{\text {viga }}=2000 \mathrm{~mm}\right)\end{array}$ & $\begin{array}{l}\text { - O pilar com espessura reduzida resultou em uma ligação com } \\
\text { baixa rigidez inicial ( } 22.261 \mathrm{kN} . \mathrm{m} / \mathrm{rad}) \text { e resistência. } \\
\text { - O trecho elástico-linear limitou-se aos estágios iniciais de } \\
\text { carregamento, sendo observada esta característica até o } \\
\text { momento fletor de } 40 \mathrm{kN} . \mathrm{m} \text {; } \\
\text { - O modelo XXW-4 apresentou resistência de } 85 \mathrm{kN} \text {.m para a } \\
\text { rotação de } 0,02 \text { radianos e uma resistência máxima de } 103 \mathrm{kN} . \mathrm{m} \\
\text { ao longo da análise. }\end{array}$ \\
\hline $\begin{array}{c}\left(\mathrm{t}_{\text {pilar }}=10,0 \mathrm{~mm} ;\right. \\
\text { sem compressão } \\
\text { axial no pilar; } \\
\quad \mathrm{F}_{2} / \mathrm{F}_{1}=1 ; \\
\left.\mathrm{L}_{\text {viga }}=500 \mathrm{~mm}\right)\end{array}$ & $\begin{array}{l}\text { - O modelo XXW-5 apresentou comportamento elástico-linear } \\
\text { para a solicitação de até } 100 \mathrm{kN} . \mathrm{m} \text {, sem a ocorrência de uma } \\
\text { rotação considerável; } \\
\text { - Verificou-se uma rigidez inicial de } 27.645 \mathrm{kN} \text {.m/rad; } \\
\text { - Ao atingir a solicitação de } 100 \mathrm{kN} \text {.m o modelo passou a sofrer } \\
\text { deformação plástica com um certo ganho de resistência até a } \\
\text { rotação de } 0,02 \text { radianos; } \\
\text { - Com uma rotação de } 0,02 \text { radianos o modelo apresentou } \\
\text { resistência de } 145 \mathrm{kN} \text {.m. Verificou-se então um trecho de } \\
\text { aumento considerável da rotação sem um ganho sensível de } \\
\text { resistência até o limite de } 148 \mathrm{kN} \text {.m e } 0,08 \text { radianos. }\end{array}$ \\
\hline $\begin{array}{r}\underline{X X} \\
\left(t_{\text {pilar }}=10\right. \\
\text { sem com } \\
\text { axial } n \\
F_{2} / F \\
L_{\text {viga }}=50\end{array}$ & $\begin{array}{l}\text { - O comportamento M- } \theta \text { do modelo XXW-6 ilustra um trecho } \\
\text { inicial de comportamento elástico-linear para solicitação de até } \\
100 \mathrm{kN} . \mathrm{m} \text {; } \\
\text { - O modelo XXW-6 apresentou } \mathrm{S}_{\mathrm{j}, \text { ini }} \text { de } 33.513 \mathrm{kN} \text {.m/rad. } \\
\text { - A curva do modelo XXW-6 apresenta certa particularidade para } \\
\text { rotações elevadas. Nota-se um aumento da resistência para } \\
\text { rotações acima de } 0,04 \text { radianos. Apesar de notável, esta } \\
\text { particularidade não deve ser considerada em uma situação de } \\
\text { projeto, visto o estágio avançado de plastificação do material; } \\
\text { - O modelo XXW-6 apresentou resistência máxima de } 180 \mathrm{kN} . \mathrm{m} \text {. } \\
\text { Para a situação de projeto (0,02 radianos), verificou-se a } \\
\text { resistência de } 149 \mathrm{kN} \text {.m. }\end{array}$ \\
\hline
\end{tabular}


Quadro 5.4 - Análise do comportamento momento-rotação dos modelos de ligação soldada

\begin{tabular}{|c|c|}
\hline $\begin{array}{r}\quad \underline{\mathbf{X X V}} \\
\text { (t }_{\text {pilar }}=10, \\
\text { compres } \\
\text { no pilar; } \\
L_{\text {viga }}=20\end{array}$ & $\begin{array}{l}\text { - O modelo XXW-7 apresentou uma pequena rigidez inicial com } \\
S_{j, \text { ini }} \text { igual à } 11.875 \mathrm{kN} \cdot \mathrm{m} / \mathrm{rad} \text {; } \\
\text { - Verificou-se um } M_{\mathrm{Rd}} \text { de } 134 \mathrm{kN} \cdot \mathrm{m} \text { para a rotação de } 0,02 \\
\text { radianos e resistência máxima de } 147 \mathrm{kN} \cdot \mathrm{m} \text { ao longo da análise. }\end{array}$ \\
\hline $\begin{array}{c}\text { TTW-1 } \\
\left(t_{\text {pilar }}=10,0 \mathrm{~mm} ;\right. \\
\text { sem compressão } \\
\text { axial no pilar; } \\
F_{2} / F_{1}=1 ; \\
\left.L_{\text {viga }}=2000 \mathrm{~mm}\right)\end{array}$ & $\begin{array}{l}\text { - A análise do modelo TTW-1 limitou-se pela não convergência } \\
\text { da solução numérica com a rotação de } 0,036 \text { radianos; } \\
\text { - Verificou-se um comportamento elástico-linear para a } \\
\text { solicitação de até } 80 \mathrm{kN} . \mathrm{m} \text {, com rigidez inicial de } 22.348 \\
\text { kN.m/rad. } \\
\text { - O modelo TTW-1 apresentou resistência de } 144 \mathrm{kN} . \mathrm{m} \text { para a } \\
\text { rotação de } 0,02 \text { radianos e uma resistência máxima de } 147 \mathrm{kN} . \mathrm{m} \\
\text { ao longo da análise. }\end{array}$ \\
\hline $\begin{array}{c}\text { TTW-3 } \\
\left(t_{\text {pilar }}=14,2 \mathrm{~mm} ;\right. \\
\text { sem compressão } \\
\text { axial no pilar; } \\
\mathrm{F}_{2} / \mathrm{F}_{1}=1 ; \\
\left.\mathrm{L}_{\text {viga }}=2000 \mathrm{~mm}\right)\end{array}$ & $\begin{array}{l}\text { - A análise do modelo TTW-3 limitou-se pela não convergência } \\
\text { da solução numérica para a rotação de } 0,043 \text { radianos; } \\
\text { - Verificou-se uma curva com amplitude elevada e um longo } \\
\text { trecho com comportamento elástico-linear, com } \mathrm{S}_{\mathrm{j}, \text { ini }} \text { igual à } \\
31.472 \mathrm{kN} \text {.m/rad; } \\
\text { - A partir do momento fletor de } 130 \mathrm{kN} \text {.m observou-se o início } \\
\text { da plastificação e o modelo passou então a obter um aumento } \\
\text { gradual de resistência, porém, com um aumento considerável da } \\
\text { rotação; } \\
\text { - O modelo TTW-3 apresentou resistência de } 227 \mathrm{kN} \text {.m para a } \\
\text { rotação de } 0,02 \text { radianos e } 243 \mathrm{kN} \text {.m como valor máximo } \\
\text { verificado na análise. }\end{array}$ \\
\hline $\begin{array}{c}\text { TTW-7 } \\
\left(\mathrm{t}_{\text {pilar }}=10,0 \mathrm{~mm} ;\right. \\
\text { sem compressão } \\
\text { axial no pilar; } \\
\mathbf{F}_{2} / \mathbf{F}_{1}=\mathbf{0} ; \\
\left.\mathrm{L}_{\text {viga }}=2000 \mathrm{~mm}\right)\end{array}$ & $\begin{array}{l}\text { - A análise do modelo TTW-7 limitou-se pela não convergência } \\
\text { da solução numérica com a rotação de } 0,048 \text { radianos; } \\
\text { - O modelo TTW-7 apresentou rigidez inicial igual à } 13.931 \\
\text { kN.m/rad; } \\
\text { - Verificou-se uma resistência máxima de } 152 \text { kN.m. Para a } \\
\text { rotação de } 0,02 \text { radianos, o modelo apresentou resistência de } \\
141 \text { kN.m. }\end{array}$ \\
\hline
\end{tabular}




\subsubsection{Ligações com a presença de diafragma externo}

A ABNT NBR 8800 (2008) cita a necessidade em se prever folgas nos furos em relação ao diâmetro nominal dos parafusos. Os modelos numéricos buscam representar com certa perfeição geométrica estas folgas. No caso deste trabalho, foi considerada uma folga de $1 \mathrm{~mm}$.

As folgas presentes na simulação numérica geram certa particularidade nas curvas momento-rotação dos modelos com o diafragma. Estas reproduzem 0 deslizamento dos parafusos após a aplicação da pré tensão e superado o efeito do atrito.

No estágio inicial da análise, o modelo apresenta um comportamento próximo ao elástico-linear. Após atingida a força limite de atrito, os parafusos sofrem o escorregamento até que exista o contato entre o fuste e as chapas. O trecho horizontal observado nas curvas momento-rotação é resultado do deslocamento horizontal dos parafusos refletindo no aumento da rotação (figura 5.58).

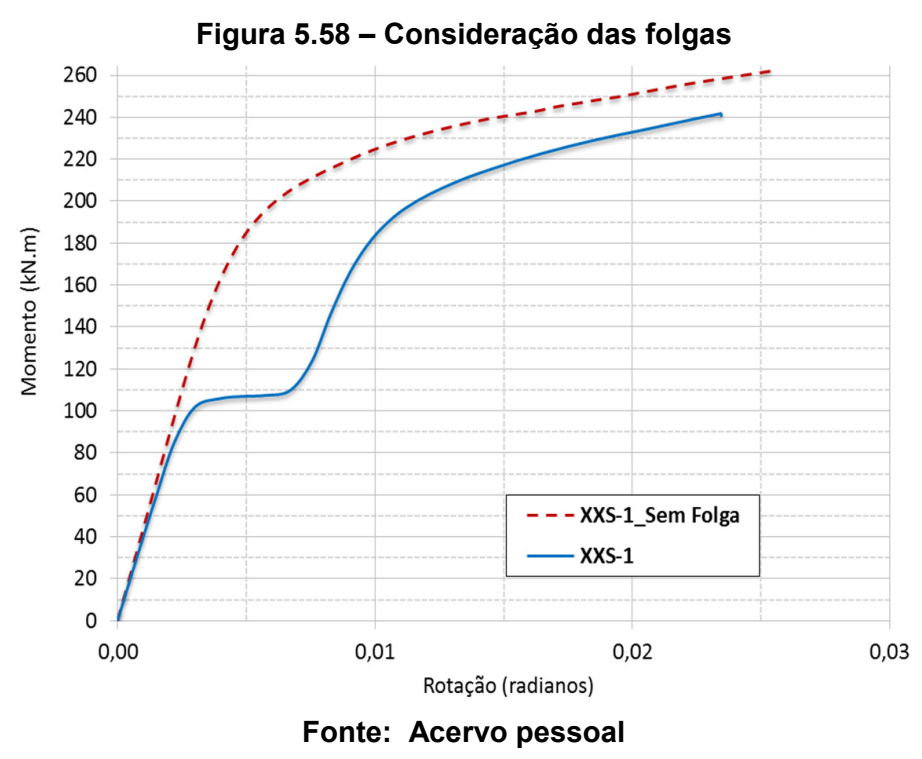

Realizado o contato entre parafuso e chapa, o modelo torna a absorver os esforços provenientes da força aplicada ocorrendo então os estágios de plastificação dos materiais até seus respectivos limites de ruptura. A figura 5.58 ilustra os resultados comparativos entre um modelo com a presença da folga e o mesmo modelo sem esta 
consideração. Nota-se que em termo de rigidez inicial e rigidez após o contato entre parafuso e chapa, os modelos são praticamente equivalentes.

A figura 5.59 e a figura 5.60 representam o comportamento momento-rotação para os modelos com a presença do diafragma externo. Verifica-se em todos os modelos apresentados um trecho sem inclinação na curva, representando o comportamento do parafuso de alta resistência em uma ligação por atrito.

Figura 5.59 - Comportamento momento-rotação para os modelos com a presença do diafragma (I/II)

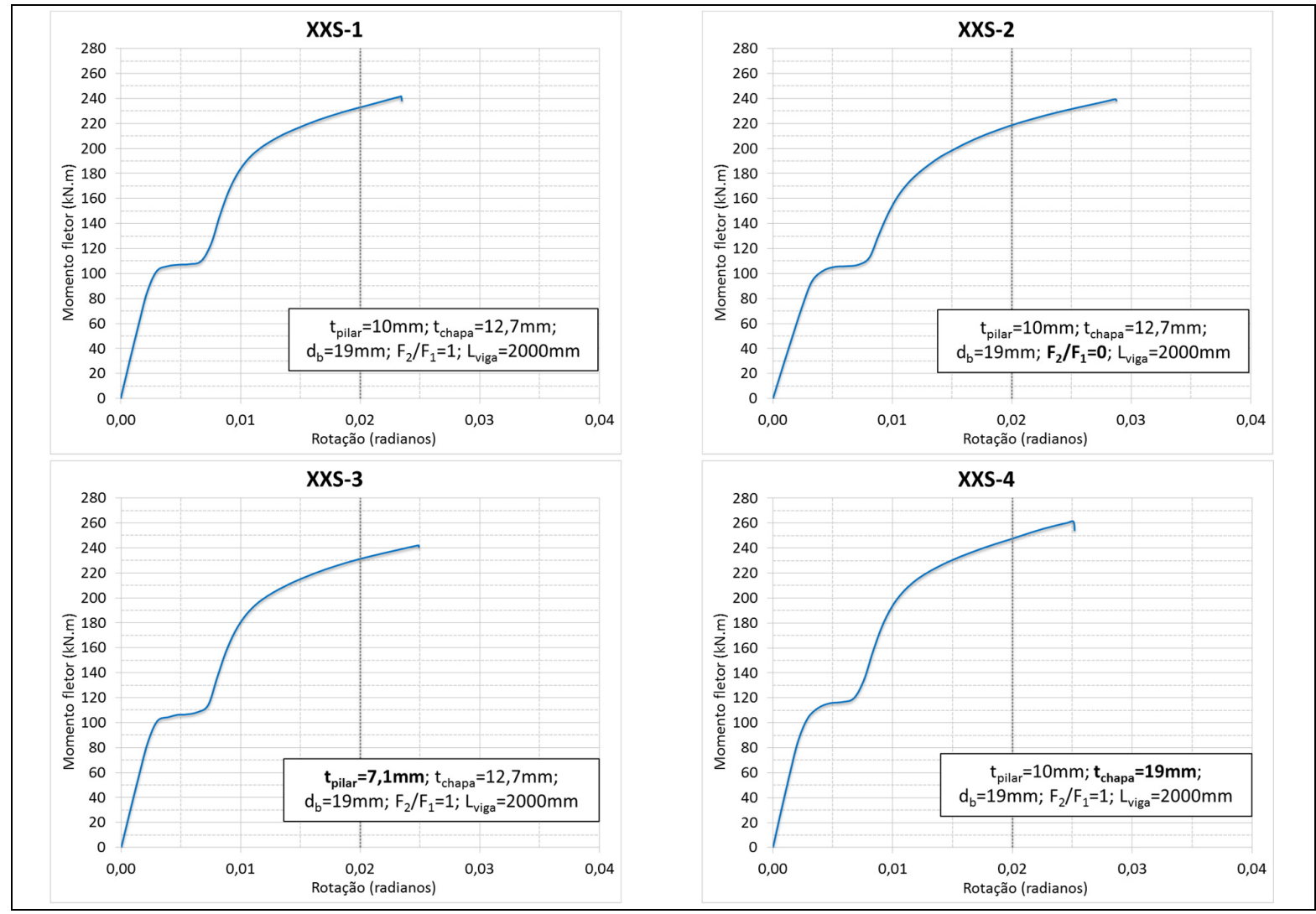

Modo de falha: Cisalhamento dos parafusos na ligação do diafragma com a mesa superior das vigas Fonte: Acervo pessoal 
Figura 5.60 - Comportamento momento-rotação para os modelos com a presença do diafragma (II/II)

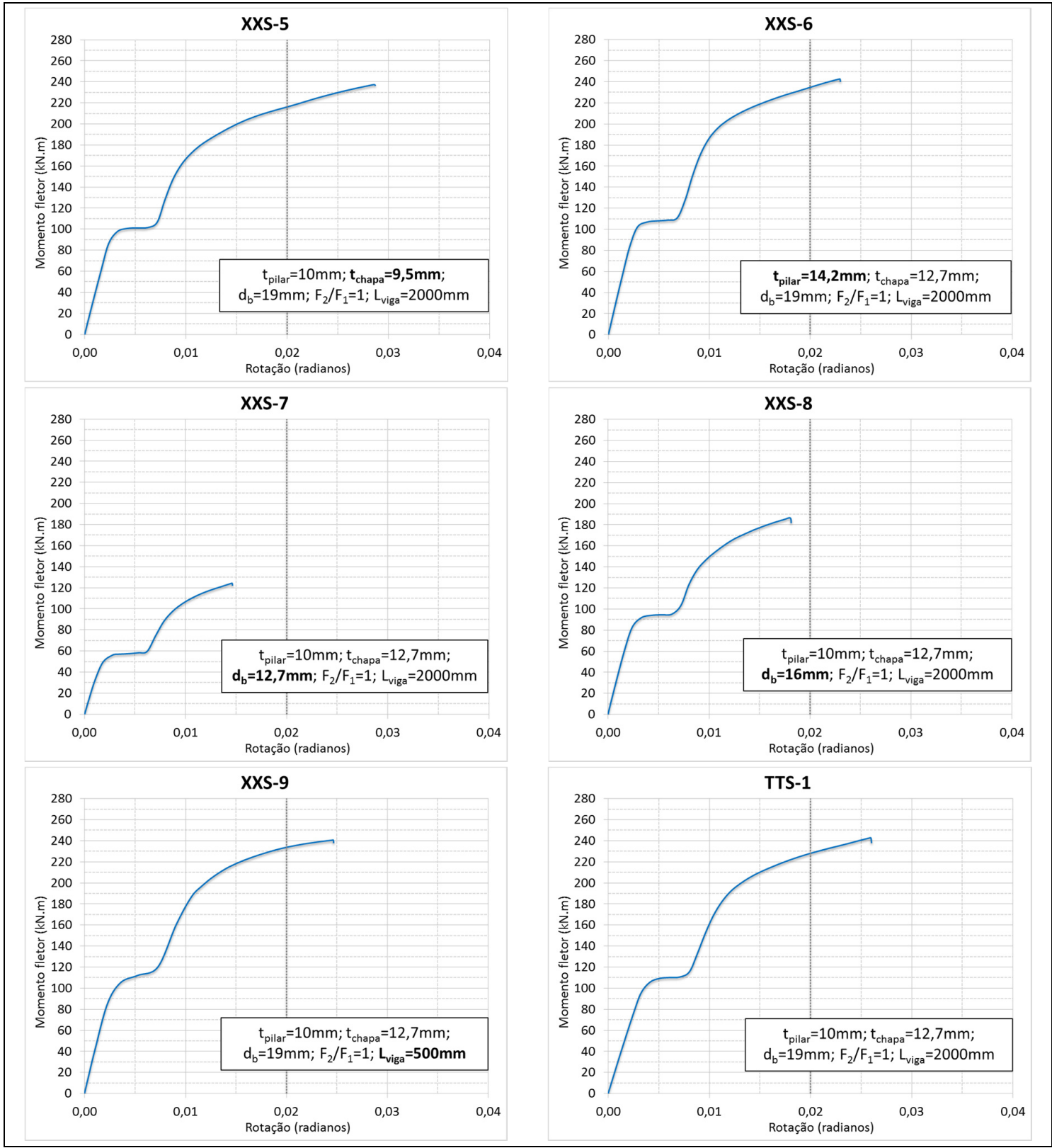

Modo de falha: Cisalhamento dos parafusos na ligação do diafragma com a mesa superior das vigas Fonte: Acervo pessoal

O quadro 5.5 apresenta os comentários relativos às curvas ilustrativas do comportamento momento-rotação dos 10 modelos de ligação com diafragma. 
Quadro 5.5 - Análise do comportamento momento-rotação dos modelos de ligação com diafragma

\begin{tabular}{|c|c|}
\hline $\begin{array}{c}\underline{X X S-1} \\
\left(t_{\text {pilar }}=10 \mathrm{~mm} ;\right. \\
t_{\text {chapa }}=12,7 \mathrm{~mm} ; \\
d_{b}=19 \mathrm{~mm} ; \\
F_{2} / F_{1}=1\end{array}$ & $\begin{array}{l}\text { - A análise do modelo XXS-1 foi interrompida para uma rotação } \\
\text { de } 0,024 \text { radianos (momento fletor de } 238 \mathrm{kN} \text {.m) devido à não } \\
\text { convergência da solução numérica; } \\
\text { - O modelo apresentou rigidez inicial igual à } 40.863 \mathrm{kN} \text {.m/rad; } \\
\text { - Verificou-se uma resistência de } 233 \mathrm{kN} . \mathrm{m} \text { para a rotação de } \\
0,02 \text { radianos. Ao longo da análise, o modelo apresentou } \\
\text { resistência máxima de } 241 \mathrm{kN} . \mathrm{m} \text {. }\end{array}$ \\
\hline $\begin{array}{c}\underline{X X S-2} \\
\left(t_{\text {pilar }}=10 \mathrm{~mm} ;\right. \\
t_{\text {chapa }}=12,7 \mathrm{~mm} ; \\
d_{b}=19 \mathrm{~mm} ; \\
F_{2} / F_{1}=0\end{array}$ & $\begin{array}{l}\text { - O modelo XXS-2 obteve } S_{j, \text { ini }} \text { igual à } 31.134 \mathrm{kN} . \mathrm{m} / \mathrm{rad} \text {. O trecho } \\
\text { pós contato dos fustes dos parafusos apresentou inclinação } \\
\text { reduzida; } \\
\text { - No Estado Limite Último o modelo apresentou rotação de } 0,029 \\
\text { radianos com momento fletor de } 238 \mathrm{kN} . \mathrm{m} \text {; } \\
\text { - O comportamento M- } \theta \text { do modelo XXS-2 demonstrou um MRd } \\
\text { de } 218 \mathrm{kN} . \mathrm{m} \text { para a rotação de } 0,02 \text { radianos. A máxima } \\
\text { resistência obtida ao longo da análise foi de } 239 \mathrm{kN} \text {.m. }\end{array}$ \\
\hline $\begin{array}{c}\underline{X X S-3} \\
\left(t_{\text {pilar }}=7,1 \mathrm{~mm} ;\right. \\
t_{\text {chapa }}=12,7 \mathrm{~mm} ; \\
d_{b}=19 \mathrm{~mm} ; \\
F_{2} / F_{1}=1 ; \\
\left.L_{\text {viga }}=2000 \mathrm{~mm}\right)\end{array}$ & $\begin{array}{l}\text { solução numérica para a rotação de } 0,025 \text { radianos com } \\
\text { momento fletor de } 240 \mathrm{kN} . \mathrm{m} \text {; } \\
\text { - A rigidez inicial do modelo foi de } 40.026 \mathrm{kN} \cdot \mathrm{m} / \mathrm{rad} \text {. } \\
\text { - Verificou-se um } \mathrm{M}_{\mathrm{Rd}} \text { de } 231 \mathrm{kN} \cdot \mathrm{m} \text { para a rotação de } 0,02 \\
\text { radianos e } 242 \mathrm{kN} \cdot \mathrm{m} \text { como valor máximo obtido ao longo da } \\
\text { análise. }\end{array}$ \\
\hline $\begin{array}{c}\underline{X X S-4} \\
\left(t_{\text {pilar }}=10 \mathrm{~mm} ;\right. \\
t_{\text {chapa }}=19 \mathrm{~mm} ; \\
d_{b}=19 \mathrm{~mm} ; \\
F_{2} / F_{1}=1 ; \\
\left.L_{\text {viga }}=2000 \mathrm{~mm}\right)\end{array}$ & $\begin{array}{l}\text { rotação de 0,025 radianos, com momento fletor de } 254 \text { kN.m; } \\
\text { - A utilização de uma chapa com maior espessura no modelo } \\
\text { XXS-4 resultou em uma ligação com resistência máxima de } 262 \\
\text { kN.m e rigidez inicial de } 43.418 \text { kN.m/rad. } \\
\text { - Para a rotação de } 0,02 \text { radianos, o modelo apresentou um } \\
\text { momento fletor de } 248 \text { kN.m. }\end{array}$ \\
\hline
\end{tabular}


Quadro 5.5 - Análise do comportamento momento-rotação dos modelos de ligação com diafragma

\begin{tabular}{|c|c|}
\hline $\begin{array}{c}\underline{X X S-5} \\
\left(t_{\text {pilar }}=10 \mathrm{~mm}\right. \\
t_{\text {chapa }}=9,5 \mathrm{~mm} \\
d_{b}=19 \mathrm{~mm} \\
F_{2} / F_{1}=1 \\
\left.L_{\text {viga }}=2000 \mathrm{~mm}\right)\end{array}$ & $\begin{array}{l}\text { - A análise do modelo XXS-5 limitou-se para uma rotação } \\
\text { máxima de } 0,29 \text { radianos com um momento fletor de } 236 \mathrm{kN} . \mathrm{m} \text {; } \\
\text { - A presença de uma chapa com pouca espessura refletiu em } \\
\text { uma curva com inclinação reduzida ( } S_{\mathrm{j}, \text { ini igual à } 38.881} \\
\mathrm{kN} . \mathrm{m} / \mathrm{rad}) \text {, sobretudo, no trecho pós contato dos fustes com a } \\
\text { chapa; } \\
\text { - O modelo XXS- } 5 \text { apresentou MRd de } 216 \mathrm{kN} \text {.m para a rotação } \\
\text { de } 0,02 \text { radianos e } 237 \mathrm{kN} \text {.m como valor máximo ao longo da } \\
\text { análise. }\end{array}$ \\
\hline $\begin{array}{c}\quad \underline{X X S-6} \\
\left(t_{\text {pilar }}=14,2 \mathrm{~mm}\right. \\
t_{\text {chapa }}=12,7 \mathrm{~mm} ; \\
d_{b}=19 \mathrm{~mm} ; \\
F_{2} / F_{1}=1 \\
\left.L_{\text {viga }}=2000 \mathrm{~mm}\right)\end{array}$ & 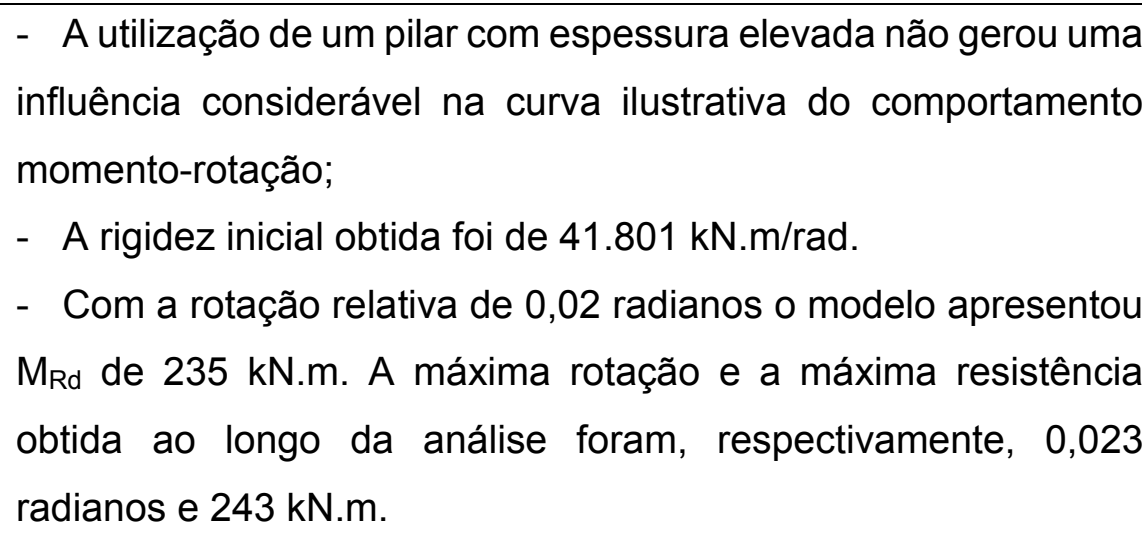 \\
\hline 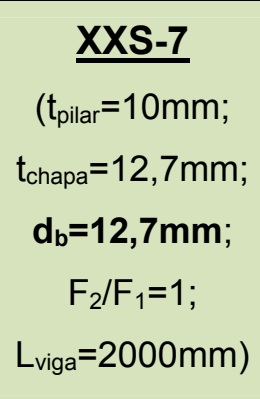 & $\begin{array}{l}\text { - A presença de parafusos com diâmetro reduzido limitou a } \\
\text { análise pela não convergência da solução numérica para uma } \\
\text { rotação de } 0,015 \text { radianos; } \\
\text { - A baixa resistência ao cisalhamento dos parafusos resultou em } \\
\text { uma ligação com resistência máxima de } 124 \mathrm{kN} \text {.m e rigidez inicial } \\
\text { de } 33.770 \mathrm{kN} . \mathrm{m} / \mathrm{rad} \text {. }\end{array}$ \\
\hline $\begin{array}{c}\underline{X X S-8} \\
\left(t_{\text {pilar }}=10 \mathrm{~mm}\right. \\
t_{\text {chapa }}=12,7 \mathrm{~mm} ; \\
d_{b}=16 \mathrm{~mm} ; \\
F_{2} / F_{1}=1 \\
\left.L_{\text {viga }}=2000 \mathrm{~mm}\right)\end{array}$ & $\begin{array}{l}\text { - A análise do modelo limitou-se para uma rotação máxima de } \\
0,18 \text { radianos; } \\
\text { - A utilização de parafusos com diâmetro intermediário não foi } \\
\text { suficiente à ponto de se obter a resistência para a rotação de } 0,02 \\
\text { radianos, tomada como referência para a situação de projeto; } \\
\text { - O modelo XXS-8 apresentou resistência máxima de } 186 \mathrm{kN} . \mathrm{m} \\
\text { ao longo da análise e rigidez inicial de } 39.367 \mathrm{kN} \text {.m/rad. }\end{array}$ \\
\hline
\end{tabular}


Quadro 5.5 - Análise do comportamento momento-rotação dos modelos de ligação com diafragma

\begin{tabular}{|c|c|}
\hline $\begin{array}{c}\underline{X X S-9} \\
\left(t_{\text {pilar }}=10 \mathrm{~mm}\right. \\
t_{\text {chapa }}=12,7 \mathrm{~mm} \\
d_{b}=19 \mathrm{~mm} \\
F_{2} / F_{1}=1 \\
\left.L_{\text {viga }}=500 \mathrm{~mm}\right)\end{array}$ & $\begin{array}{l}\text { - A análise do modelo XXS-9 limitou-se para uma rotação } \\
\text { máxima de 0,25 radianos com um momento fletor de } 238 \text { kN.m; } \\
\text { - Verificou-se uma resistência de } 234 \mathrm{kN} \text {.m para a rotação de } \\
0,02 \text { radianos. Ao longo da análise, o modelo apresentou } \\
\text { resistência máxima de } 241 \mathrm{kN} . \mathrm{m} \text { e rigidez inicial de } 40.472 \\
\text { kN.m/rad. }\end{array}$ \\
\hline 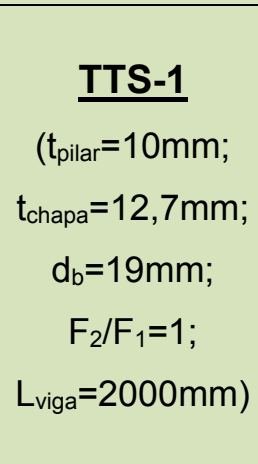 & $\begin{array}{l}\text { - O modelo numérico TTS-1 apresentou a não convergência da } \\
\text { solução numérica para a rotação de } 0,026 \text { radianos com } \\
\text { momento fletor de } 238 \mathrm{kN} . \mathrm{m} \text {; } \\
\text { - Para a rotação de } 0,02 \text { radianos o modelo apresentou um } \mathrm{M}_{\mathrm{Rd}} \\
\text { de } 228 \mathrm{kN} . \mathrm{m} \text { e } 243 \mathrm{kN} . \mathrm{m} \text { como valor máximo obtido ao longo da } \\
\text { análise. } \\
\text { - A rigidez inicial obtida na análise foi de } 31.690 \mathrm{kN} . \mathrm{m} / \mathrm{rad} \text {. }\end{array}$ \\
\hline
\end{tabular}

\subsubsection{Resistência}

A resistência ao momento fletor das ligações foi estimada analiticamente pelas formulações propostas pelo Eurocode 3 (2005) e por Winkel (1998), apresentadas no capítulo 3 deste trabalho. Para o caso das ligações soldadas a norma europeia e Winkel (1998) sugerem formulações específicas para a determinação da resistência das ligações considerando fatores como geometria da viga e do pilar, compressão axial no pilar e força vertical aplicada simultaneamente nas vigas das duas direções ortogonais.

As curvas momento-rotação apresentadas neste capítulo permitiram a obtenção do momento fletor resistente das ligações. Segundo o texto do ANSI/AISC 360-10 (2010), a resistência obtida pelo comportamento M- $\theta$ para uma rotação de 0,02 radianos pode ser tomada como valor de cálculo para a resistência da ligação. Destacam-se na tabela 5.8 e na tabela 5.9 os resultados numéricos e analíticos para 
a resistência das ligações soldadas segundo as formulações, respectivamente, do Eurocode 3 (2005) e de Winkel (1998).

Tabela 5.8 - Resistência dos modelos de ligações soldadas segundo o Eurocode 3 (2005)

\begin{tabular}{|c|c|c|c|}
\hline \multirow{2}{*}{ MODELO } & \multicolumn{2}{|c|}{$M_{\text {Rd }}$ (kN.m) } & \multirow{2}{*}{$\begin{array}{c}\text { RELAÇÃO } \\
\text { Eurocode / A.N. }\end{array}$} \\
\hline & Eurocode 3 (2005) & Análise Numérica $(0,02 \mathrm{rad})$ & \\
\hline $\begin{array}{l}X X W-1 \\
\left.\text { no pilar; } t_{\text {pilar }}=10 \mathrm{~mm} ; F_{1}=1 ; L_{\text {viga }}=2000 \mathrm{~mm}\right)\end{array}$ & 142,92 & 147,26 & 0,97 \\
\hline XXW-2 (com compressão no pilar) & 126,10 & 112,35 & 1,12 \\
\hline$\underline{X X W-3}\left(t_{\text {pilar }}=14,2 \mathrm{~mm}\right)$ & 288,18 & 233,64 & 1,23 \\
\hline XXW-4 $\left(t_{\text {pilar }}=7,1 \mathrm{~mm}\right)$ & 72,05 & 85,40 & 0,84 \\
\hline$\underline{X X W-5}\left(L_{\text {viga }}=500 \mathrm{~mm}\right)$ & 142,92 & 144,84 & 0,99 \\
\hline$\underline{X X W-6}\left(L_{\text {viga }}=5000 \mathrm{~mm}\right)$ & 142,92 & 149,27 & 0,96 \\
\hline$\underline{X X W-7}\left(F_{2} / F_{1}=0\right)$ & 107,46 & 134,10 & 0,80 \\
\hline TTW-1 ( $\mathrm{t}_{\text {pilar }}=10 \mathrm{~mm}$; s/ compressão & 107,46 & 144,16 & 0,75 \\
\hline TTW-3 $\left(t_{\text {pilar }}=14,2 \mathrm{~mm}\right)$ & 216,68 & 227,16 & 0,95 \\
\hline TTW-7 $\left(F_{2} / F_{1}=0\right)$ & 107,46 & 141,56 & 0,76 \\
\hline
\end{tabular}

Fonte: Acervo pessoal

Tabela 5.9 - Resistência dos modelos de ligações soldadas segundo Winkel (1998)

\begin{tabular}{|c|c|c|c|}
\hline \multirow{2}{*}{ MODELO } & \multicolumn{2}{|c|}{$M_{\text {Rd }}(k N . m)$} & \multirow{2}{*}{$\begin{array}{c}\text { RELAÇÃO } \\
\text { Winkel / A.N }\end{array}$} \\
\hline & Winkel (1998) & Análise Numérica $(0,02 \mathrm{rad})$ & \\
\hline $\begin{array}{l}\underline{X X W-1}\left(t_{\text {pilar }}=10 \mathrm{~mm} ; \mathrm{s} / \text { compressão }\right. \\
\left.\text { no pilar; } F_{2} / F_{1}=1 ; L_{\text {viga }}=2000 \mathrm{~mm}\right)\end{array}$ & 137,20 & 147,26 & 0,93 \\
\hline$\underline{X X W-2}$ (com compressão no pilar) & 128,52 & 112,35 & 1,14 \\
\hline$\underline{X X W-3}\left(t_{\text {pilar }}=14,2 \mathrm{~mm}\right)$ & 245,91 & 233,64 & 1,05 \\
\hline$\underline{X X W-4}\left(t_{\text {pilar }}=7,1 \mathrm{~mm}\right)$ & 76,58 & 85,40 & 0,90 \\
\hline$\underline{X X W-5}\left(L_{\text {viga }}=500 \mathrm{~mm}\right)$ & 137,20 & 144,84 & 0,95 \\
\hline$\underline{X X W-6}\left(L_{\text {viga }}=5000 \mathrm{~mm}\right)$ & 137,20 & 149,27 & 0,92 \\
\hline$\underline{X X W-7}\left(F_{2} / F_{1}=0\right)$ & 131,39 & 134,10 & 0,98 \\
\hline $\begin{array}{l}\text { TTW-1 }\left(t_{\text {pilar }}=10 \mathrm{~mm} ; \mathrm{s} / \text { compressão }\right. \\
\left.\text { no pilar; } F_{2} / F_{1}=1 ; L_{\text {viga }}=2000 \mathrm{~mm}\right)\end{array}$ & 133,20 & 144,16 & 0,92 \\
\hline$\underline{\text { TTW-3 }}\left(\mathrm{t}_{\text {pilar }}=14,2 \mathrm{~mm}\right)$ & 233,41 & 227,16 & 1,03 \\
\hline TTW-7 $\left(F_{2} / F_{1}=0\right)$ & 133,20 & 141,56 & 0,94 \\
\hline
\end{tabular}

Fonte: Acervo pessoal

As seções da viga e dos pilares de $7,1 \mathrm{~mm}, 10 \mathrm{~mm}$ e 14,2 $\mathrm{mm}$ de espessura apresentam momento resistente de, respectivamente, 246 kN.m, 220 kN.m, 313 kN.m e 433 kN.m demonstrando não serem estes os elementos responsáveis pela falha das ligações. 
Com relação às ligações com o diafragma, o texto do Eurocode 3 Part 1-8 (2005) sugere a utilização do chamado Método das Componentes. Neste caso, a determinação da resistência das ligações com o diafragma parte do princípio da verificação individualizada dos elementos componentes da ligação. Considerando os modos de falha predominantes as verificações a serem realizadas são:

a) Plastificação da face do pilar na região comprimida devido à força de compressão exercida pelo diafragma inferior;

b) Cisalhamento da face do pilar na região tracionada devido à força de tração exercida pelo diafragma superior;

c) Cisalhamento dos parafusos da alma e mesas da viga;

d) Pressão de contato e cisalhamento nas chapas de ligação, alma e mesas da viga.

Na tabela 5.10 apresentam-se os resultados numéricos e analíticos para a resistência das ligações com diafragma segundo o Eurocode 3 (2005).

Tabela 5.10 - Resistência dos modelos de ligações com diafragma segundo o Eurocode 3 (2005)

\begin{tabular}{|c|c|c|c|}
\hline \multirow{2}{*}{ MODELO } & \multicolumn{2}{|c|}{$M_{R d}$ (kN.m) } & \multirow{2}{*}{\begin{tabular}{|c|} 
RELAÇÃO \\
Eurocode / A.N.
\end{tabular}} \\
\hline & Eurocode 3 (2005) & Análise Numérica $(0,02 \mathrm{rad})$ & \\
\hline $\begin{array}{l}\underline{X X S-1}\left(t_{\text {pilar }}=10 \mathrm{~mm} ; t_{\text {chapa }}=12,7 \mathrm{~mm} ;\right. \\
\left.d_{b}=19 \mathrm{~mm} ; F_{2} / F_{1}=1 ; L_{\text {viga }}=2000 \mathrm{~mm}\right)\end{array}$ & 194,74 & 233,14 & 0,84 \\
\hline$\underline{X X S-2}\left(F_{2} / F_{1}=0\right)$ & 194,74 & 218,76 & 0,89 \\
\hline$\underline{X X S-3}\left(t_{\text {pilar }}=7,1 \mathrm{~mm}\right)$ & 193,43 & 231,14 & 0,84 \\
\hline$\underline{X X S-4}\left(t_{\text {chapa }}=19,0 \mathrm{~mm}\right)$ & 194,74 & 247,88 & 0,79 \\
\hline$\underline{X X S-5}\left(t_{\text {chapa }}=9,5 \mathrm{~mm}\right)$ & 160,42 & 216,33 & 0,74 \\
\hline$\underline{\mathrm{XXS}-6}\left(\mathrm{t}_{\text {pilar }}=14,2 \mathrm{~mm}\right)$ & 194,74 & 234,77 & 0,83 \\
\hline$\underline{X X S-7}\left(d_{b}=12,7 \mathrm{~mm}\right)$ & 91,24 & 124,48 & 0,73 \\
\hline$\underline{X X S-8}\left(d_{b}=16,0 \mathrm{~mm}\right)$ & 140,32 & 186,55 & 0,75 \\
\hline$\underline{X X S-9}\left(L_{\text {viga }}=500 \mathrm{~mm}\right)$ & 194,74 & 233,80 & 0,83 \\
\hline $\begin{array}{l}\text { TTS-1 }\left(t_{\text {pilar }}=10 \mathrm{~mm} ; \mathrm{t}_{\text {chapa }}=12,7 \mathrm{~mm} ;\right. \\
\left.\mathrm{d}_{\mathrm{b}}=19 \mathrm{~mm} ; \mathrm{F}_{2} / \mathrm{F}_{1}=1 ; \mathrm{L}_{\mathrm{viga}}=2000 \mathrm{~mm}\right)\end{array}$ & 194,74 & 228,33 & 0,85 \\
\hline
\end{tabular}

Fonte: Acervo pessoal 


\subsubsection{Classificação das ligações}

Conforme apresentado no capítulo 2, o Eurocode 3 (2005) classifica as ligações segundo a rigidez e segundo a resistência. A classificação segundo a rigidez leva em consideração a capacidade rotacional da ligação, representada pela rigidez inicial $\mathrm{S}_{\mathrm{j}, \text { ini. }}$ A classificação segundo a resistência considera o momento resistente de cálculo da ligação $\mathrm{M}_{\mathrm{j}, R d} \mathrm{e}$ o momento resistente dos elementos adjacentes à ligação (viga e pilar). Segundo a rigidez, a ligação pode ser classificada em rígida, semi-rígida ou articulada. Segundo a resistência, a ligação pode ser classificada em resistência total, resistência parcial ou articulada.

A tabela 5.11 apresenta os resultados para a rigidez inicial $\left(S_{\mathrm{j}, \text { ini }}\right)$ das ligações soldadas obtidas pela curva momento-rotação, assim como, a classificação segundo as proposições do Eurocode 3 (2005).

Tabela 5.11 - Classificação das ligações soldadas

\begin{tabular}{|c|c|c|c|}
\hline \multirow{2}{*}{ MODELO } & \multirow{2}{*}{$\frac{\text { Sj,ini }}{(k N . m / r a d)}$} & \multicolumn{2}{|c|}{ CLASSIFICAÇÃO - EUROCODE 3} \\
\hline & & RIGIDEZ & RESISTÊNCIA \\
\hline $\begin{array}{l}\underline{X X-1}\left(t_{\text {pilar }}=10 \mathrm{~mm} ; \mathrm{s} / \text { compressão }\right. \\
\text { no pilar; } F_{2} / F_{1}=1 ; L_{\text {viga }}=2000 \mathrm{~mm} \text { ) }\end{array}$ & 32.354 & Semi-rígida & Resistência parcial \\
\hline$\underline{X X W-2}$ (com compressão no pilar) & 7.856 & Semi-rígida & Resistência parcial \\
\hline$\underline{X X W-3}\left(t_{\text {pilar }}=14,2 \mathrm{~mm}\right)$ & 42.876 & Semi-rígida & Resistência parcial \\
\hline$\underline{X X W-4}\left(t_{\text {pilar }}=7,1 \mathrm{~mm}\right)$ & 22.261 & Semi-rígida & Resistência parcial \\
\hline$\underline{X X W-5}\left(L_{\text {viga }}=500 \mathrm{~mm}\right)$ & 27.645 & Semi-rígida & Resistência parcial \\
\hline$\underline{X X W-6}\left(L_{\text {viga }}=5000 \mathrm{~mm}\right)$ & 33.513 & Semi-rígida & Resistência parcial \\
\hline$\underline{X X W-7}\left(F_{2} / F_{1}=0\right)$ & 11.875 & Semi-rígida & Resistência parcial \\
\hline $\begin{array}{l}\text { TTW-1 }\left(t_{\text {pilar }}=10 \mathrm{~mm} ; \mathrm{s} / \text { compressão }\right. \\
\left.\text { no pilar; } F_{2} / F_{1}=1 ; L_{\text {viga }}=2000 \mathrm{~mm}\right)\end{array}$ & 22.348 & Semi-rígida & Resistência parcial \\
\hline TTW-3 $\left(\mathrm{t}_{\text {pilar }}=14,2 \mathrm{~mm}\right)$ & 31.472 & Semi-rígida & Resistência parcial \\
\hline TTW-7 $\left(F_{2} / F_{1}=0\right)$ & 13.931 & Semi-rígida & Resistência parcial \\
\hline
\end{tabular}

Fonte: Acervo pessoal

A rigidez das ligações, representada pela rigidez inicial $\left(S_{\mathrm{j}, \mathrm{ini}}\right)$, demonstra que a aplicação da compressão axial no pilar (XXW-2), a redução da espessura do pilar (XXW-4) e a aplicação da força nas vigas de apenas uma das direções (XXW-7 e TTW-7) tiveram efeito considerável na redução dos valores relativos à esta propriedade quando comparado ao valor obtido no modelo XXW-1 e TTW-1. 
O aumento da espessura do pilar (XXW-3 e TTW-3) teve efeito significativo no aumento da rigidez inicial das ligações. A alteração no comprimento das vigas nos modelos XXW-5 e XXW-6 não repercutiram em grandes modificações do ponto de vista de rigidez inicial quando comparado ao modelo $\mathrm{XXW}-1$.

Segundo o Eurocode 3 (2005), todos os modelos com ligação soldada apresentaram comportamento semi-rígido. Neste caso, as propriedades relativas à rigidez e resistência destas ligação devem ser consideradas em uma análise global.

A rigidez inicial e a classificação das ligações com a presença do diafragma, segundo o Eurocode 3 (2005), estão apresentadas na tabela 5.12.

Tabela 5.12 - Classificação das ligações com a presença do diafragma

\begin{tabular}{|c|c|c|c|}
\hline \multirow{2}{*}{ MODELO } & \multirow{2}{*}{$\frac{\text { Sj,ini }}{(k N . m / r a d)}$} & \multicolumn{2}{|c|}{ CLASSIFICAÇÃO - EUROCODE 3} \\
\hline & & RIGIDEZ & RESISTÊNCIA \\
\hline $\begin{array}{l}\underline{X X S-1}\left(t_{\text {pilar }}=10 \mathrm{~mm} ; \mathrm{t}_{\text {chapa }}=12,7 \mathrm{~mm} ;\right. \\
\left.d_{b}=19 \mathrm{~mm} ; F_{2} / F_{1}=1 ; L_{\text {viga }}=2000 \mathrm{~mm}\right)\end{array}$ & 40.863 & Semi-rígida & Resistência parcial \\
\hline$\underline{X X S}-2\left(F_{2} / F_{1}=0\right)$ & 31.134 & Semi-rígida & Resistência parcial \\
\hline$\underline{X X S-3}\left(t_{\text {pilar }}=7,1 \mathrm{~mm}\right)$ & 40.026 & Semi-rígida & Resistência parcial \\
\hline$\underline{X X S-4}\left(t_{\text {chapa }}=19,0 \mathrm{~mm}\right)$ & 43.418 & Semi-rígida & Resistência total \\
\hline$\underline{X X S-5}\left(t_{\text {chapa }}=9,5 \mathrm{~mm}\right)$ & 38.881 & Semi-rígida & Resistência parcial \\
\hline$\underline{\mathrm{XXS}-6}\left(\mathrm{t}_{\text {pilar }}=14,2 \mathrm{~mm}\right)$ & 41.801 & Semi-rígida & Resistência parcial \\
\hline$\underline{X X S-7}\left(d_{b}=12,7 \mathrm{~mm}\right)$ & 33.770 & Semi-rígida & Resistência parcial \\
\hline$\underline{\mathrm{XXS}-8}\left(\mathrm{~d}_{\mathrm{b}}=16,0 \mathrm{~mm}\right)$ & 39.367 & Semi-rígida & Resistência parcial \\
\hline$\underline{\mathrm{XXS}-9}\left(\mathrm{~L}_{\text {viga }}=500 \mathrm{~mm}\right)$ & 40.472 & Semi-rígida & Resistência parcial \\
\hline $\begin{array}{l}\text { TTS-1 }\left(t_{\text {pilar }}=10 \mathrm{~mm} ; \mathrm{t}_{\text {chapa }}=12,7 \mathrm{~mm} ;\right. \\
\left.\mathrm{d}_{\mathrm{b}}=19 \mathrm{~mm} ; \mathrm{F}_{2} / \mathrm{F}_{1}=1 ; \mathrm{L}_{\mathrm{viga}}=2000 \mathrm{~mm}\right)\end{array}$ & 31.690 & Semi-rígida & Resistência parcial \\
\hline
\end{tabular}

Fonte: Acervo pessoal

A redução do diâmetro dos parafusos (XXS-7), a força aplicada nas vigas de apenas uma das direções (XXS-2) e a redução da espessura da chapa do diafragma (XXS-5) foram as principais variáveis que ocasionaram a queda da rigidez inicial das ligações com diafragma.

O aumento da espessura da chapa do diafragma no modelo XXS-4 foi responsável pelo acréscimo de rigidez inicial mais sensível entre todos os modelos de ligação com diafragma. 
Em geral, os modelos apresentaram resultados próximos em termos de rigidez inicial. Destaca-se a variação na rigidez do modelo com força aplicada nas vigas de apenas uma direção (XXS-2).

Todos os modelos com diafragma apresentaram comportamento semi-rígido. No modelo XXS-4, onde foi aumentada a espessura da chapa do diafragma, verificouse um aumento da resistência (no modelo numérico) resultando na classificação "resistência total". De qualquer forma, as proposições do Eurocode 3 (2005) afirmam que mesmo neste caso não se pode idealizar a ligação em engaste perfeito e que a rigidez da ligação deve ser levada em consideração em uma análise global.

\subsubsection{Ductilidade}

A ductilidade é a propriedade da ligação em se deformar sem a perda considerável de resistência. Esta propriedade pode ser avaliada em uma simples observação visual do comportamento momento-rotação ou por meio de formulações específicas que quantifiquem esta propriedade.

A importância desta propriedade está, sobretudo, na aplicação das ligações em áreas sujeitas a sismos. A ductilidade requerida para uma estrutura contraventada em uma área que não é sujeita a abalos sísmicos, geralmente, será inferior ao requisitos para o dimensionamento em áreas altamente sujeitas a sismos.

Segundo o ANSI/AISC 360-10 (2010), uma ligação pode ser considerada com capacidade rotacional adequada, quando esta atinge a rotação de 0,03 radianos sem perda considerável de resistência. Verificou-se que todas as ligações soldadas analisadas atendem aos requisitos de ductilidade adequados, enquanto que, os resultados referentes às ligações com diafragma não permitem uma conclusão adequada a respeito desta propriedade. 


\subsection{Análise da influência das variáveis}

As variáveis analisadas nesta pesquisa dizem respeito às propriedades físicas e geométricas das ligações entre viga I e pilar circular que tendem a influenciar o comportamento das ligações. Avaliam-se na sequência deste trabalho as tensões equivalentes segundo o critério de Von Mises ao longo do carregamento, 0 comportamento momento-rotação e as propriedades de resistência e rigidez dos modelos analisados. São abordadas as seguintes variáveis:

a) Comprimento da viga;

b) Espessura da parede do pilar;

c) Força aplicada nas duas direções ortogonais;

d) Compressão axial do pilar;

e) Espessura da chapa do diafragma;

f) Diâmetro dos parafusos do diafragma.

\subsubsection{Comprimento da viga}

A análise de modelos com vigas de diferentes comprimentos gera a possibilidade de se observar o comportamento da ligação sob esforços essencialmente de flexão ou sob a atuação considerável da força cortante. A utilização de vigas com comprimento reduzido nos modelos XXW-5 e XXS-9 (Lviga $=50 \mathrm{~cm}$ ) origina essencialmente esforços cisalhantes na região da ligação viga-pilar. Em contrapartida, o aumento do comprimento da viga no modelo XXW-6 ( $\left.\mathrm{L}_{\text {viga }}=500 \mathrm{~cm}\right)$ tende a gerar uma situação onde o momento fletor tem maior relevância no comportamento da ligação.

- Ligações soldadas:

Nas ligações soldadas XXW-1 ( $\left.\mathrm{L}_{\text {viga }}=200 \mathrm{~cm}\right), \mathrm{XXW}-5\left(\mathrm{~L}_{\text {viga }}=50 \mathrm{~cm}\right)$ e XXW$6\left(L_{v i g a}=500 \mathrm{~cm}\right)$, o efeito da diferença entre os esforços atuantes pode ser visualizada por meio da distribuição de tensões nos elementos viga e pilar ao longo do 
carregamento. Observa-se na figura 5.61 a maior concentração de tensões na alma da viga no modelo XXW-5 $\left(L_{\text {viga }}=50 \mathrm{~cm}\right)$ visto a maior predominância de esforços cisalhantes. No modelo XXW-6 ( $\left.\mathrm{L}_{\text {viga }}=500 \mathrm{~cm}\right)$ o aumento do comprimento da viga resultou em uma distribuição de tensões com maior intensidade nas mesas das vigas e a redução das tensões na alma.

Figura 5.61 - Evolução das tensões de Von Mises nos modelos XXW-1, XXW-5 e XXW-6 ${ }^{15}$

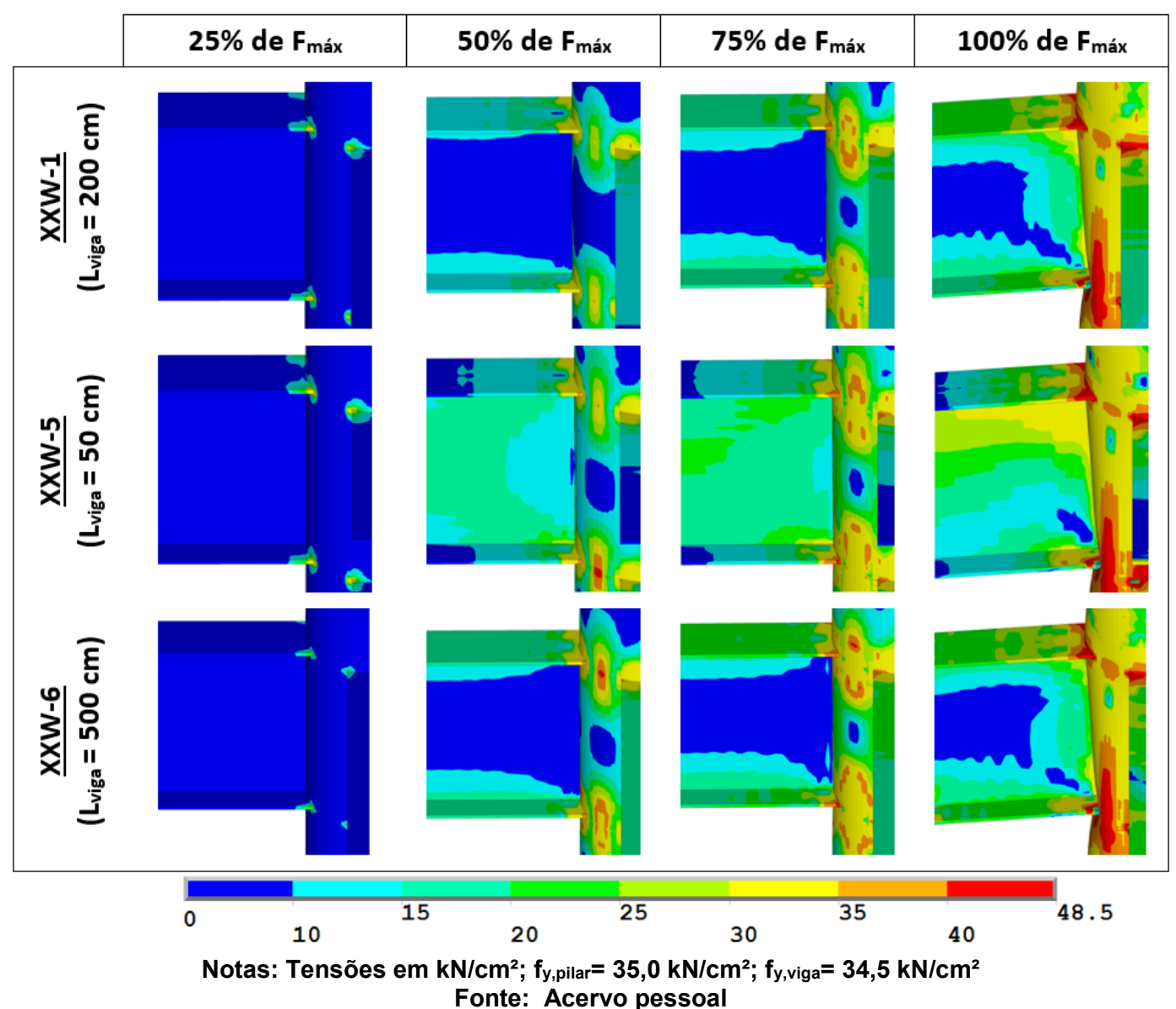

A análise procurou manter a proporcionalidade entre os resultados em termos de momento fletor atuante na ligação. O modelo XXW-5 foi carregado com uma força vertical de maior intensidade resultando em tensões mais elevadas na alma da viga. Em contrapartida, o modelo XXW-6 foi carregado com uma força vertical de pequena intensidade, sendo verificada a concentração de tensões essencialmente na mesa inferior da viga. A relação entre o comprimento da viga e a distribuição das tensões na alma e mesa inferior deste elemento pode ser melhor observada na figura 5.62.

\footnotetext{
${ }^{15}$ A designação "Fmáx" presente nas figuras deste capítulo denotam à força vertical máxima aplicada na extremidade da viga.
} 
Figura 5.62 - Tensões de Von Mises (ao final da análise) na alma e mesa da viga, nos modelos XXW-1, $X X W-5$ e XXW-6

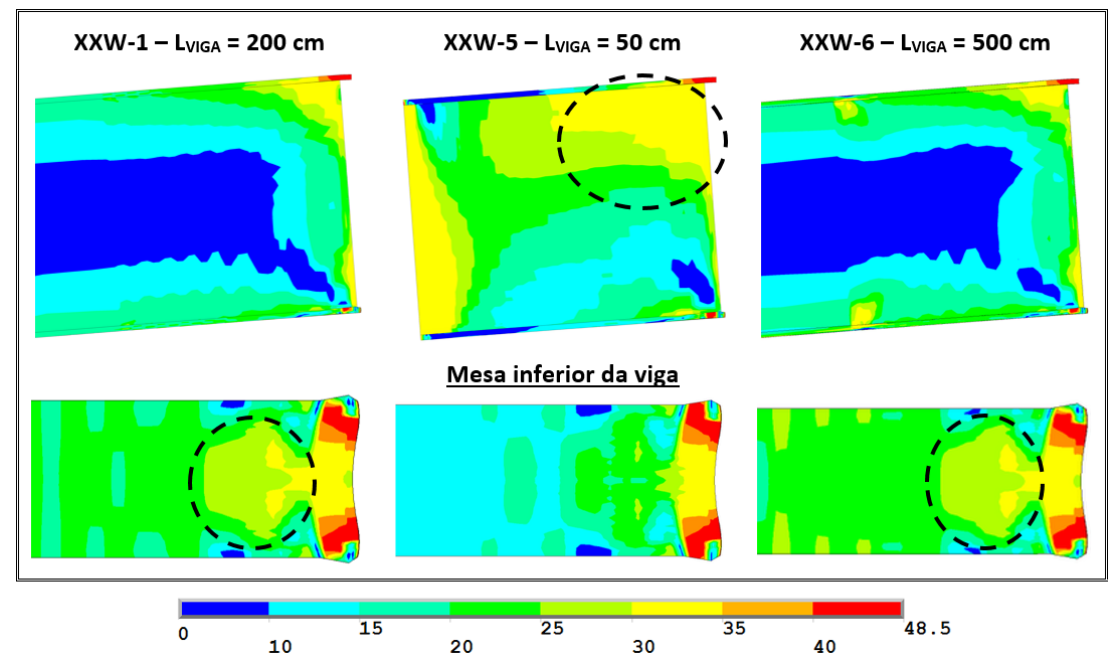

Notas: Tensões em $\mathrm{kN} / \mathrm{cm}^{2} ; f_{\mathrm{y}, \text { viga }}=34,5 \mathrm{kN} / \mathrm{cm}^{2}$ Fonte: Acervo pessoal

Os 3 modelos apresentaram o mesmo modo de falha, a plastificação da face do pilar na região comprimida pela mesa inferior das vigas. Conforme ilustrado na figura 5.63, as tensões concentram-se na face do pilar apresentando um patamar de distribuição com ordem de grandeza parecidas entre si nos modelos XXW-1, XXW-5 e XXW-6.

Figura 5.63 - Tensões de Von Mises (ao final da análise) nos modelos XXW-1, XXW-5 e XXW-6

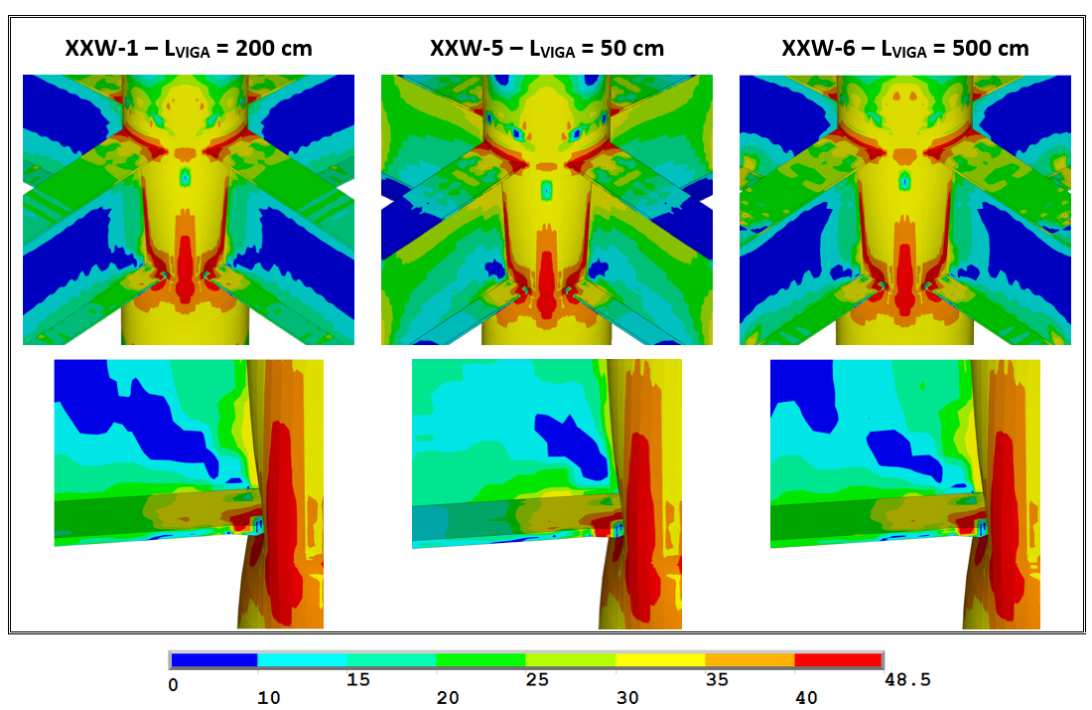

Notas: Tensões em kN/cm $; f_{y, v i g a}=34,5 \mathrm{kN} / \mathrm{cm}^{2} ; f_{y, p i l a r}=35,0 \mathrm{kN} / \mathrm{cm}^{2}$ Fonte: Acervo pessoal

Em termos de comportamento momento-rotação não se verificou grandes diferenças entre os resultados obtidos nos 3 modelos com ligação soldada. 
Figura 5.64 - Comportamento momento-rotação dos modelos XXW-1, XXW-5 e XXW-6

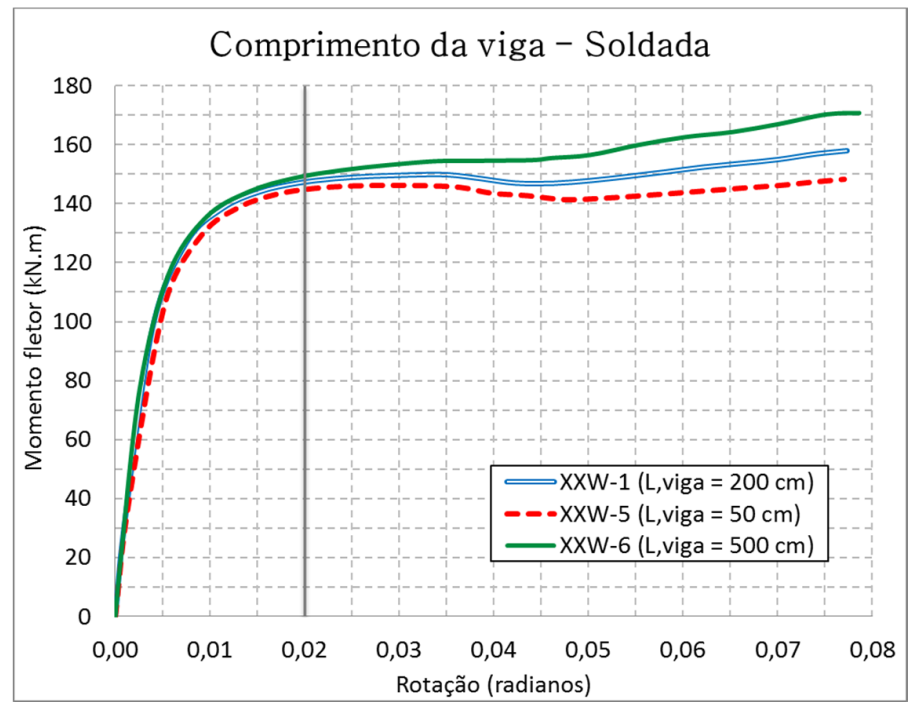

Fonte: Acervo pessoal

A figura 5.64 ilustra certa sobreposição entre as curvas $M-\theta$ dos modelos XXW-1, XXW-5 e XXW-6 para rotações de até 0,02 radianos, demonstrando a aproximação entre os resultados para os 3 modelos. Os resultados apresentados na tabela 5.13 descrevem a aproximação verificada.

Tabela 5.13 - Esforços, deslocamentos e rigidez inicial dos modelos XXW-1, XXW-5 e XXW-6

\begin{tabular}{|c|c|c|c|c|}
\hline \multirow{2}{*}{ MODELO } & $U_{(0,02 \mathrm{rad})}$ & $F_{(0,02 \mathrm{rad})}$ & $S_{\mathrm{j}, \text { ini }}$ & $M_{R d(0,02 \mathrm{rad})}$ \\
\hline & $(\mathrm{cm})$ & $(\mathbf{k N})$ & (kN.m/rad) & (kN.m) \\
\hline XXW-1 (L,viga = $200 \mathrm{~cm})$ & 1,1 & 73,9 & 32.354 & 147,3 \\
\hline XXW-5 (L,viga $=50 \mathrm{~cm})$ & 1,0 & 288,6 & 27.645 & 144,8 \\
\hline XXW-6 (L,viga $=500 \mathrm{~cm})$ & 1,4 & 30,0 & 33.513 & 149,3 \\
\hline
\end{tabular}

Notas: U - deslocamento vertical; $F$ - força vertical; $S_{j, \text { ini }}$ - rigidez inicial; $M_{R d}-$ momento resistente Fonte: Acervo pessoal

Os deslocamentos verticais nos 3 modelos (medidos no comprimento de 50 $\mathrm{cm}$ da viga) apontam uma relação direta entre o aumento do deslocamento com o aumento do comprimento da viga.

Em termos de força vertical aplicada, os valores são referentes ao ponto de aplicação, no caso, a extremidade da viga. Para se obter resultados equivalentes foi necessário aumentar a intensidade da força vertical no modelo XXW-5 ( $\left.\mathrm{L}_{\text {viga }}=50 \mathrm{~cm}\right)$ e reduzir no modelo $X X W-6\left(L_{v i g a}=50 \mathrm{~cm}\right)$.

A redução do comprimento da viga no modelo XXW-5 (Lviga $=50 \mathrm{~cm})$ resultou em uma rigidez inicial 15\% menor da verificada no modelo XXW-1 ( $L_{\text {viga }}=200 \mathrm{~cm}$ ). Considerando a atuação de um momento fletor equivalente nos 3 modelos, o efeito 
combinado com a força cortante resultou em perda de resistência e rigidez inicial da ligação no modelo XXW-5.

\section{- Ligações com a presença do diafragma externo:}

Nos modelos com a presença do diafragma verificou-se situação semelhante à observada nos modelos com ligação soldada em termos de distribuição de tensões.

Figura 5.65 - Evolução das tensões de Von Mises nos modelos XXS-1 e XXS-9

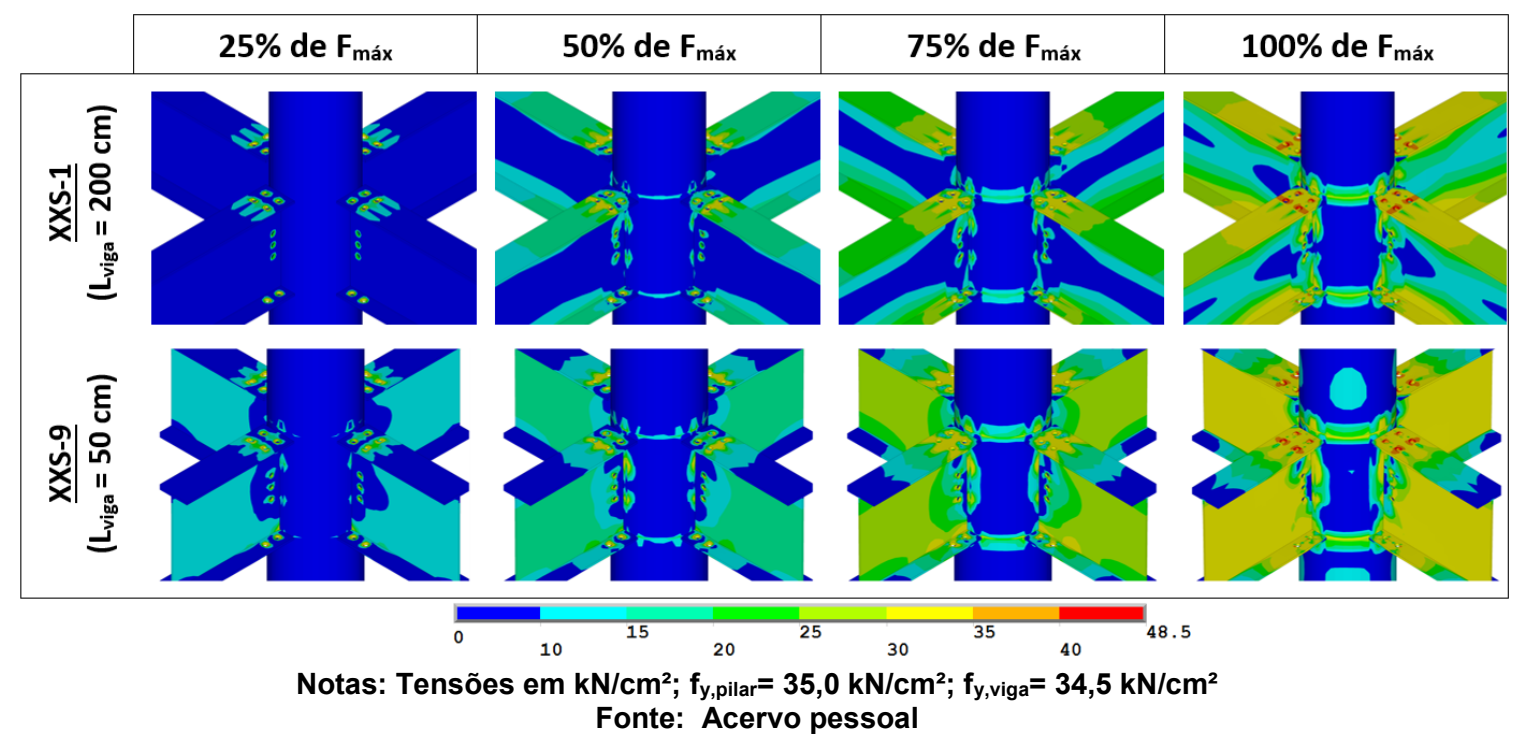

As tensões de Von Mises nos modelos XXS-1 $\left(L_{\text {viga }}=200 \mathrm{~cm}\right)$ e XXS-9 $\left(L_{\text {viga }}\right.$ $=50 \mathrm{~cm}$ ) ao longo do carregamento (figura 5.65), evidenciam a concentração de tensões na alma das vigas no modelo XXS-9 devido à redução do comprimento da viga e o aumento da força cortante.

A redução do comprimento da viga para $50 \mathrm{~cm}$ no modelo XXS-9 gerou o aumento da força cortante e, consequentemente, verificou-se uma maior intensidade na distribuição de tensões na chapa de alma ao longo do carregamento (figura 5.66). 
Figura 5.66 - Evolução das tensões de Von Mises na chapa de alma nos modelos XXS-1 e XXS-9

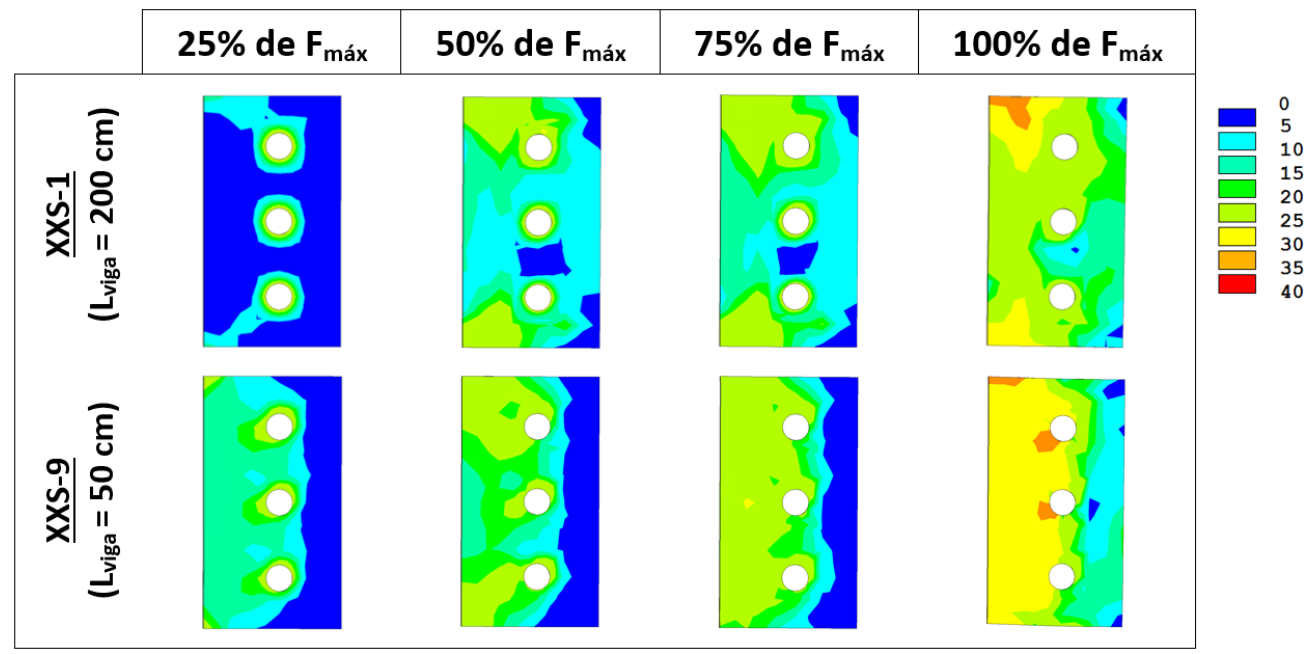

Notas: Tensões em kN/cm²; $f_{y, c h a p a}=25,0 \mathrm{kN} / \mathrm{cm}^{2}$

Fonte: Acervo pessoal

As curvas M- $\theta$ dos modelos XXS-1 $\left(L_{\text {viga }}=200 \mathrm{~cm}\right)$ e XXS-9 $\left(L_{\text {viga }}=50 \mathrm{~cm}\right)$ são, praticamente, equivalentes (figura 5.67). Apesar da disparidade entre a distribuição de tensões na chapa de alma, o modo de falha para estes modelos ocorreu na ligação parafusada da mesa superior das vigas.

Figura 5.67 - Comportamento momento-rotação dos modelos XXS-1 e XXS-9

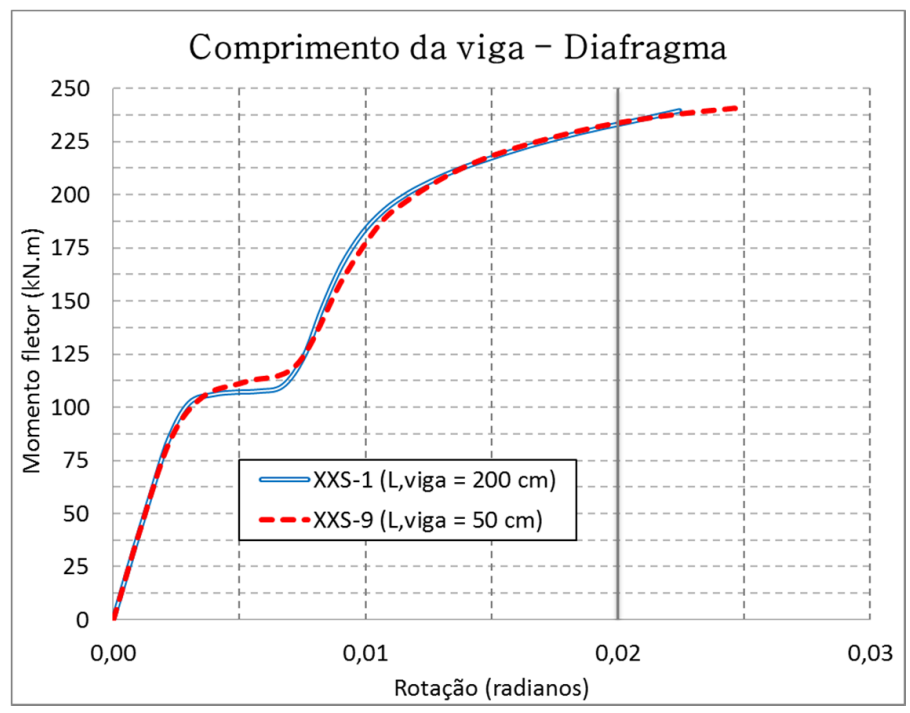

Fonte: Acervo pessoal

Os resultados apresentados na tabela 5.14, obtidos da curva momentorotação dos modelos XXS-1 e XXS-9, demonstram a aproximação entre os resultados destes modelos. A diferença na força aplicada é resultado da equivalência entre o momento fletor atuante nos dois modelos. 
Tabela 5.14 - Esforços, deslocamentos e rigidez inicial dos modelos XXS-1 e XXS-9

\begin{tabular}{|c|c|c|c|c|}
\hline \multirow{2}{*}{ MODELO } & $U_{(0,02 \mathrm{rad})}$ & $F_{(0,02 \mathrm{rad})}$ & $S_{\mathrm{j}, \text { ini }}$ & $M_{R d(0,02 \mathrm{rad})}$ \\
\hline & $(\mathrm{cm})$ & $(k N)$ & (kN.m/rad) & (kN.m) \\
\hline XXS-1 (L,viga $=200 \mathrm{~cm})$ & 1,1 & 116,5 & 40.863 & 233,1 \\
\hline XXS-9 (L,viga = $50 \mathrm{~cm})$ & 1,2 & 466,1 & 40.472 & 233,8 \\
\hline
\end{tabular}

Notas: $\mathrm{U}$ - deslocamento vertical; $\mathrm{F}$ - força vertical; $\mathbf{S}_{\mathrm{j}, \mathrm{ini}}$ - rigidez inicial; $\mathbf{M}_{\mathrm{Rd}}$ - momento resistente Fonte: Acervo pessoal

\subsubsection{Espessura da parede do pilar}

\section{- Ligações soldadas:}

Nas ligações soldadas, a evolução das tensões de Von Mises ao longo do carregamento (figura 5.68) demonstra a plastificação mais evidente no modelo XXW$4\left(t_{\text {pilar }}=7,1 \mathrm{~mm}\right)$, sobretudo nas fases iniciais do carregamento. Nota-se que para tensões em torno de $50 \%$ do carregamento final já se verifica certa plastificação da face do pilar neste modelo.

Figura 5.68 - Evolução das tensões de Von Mises na face do pilar nos modelos XXW-1, XXW-3 e XXW-4

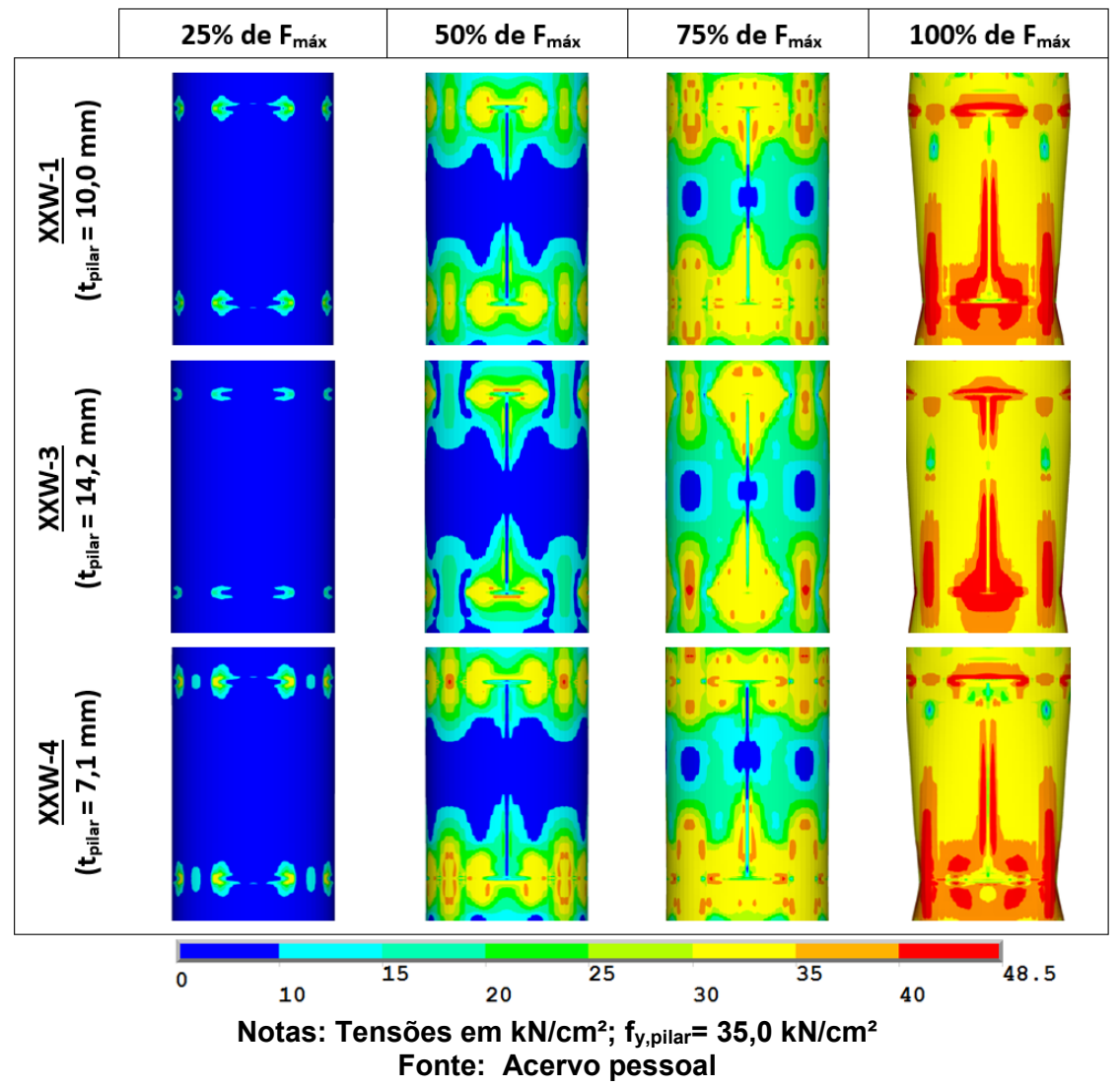


No modelo XXW-4 ( $\left.\mathrm{t}_{\text {pilar }}=7,1 \mathrm{~mm}\right)$ a plastificação da face do pilar ocorre anteriormente ao verificado nos modelos XXW-1 ( $\left.\mathrm{t}_{\text {pilar }}=10,0 \mathrm{~mm}\right)$ e XXW-3 $\left(\mathrm{t}_{\text {pilar }}=14,2\right.$ $\mathrm{mm}$ ). Este fenômeno ocasiona o caminhamento das tensões para as demais regiões do pilar em um estágio anterior no modelo XXW-4. Verificou-se portanto, tensões mais uniformes e bem distribuídas neste modelo e mais concentradas na região da interface viga-pilar no modelo XXW-3. A maior capacidade do pilar em absorver esforços (no modelo XXW-3) retardou o efeito do espalhamento das tensões.

A maior capacidade em absorver esforços no modelo XXW-3 ( $t_{\text {pilar }}=14,2 \mathrm{~mm}$ ) resultou em uma força aplicada de maior intensidade e, consequentemente, um binário de maior grandeza. O aumento do binário originou uma força de compressão superior na mesa da viga do modelo XXW-3, resultando na flambagem local da mesa (figura 5.69) e podendo conduzir a um modo de falha distinto.

Figura 5.69 - Tensões de Von Mises e flambagem local da mesa da viga nos modelos XXW-3 e XXW-4 ao final da análise

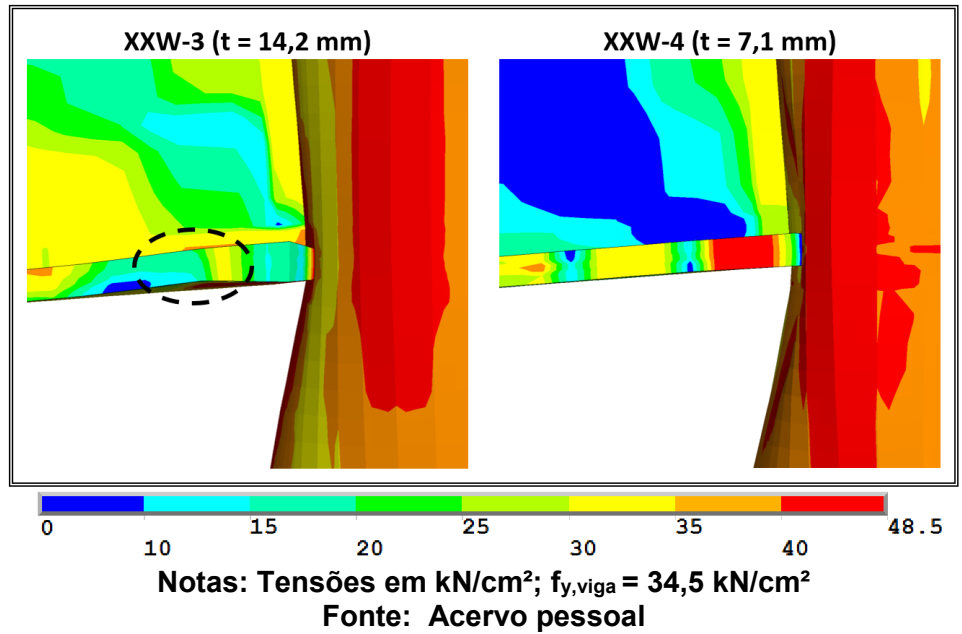

É importante lembrar que a distribuição das tensões não é referente ao mesmo carregamento nos modelos analisados. A força vertical aplicada no modelo XXW-4 é inferior à do modelo XXW-1 que, por sua vez, é inferior a aplicada no modelo XXW-3. Para se ter o mesmo resultado em termos de visualização do modo de falha é necessário carregar o modelo por meio da aplicação de deslocamentos. Neste caso, para se obter o mesmo deslocamento vertical nos 3 modelos é necessário uma força vertical superior no modelo XXW-3 ( $t_{\text {pilar }}=14,2 \mathrm{~mm}$ ) em relação a aplicada no modelo $X X W-1\left(t_{\text {pilar }}=10,0 \mathrm{~mm}\right)$ e, por sua vez, maior que a aplicada no modelo XXW-4 (t $t_{\text {pilar }}$ $=7,1 \mathrm{~mm}$ ). 
A diferença entre as forças verticais aplicadas nos 3 modelos pode ser melhor compreendida por meio da observação das tensões de Von Mises nas vigas, ao final da análise (figura 5.70). O modelo XXW-3 ( $t_{\text {pilar }}=14,2 \mathrm{~mm}$ ) com o pilar de maior resistência foi solicitado por uma força vertical de maior intensidade e, consequentemente, verificou-se o aumento das tensões nas vigas.

Figura 5.70 - Distribuição das tensões de Von Mises ao longo do comprimento da viga nos modelos XXW-1, XXW-3 e XXW-4 ao final da análise

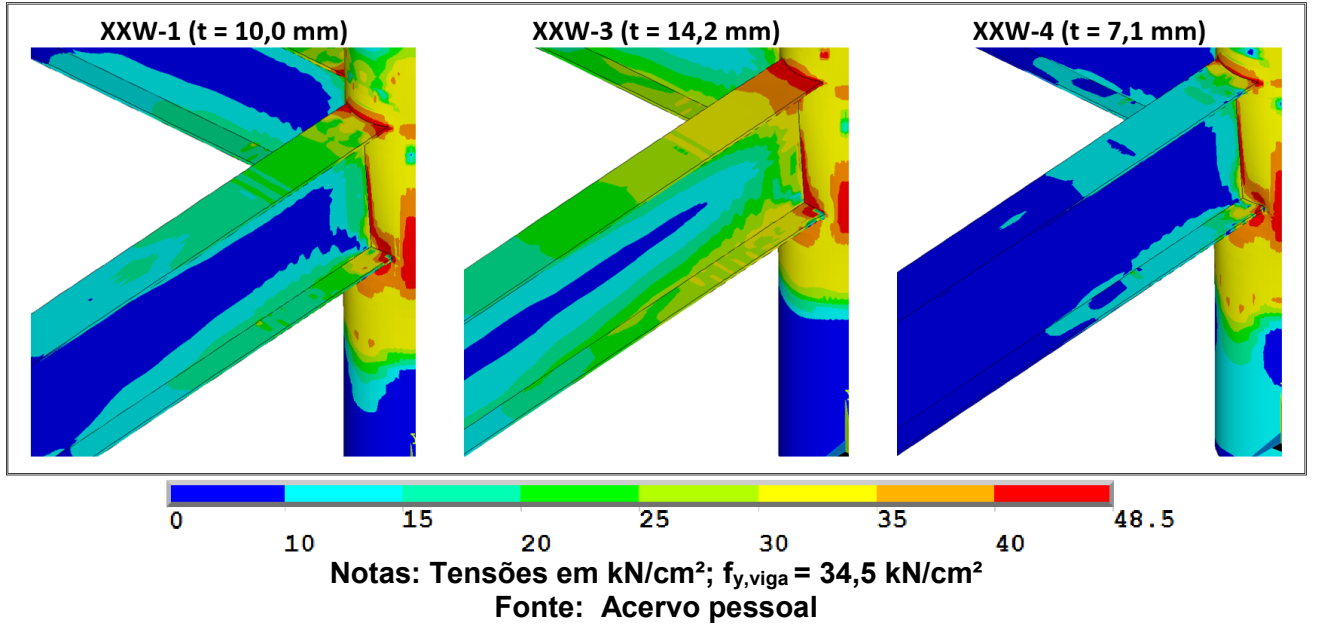

O comportamento momento-rotação ilustrado na figura 5.71 apresenta a relação direta entre aumento da espessura do pilar com o aumento das propriedades de rigidez e resistência da ligação.

Figura 5.71 - Comportamento momento-rotação dos modelos XXW-1, XXW-3 e XXW-4

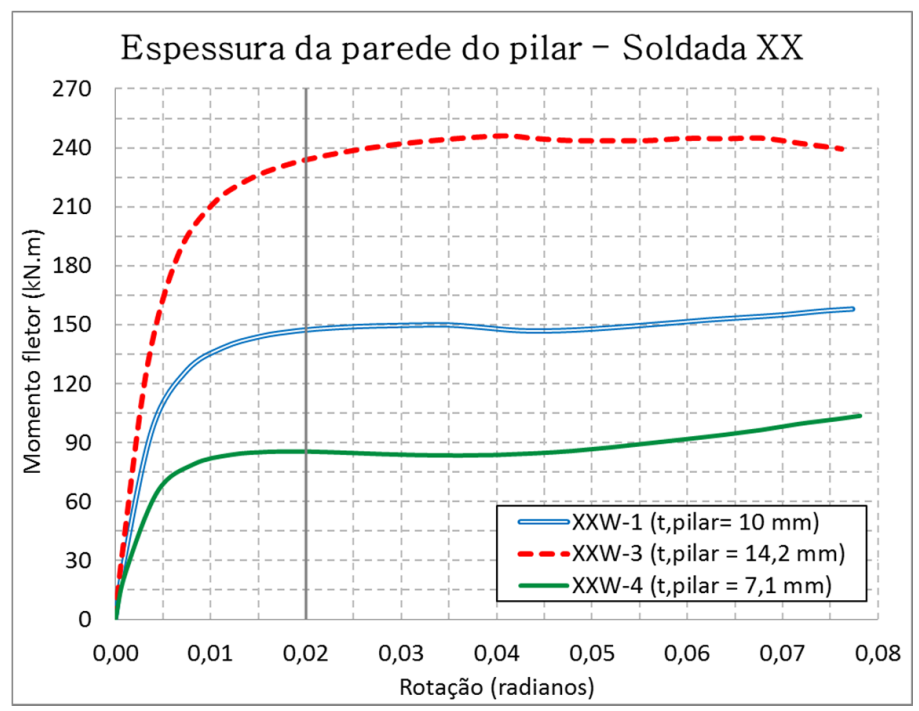

Fonte: Acervo pessoal 
Observa-se na figura 5.71 a considerável diferença entre o comportamento momento-rotação nos 3 modelos citados. A tabela 5.15 apresenta os resultados obtidos das curvas M- $\theta$.

Tabela 5.15 - Esforços, deslocamentos e rigidez inicial dos modelos XXW-1, XXW-3 e XXW-4

\begin{tabular}{|c|c|c|c|c|}
\hline \multirow{2}{*}{ MODELO } & $U_{(0,02 \mathrm{rad})}$ & $F_{(0,02 \mathrm{rad})}$ & $S_{\mathrm{j}, \text { ini }}$ & $M_{\mathrm{Rd}(0,02 \mathrm{rad})}$ \\
\hline & $(\mathrm{cm})$ & $(\mathrm{kN})$ & (kN.m/rad) & (kN.m) \\
\hline XXW-1 (t,pilar= $10 \mathrm{~mm})$ & 4,5 & 73,9 & 32.354 & 147,3 \\
\hline XXW-3 (t,pilar = 14,2 mm) & 4,7 & 116,7 & 42.876 & 233,6 \\
\hline XXW-4 (t,pilar = 7,1 mm) & 4,3 & 42,7 & 22.261 & 85,4 \\
\hline
\end{tabular}

Notas: U - deslocamento vertical; $F$ - força vertical; $S_{j, i n i}$ - rigidez inicial; $M_{R d}-$ momento resistente Fonte: Acervo pessoal

A rigidez inicial no modelo $X X W-3$ (t superior ao observado no modelo $X X W-4$ ( $t_{\text {pilar }}=7,1 \mathrm{~mm}$ ). Verificou-se no modelo $\mathrm{XXW}-3$ um momento fletor resistente $59 \%$ maior que o do modelo $\mathrm{XXW}-1\left(\mathrm{t}_{\text {pilar }}=10\right.$ $\mathrm{mm})$.

Nos modelos de ligação soldada do tipo TT (quadro 5.6), o aumento da espessura do pilar apresentou o mesmo efeito verificado nos modelos de ligação soldada do tipo XX.

Quadro 5.6 - Resultados para os modelos TTW-1 e TTW-3

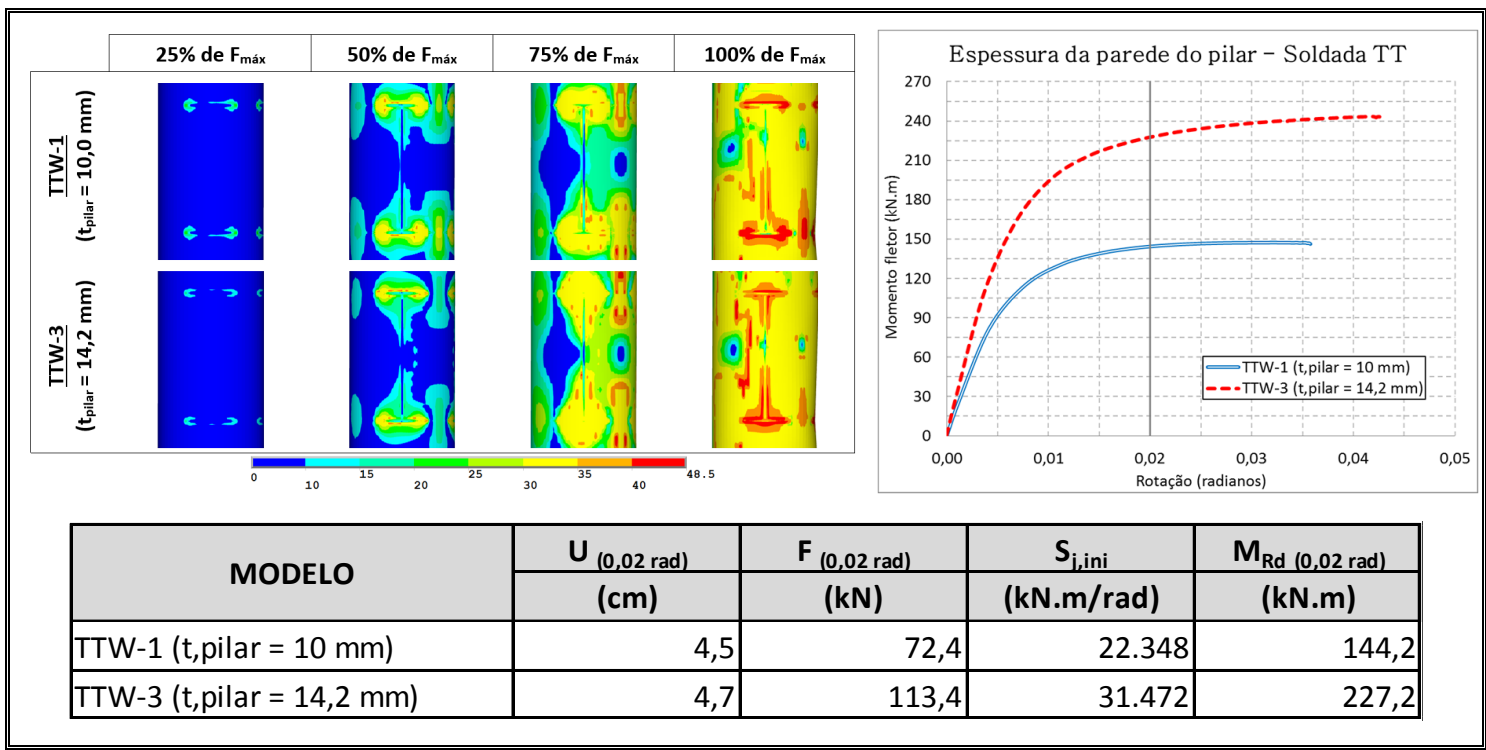

Notas: Tensões em kN/cm ${ }^{2} f_{y, p i l a r}=35,0 \mathrm{kN} / \mathrm{cm}^{2}$ Fonte: Acervo pessoal

As curvas momento-rotação e os resultados referentes ao momento fletor resistente para a rotação de 0,02 radianos nos modelos TTW-1 ( $t_{\text {pilar }}=10 \mathrm{~mm}$ ) e TTW- 
$3\left(t_{\text {pilar }}=14,2 \mathrm{~mm}\right)$ demonstram a relevância da espessura do pilar no comportamento das ligações soldadas. Destaca-se a rigidez $41 \%$ superior do modelo TTW-3 em relação ao modelo TTW-1.

\section{- Ligações com a presença do diafragma externo:}

A utilização do diafragma para a transmissão dos esforços de tração e compressão para a face do pilar gera um aumento da superfície responsável por essa transferência. Nos modelos com a presença do diafragma, o modo de falha ocorreu na ligação parafusada com a mesa superior da viga. Espera-se, portanto, que o aumento da espessura do pilar para as geometrias analisadas não apresente influência considerável no comportamento da ligação.

A figura 5.72 ilustra a evolução das tensões de Von Mises na face do pilar nos modelos XXS-1 ( $\left.t_{\text {pilar }}=10,0 \mathrm{~mm}\right), X X S-6\left(t_{\text {pilar }}=14,2 \mathrm{~mm}\right)$ e XXS-3 $\left(t_{\text {pilar }}=7,1 \mathrm{~mm}\right)$.

Figura 5.72 - Evolução das tensões de Von Mises na face do pilar nos modelos XXS-1, XXS-6 e XXS-3

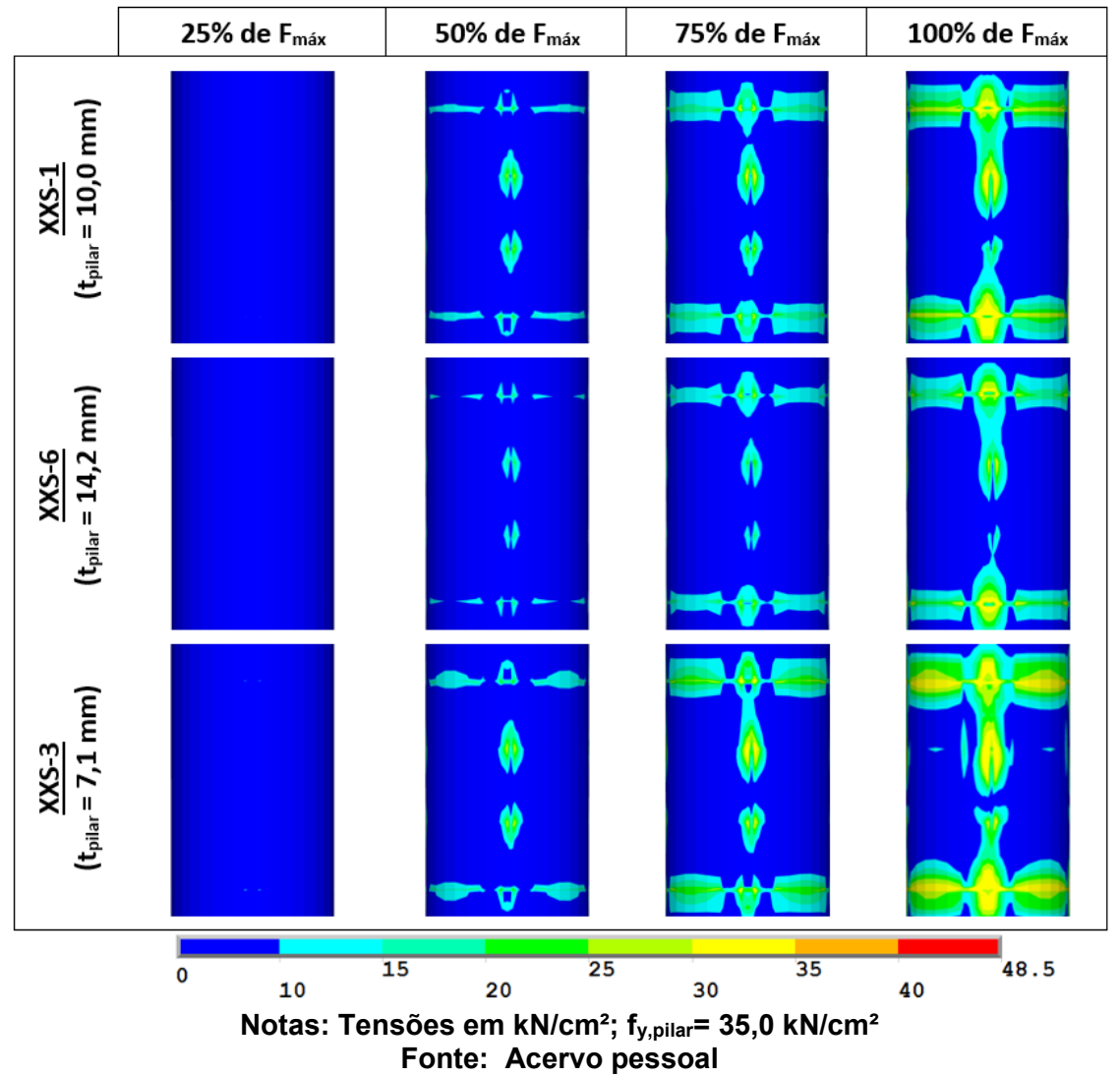

Nota-se na figura 5.72 a eminência da plastificação do pilar no modelo XXS-3 ao final do carregamento. Apesar disso, a utilização do pilar de menor espessura neste 
modelo não foi suficiente para atingir o limite de escoamento do material do tubo $\left(f_{y, p i l a r}\right.$ $\left.=35,0 \mathrm{kN} / \mathrm{cm}^{2}\right)$.

As curvas representativas do comportamento momento-rotação dos modelos XXS-1, XXS-6 e XXS-3 (figura 5.73) demonstram uma aproximação considerável entre o comportamento dos 3 modelos.

Figura 5.73 - Comportamento momento-rotação dos modelos XXS-1, XXS-6 e XXS-3

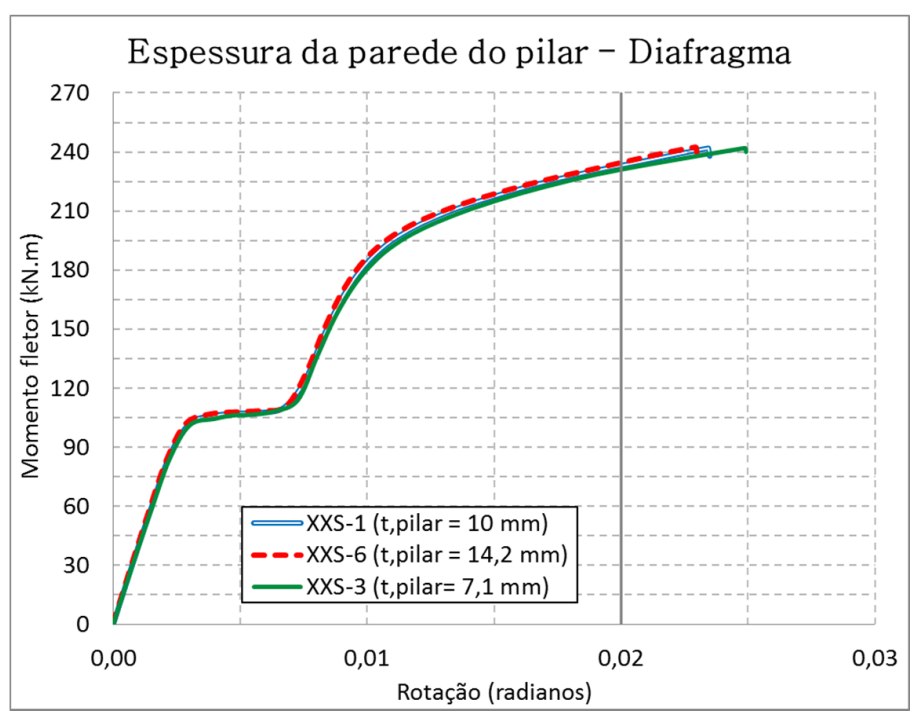

Fonte: Acervo pessoal

A redução da espessura do pilar no modelo $X X S-3$ ( $t_{\text {pilar }}=7,1 \mathrm{~mm}$ ) resultou em uma rigidez inicial 5\% menor que a do modelo XXS-6 ( $t_{\text {pilar }}=14,2 \mathrm{~mm}$ ). A resistência das ligações nos 3 modelos com diafragma são, praticamente, equivalentes.

Os principais resultados relativos aos modelos numéricos XXS-1, XXS-6 e XXS-3 são apresentados na tabela 5.16. Comprovando as constatações observadas, verificou-se uma considerável proximidade entre os resultados nos 3 modelos evidenciando a reduzida influência da espessura do pilar no comportamento dos modelos com os diafragmas analisados.

Tabela 5.16 - Esforços, deslocamentos e rigidez inicial dos modelos XXS-1, XXS-6 e XXS-3

\begin{tabular}{|c|c|c|c|c|}
\hline \multirow{2}{*}{ MODELO } & $U_{(0,02 \mathrm{rad})}$ & $F_{(0,02 \mathrm{rad})}$ & $S_{\mathrm{j}, \text { ini }}$ & $M_{R d(0,02 \mathrm{rad})}$ \\
\hline & $(\mathrm{cm})$ & $(\mathrm{kN})$ & (kN.m/rad) & (kN.m) \\
\hline XXS-1 (t,pilar = $10 \mathrm{~mm})$ & 4,5 & 116,5 & 40.863 & 233,1 \\
\hline XXS-6 (t, pilar $=14,2 \mathrm{~mm})$ & 4,5 & 117,5 & 41.801 & 234,8 \\
\hline XXS-3 (t,pilar= 7,1 mm) & 4,5 & 115,0 & 40.026 & 231,1 \\
\hline
\end{tabular}

Notas: $U$ - deslocamento vertical; $F$ - força vertical; $S_{j, i n i}-$ rigidez inicial; $M_{R d}$ - momento resistente Fonte: Acervo pessoal 


\subsubsection{Força aplicada nas duas direções ortogonais}

\section{- Ligações soldadas:}

O comportamento de ligações entre viga de seção I e pilar de seção tubular circular apresenta certas particularidades em função da presença da geometria circular. A seção circular quando solicitada transversalmente apresenta comportamento distinto dos comumente verificados em outras seções geométricas.

Para se entender o mecanismo de transferência de esforços e propriedades relativas à deformação da seção tubular circular é importante realizar algumas variações na aplicação das forças. Considerando as ligações estudadas, denominase $F_{1}$ a força vertical aplicada nas vigas de uma direção e $F_{2}$ a força vertical aplicada nas vigas na direção ortogonal a primeira conforme a figura 5.74 .

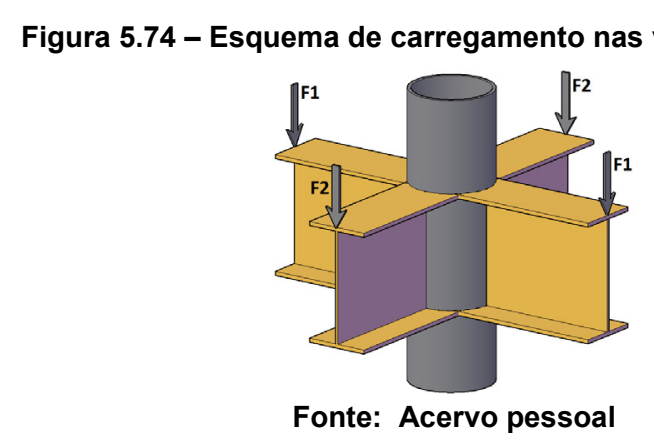

A força vertical $(F)$ aplicada na extremidade da viga gera duas componentes de esforços que atuam na ligação, a componente vertical $(F)$ e o momento fletor (M). Por sua vez, o momento fletor $(\mathrm{M})$ gera um binário $(\mathrm{H})$ composto por uma força de compressão transmitida pela mesa inferior das vigas e uma força de tração transmitida pela mesa superior (figura 5.75 ).

Figura 5.75 - Esforços internos na ligação viga-pilar

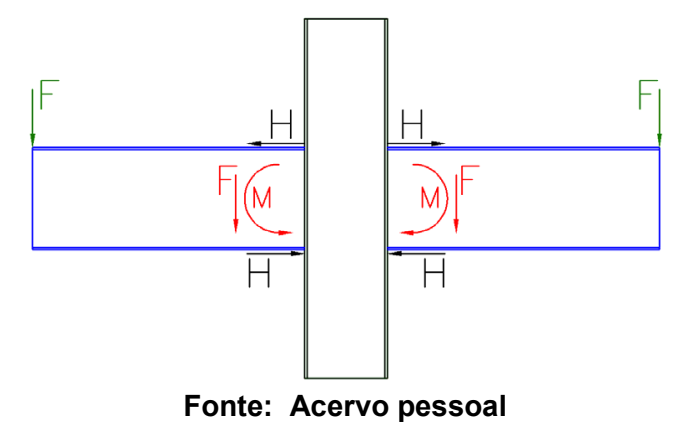


Considerando a maior eminência da plastificação da seção do pilar na região comprimida, as forças exercidas pela mesa inferior das vigas nos modelos $\mathrm{XXW}-1$ $\left(F_{2} / F_{1}=1\right)$ e $X X W-7\left(F_{2} / F_{1}=0\right)$ estão ilustradas na figura 5.76.

Figura 5.76 - Reação da mesa inferior na ligação viga-pilar XXW-1

XXW-7
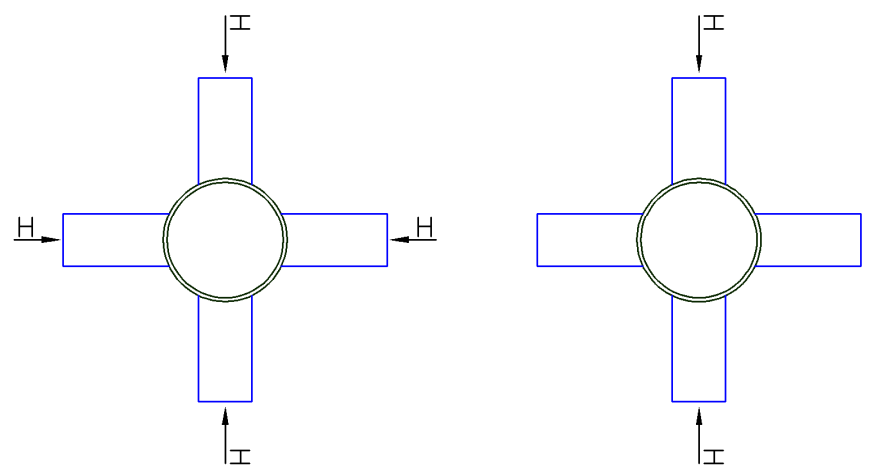

Fonte: Acervo pessoal

No modelo XXW-1 $\left(\mathrm{F}_{2} / \mathrm{F}_{1}=1\right)$ optou-se por carregar as 4 vigas com uma força no sentido gravitacional. As forças aplicadas geram reações de compressão exercidas pela mesa inferior das vigas. Com as 4 vigas carregadas, tem-se a compressão em quase todo o perímetro do pilar. A compressão em todo perímetro da circunferência gera o chamado efeito de confinamento. O efeito de confinamento na seção do tubo reduz a eminência da deformação resultando em acréscimo de resistência e rigidez inicial da ligação.

Em uma situação crítica, considera-se o carregamendo atuando apenas nas vigas situadas na mesma direção. Este caso verificado no modelo XXW-7 $\left(F_{2} / F_{1}=0\right)$ resulta em uma situação distinta da observada no modelo $X X W-1\left(F_{2} / F_{1}=1\right)$.

A compressão exercida apenas em uma direção evidencia a deformação do tubo resultando no chamado fenômeno de ovalização (ovalization), neste caso, não há a restrição à deformação anteriormente exercida pelas vigas carregadas na outra direção. Espera-se portanto, rigidez inicial e resistência da ligação inferiores as do modelo $X X W-1 \quad\left(F_{2} / F_{1}=1\right)$. A figura 5.77 ilustra, em escala amplificada, as duas situações descritas, o efeito de confinamento no modelo $X X W-1 \quad\left(F_{2} / F_{1}=1\right)$ e a ovalização no modelo XXW-7 $\left(F_{2} / F_{1}=0\right)$. 
Figura 5.77 - Efeito de confinamento do pilar no modelo XXW-1 e ovalização no modelo XXW-7
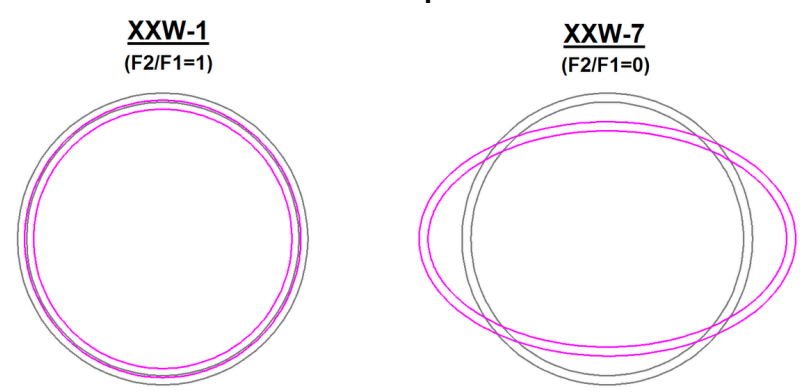

- SITUAÇÃO DEFORMADA

- SITUAÇÃO NÃO DEFORMADA

Fonte: Acervo pessoal

Os fenômenos descritos podem ser visualizados por meio da evolução das tensões de Von Mises na face do pilar ao longo do carregamento nos modelos XXW1 e XXW-7 (figura 5.78).

Figura 5.78 - Tensões de Von Mises na face do pilar e vista superior nos modelos XXW-1 e XXW-7

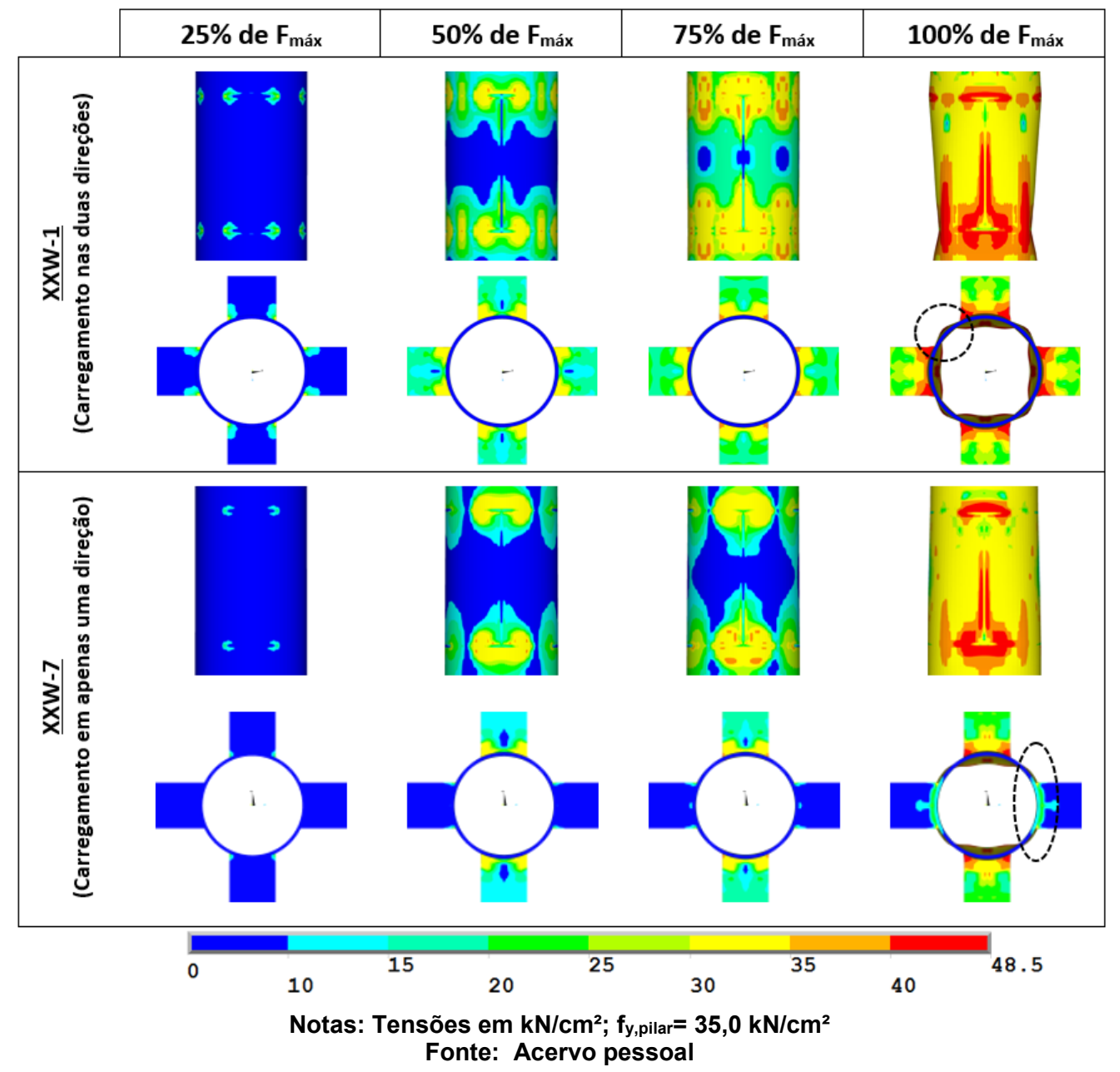

A compressão exercida pela mesa inferior das 4 vigas no modelo $X X W-1$ $\left(F_{2} / F_{1}=1\right)$ resultou em uma concentração de tensões na região do pilar localizada 
entre 2 vigas ortogonais. No modelo $X X W-7\left(F_{2} / F_{1}=0\right)$ verificou-se a concentração das tensões apenas na região da interface viga-pilar. A vista superior da seção do pilar permite ainda visualizar o fenômeno de ovalização no modelo XXW-7.

O comportamento momento-rotação dos modelos $X X W-1\left(F_{2} / F_{1}=1\right)$ e $X X W-$ $7\left(F_{2} / F_{1}=0\right)$ reiteram o resultado teoricamente esperado. A força aplicada nas 4 vigas no modelo XXW-1 resultou em uma curva com inclinação superior (maior rigidez inicial) e maior resistência ao momento fletor, conforme verificado no quadro 5.7.

Quadro 5.7 - Comportamento momento-rotação dos modelos XXW-1 e XXW-7

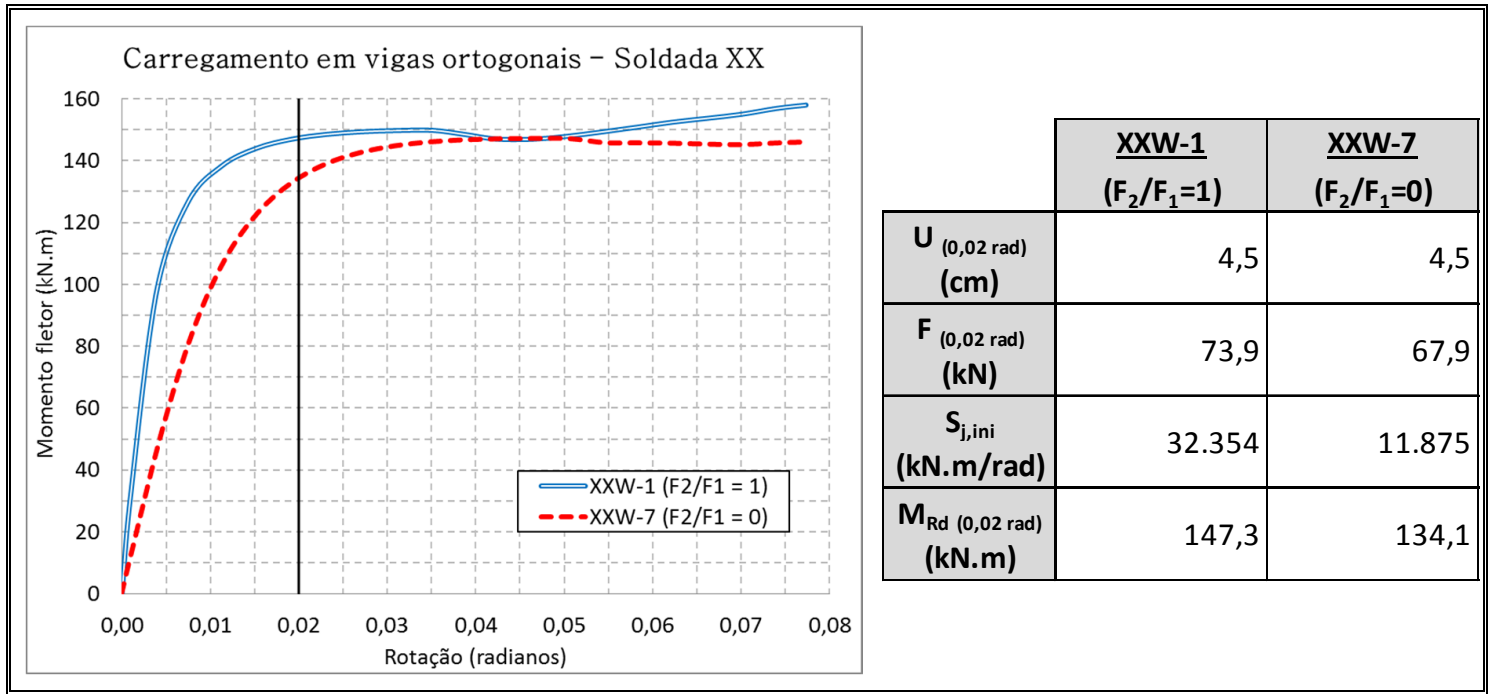

Notas: U - deslocamento vertical; $F$ - força vertical; $S_{j, i n i}$ - rigidez inicial; $M_{R d}-$ momento resistente Fonte: Acervo pessoal

A restrição exercida pelas vigas ortogonais carregadas simultaneamente no modelo XXW-1 resultou em uma rigidez inicial 173\% superior e resistência ao momento fletor (para rotação de 0,02 radianos) 10\% maior. A medida em que a plastificação da face do pilar passa a ser predominante, o comportamento dos dois modelos se aproxima e verificam-se valores de resistência próximos.

Nos modelos com ligação TT soldadas, o efeito da restrição passou a ser menos considerável, visto a presença de apenas 2 vigas. Neste caso, os resultados verificados no quadro 5.8 apresentam maior aproximação. De qualquer maneira, a influência do carregamento simultâneo nas duas direções ortogonais também apresentou relevância no comportamento dos modelos do tipo TT. 
Quadro 5.8 - Resultados para os modelos TTW-1 e TTW-7

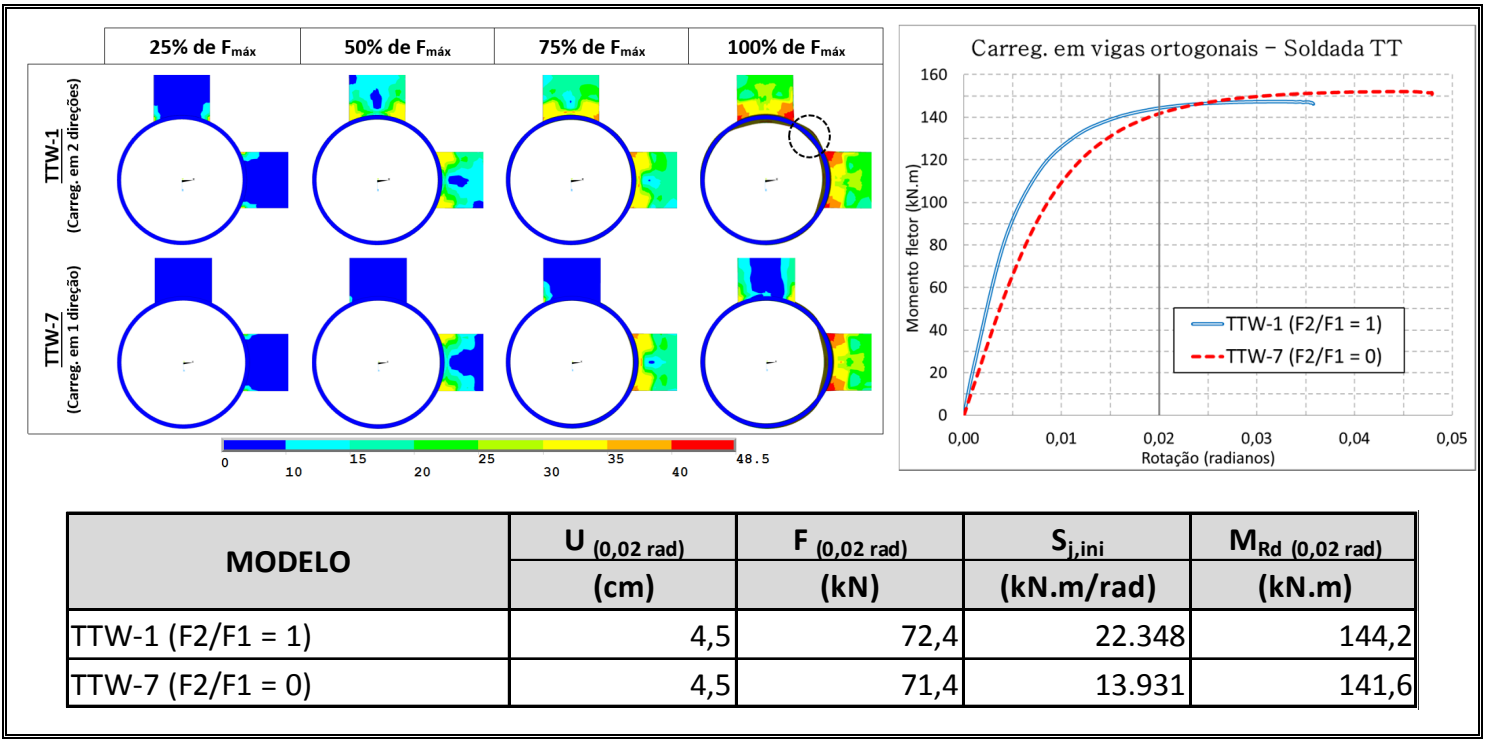

Notas: Tensões em kN/cm²; $f_{y, p i l a r}=35,0 \mathrm{kN} / \mathrm{cm}^{2}$

Fonte: Acervo pessoal

- Ligações com a presença do diafragma externo:

No modelo $X X S-1\left(F_{2} / F_{1}=1\right)$, a força aplicada nas vigas das duas direções gerou um estado de tensão mais uniforme na chapa superior do diafragma, conforme demonstra a figura 5.79 .

Figura 5.79 - Tensões de Von Mises na chapa do diafragma superior nos modelos XXS-1 e XXS-2

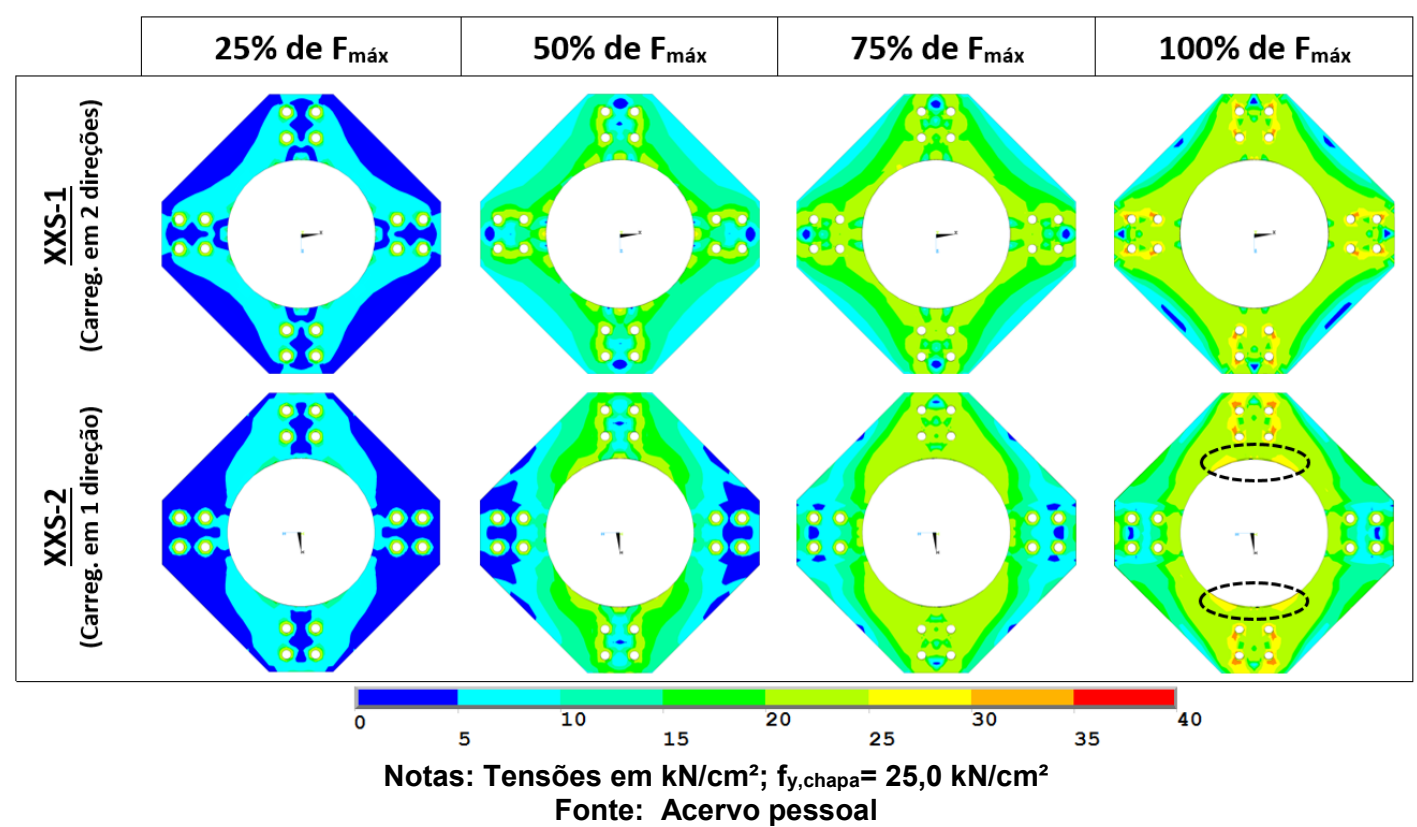

A solicitação das vigas de apenas uma direção no modelo $X X S-2\left(F_{2} / F_{1}=0\right)$ criou uma zona de concentração de tensões na interface chapa-pilar na direção das 
vigas carregadas. A concentração de tensão próxima à ligação parafusada gerou um aumento da solicitação nos parafusos. Em função da predominância do modo de falha do cisalhamento dos parafusos, o aumento da solicitação nestes elementos resultou em uma redução na resistência da ligação conforme ilustrado no quadro 5.9.

Nos modelos com diafragma a diferença entre os modelos $X X S-1\left(F_{2} / F_{1}=1\right)$ e XXS-2 $\left(F_{2} / F_{1}=0\right)$ ocorreu em função da restrição à deformação exercida pelas vigas carregadas na direção ortogonal. A força aplicada simultaneamente (de mesma intensidade) nas duas direções ortogonais $\left(\mathrm{F}_{2} / \mathrm{F}_{1}=1\right)$ gerou uma restrição à deformação do tubo havendo a necessidade de uma força aplicada de maior intensidade para que o modelo XXS-1 atingisse o estado plástico. O comportamento momento-rotação ilustrado no quadro 5.9 demonstra o aumento da rigidez inicial em função da restrição exercida pelas vigas do modelo XXS-1.

Quadro 5.9 - Comportamento momento-rotação dos modelos XXS-1 e XXS-2

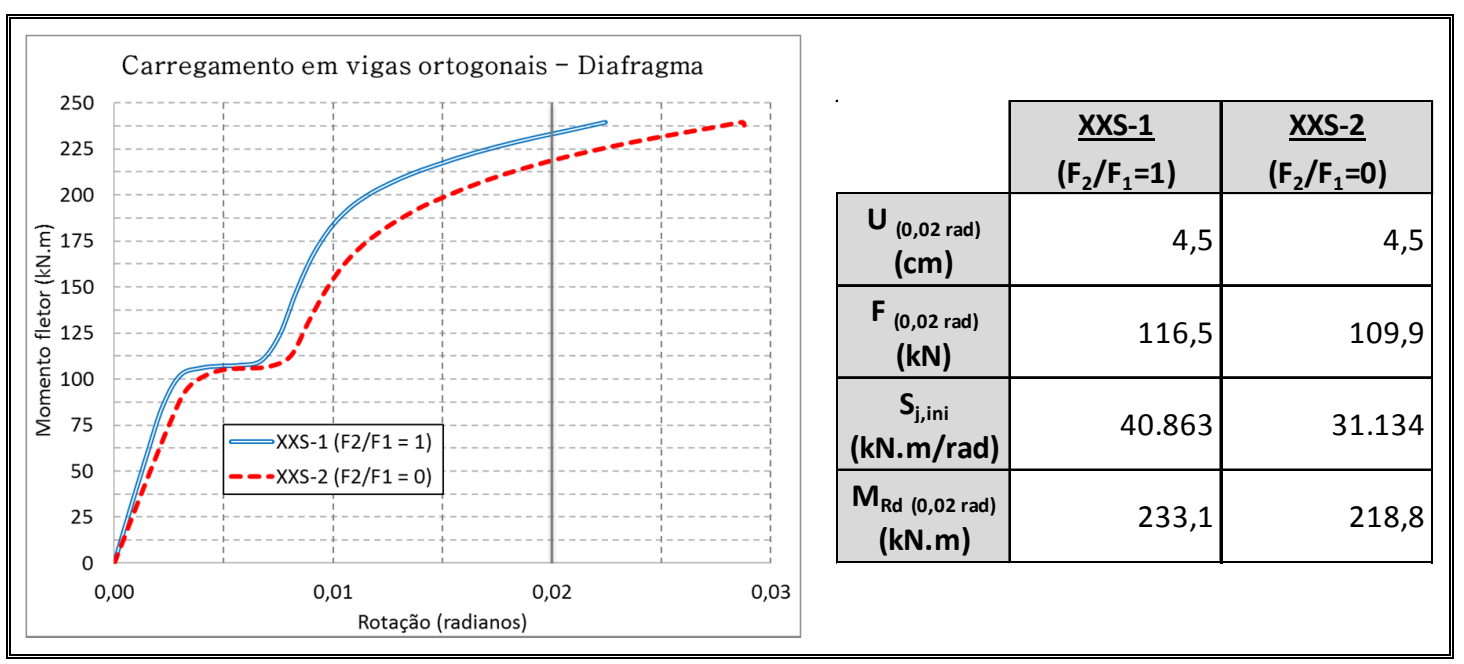

Notas: U - deslocamento vertical; $F$ - força vertical; $S_{j, \text { ini }}$ - rigidez inicial; $M_{R d}$ - momento resistente Fonte: Acervo pessoal

A solicitação nas duas direções ortogonais no modelo $X X S-1 \quad\left(F_{2} / F_{1}=1\right)$ resultou em uma rigidez inicial $31 \%$ superior e um momento fletor resistente $7 \%$ maior. A menor resistência do modelo XXS-2 $\left(F_{2} / F_{1}=0\right)$ fica evidenciada pela força vertical $6 \%$ inferior no modelo XXS-2 para se obter o mesmo resultado em termos de deslocamento no modelo XXS-1.

\section{- Comentários:}

Os resultados para a distribuição das tensões de Von Mises e o comportamento momento-rotação dos modelos analisados demonstram que apesar 
da ocorrência de fenômenos de ovalização e confinamento nos modelos de ligação soldada, o aumento da rigidez inicial e resistência da ligação independe da plastificação da seção do pilar.

A observação dos resultados nos estágios iniciais de carregamento demonstram diferenças ainda no estado elástico dos modelos. A força aplicada nas vigas da direção ortogonal $\left(F_{2} / F_{1}=1\right)$ retardou o início da plastificação do pilar, sendo necessária uma força aplicada de maior intensidade para atingir o limite de escoamento do material. Tem-se assim o aumento da rigidez inicial e resistência das ligações nos modelos XXW-1, TTW-1 e XXS-1.

\subsubsection{Compressão axial do pilar}

O carregamento axial do pilar por meio de uma força de compressão resultou na redução da rigidez inicial e resistência das ligações devido ao aumento da intensidade das tensões na face do pilar nas fases iniciais do carregamento (figura 5.80).

Figura 5.80 - Evolução das tensões de Von Mises na face do pilar nos modelos XXW-1 e XXW-2

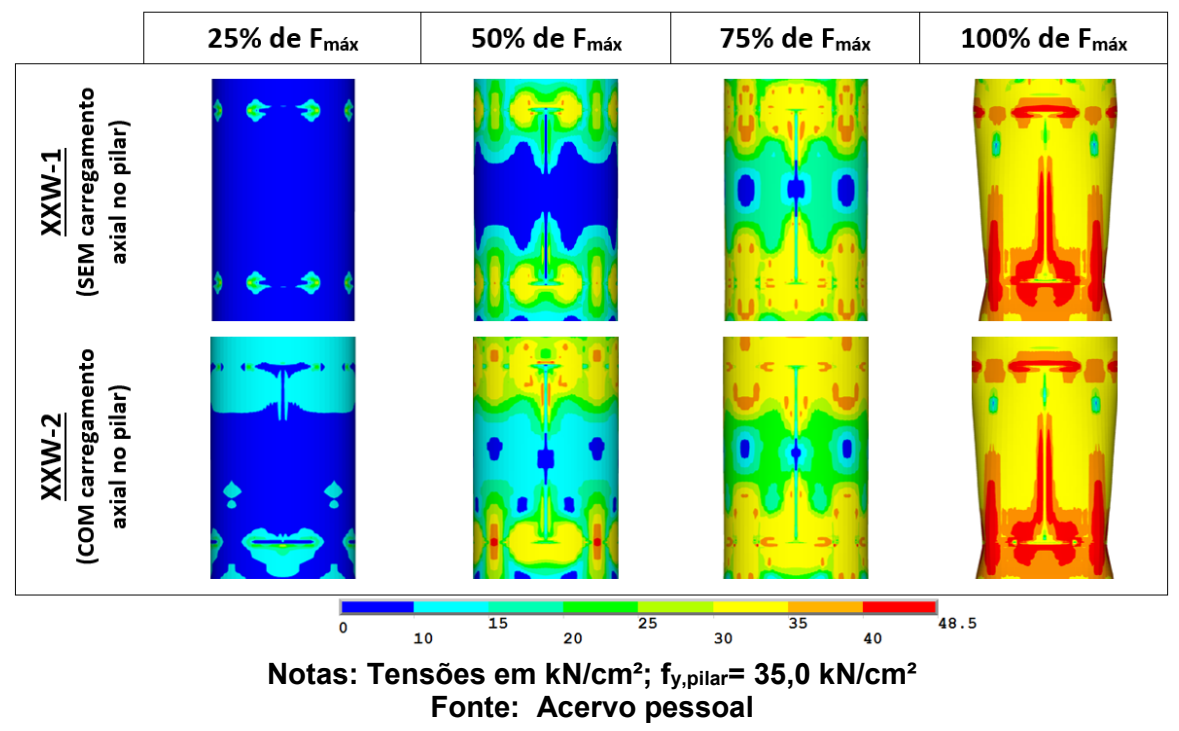

O modelo de ligação soldada XXW-2 foi analisado com a mesma configuração geométrica do modelo XXW-1. No modelo XXW-2 acrescentou-se uma força de compressão axial no pilar de $0,40 \mathrm{~N}_{\mathrm{Rd}}$. 
A distribuição das tensões de Von Mises demonstra o início precoce da plastificação da seção do pilar no modelo XXW-2 (com compressão axial do pilar). Verifica-se nas etapas iniciais de carregamento tensões superiores no modelo XXW2. A plastificação da seção do pilar iniciou-se com cerca de $50 \%$ do carregamento no modelo XXW-2 e 75\% no modelo XXW-1 (sem compressão axial do pilar).

O comportamento momento-rotação dos dois modelos demonstra que a intensidade superior das tensões observada nos estágios iniciais no modelo XXW-2 resultou numa ligação com menor rigidez inicial. A figura 5.81 ilustra o comportamento momento-rotação dos modelos XXW-1 e XXW-2.

Figura 5.81 - Comportamento momento-rotação dos modelos XXW-1 e XXW-2

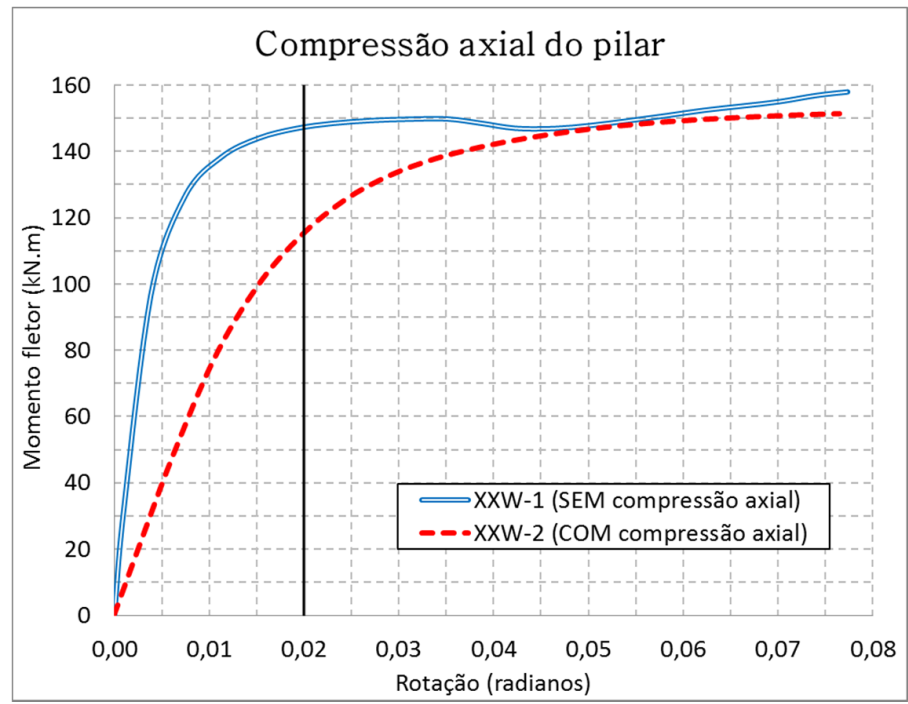

Fonte: Acervo pessoal

Freitas (2009) constatou em sua pesquisa que a força de compressão axial aplicada no pilar não gera influência significativa no comportamento da ligação para solicitações de até 0,6 $\mathrm{N}_{\mathrm{Rd}}$. Contudo, o autor destaca que para solicitações de até 0,4 $N_{R d}$ verificou-se um $M_{R d}$ (para 0,02 radianos) em torno de $15 \%$ menor. No caso da presente análise, esta diferença foi maior, em torno de $23 \%$, conforme demonstrado na tabela 5.17.

Tabela 5.17 - Esforços, deslocamentos e rigidez inicial dos modelos XXW-1 e XXW-2

\begin{tabular}{|c|c|c|c|c|}
\hline \multirow{2}{*}{ MODELO } & $U_{(0,02 \mathrm{rad})}$ & $F_{(0,02 \mathrm{rad})}$ & $S_{\mathrm{j}, \text { ini }}$ & $M_{R d(0,02 \mathrm{rad})}$ \\
\hline & $(\mathrm{cm})$ & $(\mathrm{kN})$ & (kN.m/rad) & (kN.m) \\
\hline XXW-1 (SEM compressão axial) & 4,5 & 73,9 & 32.354 & 147,3 \\
\hline XXW-2 (COM compressão axial) & 1,5 & 57,7 & 7.856 & 112,4 \\
\hline
\end{tabular}

Notas: U - deslocamento vertical; $F$ - força vertical; $S_{j, i n i}$ - rigidez inicial; $M_{R d}-$ momento resistente Fonte: Acervo pessoal 
A menor rigidez inicial do modelo XXW-2 ocasionou a perda de resistência da ligação para rotações consideradas adequadas $(0,02$ radianos) em situação de serviço. Verificou-se uma rigidez inicial $75 \%$ inferior no modelo XXW-2.

\subsubsection{Espessura da chapa do diafragma}

As propriedades da ligação parafusada da mesa superior das vigas com o diafragma é determinada pelas características geométricas das chapas e parafusos. Neste item, verifica-se a influência que a espessura da chapa do diafragma tem no comportamento da ligação. A figura 5.87 ilustra as tensões de Von Mises na chapa superior ao longo do carregamento.

Figura 5.82 - Tensões de Von Mises no diafragma superior nos modelos XXS-1 e XXS-4 e XXS-5

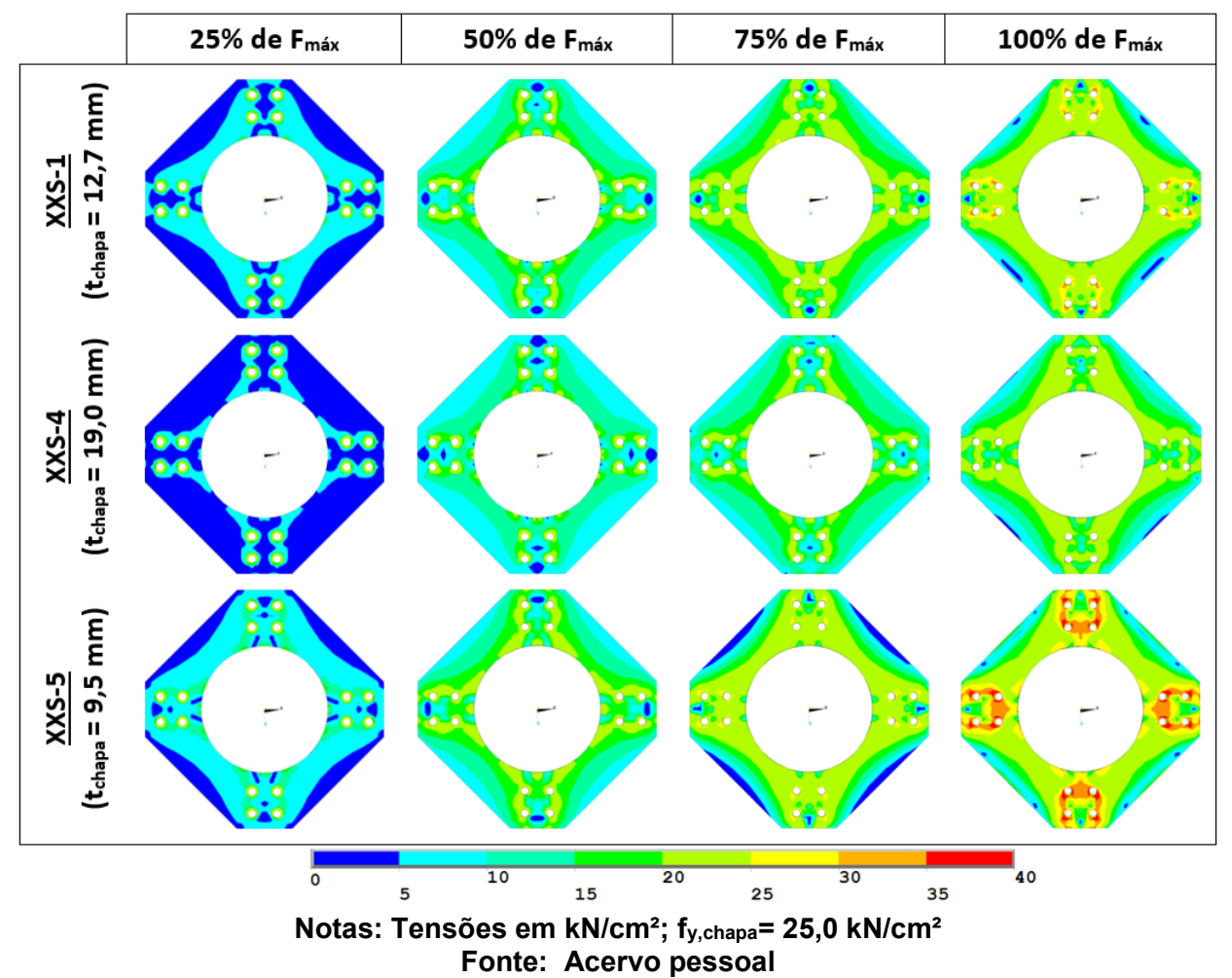

A utilização da chapa com espessura reduzida no modelo XXS-5 (t $t_{\text {chapa }}=9,5$ $\mathrm{mm}$ ) resultou em tensões próximas do limite de ruptura do material na região dos furos. No estágio de $75 \%$ do carregamento final já é possível verificar tensões acima 
do limite de escoamento do material, em algumas regiões da chapa no modelo XXS5, evidenciando o início da plastificação da região do furo.

Considerando as geometrias adotadas, verificou-se que apenas o modelo XXS-4 (t $\mathrm{t}_{\text {chapa }}=19,0 \mathrm{~mm}$ ) não apresentou plastificação da seção da chapa até o final da análise. O modelo XXS-1 ( $\mathrm{t}_{\text {chapa }}=12,7 \mathrm{~mm}$ ), ao final da análise, apresentou tensões elevadas na região dos furos. Destaca-se ainda, a considerável intensidade das tensões no modelo XXS-5 ( $\left.t_{\text {chapa }}=9,5 \mathrm{~mm}\right)$ mesmo nos estágios iniciais.

A intensidade das tensões na mesa superior das vigas nos modelos da figura 5.83 é diretamente proporcional ao aumento da espessura da chapa do diafragma. $O$ aumento da espessura da chapa ocasionou o enrijecimento da ligação e maior capacidade em resistir à solicitações no estado limite último. A viga que não sofreu alterações geométricas passou a receber uma solicitação maior em função do enrijecimento de outro componente da ligação. Verifica-se na figura 5.83 a plastificação da região dos furos nos modelos XXS-1 ( $t_{\text {chapa }}=12,7 \mathrm{~mm}$ ) e XXS-5 ( $\mathrm{t}_{\text {chapa }}$ $=19 \mathrm{~mm}$ ) e a plastificação da seção transversal da viga no modelo XXS-4 (t tchapa $=9,5$ $\mathrm{mm})$.

Figura 5.83 - Tensões de Von Mises na mesa superior dos modelos XXS-1, XXS-4 e XXS-5 ao final da análise

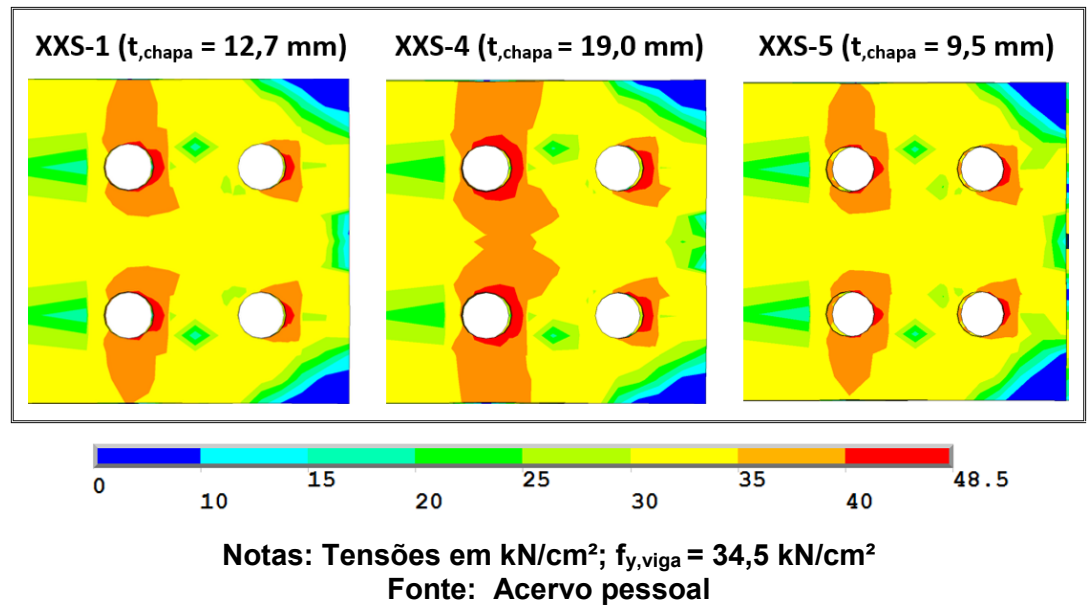

A distribuição de tensões apresentada evidencia a influência da espessura da chapa no comportamento da ligação. A observação do comportamento momentorotação dos 3 modelos (figura 5.84) comprova a diferença existente. 
Figura 5.84 - Comportamento momento-rotação dos modelos XXS-1 e XXS-4 e XXS-5

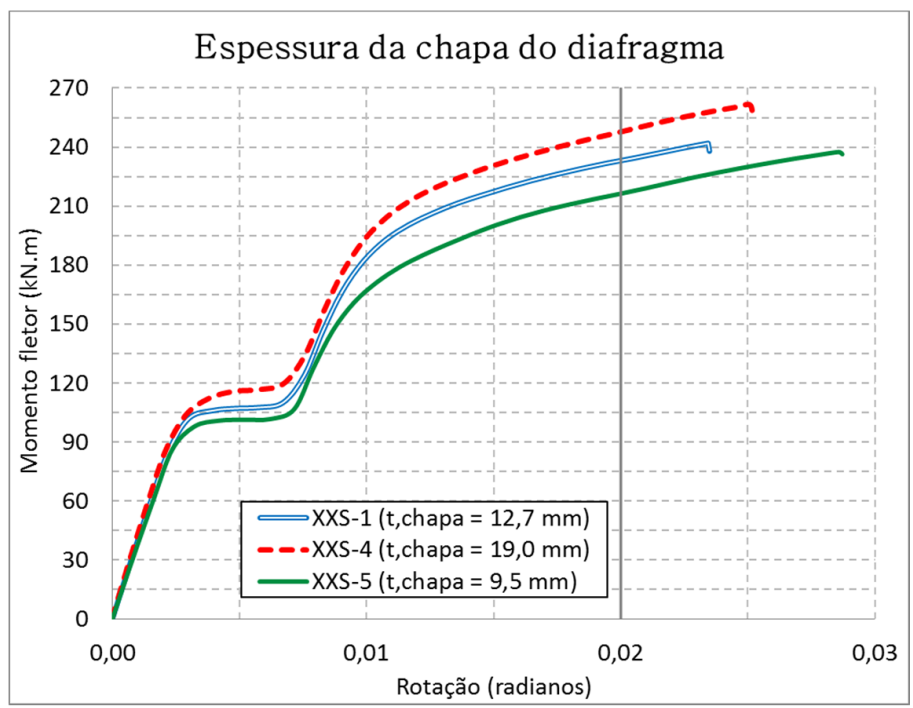

Fonte: Acervo pessoal

Os resultados obtidos pelas curvas M- $\theta$ dos modelos XXS-1, XXS-4 e XXS-5 estão descritos na tabela 5.18. O modelo XXS-4 ( $\mathrm{t}_{\text {chapa }}=19,0 \mathrm{~mm}$ ) apresentou rigidez inicial $6 \%$ superior ao modelo XXS-1 e 12\% maior que do modelo XXS-5. Em termos de resistência ao momento fletor, a ligação do modelo XXS-4 obteve resistência $6 \%$ superior à do modelo XXS-1 e 15\% maior que a do modelo XXS-5.

Tabela 5.18 - Esforços, deslocamentos e rigidez inicial dos modelos XXS-1, XXS-4 e XXS-5

\begin{tabular}{|c|c|c|c|c|}
\hline \multirow{2}{*}{ MODELO } & $U_{(0,02 \mathrm{rad})}$ & $F_{(0,02 \mathrm{rad})}$ & $S_{j, \text { ini }}$ & $M_{R d(0,02 \mathrm{rad})}$ \\
\hline & $(\mathrm{cm})$ & (kN) & (kN.m/rad) & (kN.m) \\
\hline XXS-1 (t,chapa = 12,7 mm) & 4,51 & 116,52 & 40.863 & 233,14 \\
\hline XXS-4 $(\mathrm{t}$,chapa $=19,0 \mathrm{~mm})$ & 4,52 & 124,03 & 43.418 & 247,88 \\
\hline XXS-5 (t,chapa $=9,5 \mathrm{~mm})$ & 4,49 & 108,77 & 38.881 & 216,33 \\
\hline
\end{tabular}

Notas: U - deslocamento vertical; $F$ - força vertical; $S_{j, \text { ini }}$ - rigidez inicial; $M_{R d}-$ momento resistente Fonte: Acervo pessoal

Os resultados descritos comprovam a influência representativa da espessura da chapa no comportamento das ligações com diafragma. O aumento da espessura da chapa gerou um acréscimo de resistência da seção tornando-a capaz de absorver os esforços solicitantes dos parafusos sem a ocorrência da plastificação. Em contrapartida, a redução na seção da chapa evidenciou a concentração das tensões neste elemento, colaborando para a limitação das propriedades de resistência e rigidez das ligações. 


\subsubsection{Diâmetro dos parafusos do diafragma}

No caso das ligações parafusadas, o comportamento da ligação é governado pelas propriedades de parafusos e chapas de ligação. Os resultados apresentados ao longo deste capítulo denotam a significativa influência da resistência dos parafusos do diafragma no comportamento das ligações. O diâmetro dos parafusos é o principal fator limitador da resistência destes elementos.

A evolução do carregamento nos modelos XXS-1 $\left(\mathrm{d}_{\mathrm{b}}=19 \mathrm{~mm}\right), \mathrm{XXS}-7\left(\mathrm{~d}_{\mathrm{b}}=\right.$ $12,7 \mathrm{~mm})$ e XXS-8 $\left(\mathrm{d}_{\mathrm{b}}=16 \mathrm{~mm}\right.$ ) ilustra a concentração das tensões no fuste dos parafusos em todos os modelos. Verifica-se tensões acima do limite de escoamento do material nos 3 modelos descritos na figura 5.85 .

Figura 5.85 - Evolução das tensões de Von Mises nos parafusos do diafragma superior nos modelos XXS-1 e XXS-7 e XXS-8

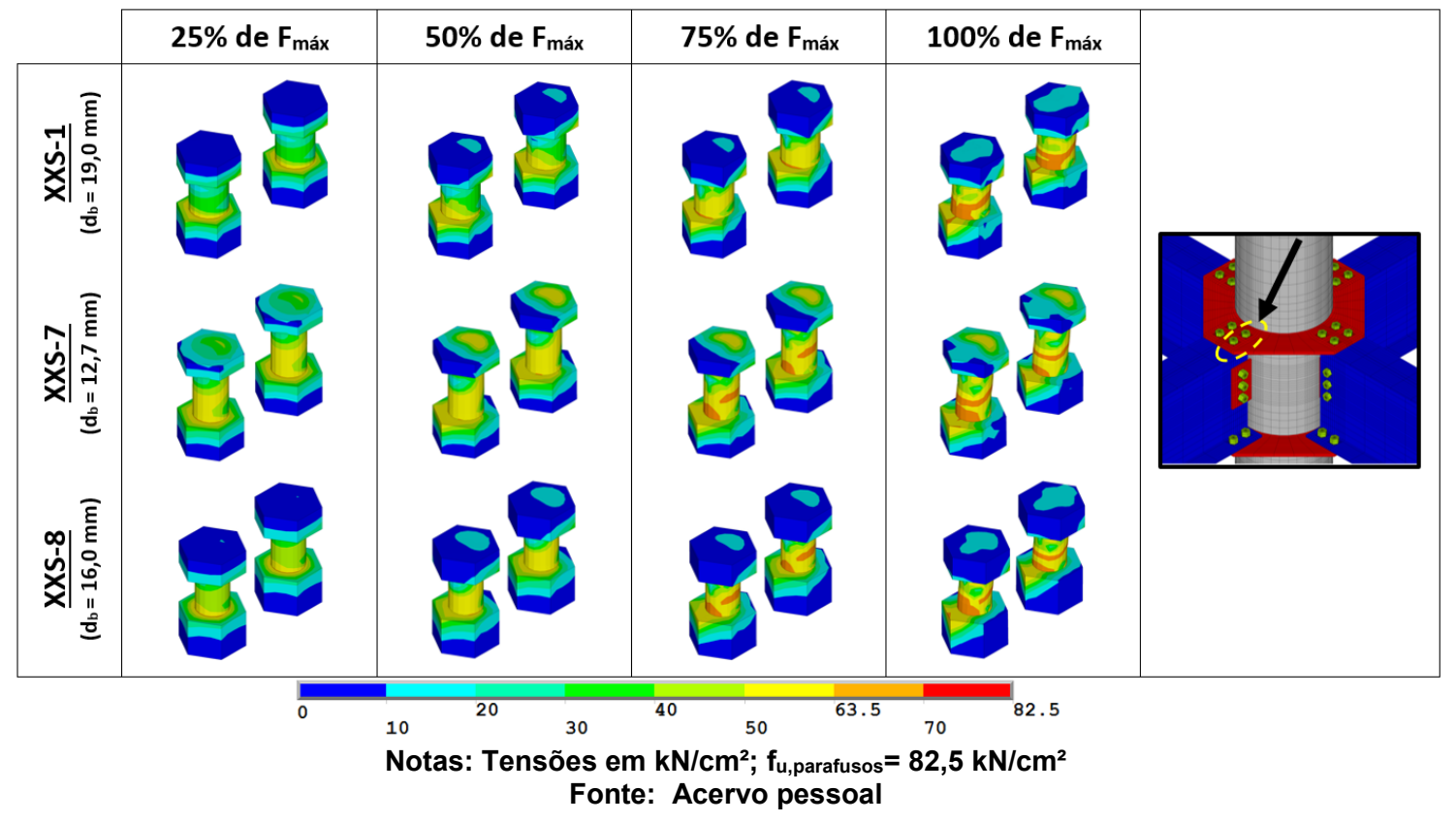

A influência do diâmetro dos parafusos fica melhor evidenciada nos estágios iniciais do carregamento. Com cerca de $25 \%$ do carregamento já é possível observar tensões acima de $50 \mathrm{kN} / \mathrm{cm}^{2}$ ao longo do fuste dos parafusos do modelo XXS-7 ( $\mathrm{d}_{\mathrm{b}}=$ $12,7 \mathrm{~mm})$. Neste mesmo estágio, nos modelos XXS-1 $\left(\mathrm{d}_{\mathrm{b}}=19 \mathrm{~mm}\right)$ e XXS-8 $\left(\mathrm{d}_{\mathrm{b}}=16\right.$ $\mathrm{mm}$ ), verifica-se tensões em torno de $30 \mathrm{kN} / \mathrm{cm}^{2}$ no primeiro e $40 \mathrm{kN} / \mathrm{cm}^{2}$ no segundo. 
A redução do diâmetro dos parafusos nos modelos XXS-7 $\left(d_{b}=12,7 \mathrm{~mm}\right)$ e XXS-8 $\left(d_{b}=16 \mathrm{~mm}\right)$ resultou em tensões elevadas ainda nos estágios iniciais de carregamento. No modelo XXS-1 ( $\left.\mathrm{d}_{\mathrm{b}}=19 \mathrm{~mm}\right)$, com cerca de $80 \%$ da força aplicada verificou-se o aumento considerável da deformação dos parafusos.

O diâmetro dos parafusos pode ser considerado o principal fator geométrico modificador da distribuição de tensões nas ligações com a presença do diafragma. A figura 5.86 demonstra o aumento da concentração de tensões nos elementos da ligação conforme o aumento do diâmetro dos parafusos. Este fenômeno é similar ao observado no enrijecimento da parede do pilar nas ligações soldadas.

Figura 5.86 - Tensões de Von Mises na região da ligação dos modelos XXS-1, XXS-7 e XXS-8 ao final da análise

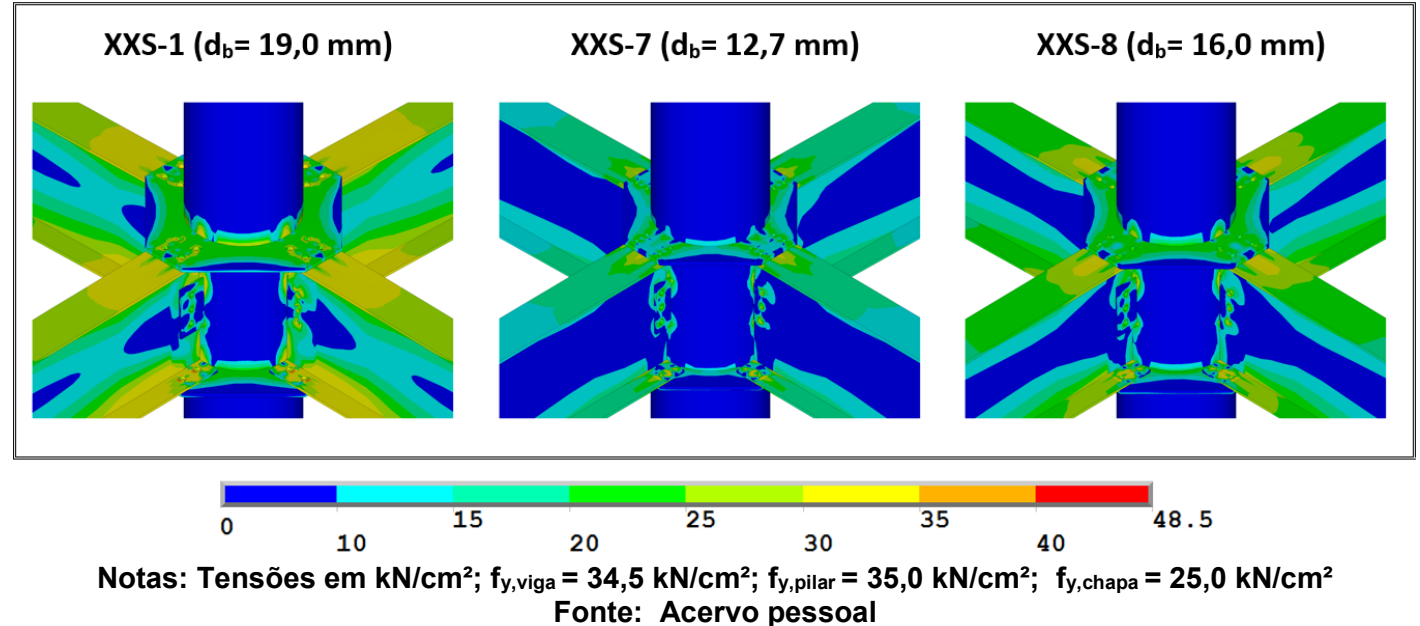

Considerando a maior capacidade em absorver esforços antes de atingir o E.L.U. ${ }^{16}$, a força aplicada no modelo XXS-1 $\left(\mathrm{d}_{\mathrm{b}}=19 \mathrm{~mm}\right)$ possui maior intensidade em relação aos modelos XXS-7 $\left(d_{b}=12,7 \mathrm{~mm}\right)$ e XXS-8 $\left(d_{b}=16 \mathrm{~mm}\right)$. O aumento da força aplicada resulta no aumento das tensões nos demais elementos da ligação. Inversamente ao verificado no modelo XXS-1, no modelo XXS-7 a força aplicada possui menor intensidade em relação aos demais e as tensões atuantes nas vigas $e$ no pilar passa a ser inferior.

Nas chapas do diafragma dos 3 modelos observou-se situação semelhante em relação ao aumento do diâmetro dos parafusos e o aumento da resistência da ligação. A maior capacidade em absorver esforços refletiu em tensões mais elevadas

16 Estado Limite Último 
na região dos furos da chapa superior do diafragma do modelo XXS-1 ( $\left.d_{b}=19 \mathrm{~mm}\right)$, conforme apresentado na figura 5.87.

Figura 5.87 - Tensões de Von Mises no diafragma superior nos modelos XXS-1 e XXS-7 e XXS-8

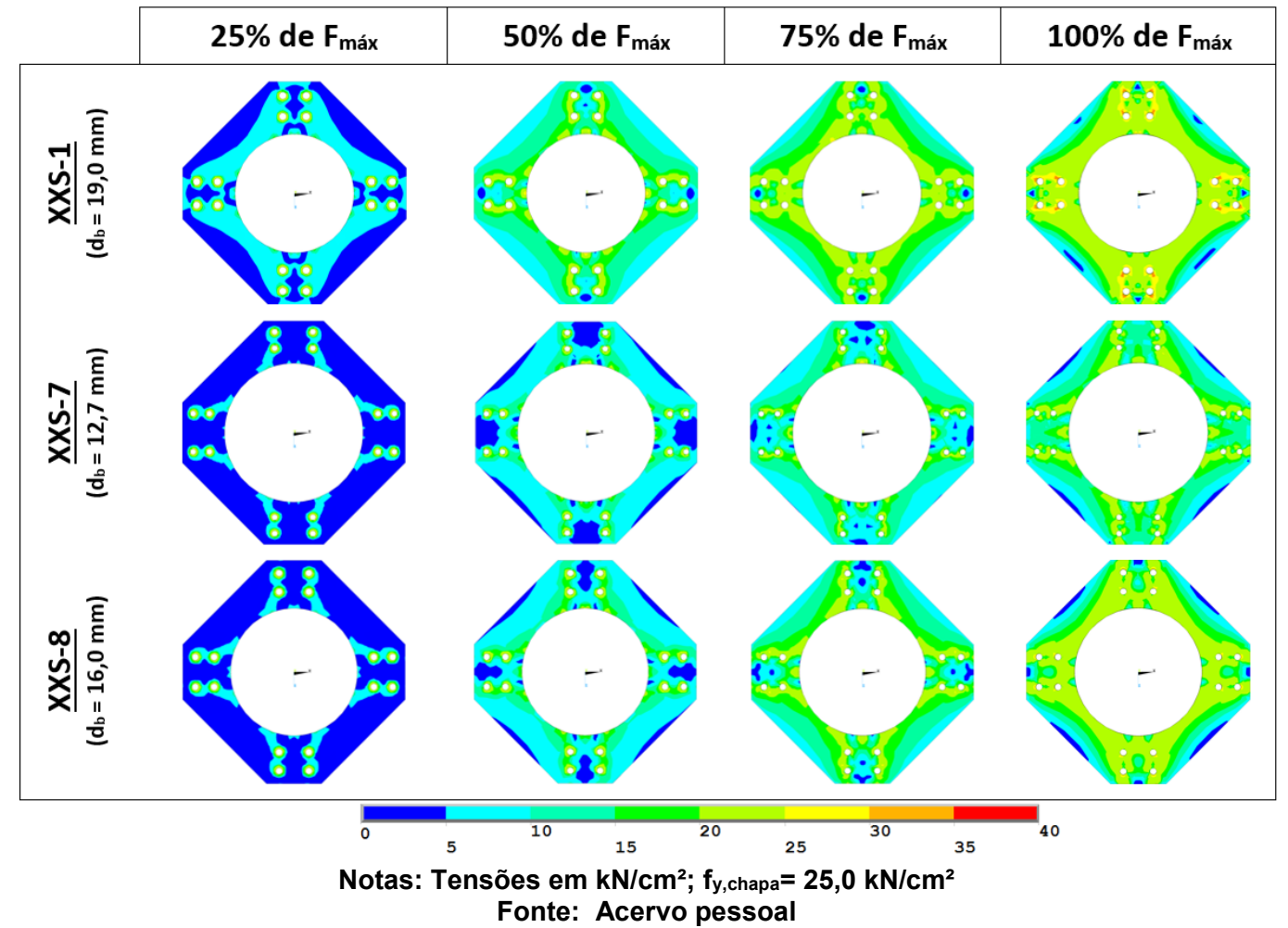

Destacam-se no quadro 5.10 os resultados relativos ao comportamento momento-rotação dos modelos XXS-1, XXS-7 e XXS-8 ratificando a relevância do diâmetro dos parafusos no comportamento da ligação.

Quadro 5.10 - Comportamento momento-rotação dos modelos XXS-1, XXS-7 e XXS-8

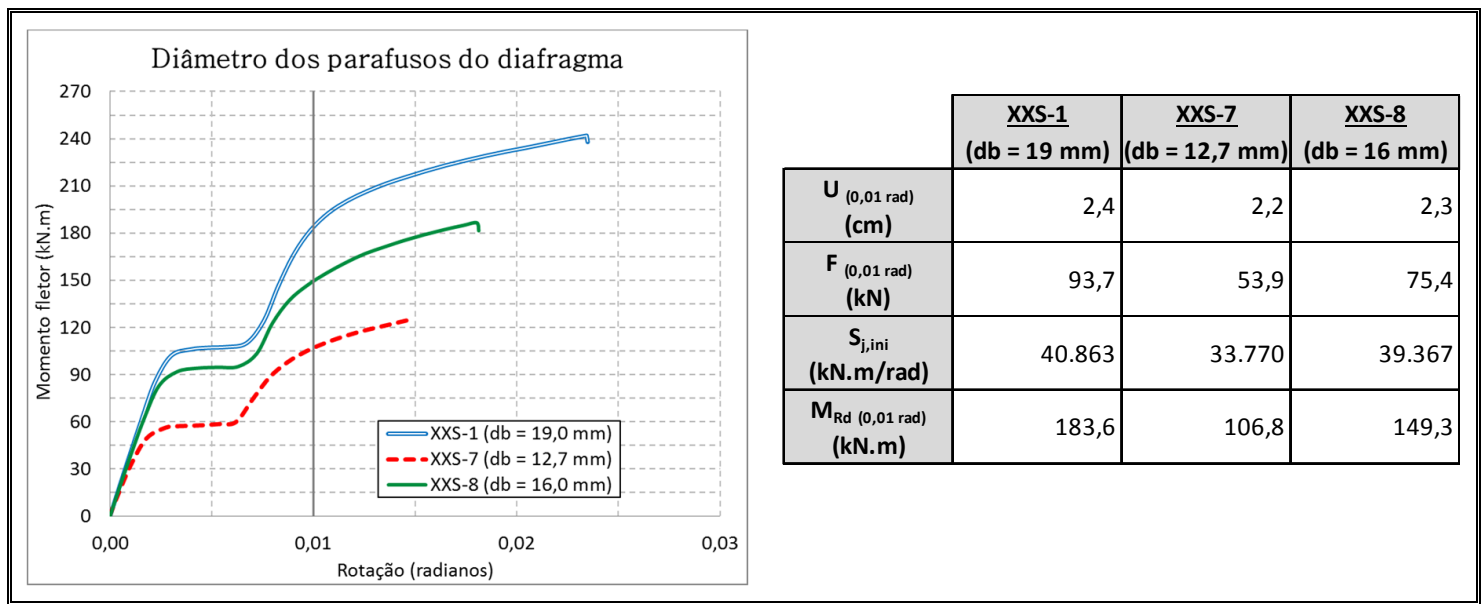

Notas: U - deslocamento vertical; F - força vertical; $S_{\mathrm{j}, \mathrm{ini}}$ - rigidez inicial; $\mathbf{M}_{\mathrm{Rd}}$ - momento resistente Fonte: Acervo pessoal 
Nos 3 modelos a análise limitou-se pela ruptura dos parafusos do diafragma superior. No modelo XXS-7 $\left(d_{b}=12,7 \mathrm{~mm}\right)$, a baixa resistência ao cisalhamento dos parafusos não permitiu deformações acima de 0,015 radianos $\left(0,86^{\circ}\right)$ com o acréscimo da força aplicada.

Comparando-se a resistência dos 3 modelos, para uma rotação de 0,01 radianos, observou-se um valor $72 \%$ superior no modelo $X X S-1\left(d_{b}=19 \mathrm{~mm}\right)$ em relação ao XXS-7 $\left(d_{b}=12,7 \mathrm{~mm}\right)$ e $23 \%$ maior que do modelo XXS-8 $\left(d_{b}=16 \mathrm{~mm}\right)$. A rigidez inicial do modelo XXS-1 mostrou-se $21 \%$ maior que do modelo XXS-7 e $4 \%$ superior à do modelo XXS-8. Em termos de ductilidade, a visualização das 3 curvas sobrepostas já é suficientemente conclusiva evidenciando o modelo XXS-1 com uma ductilidade muito superior aos demais.

\subsection{Análise comparativa entre ligações soldadas e com diafragma}

O mecanismo de enrijecimento da ligação por meio do acréscimo do diafragma é uma solução considerada prática do ponto de vista de execução e eficiente do ponto de vista de comportamento da ligação. A chapa soldada ao redor do pilar aumenta a superfície de redistribuição das forças de compressão para o tubo. A distribuição das tensões de Von Mises nos modelos XXW-1 e XXS-1 (figura 5.88), ao longo do carregamento, ilustra a eficiência do diafragma em redistribuir as tensões ao longo do perímetro do tubo por meio do anel soldado. 
Figura 5.88 - Tensões de Von Mises na face do pilar nos modelos XXW-1 e XXS-1

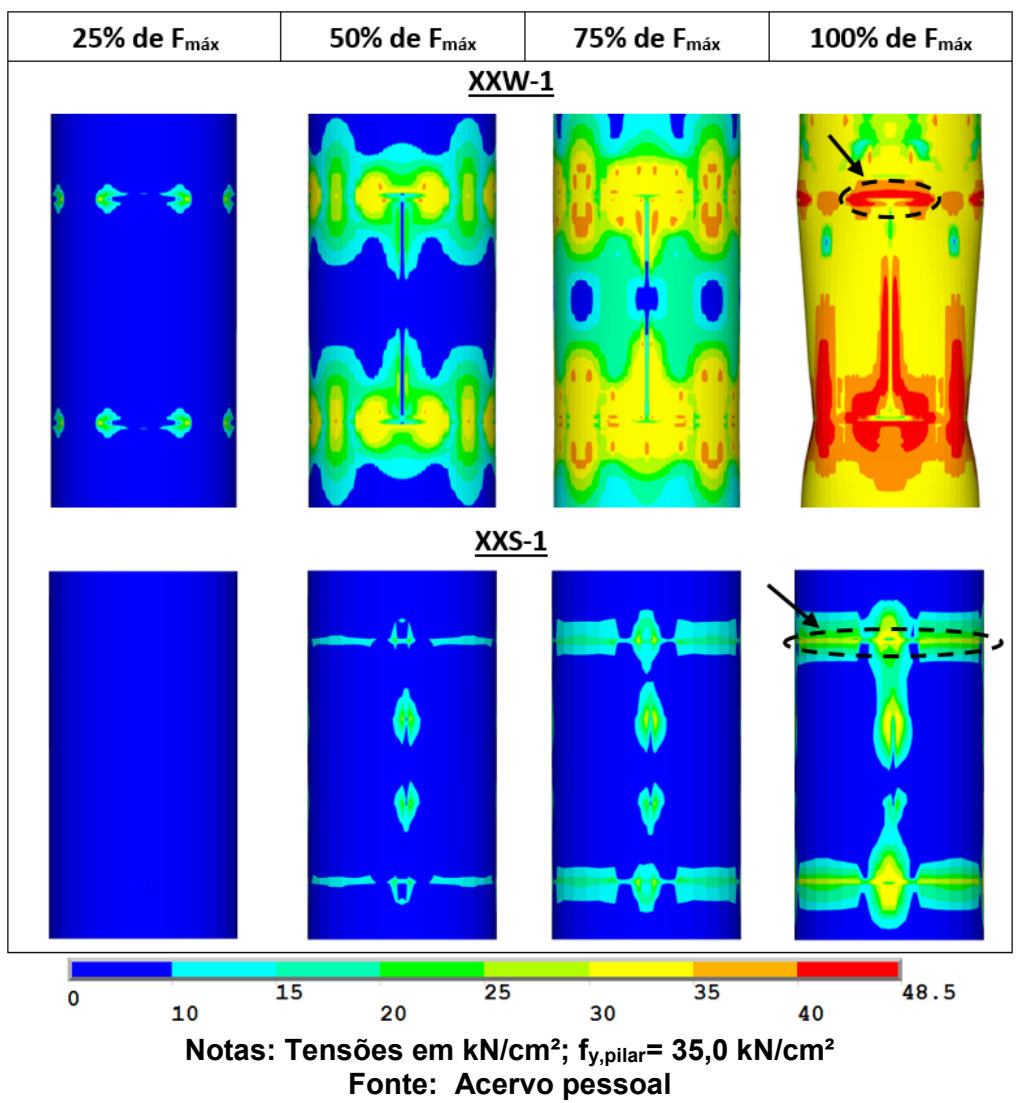

comportamento momento-rotação dos modelos XXW-1 e XXS-1 (figura 5.89) demonstra o aumento da rigidez inicial e resistência do modelo XXS-1 em função da utilização do diafragma.

Figura 5.89 - Curvas momento-rotação dos modelos XXW-1 e XXS-1

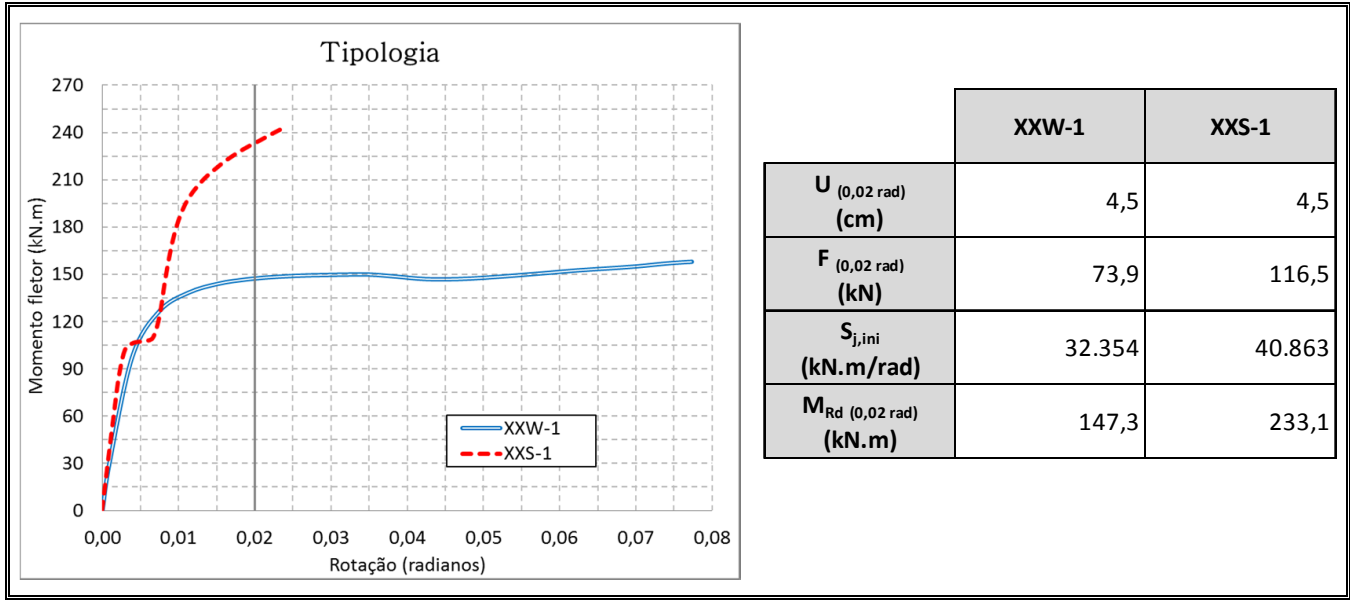

Fonte: Acervo pessoal

A rigidez inicial no modelo XXS-1 apresentou valor $26 \%$ superior ao do modelo com ligação soldada. Em termos de resistência, a influência do diafragma se torna 
mais evidente verificando-se um valor $59 \%$ maior no modelo XXS-1. A capacidade de absorver esforços sob rotações elevadas demonstra a maior ductilidade dos modelos com ligação soldada.

Conforme observado ao longo deste capítulo, a redução da espessura do pilar no modelo XXS-3 (t $t_{\text {pilar }}=7,1 \mathrm{~mm}$ ) não resultou em alterações consideráveis nas propriedades de rigidez inicial e resistência da ligação. Verificou-se no modelo XXS-3 um aumento importante na intensidade das tensões na face do pilar evidenciando um melhor aproveitamento frente ao modelo XXS-1 ( $\left.t_{\text {pilar }}=10 \mathrm{~mm}\right)$.

Em uma situação hipotética, considerando a necessidade de modelos equivalentes em termos de rigidez e resistência e com tipologias distintas (soldada ou com diafragma), os modelos XXW-3 ( $t_{\text {pilar }}=14,2 \mathrm{~mm}$ ) e XXS-3 ( $\mathrm{t}_{\text {pilar }}=7,1 \mathrm{~mm}$ ) são os que melhor se adequariam ao caso. O comportamento momento-rotação dos dois modelos (figura 5.90) ilustra esta proximidade entre eles.

Figura 5.90 - Curvas momento-rotação dos modelos XXW-3 e XXS-3

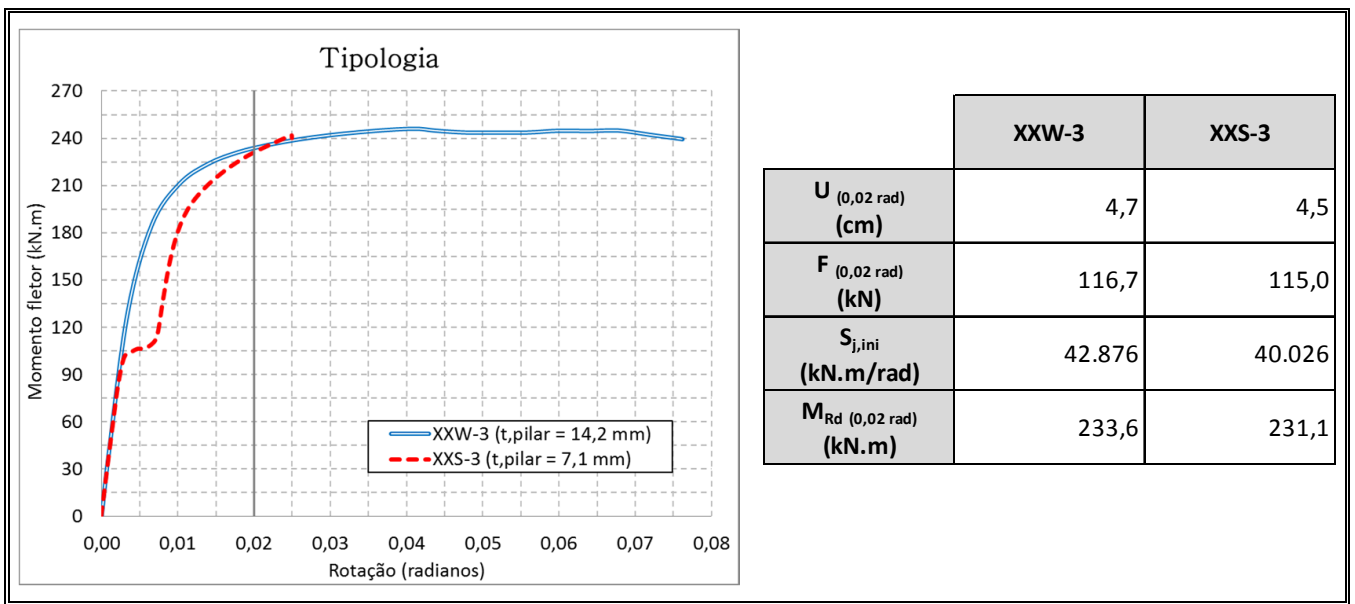

Fonte: Acervo pessoal

No modelo XXW-3 ( $\left.\mathrm{t}_{\text {pilar }}=14,2 \mathrm{~mm}\right)$ foi utilizada uma seção tubular com 109 $\mathrm{kgf} / \mathrm{m}$, enquanto que, no modelo XXS-3 ( $\left.t_{\text {pilar }}=7,1 \mathrm{~mm}\right)$ o pilar pesa $56 \mathrm{kgf} / \mathrm{m}$. No modelo XXS-3 há ainda o acréscimo do peso das chapas (40 kgf) e a consideração da presença dos parafusos.

Em termos de execução, em geral, o modelo XXS-3 apresenta a facilidade da ligação parafusada, enquanto que, o modelo XXW-3 possui um custo adicional do material e a necessidade de execução de uma solda de qualidade em campo. $O$ reduzido número de elementos na ligação do modelo XXW-3 é um ponto positivo para 
a escolha desta tipologia de ligação. O quadro 5.11 apresenta de forma resumida a análise comparativa entre ligações soldadas e com diafragma com base nos resultados obtidos ao longo desta pesquisa.

Quadro 5.11 - Análise comparativa entre ligações soldadas e com diafragma

\begin{tabular}{|c|c|}
\hline Ligação soldada & Ligação com o diafragma \\
\hline$\frac{\underline{X X W-3}}{\left(t_{\text {pilar }}=14,2 \mathrm{~mm}\right)}$ & $\frac{\underline{X X S-3}}{\left(t_{\text {pilar }}=7,1 \mathrm{~mm} ; t_{\text {chapa }}=12,7 \mathrm{~mm} ; d_{b}=19 \mathrm{~mm}\right)}$ \\
\hline $\begin{array}{l}\text { - } \quad \text { Massa linear do pilar: } 109 \text { kgf/m; } \\
\text { - } \quad \text { Presença de solda de campo; } \\
+\quad \text { Número reduzido de elementos; } \\
+\quad \text { Velocidade de execução; } \\
+\quad \text { Alta ductilidade. }\end{array}$ & $\begin{array}{l}+ \text { Massa linear do pilar: } 56 \text { kgf/m; } \\
+\quad \text { Presença de ligações parafusadas; } \\
\text { - } \quad \text { Grande quantidade de elementos; } \\
\text { - } \quad \text { Velocidade de execução; } \\
\text { - } \quad \text { Baixa ductilidade. }\end{array}$ \\
\hline
\end{tabular}

Notas: O símbolos "." e "+" denotam, respectivamente, uma característica negativa e positiva. Fonte: Acervo pessoal

A escolha pela tipologia de ligação está atrelada aos requisitos de resistência e rigidez do sistema mas, sobretudo, aos custos gerais de fabricação e montagem envolvidos. Pode-se dizer, resumidamente, que é possível atingir as propriedades de resistência e rigidez dos modelos com diafragma utilizando a ligação soldada, mas, os custos globais envolvidos neste trabalho devem ser avaliados criteriosamente pelo projetista.

\subsection{Comentário gerais}

Ao longo deste capítulo destacaram-se os resultados relativos à análise numérica dos modelos com ligação soldada e com o diafragma. Realizou-se uma abordagem comparativa no âmbito numérico-experimental a fim de consolidar a metodologia de modelagem numérica utilizada nesta pesquisa. Foram destacados os principais resultados da análise numérica para os modelos deste trabalho. Por fim, verificou-se a influência das principais variáveis em relação ao comportamento das ligações destacando-se a espessura do pilar nas ligações soldadas e o diâmetro dos parafusos nas ligações com o diafragma. 
A seguir, no capítulo 6, apresentam-se as principais conclusões relativas aos resultados destacados ao longo do presente capítulo em relação à análise numérica realizada. São destacadas as principais conclusões a respeito desta pesquisa no que diz respeito à análise estrutural de ligações entre viga de seção I e pilar de seção tubular circular. 


\section{Capítulo 6}

\section{Conclusão}

Apresenta-se à seguir as conclusões à respeito dos resultados e estudos inerentes à este trabalho. São enfatizados os tópicos relativos a validade das expressões analíticas apresentadas no capítulo 3, o comportamento das ligações analisadas e a influência das variáveis, além de propostas para trabalhos futuros sobre ligações entre viga de seção I e pilar de seção tubular circular.

\subsection{Validade das expressões analíticas}

Em geral, a resistência das ligações soldadas obtidas analiticamente pelas formulações do Eurocode 3 (2005) e de Winkel (1998) apresentaram boa aproximação com os resultados obtidos numericamente. Considerando a numerosidade de variáveis físicas e geométricas nas expressões e a melhor proximidade com os resultados numéricos, as formulações de Winkel (1998) podem ser consideradas melhor adaptadas para as ligações soldadas do tipo XX e TT.

Nas expressões analíticas avaliadas, em comparação com a análise numérica, a variável relativa à compressão axial do pilar apresentou melhor correlação na formulação de Winkel (1998). O autor considera as características geométricas dos elementos da ligação na influência da compressão axial do pilar. A expressão do Eurocode 3 (2005) leva em consideração apenas a intensidade do carregamento, a área da seção do pilar e a tensão de escoamento do material.

A influência da compressão simultânea nas duas direções ortogonais, gerando o efeito de confinamento na seção do pilar, apresentou resultados mais 
próximos da análise numérica com a utilização das formulações de Winkel (1998). O fator utilizado por Winkel (1998) para ponderar a resistência da ligação possui relação com a geometria da viga e do pilar.

O Eurocode 3 (2005) sugere a utilização do fator $\mu$ para ligações do tipo XX ou TT, em banzos de treliças tubulares comprimidos simultaneamente nas duas direções ortogonais. Nesta pesquisa, optou-se por realizar uma analogia para ligações entre viga I e pilar circular, entretanto, verificou-se resistências superestimadas para as ligações. $O$ fator $\mu$ não considera a geometria das vigas e do pilar em sua formulação. O texto da norma europeia apenas especifica a consideração da intensidade e sentido da força aplicada nas duas direções.

Verificou-se que a analogia tomada como referência não representa, satisfatoriamente, os elementos da ligação e que esta consideração pode culminar numa resistência superestimada. Deste modo, a consideração adequada para estimar a resistência de ligações do tipo TT e XX soldadas, segundo o Eurocode 3 (2005), seria a utilização das expressões para ligações do tipo $X$, descartando-se o coeficiente $\mu$.

Nas ligações com a presença do diafragma, o Método das Componentes do Eurocode 3 (2005) se mostrou a favor da segurança estrutural, porém, verificou-se um aproveitamento de apenas $80 \%$ da resistência das ligações. O fato de não considerar a interação entre os dispositivos componentes da ligação resultou em resistências subestimadas. Apesar dos fatos observados, na ausência de metodologias específicas de dimensionamento para o tipo de ligação em questão, as formulações do Eurocode 3 (2005) apresentam-se como uma boa alternativa para o dimensionamento.

\subsection{Comportamento das ligações}

- Influência das variáveis:

O comportamento das ligações analisadas neste trabalho apresenta considerações importantes a respeito das variáveis capazes de influenciar as 
propriedades de resistência, rigidez e ductilidade de ligações entre viga I e pilar tubular circular. Com relação às variáveis estudadas observou-se as seguintes conclusões:

\section{a) Comprimento da viga}

A modificação no comprimento da viga, de modo a gerar a predominância de esforços de naturezas distintas, não resultou em grandes diferenças no comportamento das ligações. Nas ligações soldadas, a redução do comprimento da viga representou um aumento na compressão axial na parede do tubo, porém, de valor ínfimo comparado à resistência do tubo à compressão. Nas ligações com o diafragma verificou-se o aumento das tensões na chapa de alma e nos parafusos da alma ao reduzir o comprimento das vigas, entretanto, esta consideração não alterou o Estado Limite Último ocorrido pelo cisalhamento dos parafusos do diafragma superior.

\section{b) Espessura da parede do pilar}

O presente trabalho verificou que o aumento da espessura da parede do pilar foi capaz de aumentar consideravelmente a resistência e rigidez inicial das ligações soldadas. Esta consideração mostrou-se eficiente do ponto de vista estrutural, porém, com influência no peso da seção transversal do pilar. Nas ligações com o diafragma a influência apresentou-se menos significativa visto à predominância do modo de falha pelo cisalhamento dos parafusos.

c) Força aplicada nas duas direções ortogonais

Nos modelos de ligação soldada do tipo XX, o carregamento de mesma direção e intensidade simultaneamente nas 4 vigas ortogonais resultou em uma melhoria nas propriedades de resistência e rigidez inicial das ligações. $O$ efeito de confinamento da seção do pilar restringiu a deformação do pilar no sentido de ovalização da seção do pilar. A ausência do carregamento das vigas do sentido ortogonal resultou em uma ligação com resistência e rigidez inicial inferior em função da não restrição à deformação do pilar. Nos modelos de ligação soldada do tipo TT verificou-se um comportamento semelhante.

Nas ligações com a presença do diafragma, a influência do carregamento simultâneo nas 4 vigas foi menos representativa e restringiu-se ao estado elástico de 
carregamento. A restrição à deformação do pilar exercida pelas vigas na direção ortogonal apresentou acréscimo da resistência e rigidez inicial das ligações.

d) Compressão axial do pilar

O efeito da compressão axial do pilar no comportamento da ligação apresentou relevância considerável, sobretudo, nos estágios iniciais de plastificação. Verificou-se uma queda acentuada na rigidez inicial quando da presença da compressão no pilar. A resistência das ligações apresentou diferença considerável para rotações de até 0,02 radianos. Com o aumento da plastificação dos componentes da ligação verificou-se uma redução de $10 \%$ da resistência das ligações para um carregamento axial de 0,40 $\mathrm{N}_{\mathrm{Rd}}$. Em geral, esta variável apresentou importância considerável no comportamento da ligação em função da plastificação precoce da seção do pilar.

e) Espessura da chapa do diafragma

A redução na espessura da chapa do diafragma resultou em uma ligação com menor resistência e rigidez inicial. O modo de falha nos modelos com o diafragma ocorreu na ligação parafusada com a mesa superior das vigas e, portanto, os elementos desta ligação foram os principais fatores influenciadores do comportamento desta tipologia de ligação.

f) Diâmetro dos parafusos do diafragma

Nas ligações com a presença do diafragma a principal variável que influenciou o comportamento da ligação foi o diâmetro dos parafusos do diafragma. A ocorrência do modo de falha pelo cisalhamento dos parafusos resultou na relação direta entre a resistência destes elementos e as propriedades de rigidez inicial e resistência das ligações.

Observou-se ainda algumas constatações importantes sobre 0 comportamento das ligações analisadas em termos de ductilidade, modo de falha predominante, classificação das ligações e a análise comparativa entre ligações soldadas e com diafragma. 
- Ductilidade:

Os modelos com a ligação soldada apresentaram ductilidade muito superior à observada nos modelos com a presença do diafragma. Os modelos com ligação soldada demonstraram capacidade de absorver esforços em rotações elevadas (acima de 0,08 radianos). As ligações com diafragma apresentaram requisitos de ductilidade inferiores ao mínimo ${ }^{17}$ estipulado pelo ANSI/AISC 360-10 (2010). É importante destacar que estes requisitos referem-se à aplicações em zonas sísmicas.

- Modos de falha:

Nos modelos de ligação soldada, as ligações apresentaram modo de falha pela plastificação da face do pilar. O comportamento das ligações soldadas é influenciado, principalmente, pelas propriedades da seção transversal do pilar. Nos modelos com a presença do diafragma externo, a concentração de tensões na ligação parafusada com a mesa superior das vigas limitou a análise pela não convergência dos modelos numéricos em função do cisalhamento dos parafusos.

- Classificação das ligações:

Todas as ligações apresentaram comportamento semi-rígido o que demonstra que mesmo a utilização dos diafragmas não foi capaz de enrijecer as ligações a ponto de classificá-las no limite de ligações rígidas. Considerando a classificação atribuída, os 20 modelos de ligação avaliados nesta pesquisa devem ter suas propriedades de rigidez e resistência consideradas em uma análise global da estrutura.

- Ligações soldadas versus ligações com a presença do diafragma:

A utilização do diafragma externo e o aumento da espessura da parede do pilar apresentaram-se como alternativas eficazes no enrijecimento das ligações. A ligação soldada possui a facilidade de execução, porém, acarreta a utilização de mãode-obra especializada na execução de uma solda de campo adequada e no aumento dos custos do material para o aumento da espessura do pilar. A ligação com o diafragma apresenta maior facilidade de execução no campo e custos de materiais reduzidos, porém, maior número de dispositivos de ligação e ausência de

17 O ANSI/AISC 360-10 (2010) estipula que uma ligação viga-pilar para aplicações em zonas sísmicas deve apresentar rotação mínima de 0,03 radianos sem perda considerável de resistência. 
metodologias específicas para o dimensionamento. A escolha pela melhor alternativa deve avaliar criteriosamente os custos globais atrelados à obtenção de requisitos de rigidez e resistência equivalentes nas duas tipologias.

\subsection{Proposta para trabalho futuro}

No Brasil, as pesquisas em ligações envolvendo seções tubulares ainda se encontram em estágio inicial. Destacam-se a seguir alguns tópicos importantes a serem trabalhados em pesquisas futuras envolvendo seções tubulares:

a) Estudo de outras tipologias de ligação capazes de enrijecer a ligação sem o aumento considerável dos custos;

b) Estudo paramétrico de ligações com diafragma externo de forma a gerar formulações analíticas para estimar a resistência e rigidez desta tipologia de ligação;

c) Desenvolvimento de formulação analítica para estimar a rigidez inicial e rigidez secante de ligações soldadas entre viga I e pilar tubular circular;

d) Continuidade aos estudos desenvolvidos no Departamento de Engenharia de Estruturas da EESC ${ }^{18}$ em pilares de seção tubular retangular. Estender a pesquisa à análise da influência do aumento da espessura do pilar retangular e ao efeito do confinamento do tubo pelas vigas carregadas ortogonalmente.

e) Continuidade aos estudos desenvolvidos no Departamento de Engenharia de Estruturas da EESC em relação ao efeito do preenchimento com concreto (armado ou não) na resistência, rigidez e ductilidade das ligações soldadas. Avaliação de um estudo de caso considerando os custos globais da aplicação.

${ }^{18}$ Escola de Engenharia de São Carlos 


\section{Referências bibliográficas}

AMERICAN NATIONAL STANDARDS INSTITUTE; AMERICAN INSTITUTE OF STEEL CONSTRUCTION. (2010). Specification for structural steel buildings. ANSI/AISC 360-10. 609 p. Chicago.

ASSOCIAÇÃO BRASILEIRA DE NORMAS TÉCNICAS. (2008). NBR 8800: Projeto de estruturas de aço e de estruturas mistas de aço e concreto de edifícios. Rio de Janeiro.

ATTIOGBE, E.; MORRIS, G. (1991). Moment-rotation functions for steel connections. Journal of Structural Engineering, Reston, v. 117, n. 6, p. 1703-1718.

BESSA, W. O. (2004). Análise numérica tridimensional de ligações viga-coluna com chapa de topo na direção do eixo de menor inércia do pilar. $170 \mathrm{p}$. Dissertação (Mestrado) - Escola de Minas, Universidade Federal de Ouro Preto, Ouro Preto, 2004.

BJORHOVDE, R.; COLSON, A.; BROZZETTI, J. (1990). Classification system for beam-to-column connections. Journal of Structural Engineering, Reston, v. 116, $n$. 11, p. 3059-3076.

CARVALHO, P. H. (2005). Avaliação numérica do comportamento estrutural de ligação entre pilar de seção tubular circular e viga de seção "I". 106 p. Dissertação (Mestrado) - Escola de Minas, Universidade Federal de Ouro Preto, Ouro Preto, 2005. 
CHEN, W. F.; LORENZ, R. F.; KATO, B. (1993). Semi-rigid connections in steel frames: Council on tall buildings and urban habitat. New York: Mcgraw Hill. 318 p.

CHEN, W. F.; LUI, L. M. (Ed.). (2005). Handbook of structural engineering. 2. ed. Boca Raton: CRC Press. 1741 p.

CHOO, Y. S. et al. (2004). Static strength of doubler plate reinforced CHS X-joints loaded by in-plane bending. Journal of Constructional Steel Research, London, v. 60 , n. 12 , p. $1725-1744$.

CHRISTOPHER, J. E.; BJORHOVDE, R. (1999). Semi-rigid frame design methods for practicing engineers. Engineering Journal, Chicago, p. 12-28, jan./mar.

EUROPEAN COMMITTEE FOR STANDARDIZATION. (2005). Design of steel structures: Part 1-8 - Design of Joints. Eurocode 3 Part 1-8, EN 1993-1-8:2005, Brussels.

FIRMO, C. S. (2005). Arquitetura com perfis tubulares: uma nova linguagem. Trabalho apresentado à III Feira Internacional de Tubos, Válvulas, Conexões e Componentes, Tubotech, São Paulo.

FREITAS, P. C. B. (2009). Análise numérica de ligações metálicas viga-coluna com coluna tubular circular. 188 p. Dissertação (Mestrado) - Escola de Engenharia de São Carlos, Universidade de São Paulo, São Carlos, 2009.

KAMBA, T. et al. (1982). Tests on the local failures of tubular column to H-beam connections in steel structures: A study on the tubular column to beam connection Part 1 [in Japanese]. Journal of Structural and Construction Engineering. Transactions of the Architectural Institute of Japan, Tokyo, n. 322, p. 44-51.

KAMBA, T. et al. (1983). Empirical formulae for strength of steel tubular column to $\mathrm{H}$ beam connections: A study on the tubular column to beam connection Part 2 [in Japanese]. Journal of Structural and Construction Engineering. Transactions of the Architectural Institute of Japan, Tokyo, n. 325, p. 67-73. 
KAMBA, T.; KANATANI, H. (1993). Design formulae for CHS column-to-beam connections with exterior diaphragms. Proceedings of the $\mathrm{V}$ International Symposium on Tubular Structures, Nottingham, p. 249-256.

KAMBA, T.; KANATANI, H.; TABUCHI, M. (1986). Local strength of tubular column to H-beam connections: Study of connections subjected to vertical or horizontal loading. Journal of Structural and Construction Engineering. Transactions of the Architectural Institute of Japan, Tokyo, n. 360, p.147-156.

KAMBA, T.; NAMBA, H.; ETOU, O. (1998). Elastic-plastic behavior of tubular column to $\mathrm{H}$-beam connections which thickness of column at connections is increased. Journal of Structural and Construction Engineering. Transactions of the Architectural Institute of Japan, Tokyo, n. 513, p. 151-157.

KUROBANE, Y. et al. (2004). CIDECT design guide 9: Design guide for structural hollow section column connections. Köln: CIDECT and Verlag TÜV Rheinland. 213 p.

LEE, S. S.; MOON, T. S. (2002). Moment-rotation model of semi-rigid connections with angles. Engineering Structures, London, v.24, p.227-237.

MAGGI, Y. I. (2000). Análise numérica via M.E.F., do comportamento de ligações parafusadas viga-coluna com chapa de topo. 255 p. Dissertação (Mestrado) Escola de Engenharia de São Carlos, Universidade de São Paulo, São Carlos, 2000.

MAGGI, Y. I. (2004). Análise do comportamento estrutural de ligações parafusadas viga-pilar com chapa de topo estendida. 269 p. Tese (Doutorado) Escola de Engenharia de São Carlos, Universidade de São Paulo, São Carlos, 2004.

MASIOLI, C. Z. (2011). Análise teórica e experimental de ligações em aço entre pilar tubular de seção circular e viga de seção I. 137 p. Dissertação (Mestrado) Escola de Engenharia de São Carlos, Universidade de São Paulo, São Carlos, 2011. 
MOHAMADI-SHORE, M. R.; MOFID, M. (2011). New modeling for moment-rotation behavior of bolted endplate connections. Scientia Iranica, Transactions A, Tehran, Iran, v.18, n.4, p.827-834.

NETHERCOT, D. A.; LI, T. Q.; AHMED, B. (1998). Unified classification system for beam-to-column connections. Journal of Constructional Steel Research, London, v. 45, n. 1 , p. $39-65$.

PACKER, J. A.; HENDERSON, J. E. (1997). Hollow structural section connections and trusses. Alliston: Canadian Institute of Steel Construction. 465 p.

PACKER, J. A.; SHERMAN, D.; LECCE, M. (2010). AISC steel design guide 24: Hollow structural section connections. Chicago: American Institute of Steel Construction. 153 p.

PIRMOZ, A. et al. (2009). Moment-rotation behavior of bolted top-seat angle connections. Journal of Constructional Steel Research, London, v. 65, p. 973-984.

PROENÇA, S. P. B. (2010). Análise não-linear de estruturas. 216 p. Notas de aula - Escola de Engenharia de São Carlos, Universidade de São Paulo, São Carlos, 2010.

REIS, S. L. F. (2011). Análise teórico-experimental de ligações metálicas soldadas entre coluna em perfil tubular circular e viga em perfil de seção transversal "I". 105 p. Dissertação (Mestrado) - Escola de Minas, Universidade Federal de Ouro Preto, Ouro Preto, 2011.

RIBEIRO, L. F. L. (1998). Estudo do comportamento estrutural de ligações parafusadas viga-coluna com chapa de topo: Análise teórico-experimental. 560 p. Tese (Doutorado) - Escola de Engenharia de São Carlos, Universidade de São Paulo, São Carlos, 1998.

ROMANO, V. P. (2001). Dimensionamento de ligações viga-coluna com chapa de topo: Modelo do Eurocode 3. 299 p. Dissertação (Mestrado) - Escola de Minas, Universidade Federal de Ouro Preto, Ouro Preto, 2001. 
SANTOS, L. B. (1998). Influência da rigidez das ligações em estruturas de aço. 193 p. Dissertação (Mestrado) - Escola de Engenharia de São Carlos, Universidade de São Paulo, São Carlos, 1998.

STARK, J. W. B.; BIJLAARD, F. S. K. (1988). Structural properties of connections in steel frames. BJORHOVDE, R.; BROZZETTI, J.; COLSON, A. Connections in steel structures: Behaviour, strength and design. London: Elsevier Applied Science Publishers Ltd. p. 186-194.

SUI, W. N.; CHEN, Y. Y. (2010). Behavior of external diaphragm connection of CHS column with $\mathrm{H}$-shaped beams. Proceedings of the XIII International Symposium on Tubular Structures, Hong Kong, p. 167-174.

SUI, W.; YAMANARI, M. (2007). Evaluation of the characteristics of external diaphragm connections with steel CHS columns and wide-flange steel beams. Proceedings of the VIII Pacific Structural Steel Conference: Steel Structures in Natural Hazards, Wairakei.

WARDENIER, J. et al. (2008). CIDECT design guide 1: Design guide for circular hollow section (CHS) joints under predominantly static loading. 2.ed. Köln: CIDECT and Verlag TÜV Rheinland. $142 \mathrm{p}$.

WARDENIER, J. et al. (2010). Hollow sections in structural applications. 2.ed. Geneva: CIDECT and Verlag TÜV Rheinland. 240 p.

WEYNAND, K.; JASPART, J. P.; LY, L. (2003). Application of the component method to joints between hollow and open sections. CIDECT research project $5 \mathrm{BM}$, Liège, $83 \mathrm{p}$.

WINKEL, G. D. de. (1998). The static strength of I-beam to circular hollow section column connections. 263 p. Dissertation (PhD) - Faculty of Civil Engineering and Geosciences, Delft University of Technology, Delft, 1998. 
WINKEL, G. D. de. et al. (1993). The behavior and the static strength of unstiffened I-beam to circular column connections under multiplanar in-plane bending moments. Proceedings of the Third International Offshore and Polar Engineering Conference, Singapore, v. 4.

WINKEL, G.D. de.; WARDENIER, J. (1996). Parametric study on the static behavior of uniplanar I-beam-to-tubular column connections loaded with inplane bending moment combined with pre-stressed columns. International Society of Offshore and Polar Engineers. Proceedings of the VII International Symposium on Tubular Structures, Miskolc, p. 229-236. 